\title{
VicHealth Coronavirus
Victorian Wellbeing Impact Study
}

Report for survey \#1

How the first coronavirus lockdown impacted the health and wellbeing of Victorians

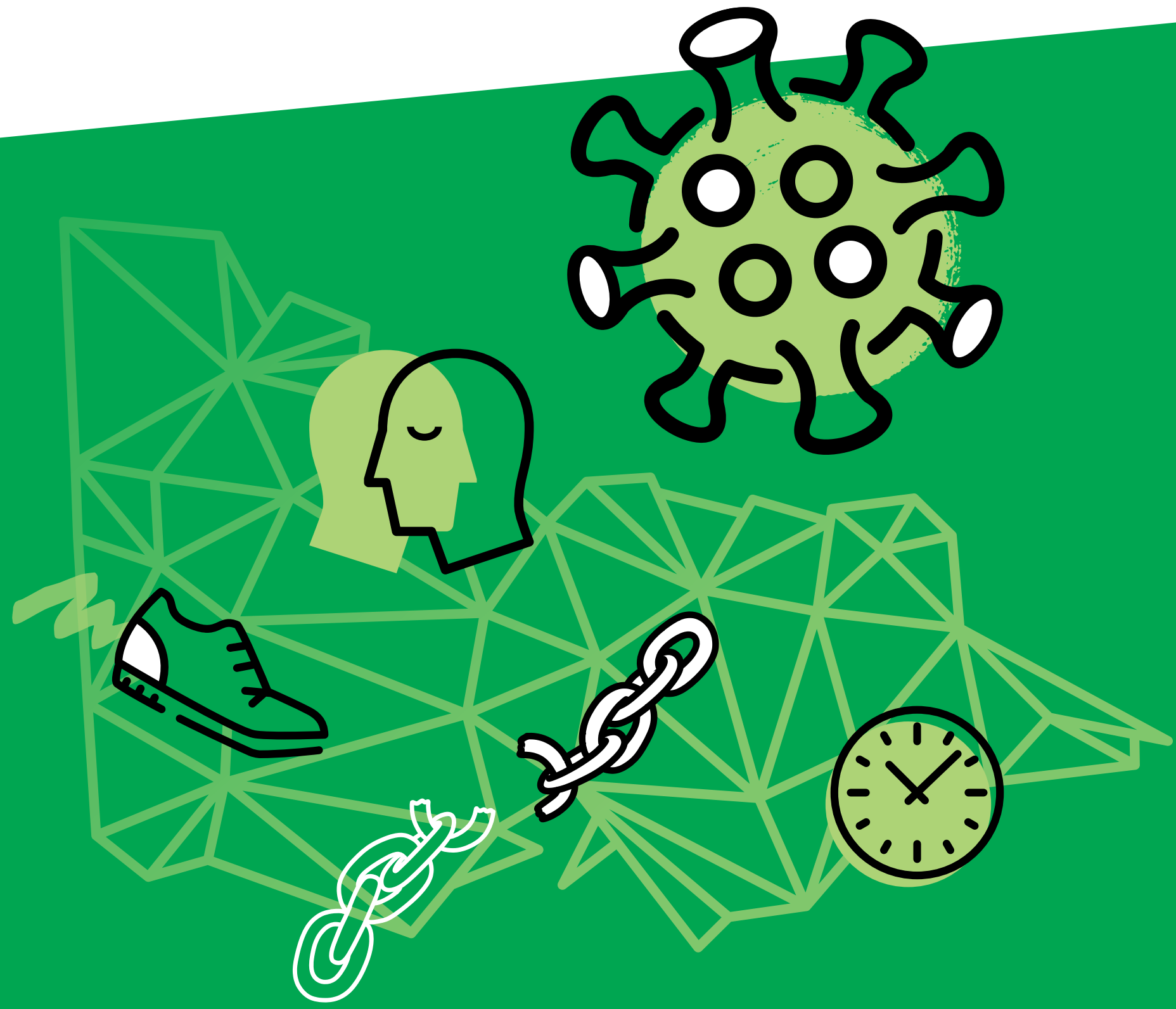




\section{Foreword by VicHealth CEO}

In the midst of this global coronavirus pandemic, protecting health and wellbeing is more important than ever. While the pandemic has affected all of us, certain individuals, families and communities have been hardest hit. These impacts will be felt for many years to come.

To be able to respond and support Victorians effectively, we must understand how they are being impacted. An equitable recovery requires us to identify who in our community bears the burden of this pandemic. Like the response to the coronavirus pandemic itself, we must be armed with evidence to guide us in recovery.

At VicHealth, we value the voices and experiences of all Victorians - no matter their postcode, income or background. Our deep commitment to supporting and listening to Victorians has led to the development of this survey.

During the initial coronavirus restrictions of 2020 , VicHealth surveyed 2,000 Victorians to explore how their health and wellbeing was affected, comparing these results with two previous surveys carried out in 2017 and 2015.

This comprehensive survey covers general wellbeing, social connection, healthy eating, physical activity, financial hardship, smoking, alcohol consumption, as well as working and home life. It shows the negative and positive impacts of the first lockdown on people according to age, gender, income, location and community.

The findings, summarised in this report, are intended to inform our focus, investment and policy decisions to ensure the most significantly affected Victorians get the support they need, to achieve, regain and maintain good health.

To get a fuller picture of the impacts of this pandemic, VicHealth will conduct a follow up survey in September 2020.

We continue to work with our government partners and stakeholders across the state to support Victorians on their road to recovery.

\section{Dr Sandro Demaio CEO, VicHealth}

\section{Acknowledgements}

This report was prepared in collaboration with the Social Research Centre.

Thank you to the 2000 Victorians who agreed to participate in this study.

\section{Suggested citation}

VicHealth Coronavirus Victorian Wellbeing Impact Study (2020), Victorian Health Promotion

Foundation, Melbourne (https://doi.org/10.37309/2020.PO909) 


\section{Contents}

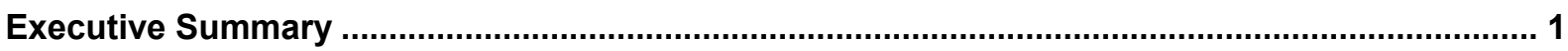

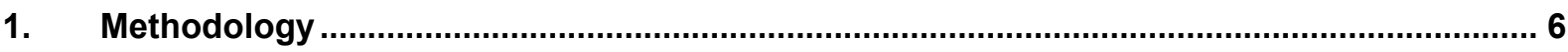

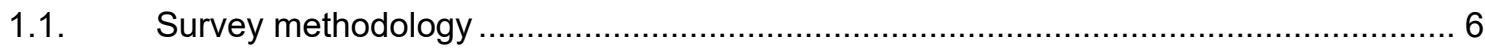

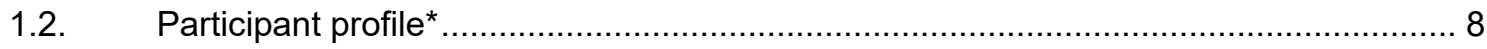

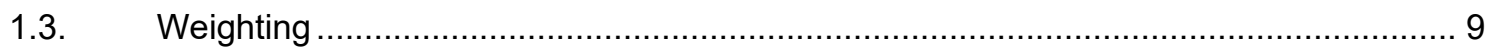

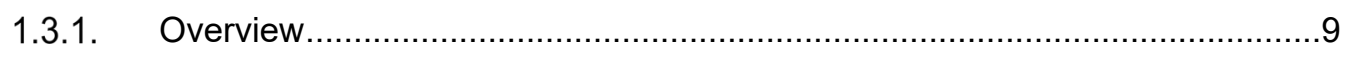

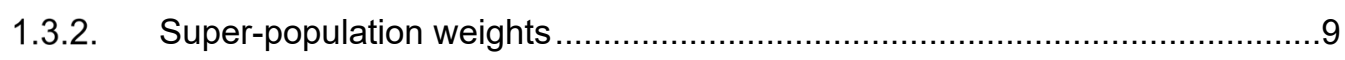

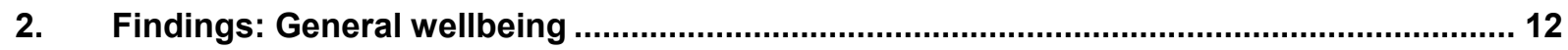

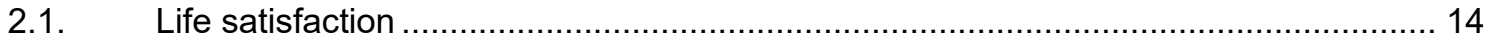

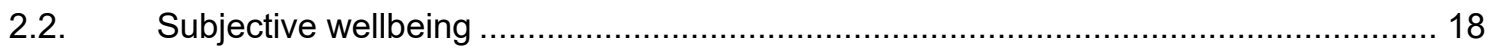

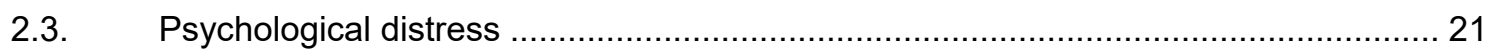

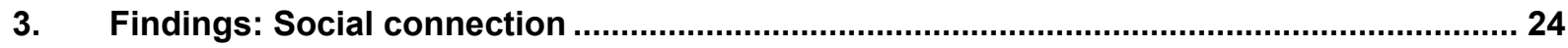

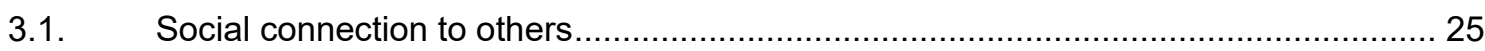

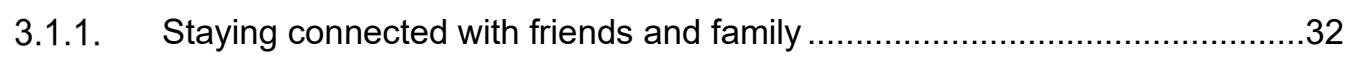

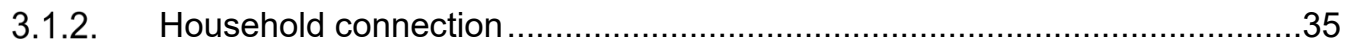

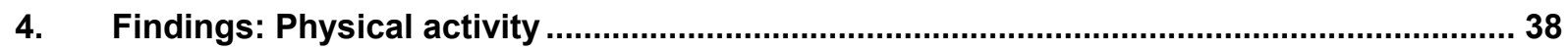

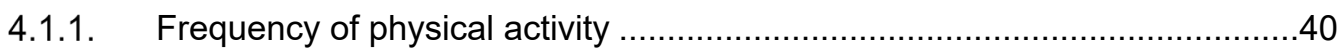

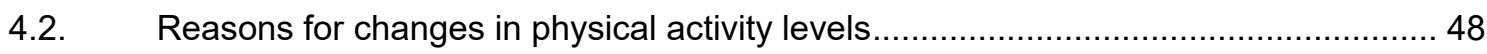

4.2.1. Reasons for decreased physical activity levels .......................................48

4.2.2. Reasons for increased or maintained physical activity levels ......................49

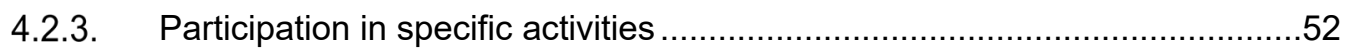

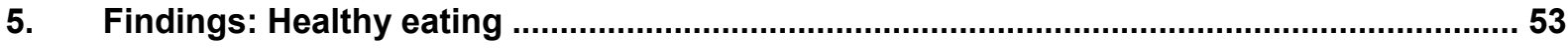

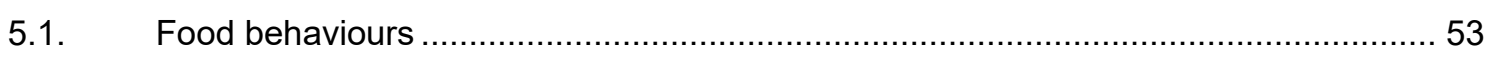

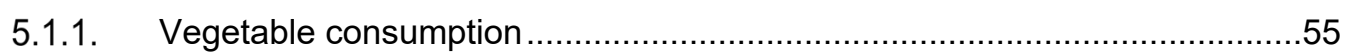

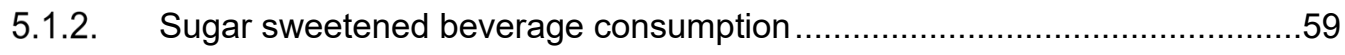

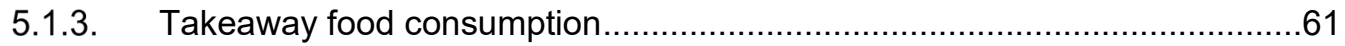

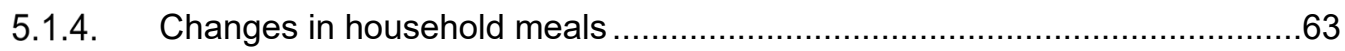

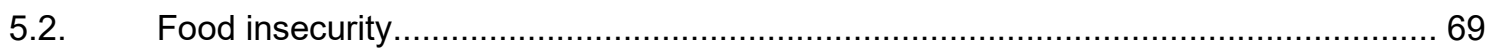

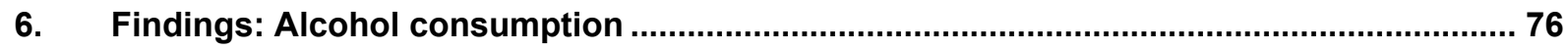

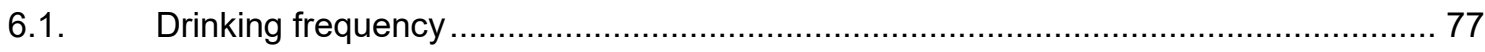

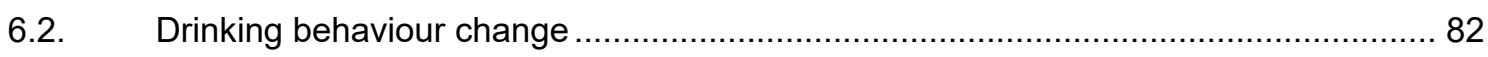

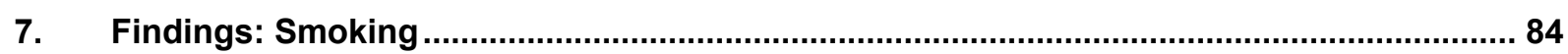

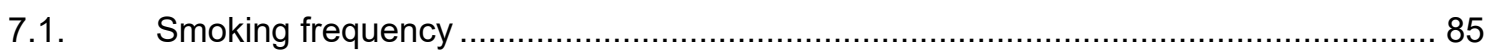

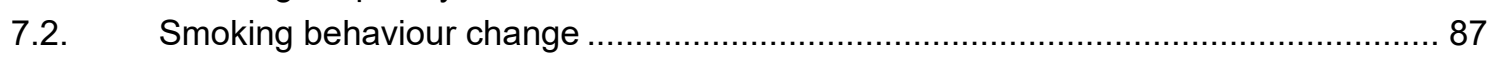

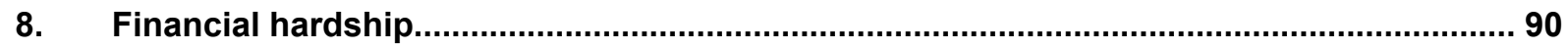

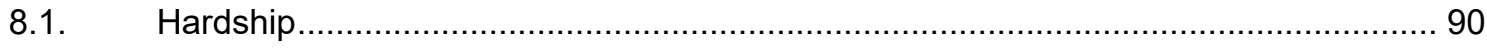

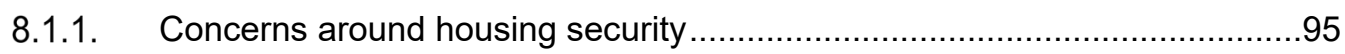

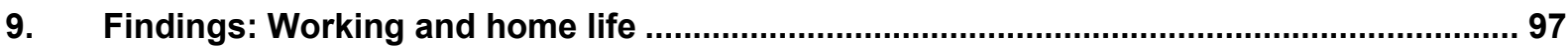

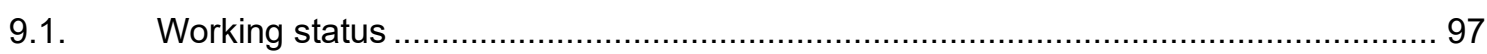

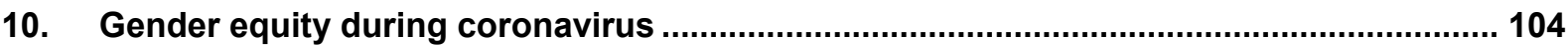

10.1. Childcare responsibilities between parents ...................................................... 104 
11. Positive impacts of the first coronavirus lockdown ................................................... 106

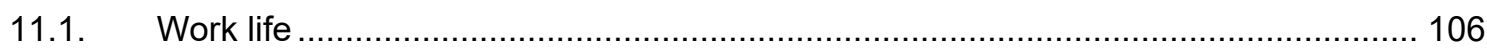

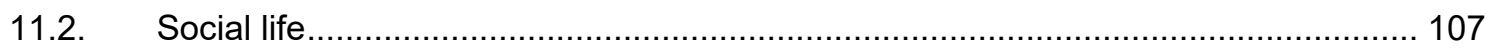

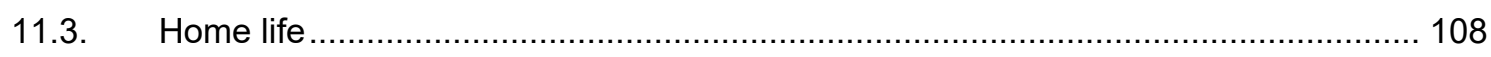

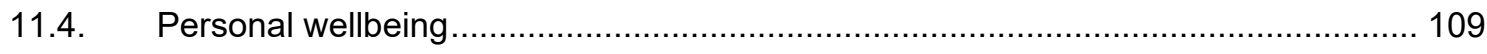

12. Key indicators: Bushfire affected area ................................................................... 110

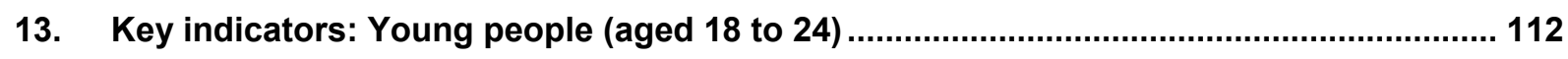

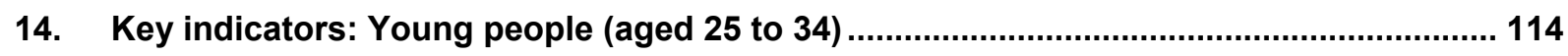

15. Key indicators: Aboriginal and Torres Strait Islander people ....................................... 116

16. Key indicators by geographic region.................................................................. 118

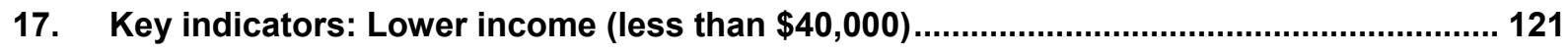

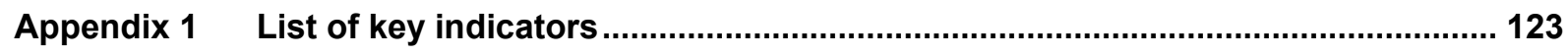

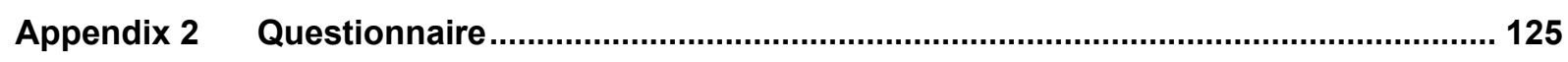

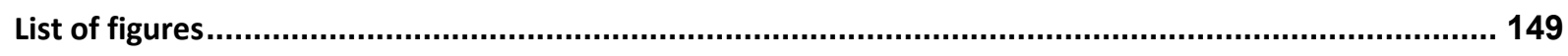

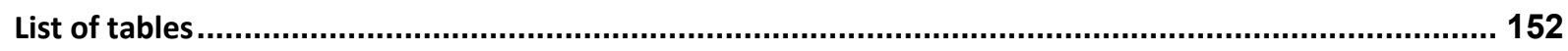




\section{Executive Summary}

\section{About this report}

VicHealth undertook a survey to understand the impact on Victorians of the first coronavirus related restrictions that took place in March-May 2020, now known as the first lockdown. A series of questions were asked covering a range of health and lifestyle areas to establish whether the lockdown had changed people's healthy lifestyles compared to life in February 2020, and to understand factors that may have influenced these changes. Variation by sociodemographics and recent experiences, such as job loss and the 2020 summer bushfires, were also examined.

The results will enable a more detailed understanding of the response required by VicHealth and its stakeholders to support the health and wellbeing of Victorians during coronavirus restrictions and beyond.

\section{Methodology}

A survey of 2,000 Victorians was conducted via a non-probability online panel. Data was calibrated with probability-based data collected by Life in Australia' ${ }^{\mathrm{TM}}$ and weighted to Australian Bureau of Statistics (ABS) population statistics to overcome some of the biases associated with data collection via non-probability panels. The average survey length was 20 minutes.

Data was analysed using IBM SPSS Survey Reporter, with demographic proportions tested against the total Victorian sample. Survey reporter uses an automated process of comparing the total survey result with a subsample result. Where it detects overlapping data, it adjusts for this (known as the overlap adjustment) to enable significance testing to be performed to establish whether the difference in the compared values (full sample vs sub-sample) is significant or not. Findings were treated as statistically significant at $p<0.05$.

Throughout this report, comparisons are made to people's subjective recollection of their healthy lifestyle experiences and behaviours in February 2020. Comparisons are also made to relevant population surveys that have used similar measures in recent years ${ }^{1}$. However, this is a reference only and absolute comparisons cannot be made due to differences in data collection and sampling methods. The comparison surveys are intended to assist understanding of the level of wellbeing and behaviour rates under 'usual' circumstances.

\section{Impact on general wellbeing}

People's general satisfaction with life appears to have declined during coronavirus lockdown restrictions. Across the measures of satisfaction with current life situation, subjective wellbeing and psychological distress, a higher proportion of respondents had less favourable outcomes than in previously conducted surveys.

- One in two (49\%) respondents reported low-medium life satisfaction (a score of 0 to 6 out of 10) during coronavirus restrictions. When asked to rate their life satisfaction pre-restrictions in February 2020 one in three (33\%) respondents reported low-medium life satisfaction.

\footnotetext{
1 VPHS 2017 -https://www2.health.vic.gov.au/public-health/population-health-systems/health-status-of-victorians/survey-data-andreports/victorian-population-health-survey/victorian-population-health-survey-2017 VHI 2015 - https://www.vichealth.vic.gov.au/media-and-resources/publications/vichealth-indicators-report-2015
} 
These results are less favourable than VPHS 2017 life satisfaction results where the rate of low-medium life satisfaction was one in five (20.5\%).

- Subjective wellbeing among respondents (65 out of 100), was lower than the 2015 comparison survey (77 out of 100$)$.

- The proportion of people experiencing high psychological distress, indicative of a serious mental health problem, was $16 \%$. Although using a different scale, the comparison survey measuring high psychological distress showed a similar result(15.4\%) in 2017.

\section{Impact on social connection}

- Two in five $(37 \%)$ agreed they felt connected to others during lockdown restrictions, down from three in five $(57 \%)$ in February 2020. Those disagreeing that they felt connected with others increased from $10 \%$ in February to $23 \%$ during lockdown.

- Social solidarity is a metric used to determine how close people feel with their communities using a combined score across six measures. The average social solidarity score for respondents was 21.2 out of a maximum of 30 , higher results being indicative of feeling more connected to others in the community.

- Three in ten respondents (30\%) reported that they had found staying connected to friends and family hard or very hard during coronavirus. One in five $(20 \%)$ living in a household with other people reported feeling that their relationship with the people they live with had become more strained due to the coronavirus lockdown restrictions.

\section{Impact on physical activity}

- The coronavirus lockdown restrictions have impacted Victorians physical activity frequency and the types of physical activity they undertook. Two in five respondents $(37 \%)$ reported that they were doing less physical activity during coronavirus lockdown restrictions, compared with February.

- The proportion of Victorians who were physically active 5 or more days a week during lookdown declined slightly from February to a level similar to a 2015 comparison survey (32\% during coronavirus restrictions, 37\% during February 2020, 30\% 2015 comparison survey).

- Similar variations were seen for those physically active one or fewer times each week $(27 \%$ during coronavirus restrictions, 20\% during February 2020, 27\% 2015 comparison survey).

- The types of physical activity undertaken during coronavirus restrictions remained similar to activities undertaken during February 2020. Walking remained the most common form of physical activity (73\% during coronavirus restrictions, $77 \%$ during February 2020). Muscle strengthening exercises at home was the next most common form of physical activity ( $29 \%$ during coronavirus restrictions, 23\% during February 2020).

\section{Impact on healthy eating}

- Overall, the food behaviours of Victorians have improved slightly during the coronavirus restrictions, however, there are some worrying trends in regard to food access and food insecurity.

- People were eating slightly more serves of vegetables than before coronavirus restrictions (2.5 serves each day during restrictions, 2.2 serves 2017 comparison survey). 
- Respondents reported lower levels of eating takeaway meals (4\% eating takeaway 3 or more times a week during coronavirus restrictions, 10\% 2015 comparison survey).

- One in three respondents reported eating takeaway food less frequently during the lockdown $(34 \%)$ and a similar proportion reported that they were cooking dinner more frequently (28\%).

- The proportion of respondents who reported drinking sugar sweetened beverages daily was $32 \%$, a much higher proportion than a 2017 comparison survey $(10.1 \%)$.

- $7 \%$ of respondents stated they ran out of food and couldn't afford to buy more during lockdown, compared to a 2014 comparison survey result of $4 \%$.

- One in four $(23 \%)$ reported that they had relied on low-cost unhealthy food because of financial concerns during the lockdown, a higher proportion than a 2014 comparison survey result of $13 \%$.

\section{Impact on alcohol consumption}

- Consumption of alcohol consistent with levels defined as causing short term harm (more than 4 drinks in a session at least weekly) was largely unchanged due to coronavirus restrictions (11\%) compared to a 2017 comparison survey (11.5\%).

- The proportion of those consuming at 3 or more standard drinks of alcohol at least 5 days a week which is consistent with long term harm also was $7 \%$.

\section{Impact on smoking}

- The proportion of respondents who smoked daily was $12 \%$ which is consistent with the 2017 comparison survey $(12.4 \%)$.

- The restrictions may have been a catalyst to stop smoking for some, with $13 \%$ of smokers $(n=424)$ attempting to quit and $7 \%$ reporting they were successful in quitting.

\section{Parenting responsibilities during coronavirus}

- Among female respondents, the majority indicated they were the spending the most time helping their child with school at home $(72 \%)$, compared to only one in four male respondents who indicated they were spending the most time helping with homeschool (26\%).

\section{Impact on financial hardship and employment}

- One in four respondents $(24 \%)$ reported experiencing some form of hardship during the first lockdown. This is higher than the proportion who reported experiencing hardship during February 2020 (16\%).

- The most common forms of financial hardship during the first Victorian coronavirus lockdown were being worried about not having enough money to buy food $(17 \%)$ and asking friends or family for financial help (12\%).

- Concerns for the future were also common, three in ten respondents $(29 \%)$ were concerned about their future employment prospects and one in five (19\%) concerned about the stability of their housing situation. 


\section{Positive impacts of coronavirus lockdown}

- Two in five (44\%) respondents indicated that there were positive aspects of the coronavirus period that they would like to maintain after restrictions stopped. The most common responses were:

- Work life

○ $25 \%$ working from home

○ $10 \%$ flexible work hours.

- Social life

- $17 \%$ staying in touch with people through technology (e.g. Zoom, FaceTime).

- $11 \%$ socialise more, have more contact with people.

- Home life

- $26 \%$ spending time with family and friends

$\circ \quad 12 \%$ gardening.

- Personal wellbeing

- $25 \%$ keep exercising

- $8 \%$ maintain a healthy lifestyle.

\section{Impacts on sub-populations}

The coronavirus pandemic has impacted us all - but in terms of health and wellbeing, some Victorians have been impacted more than others. It's critical we ensure those who need the greatest support are at the centre of our recovery efforts.

- Amongst young people aged 18-24 years, daily consumption of sugary drinks (50\%) and risk of short term harm from alcohol (17\%) were amongst the highest in the state. Around a quarter $(26 \%)$ of young women lost their job during the first lockdown, compared to $11 \%$ of young men of the same age group. This age group report higher rates of strengthening of relationships with others in their household during the first lockdown $(30 \%)$ compared to Victorians overall (21\%), but also has the highest rate of high psychological distress $(23 \%)$ compared to all other age groups.

- Respondents living in areas impacted by the 2019/2020 Victorian bushfires have the highest rate of psychological distress $(41 \%)$ of all sub-populations examined. Daily consumption of sugary drinks (55\%), risk of short term (33\%) and long term (19\%) alcohol harm, running out of food and being unable to afford more (28\%), and financial hardship $(47 \%)$ are also all significantly higher than the state rate. However, they have amongst the highest rates of perceived community connection with an average social solidarity score 23.2 out of 30 .

- Aboriginal or Torres Strait Islanders were experiencing higher rates of high psychological distress $(28 \%)$, financial hardship $(74 \%)$, risk of short term harm from alcohol $(48 \%)$, daily sugary drink consumption ( $80 \%$ ) and running out of food and unable to afford more $(46 \%)$ than Victoria overall, but very favourable rates of sufficient physical activity $(38 \%)$, daily serves of vegetables (3.0) and relatively low rates of daily smoking (9\%). It is important to 
note that these results have not been analysed for statistically significant difference to results for Victorians overall due to the lower number of respondents in this group $(n=61)$.

- Of all Victorian geographic regions, inner metro council areas had higher rates food insecurity such as running out of food (12\%) and financial hardship (36\%), as well as daily sugary drink consumption ( $42 \%)$ and risk of short term harm from alcohol $(17 \%)$, but the most favourable results for physical activity. Outer metro and regional cities had less favourable results for social connection. Interface council areas (those between metro and rural areas e.g. Melton, Yarra Ranges) had the lowest rates of meeting vegetable guidelines $(4 \%)$ and were more likely to rely on a low-cost unhealthy food due to money shortage (29\%). Inner metro areas had significantly higher rates of high psychological distress (24\%) compared to the Victorian rate $(16 \%)$ whereas regional city rates were significantly lower $(10 \%)$.

- Low-income earners (less than $\$ 40,000 /$ year) had amongst the highest rates for lowmedium life satisfaction $(58 \%)$, disagreeing that they feel connected with others $(30 \%)$ as well as low rates of subjective wellbeing (61.4). 


\section{Methodology}

\subsection{Survey methodology}

The VicHealth Coronavirus Victorian Wellbeing Impact Survey was conducted via an opt-in 'research only' online panel. The in-scope population for the survey was Victorian residents who were 18 years and over. The survey commenced 31 May 2020 and concluded 8 June 2020.

The in-scope population for the survey was Victorians adults (aged 18 years or over). The total achieved sample size was $n=2,000$.

A summary of the final achieved sample profile is provided in the table below.

Table 1 Sample profile

\begin{tabular}{|c|c|c|c|}
\hline \multicolumn{2}{|c|}{ Demographic characteristic } & $\begin{array}{l}\text { Unweighted } \\
(n=2,000)\end{array}$ & $\begin{array}{l}\text { Weighted }^{2} \\
(n=2,000)\end{array}$ \\
\hline \multirow{2}{*}{ Gender } & Male & $45.6 \%$ & $49.2 \%$ \\
\hline & Female & $54.4 \%$ & $50.8 \%$ \\
\hline \multirow{7}{*}{ Age groups } & 18-24 years & $12.8 \%$ & $12.4 \%$ \\
\hline & $25-34$ years & $14.8 \%$ & $20.1 \%$ \\
\hline & $35-44$ years & $19.0 \%$ & $17.5 \%$ \\
\hline & $45-54$ years & $19.6 \%$ & $16.1 \%$ \\
\hline & $55-64$ years & $18.1 \%$ & $14.2 \%$ \\
\hline & $65-74$ years & $11.9 \%$ & $14.5 \%$ \\
\hline & $75+$ years & $3.9 \%$ & $5.2 \%$ \\
\hline \multirow{2}{*}{ Location } & Capital city & $77.0 \%$ & $76.2 \%$ \\
\hline & Rest of state & $23.1 \%$ & $23.8 \%$ \\
\hline
\end{tabular}

The opt-in panel used for the survey was LiveTribe, a research only panel operated and managed by i-Link Research. LiveTribe panellists are recruited via a blend of print media, online marketing initiatives, direct mail, social media platforms, affiliate partnerships, personal invitations and a range of other ad hoc initiatives. Respondents of the survey received a nominal incentive for their participation in line with panel guidelines.

The 20-minute survey questionnaire was developed by VicHealth in consultation with the Social Research Centre. The broad areas included in the questionnaire were:

- general wellbeing

- physical activity

- connecting with others

\footnotetext{
${ }^{2}$ See section 2.3 for details of the weighting process 
- healthy eating

- alcohol and smoking behaviours

- working and home life during the first lockdown

- sociodemographics and other covariates.

Different question styles were used to minimise respondent fatigue and enhance engagement with the survey. Examples include the use of Likert scales, closed ended questions and open-ended questions. Current guidelines were followed to ensures questions were as user-friendly as possible for respondents, regardless of which device is used to access the survey, for example mobile phones, tablets, desktops or laptops. The key indicators and associated scoring method are summarised in Appendix 1 and the survey questionnaire is appended in Appendix 2.

Ethics approval for this study was provided by the Australian National University Human Research Ethics Committee (2020/264) on 20 May 2020. 


\subsection{Participant profile*}
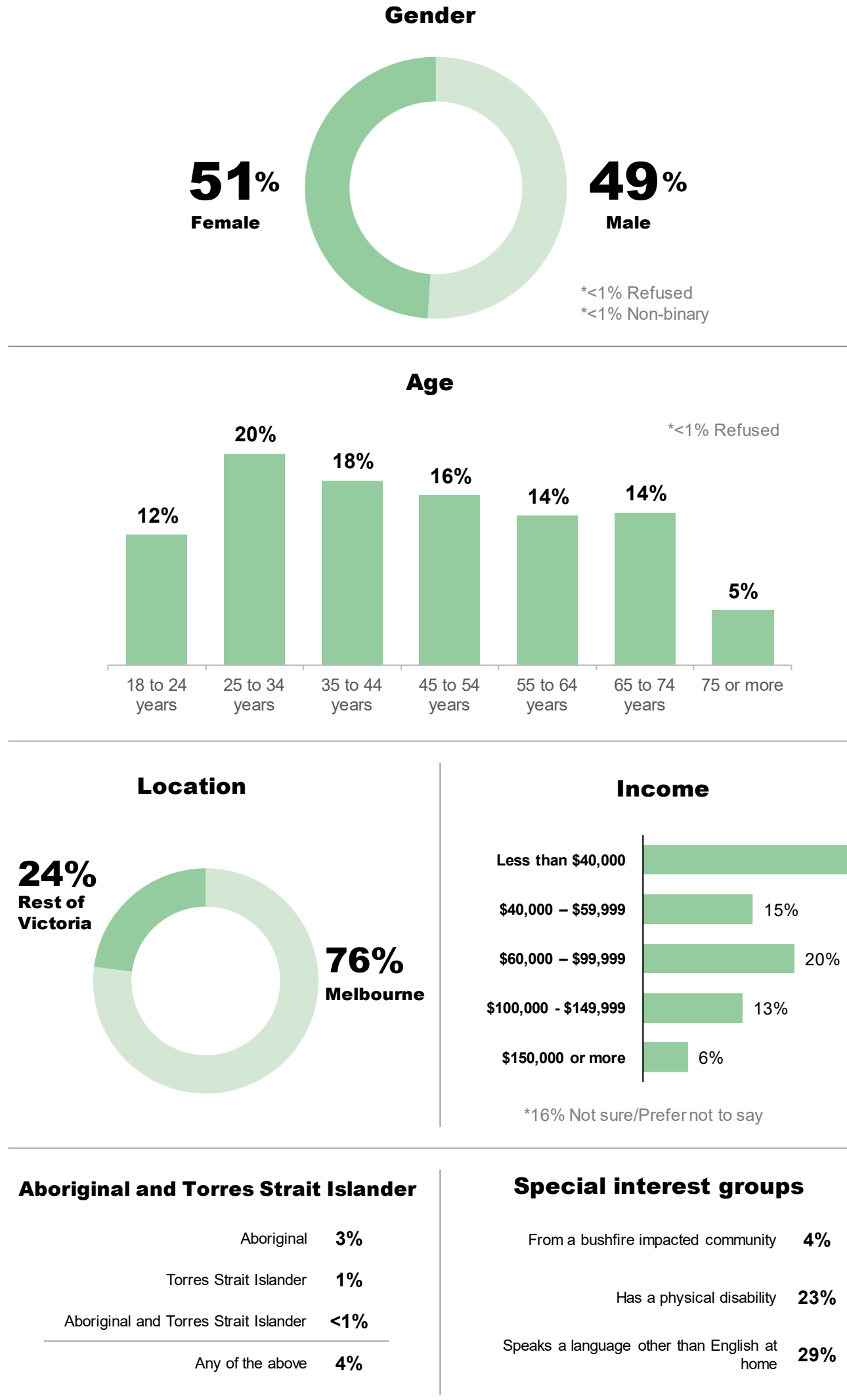

*weighted results 


\subsection{Weighting}

\subsubsection{Overview}

Unlike a probability survey, the selection mechanism for a non-probability survey is unknown. Therefore, it is not possible to calculate selection probabilities for use in making statistical inferences about the population. To address this issue, we have used a super-population approach to derive weights for each respondent in the non-probability sample. Population distributions for demographic characteristics were obtained from the Australian Bureau of Statistics, and those for lifestyle characteristics and key survey outcomes were obtained from Life in Australia ${ }^{\mathrm{TM}}$.

Super-population models fit models to the non-probability survey's analytic variables and projects these to the full population ${ }^{3}$. By including variables in the models that are correlated with the survey outcomes and for which population distributions are known, it is possible to calculate weights that align the non-probability more closely to the population of interest.

\subsubsection{Super-population weights}

Given the number of covariates available in the dataset, many different combinations were trialled in an effort to align the non-probability sample as closely as possible to the population of Victorian adults. To identify the "optimal" combination, the following steps were repeated many thousands of times 4 :

1. Randomly select a set of adjustment characteristics ${ }^{5}$.

2. Calculate weights so that they reflect the population distributions for the selected set of characteristics.

3. Calculate weighted estimates for the remaining ${ }^{6}$ characteristics.

4. Calculate the bias for each characteristic as the difference between the weighted estimate and its population value. Benchmark values were obtained from the Australian Bureau of Statistics for demographic characteristics and from Life in Australia ${ }^{\top \mathrm{m}}$ for all other variables. For each variable, the modal category (that with the highest estimated proportion) was used, following Yeager et al. (2011) ${ }^{7}$.

5. Find the average absolute bias across each characteristic type (demographic, lifestyle and outcome).

The optimal weighting solution was the one yielding a low average absolute bias (primary consideration) along with an acceptable level of variation ${ }^{8}$ in the weights.

\footnotetext{
${ }^{3}$ Valliant, R. (2019). Comparing alternatives for estimation from nonprobability samples. Journal of Survey Statistics and Methodology, 8(2), 31-263. doi.org/10.1093/jssam/smz003.

${ }^{4}$ The steps listed here were repeated for more than 50,000 random selections of adjustment variables.

${ }^{5}$ Between one and six characteristics were chosen at random, the upper value being set to restrict the extent of variance introduced through weighting. In principle, weighting by all available characteristics would produce the least biased weights, but these would be severely impacted by instability and variability.

${ }^{6}$ Variables used for adjustment were excluded from the bias assessment. For instance, if age and education were used for weighting, these variables were excluded from the bias assessment since their estimated bias would be zero.

${ }^{7}$ Yeager, D.S., J.A. Krosnick, L. Chang, H.S. Javitz, M.S. Levendusky, A. Simpser, and R. Wang (2011). Comparing the accuracy of RDD telephone surveys and internet surveys conducted with probability and non-probability samples. Public Opinion Quarterly 75(4), $709-747$. ${ }^{8}$ Defined here as the weighting efficiency (Kish, 1965; Kish, 1992), which varies from $0 \%$ to $100 \%$. If the base weights for many respondents need to be adjusted heavily, the efficiency will be low. The greater the percentage the more balanced is the sample, where higher efficiency is better. Kish, L. (1965) Survey Sampling, New York: Wiley. Kish, L. (1992) Weighting for unequal Pi. Journal of Official Statistics 8(2), 183-200.
} 
As the weighting solutions become more complex, the average bias across variable types improves (tends towards zero) but this is offset by declining weighting efficiency. The final adopted solution reduced the average bias by more than $50 \%$ compared to the unweighted solution, while still achieving an acceptable level of variability in the weights. The population characteristics corresponding to the final set of adjustment characteristics is shown in Table 2.

Table 2 Variables used for calculating final weights for the non-probability sample, with population distributions and data sources

\begin{tabular}{|c|c|c|c|c|c|}
\hline Category & $\begin{array}{c}\text { Benchmark } \\
\text { target (\#) }\end{array}$ & $\begin{array}{c}\text { Benchmark } \\
\text { target }(\%)\end{array}$ & $\begin{array}{l}\text { Sample } \\
(\#)\end{array}$ & $\begin{array}{l}\text { Unweighted } \\
(\%)\end{array}$ & $\begin{array}{l}\text { Weighted } \\
(\%)\end{array}$ \\
\hline \multicolumn{6}{|l|}{ Qs2 - Age (A) } \\
\hline 18-24 years & 653,256 & 12.62 & 260 & 13.00 & 12.62 \\
\hline 25-34 years & $1,053,306$ & 20.35 & 297 & 14.85 & 20.35 \\
\hline $35-44$ years & 894,432 & 17.28 & 379 & 18.95 & 17.28 \\
\hline $45-54$ years & 824,507 & 15.93 & 390 & 19.50 & 15.93 \\
\hline $55-64$ years & 732,468 & 14.15 & 359 & 17.95 & 14.15 \\
\hline $65+$ years & $1,018,572$ & 19.68 & 315 & 15.75 & 19.68 \\
\hline \multicolumn{6}{|l|}{$\begin{array}{l}\text { Qs12 - highest post-school educational } \\
\text { qualification that you have obtained? }(\mathrm{A})\end{array}$} \\
\hline Bachelor degree or higher & $1,459,567$ & 28.20 & 836 & 41.80 & 28.20 \\
\hline Less than Bachelor degree & $3,716,974$ & 71.80 & 1,164 & 58.20 & 71.80 \\
\hline \multicolumn{6}{|l|}{ Qs1 - Gender (A) } \\
\hline Male & $2,537,502$ & 49.02 & 910 & 45.50 & 49.02 \\
\hline Female & $2,639,039$ & 50.98 & 1,084 & 54.50 & 50.98 \\
\hline \multicolumn{6}{|l|}{ Qs6 - housing situation? (A) } \\
\hline Own outright & $1,790,909$ & 34.60 & 624 & 31.20 & 34.60 \\
\hline Own with a mortgage & $1,980,898$ & 38.27 & 631 & 31.55 & 38.27 \\
\hline Other & $1,404,735$ & 27.14 & 745 & 37.25 & 27.14 \\
\hline \multicolumn{6}{|l|}{ Qs10 - language $(A)$} \\
\hline $\begin{array}{l}\text { Speaks a language other than English at } \\
\text { home }\end{array}$ & $1,495,861$ & 28.90 & 371 & 18.55 & 28.90 \\
\hline Speaks only English at home & $3,680,680$ & 71.10 & 1,629 & 81.45 & 71.10 \\
\hline \multicolumn{6}{|c|}{$\begin{array}{l}\text { Qg6 - Required to take paid leave - have you } \\
\text { experienced any of the following? (B) }\end{array}$} \\
\hline Yes & 305,995 & 5.91 & 173 & 8.65 & 5.91 \\
\hline No & $1,569,251$ & 30.31 & 980 & 49.00 & 30.31 \\
\hline Not applicable & $3,301,295$ & 63.77 & 847 & 42.35 & 63.77 \\
\hline
\end{tabular}

Sources:

(A) ABS Table Builder Census 2016 and ABS Australian Demographic Statistics September 2019

(B) Life in Australia ${ }^{\mathrm{TM}}$ 


\subsection{Analysis}

Significance testing of differences between sub-population groups and the Victorian rate or average has been conducted on survey results presented in this report using t-tests using Survey Reporter which is a derivative of IBM SPSS Statistics 10.

It allows for an automated process of comparing the total survey result with a subsample result. Where it detects overlapping data, it adjusts for this (known as the overlap adjustment) to enable a t-test to be performed to establish whether the difference in the full sample value and the sub-sample value is significant or not. The key indicators used in the analysis and the associated derived variables are summarised in Appendix 1.

Differences that have a p-value of 0.05 or below are shown. This means there is a $95 \%$ confidence that the differences presented are due to actual findings and not random chance. Chart legends indicate significant differences.

Where possible, results related to survey questions, also known as indicators, are compared to responses to the same or similar questions that have been used in previous Victorian population surveys to gain insights into change in healthy lifestyle indicators over time (see Apeendix 1). However, this is a reference only and absolute comparisons cannot be made due to differences in data collection and sampling methods.

The comparison surveys are intended to assist understanding of the level of wellbeing and behaviour rates are under usual circumstances.

The most recent sources available for each indicator are used and include either the 2017 Victorian Population Health Survey (2017 comparison survey) $)^{9}$, the 2015 VicHealth Indicators Survey (2015 comparison survey) $)^{10}$ or the 2014 Victorian Population Health Survey (2014 comparison survey) ${ }^{11}$, No significance testing has been conducted with results from these comparison surveys.

\footnotetext{
9 VPHS 2017 -https://www2.health.vic.gov.au/public-health/population-health-systems/health-status-of-victorians/survey-data-andreports/victorian-population-health-survey/victorian-population-health-survey-2017

10 VHI 2015 - https://www.vichealth.vic.gov.au/media-and-resources/publications/vichealth-indicators-report-2015

11 VPHS 2014 - https://www2.health.vic.gov.au/public-health/population-health-systems/health-status-of-victorians/survey-data-and-reports/victorianpopulation-health-survey/victorian-population-health-survey-2014
} 


\section{GENERAL WELLBEING}

Vichealth

VicHealth Coronavirus Victorian Wellbeing Impact Study

A comprehensive survey of 2,000 Victorians in the first coronavirus lockdown of 2020 showed high psychological distress and lower levels of life satisfaction.

1 in 6 Victorians experienced high psychological distress in the first lockdown
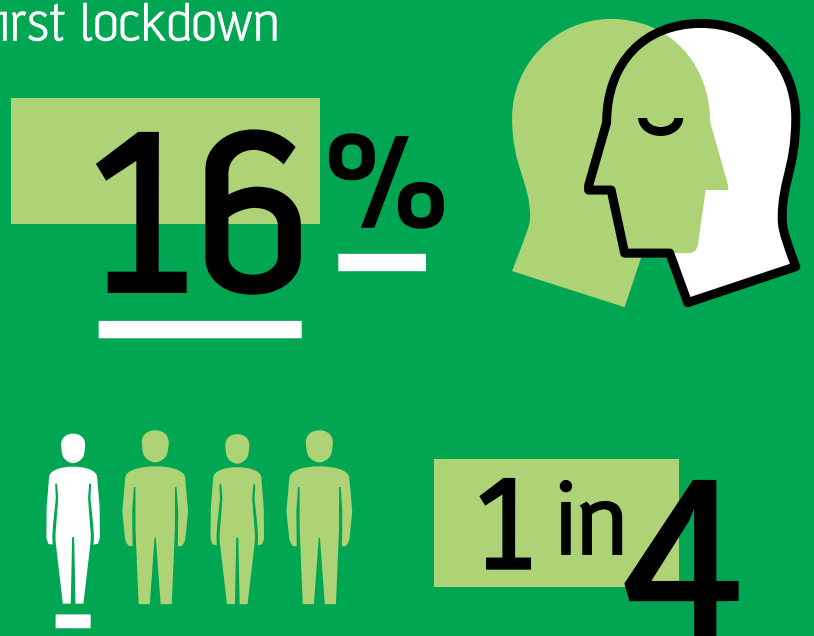

1 in 4 young Victorians

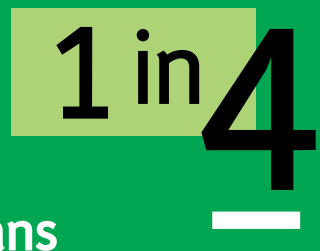

experienced high psychological distress

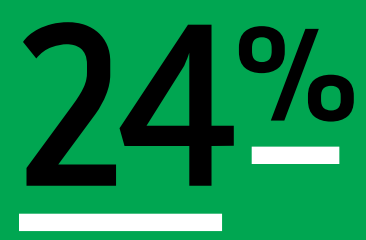

of Victorians in inner

metro areas experienced

high psychological

distress compared to $10 \%$ in regional cities

4 in 10 of those from bushfire affected communities experienced high psychological distress
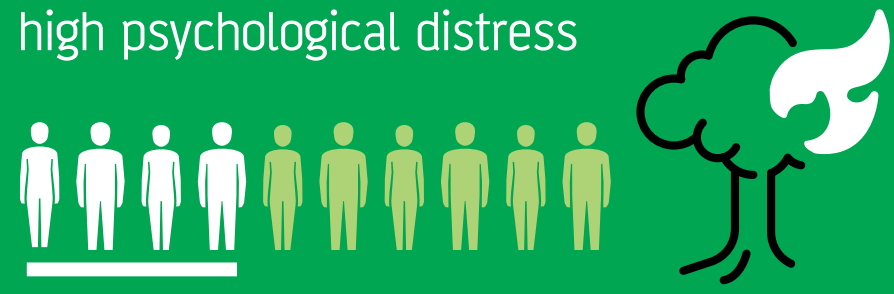
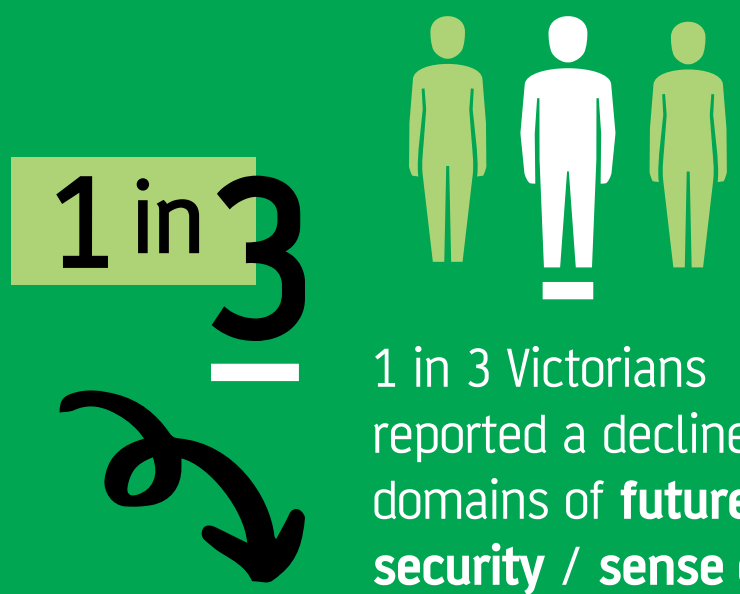

1 in 3 Victorians reported a decline in domains of future security / sense of safety

Nearly half of Victorians had lower levels of life satisfaction compared to 1 in 5 in 2017

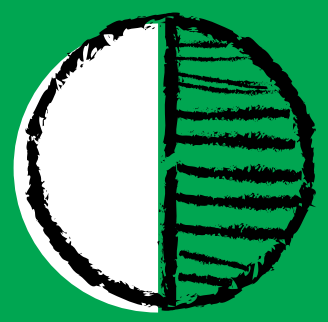

Other Victorians facing wellbeing impact People with a disability

$29 \%$ high psychological

$62 \%$ low-medium

People on JobSeeker*

$26 \%$ high psychological $58 \%$ low-medium

Aboriginal \& Torres Strait Islander people

$28 \%$ high psychological $70 \%$ low-medium

20 distress life satisfaction

*Similar rates for JobKeeper 


\section{Findings: General wellbeing}

To measure the general wellbeing impacts of the coronavirus lockdown period, survey respondents were asked questions related to their overall life satisfaction, subjective wellbeing and level of psychological distress.

\section{General wellbeing}

\section{Impact on general wellbeing}

People's general wellbeing appears to have declined during coronavirus lockdown restrictions across the measures of satisfaction with current life situation, subjective wellbeing and psychological distress when compared to earlier surveys.

- One in two $(49 \%)$ respondents had low-medium life satisfaction during coronavirus restrictions, compared to one in three (33\%) in February 2020 . These results are less favourable than a 2017 comparison survey where one in five $(20.5 \%)$ reported low to medium levels of life satisfaction.

- The subjective wellbeing score among respondents (65.0), was lower than the 2015 comparison survey (77.3). Previous measures of Victorians using this Index in 2007 (76.6) and 2011 (77.5) indicate that this measure has previously remained fairly stable over time, until this year.

- The proportion of people experiencing high psychological distress was $16 \%$ with a similar result found in the 2017 comparison survey at $15.4 \%$.

\section{Factors influencing these changes}

- One in three respondents reported a decline in satisfaction in the following subjective wellbeing domains during coronavirus restrictions:

○ their future security $(36 \%)$

○ what they were currently achieving (33\%)

○ their standard of living (33\%)

$\circ \quad$ their sense of safety $(31 \%)$

- their connection with the community $(30 \%)$.

- Of the psychological distress indicators measured, the largest increases were seen in the number of people feeling more nervous $(31 \%)$ and more restless $(24 \%)$.

\section{Variation by subgroups}

Impacts of coronavirus restrictions on respondents showed significant variation by sociodemographic subgroups.

- Less favourable results were seen across all three measures for:

- Aboriginal and Torres Strait Islanders $(70 \%$ low-medium rating of life satisfaction, 60.9 Personal Wellbeing Index score, $28 \%$ high psychological distress) *(Note: significance testing was limited for this group due to small base sizes) 
○ those with a self-reported disability (62\% low-medium rating of life satisfaction, 59.1 Personal Wellbeing Index score, 29\% high psychological distress).

- Life satisfaction and subjective wellbeing levels were less favourable than the Victorian level amongst unemployed people, people earning less than $\$ 40,000$, and single parents.

- Younger Victorians aged 18-24 years had the highest rate of high psychological distress $(23 \%)$ of all age groups. High psychological distress was also more common among those living in inner metro Melbourne (24\%), those speaking a language other than English at home $(25 \%)$, unemployed persons $(27 \%)$, people from bushfire affected areas $(41 \%)$ and those eligible for JobKeeper $(27 \%)$ or JobSeeker $(26 \%)$.

- Those living outside of metropolitan Melbourne (11\%), and in particular regional cities $(10 \%)$, were less likely to be experiencing high psychological distress, as were people from households with incomes of $\$ 100,000$ to $\$ 149,999$ (10\%) or $\$ 150,000$ or more (9\%).

\begin{tabular}{|l|c|c|}
\hline Key Indicator & COVID-19 Survey Result & Comparison Survey Result \\
\hline $\begin{array}{l}\text { Low-Medium Life Satisfaction } \\
\text { (rating 0 to 6 out of 10) }\end{array}$ & $49 \%$ & $\mathbf{2 0 . 5 \%}(2017)$ \\
\hline $\begin{array}{l}\text { Personal Wellbeing Index } \\
\text { (rating out of 100) }\end{array}$ & 65.0 & $\mathbf{7 7 . 3}(2015)$ \\
\hline $\begin{array}{l}\text { Psychological Distress* } \\
\text { (probable mental health issue) }\end{array}$ & $16 \%$ & $\mathbf{1 5 . 4 \% ( 2 0 1 7 )}$ \\
\hline
\end{tabular}

*Note: VicHealth Coronavirus Victorian Wellbeing Impact Study results collected using the Kessler 6 scale and VPHS use the Kessler 10 scale

VPHS 2017 - https://www2.health.vic.gov.au/public-health/population-health-systems/health-status-of-victorians/survey-data-andreports/victorian-population-health-survey/victorian-population-health-survey-2017

VHI 2015 - https://www.vichealth.vic.gov.au/media-and-resources/publications/vichealth-indicators-report-2015 


\subsection{Life satisfaction}

To get a measure of overall life satisfaction among Victorian respondents during the first lockdown, respondents were asked to rate their satisfaction with their life as a whole, on a scale of 0 (completely dissatisfied) to 10 (completely satisfied). They were also asked to provide a rating of their life satisfaction during February 2020 using the same scale. A score of 6 or lower was determined to be low-medium life satisfaction in line with definitions used in the Victorian Population Health Survey.

One in two Victorians (49\%) had low-medium (0 to 6 ) satisfaction with their life situation during coronavirus restrictions. This is higher than the one in three respondents $(33 \%)$ providing a lowmedium (0 to 6 ) life satisfaction rating in February 2020.

Figure 1 Satisfaction with life as a whole

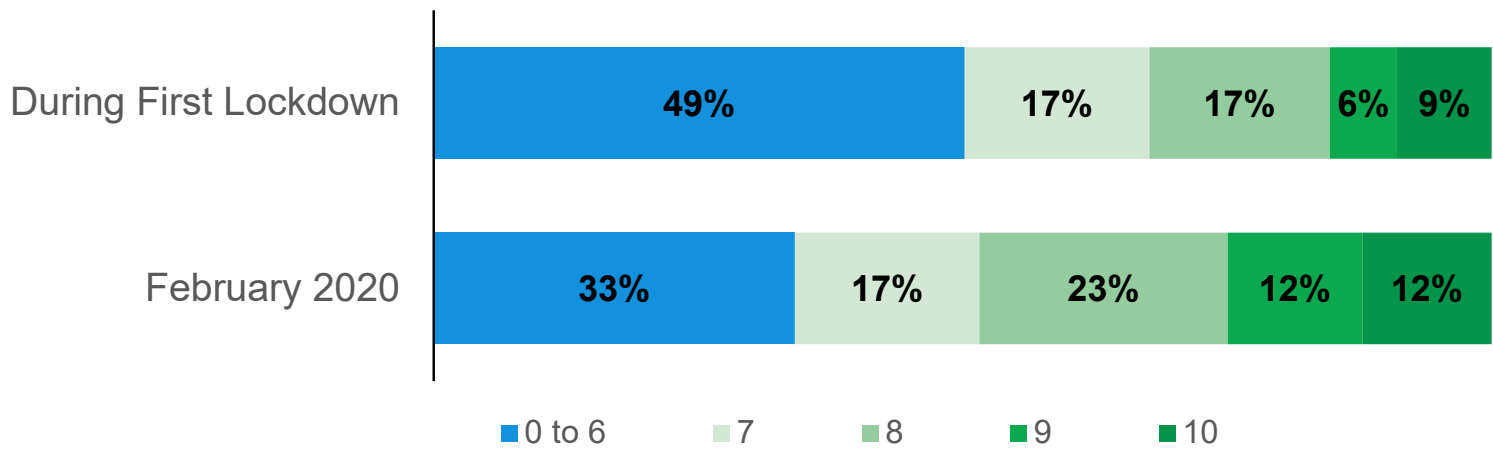

A1W Thinking about your own life and your personal circumstances, how satisfied are you with your life as a whole? Please use a scale from $0-10$, where 0 is completely dissatisfied and 10 is completely satisfied.

Base: $\quad$ All $(n=2,000)$

Note: $\quad$ Not shown; not sure $(2 \%, 2 \%)$, prefer not to say $(1 \%, 1 \%)$

The following figures show subgroup differences of those who provided a low-medium rating ( 0 to 6 out of 10) for their life satisfaction during the first coronavirus lockdown and during February 2020. 
Figure 2 Low-medium life satisfaction - Victorian and sub-population frequencies during first lockdown Note: Responses that are significantly more favourable than the Victorian overall result are on the right, highlighted in green. Responses that are significantly less favourable than the Victorian overall result are on the left, highlighted in blue.

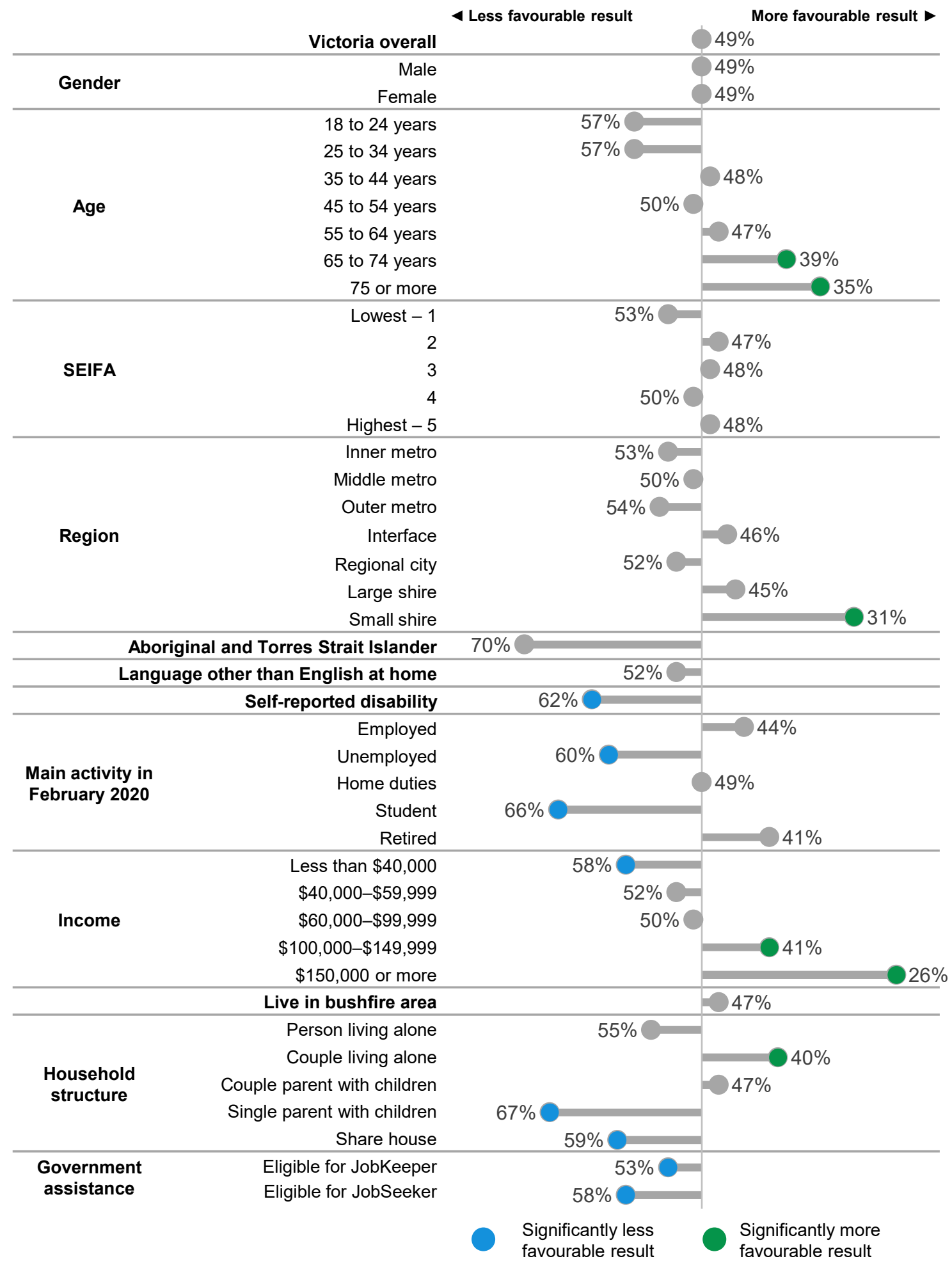

A1W Thinking about your own life and your personal circumstances, how satisfied are you with your life as a whole? Please use a scale from $0-10$, where 0 is completely dissatisfied and 10 is completely satisfied.

Base: $\quad$ All $(n=2,000)$

Note: $\quad$ Results for some subgroups are higher than others and not significantly different to the overall results due to small base sizes. 
Figure 3 Low-medium life satisfaction - Victorian and sub-population frequencies during February 2020 Note: Responses that are significantly more favourable than the Victorian overall result are on the right, highlighted in green. Responses that are significantly less favourable than the Victorian overall result are on the left, highlighted in blue.

\begin{tabular}{|c|c|c|c|}
\hline & & 4 Less favourable result & More favourable result - \\
\hline & Victoria overall & & \\
\hline Gonder & Male & & \\
\hline Getiat & Female & $35 \%$ & \\
\hline & 18 to 24 years & $35 \% \mathrm{C}$ & \\
\hline & 25 to 34 years & $35 \%$ & \\
\hline & 35 to 44 years & $34 \%$ & \\
\hline Age & 45 to 54 years & $37 \%$ & \\
\hline & 55 to 64 years & & \\
\hline & 65 to 74 years & & $22 \%$ \\
\hline & 75 or more & & $25 \%$ \\
\hline & Lowest - 1 & $35 \%$ & \\
\hline & 2 & & \\
\hline SEIFA & 3 & & \\
\hline & 4 & $37 \%$ & \\
\hline & Highest -5 & & $7 \%$ \\
\hline & Inner metro & $36 \%$ & \\
\hline & Middle metro & & \\
\hline & Outer metro & $38 \%$ & \\
\hline Region & Interface & & \\
\hline & Regional city & & \\
\hline & Large shire & & \\
\hline & Small shire & $35 \% \bigcirc$ & \\
\hline Abo & and Torres Strait Islander & $47 \%$ & \\
\hline Lang & ther than English at home & $34 \%$ & \\
\hline & Self-reported disability & $45 \%$ & \\
\hline & Employed & & \\
\hline & Unemployed & $43 \%$ & \\
\hline February 2020 & Home duties & & \\
\hline & Student & & \\
\hline & Retired & & $26 \%$ \\
\hline & Less than $\$ 40,000$ & $44 \%$ & \\
\hline & $\$ 40,000-\$ 59,999$ & $34 \%$ & \\
\hline Income & $\$ 60,000-\$ 99,999$ & & \\
\hline & $\$ 100,000-\$ 149,999$ & & $24 \%$ \\
\hline & $\$ 150,000$ or more & & $13 \%$ \\
\hline & Live in bushfire area & $39 \% \bigcirc$ & \\
\hline & Person living alone & $43 \% \bigcirc$ & \\
\hline Houcohold & Couple living alone & & $24 \%$ \\
\hline structure & Couple parent with children & & \\
\hline & Single parent with children & $44 \%$ & \\
\hline & Share house & $37 \%$ & \\
\hline Government & Eligible for JobKeeper & $34 \%$ & \\
\hline assistance & Eligible for JobSeeker & $43 \%$ & \\
\hline & & $\begin{array}{l}\text { Significantly less } \\
\text { favourable result }\end{array}$ & $\begin{array}{l}\text { Significantly more } \\
\text { favourable result }\end{array}$ \\
\hline
\end{tabular}

A1W Thinking about your own life and your personal circumstances, how satisfied are you with your life as a whole? Please use a scale from $0-10$, where 0 is completely dissatisfied and 10 is completely satisfied.

Base: $\quad$ All $(n=2,000)$

Note: Results for some subgroups are higher than others and not significantly different to the overall results due to small base sizes. 
Figure 4 Low-medium life satisfaction - Victorian and sub-population frequencies - comparison of first lockdown to February 2020

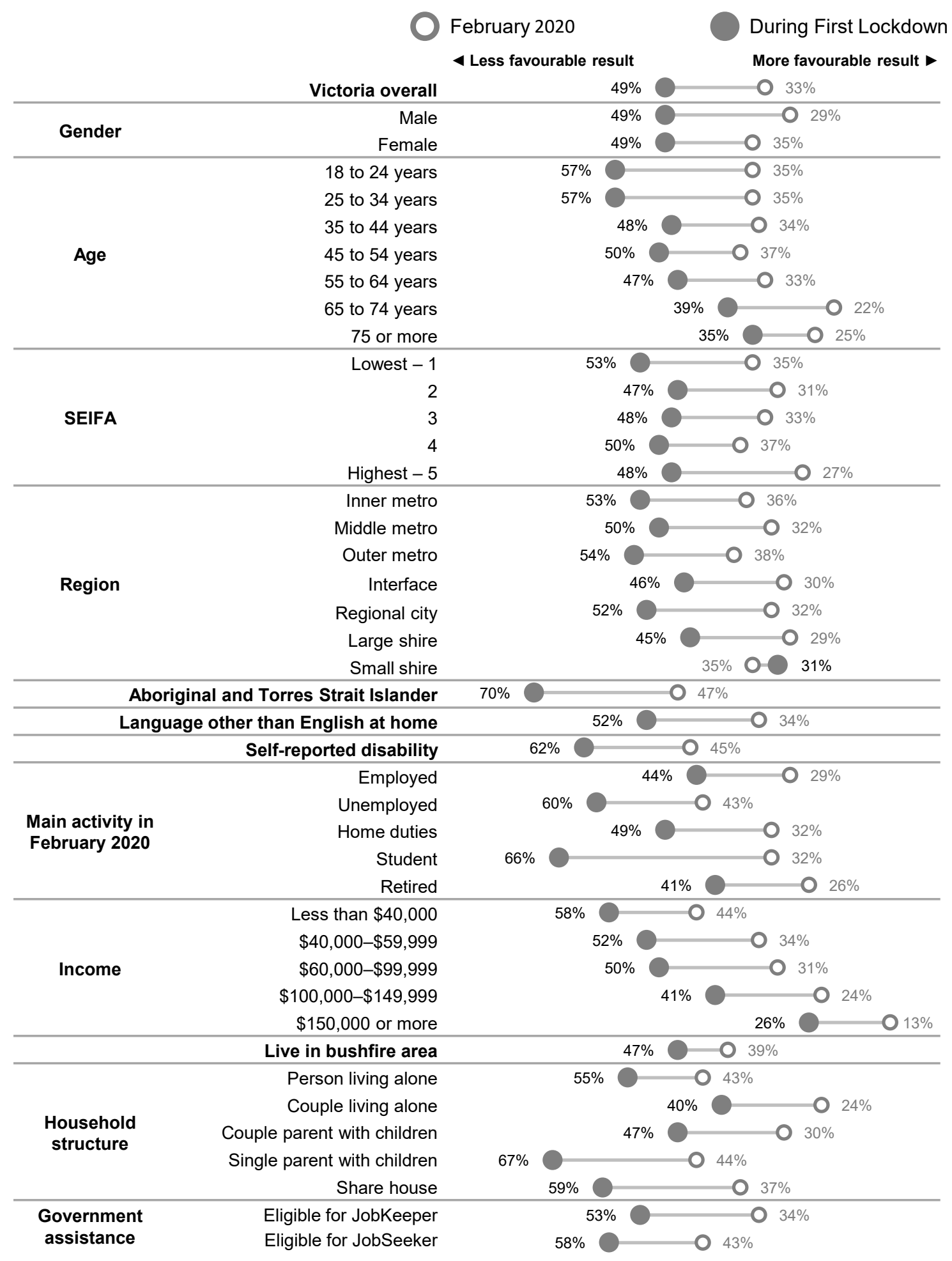

\footnotetext{
A1W Thinking about your own life and your personal circumstances, how satisfied are you with your life as a whole? Please use a scale from $0-10$, where 0 is completely dissatisfied and 10 is completely satisfied.

Base: $\quad$ All $(n=2,000 ; n=2,000)$
} 


\subsection{Subjective well being}

The Personal Wellbeing Index ${ }^{12}$ was used as a measure of subjective wellbeing. Respondents were asked to rate their satisfaction with a variety of life aspects that divide life satisfaction into seven domains. Response options were on a scale of 0 (completely dissatisfied) to 10 (completely satisfied).

On average, Victorians were most satisfied with their health, their personal relationships and their standard of living. Lower average scores were observed for Victorians in their ratings for their future security and their sense of community.

Figure 5 Satisfaction with aspects of life

How satisfied are you with ...? (score out of 10 , higher is better)

\begin{tabular}{|c|c|c|}
\hline Your health & & 6. \\
\hline Your personal relationships & & 6.8 \\
\hline Your standard of living & & 6.8 \\
\hline How safe you feel & & 6.7 \\
\hline $\begin{array}{r}\text { What you are currently } \\
\text { achieving in life }\end{array}$ & 6. & \\
\hline Your future security & 6.1 & \\
\hline Feeling part of your community & 5.8 & \\
\hline Combined wellbeing indicator & & 65 \\
\hline
\end{tabular}

A2 Turning now to various areas of your life. How satisfied are you with...?

Base: $\quad$ All $(n=1,710)$

Note: Excludes; not sure, prefer not to say

The Personal Wellbeing Index provides a combined subjective wellbeing score calculated as the average score across all seven domains which is then scaled up to a score out of 100 . The Personal Wellbeing Index score for each subgroup is reported in comparison to the Victorian overall result in the following figures.

\footnotetext{
12 Cummins RA, Eckersley R, Pallant J, Van Vugt J, Misajon R. Developing a national index of subjective wellbeing: The Australian Unity Wellbeing Index. Soc Indic Res. 2003;64(2):159-90.
} 
Figure 6 Subjective wellbeing - Victorian and sub-population scores during the first lockdown

Note: Responses that are significantly more favourable than the Victorian overall result are on the right, highlighted in green.

Responses that are significantly less favourable than the Victorian overall result are on the left, highlighted in blue.

\begin{tabular}{|c|c|c|c|}
\hline \multirow{2}{*}{\multicolumn{2}{|c|}{ Victoria overall }} & \multirow[t]{2}{*}{4 Less favourable result } & \multirow[t]{2}{*}{ More favourable result } \\
\hline & & & \\
\hline \multirow{2}{*}{ Gender } & Male & 64.70 & \\
\hline & Female & & 65.5 \\
\hline \multirow{7}{*}{ Age } & 18 to 24 years & 64.70 & \\
\hline & 25 to 34 years & $61.8 \mathrm{C}$ & \\
\hline & 35 to 44 years & $63.3 \mathrm{C}=$ & \\
\hline & 45 to 54 years & $63.9 \mathrm{C}$ & \\
\hline & 55 to 64 years & $64.3 \mathrm{C}$ & \\
\hline & 65 to 74 years & & 70.2 \\
\hline & 75 or more & & 74.1 \\
\hline \multirow{5}{*}{ SEIFA } & Lowest - 1 & $64.2 \mathrm{C}$ & \\
\hline & 2 & & 65.2 \\
\hline & 3 & 64.60 & \\
\hline & 4 & & 65.3 \\
\hline & Highest -5 & & 65.4 \\
\hline \multirow{7}{*}{ Region } & Inner metro & $63.3 \mathrm{C}=$ & \\
\hline & Middle metro & $64.6 \mathrm{O}$ & \\
\hline & Outer metro & $63.1 \mathrm{C}=$ & \\
\hline & Interface & 63.9 & \\
\hline & Regional city & & 66.5 \\
\hline & Large shire & & 70.9 \\
\hline & Small shire & & 68.8 \\
\hline \multicolumn{2}{|c|}{ Aboriginal and Torres Strait Islander } & $60.9 \mathrm{C}$ & \\
\hline \multicolumn{2}{|c|}{ Language other than English at home } & $61.3 \mathrm{O}$ & \\
\hline & Self-reported disability & $59.1 O_{-}^{-=}$ & \\
\hline \multirow{5}{*}{$\begin{array}{c}\text { Main activity in } \\
\text { February } 2020\end{array}$} & Employed & & 07.3 \\
\hline & Unemployed & $57.3 \bigcirc$ & \\
\hline & Home duties & & 66.0 \\
\hline & Student & $62.7 \mathrm{C}$ & \\
\hline & Retired & & \begin{tabular}{|c|} 
\\
\end{tabular} \\
\hline \multirow{6}{*}{ Income } & Less than $\$ 40,000$ & $61.4 \bigcirc$ & \\
\hline & $\$ 40,000-\$ 59,999$ & $64.4 \mathrm{O}$ & \\
\hline & $\$ 60,000-\$ 99,999$ & & 66.6 \\
\hline & $\$ 100,000-\$ 149,999$ & & 67.4 \\
\hline & $\$ 150,000$ or more & & 74.4 \\
\hline & Live in bushfire area & $63.3 \mathrm{C}$ & \\
\hline \multirow{5}{*}{$\begin{array}{l}\text { Household } \\
\text { structure }\end{array}$} & Person living alone & $61.5 O_{-1}$ & \\
\hline & Couple living alone & & 69.7 \\
\hline & Couple parent with children & & 66.4 \\
\hline & Single parent with children & $58.1 \bigcirc$ & \\
\hline & Share house & $57.6 \mathrm{O}=$ & \\
\hline \multirow[t]{2}{*}{$\begin{array}{l}\text { Government } \\
\text { assistance }\end{array}$} & $\begin{array}{l}\text { Eligible for JobKeeper } \\
\text { Eligible for JobSeeker }\end{array}$ & $64.2 \mathrm{O}$ & \\
\hline & & $\begin{array}{l}\text { Significantly less } \\
\text { favourable result }\end{array}$ & $\begin{array}{l}\text { Significantly more } \\
\text { favourable result }\end{array}$ \\
\hline
\end{tabular}

A2 Turning now to various areas of your life. How satisfied are you with...?

Base: $\quad$ All $(n=1,710)$

Note: Excludes; not sure, prefer not to say

Note: Results for some subgroups are higher than others and not significantly different to the overall results due to small base sizes 
Figure 7 Change in satisfaction with aspects of life (more, same, less)

How satisfied are you with ...? (more or less during first lockdown)

\begin{tabular}{|c|c|c|c|}
\hline Your future security & $6 \%$ & $46 \%$ & $12 \%$ \\
\hline $\begin{array}{r}\text { What you are currently } \\
\text { achieving in life }\end{array}$ & $5 \% \quad 33 \%$ & $49 \%$ & $14 \%$ \\
\hline Your standard of living & $4 \%$ & $50 \%$ & $13 \%$ \\
\hline How safe you feel & $5 \%$ & $50 \%$ & $14 \%$ \\
\hline $\begin{array}{l}\text { Feeling part of your } \\
\text { community }\end{array}$ & $7 \%$ & $50 \%$ & $12 \%$ \\
\hline Your personal relationships & $5 \% \quad 24 \%$ & $53 \%$ & $18 \%$ \\
\hline Your health & $4 \% \quad 23 \%$ & $58 \%$ & $15 \%$ \\
\hline
\end{tabular}

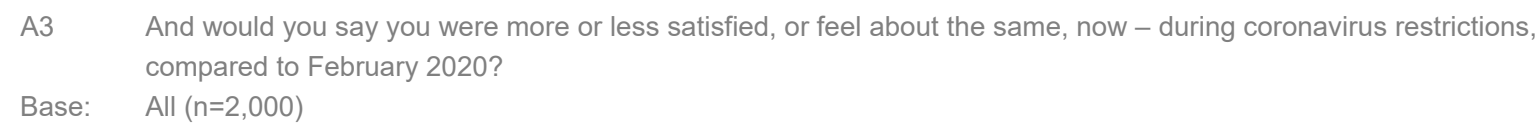

The above figure shows respondents' perceived change in the subjective wellbeing domains relative to February 2020. Roughly half of respondents reported no change in their satisfaction with their life between February 2020 and during the first lockdown (between $46 \%$ and 58\%). Across all domains, less than one in five respondents reported being more satisfied with their current situation during the first Victorian coronavirus lockdown than in February 2020. This was consistently lower than the proportion who were less satisfied during the first lockdown.

The largest perceived negative impact was in how respondents rated their outlook for the future, over one in three $(36 \%)$ were less satisfied with their future security during the first lockdown than they were in February 2020. Large proportions of the population also felt less satisfied with their current achievement in life $(33 \%)$ and their standard of living (33\%). 


\subsection{Psychological distress}

The Kessler Psychological Distress Scale-6 (K6) is a scale of psychological distress comprised of 6 questions. It was developed as a measure of non-specific psychological distress on the anxietydepression spectrum ${ }^{13}$. Respondents rated how often in the last month they experienced each indicator of psychological distress. The cut off score of 19 or more out of 30 is used here as recommended by the $\mathrm{ABS}^{13}$ and is indicative of a serious mental health condition such as a Depression or Anxiety Disorder. The $16 \%$ of respondents categorised as having high psychological distress in this survey was similar to the result in the 2017 comparison survey that showed that $15.4 \%$ of Victorians had high psychological distress as measured by the K10 which is a longer form of the $\mathrm{K} 6^{13}$.

Figure 8 shows the proportion of each subgroup with high levels of psychological distress.

\footnotetext{
${ }^{13}$ https://www.abs.gov.au/ausstats/abs@.nsf/lookup/4817.0.55.001Chapter92007-08, and Kessler, R.C., Green, J.G., Gruber, M.J., Sampson, N.A., Bromet, E., Cuitan, M., Furukawa, T.A., Gureje, O., Hinkov, H., Hu, C.-Y, Lara, C., Lee, S., Mneimneh, Z., Myer, L., Oakley-Browne, M., Posada-Villa, J., Sagar, R., Viana, M.C. \& Zaslavsky, A.M. (2010) 'Screening for Serious Mental Illness in the General Population with the K6 screening scale: results from the WHO World Mental Health (WMH) survey initiative', International Journal of Methods in Psychiatric Research, Vol 19: 4-22. 
Figure 8 High psychological distress - Victorian and sub-population frequencies during first lockdown Note: Responses that are significantly more favourable than the Victorian overall result are on the right, highlighted in green. Responses that are significantly less favourable than the Victorian overall result are on the left, highlighted in blue.

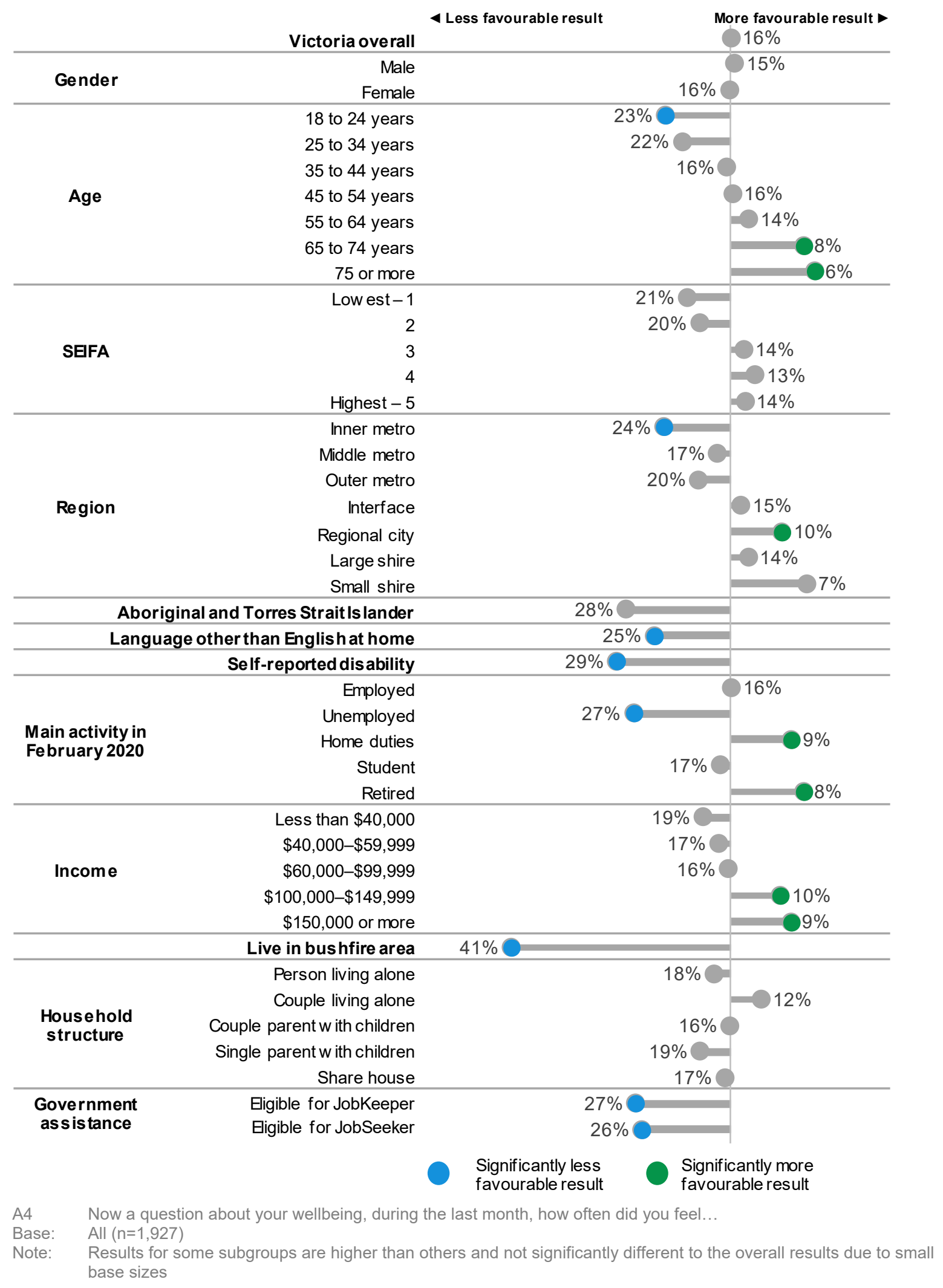


Figure 9 Changes in psychological distress indicators (more, same, less)

Changes in frequency of distress indicators (more or less during first lockdown)

\begin{tabular}{r|cccc} 
Nervous & $5 \%$ & $18 \%$ & $47 \%$ & $31 \%$ \\
\hline Restless or fidgety & $6 \%$ & $18 \%$ & $52 \%$ & $24 \%$ \\
\hline Hopeless & $7 \%$ & $18 \%$ & $54 \%$ & $21 \%$ \\
\hline That everything was an effort & $7 \%$ & $17 \%$ & $55 \%$ & $21 \%$ \\
\hline So depressed that nothing & $7 \%$ & $18 \%$ & $59 \%$ & $17 \%$ \\
could cheer you up & & & & \\
\hline Worthless & $7 \%$ & $16 \%$ & $64 \%$ & $12 \%$
\end{tabular}

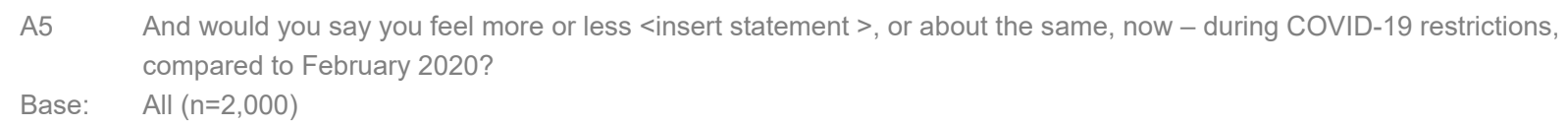

Across all of the six distress indicators roughly half of respondents rated their current level of psychological distress as unchanged during the first lockdown in comparison to February 2020. Feeling nervous was the distress indicator most commonly reported as increasing during coronavirus restrictions $(31 \%)$, followed by feeling restless or fidgety $(25 \%)$. 


\section{SOCIAL CONNECTION}

\section{QvicHealth}

VicHealth Coronavirus Victorian Wellbeing Impact Study

A comprehensive survey of 2,000 Victorians in the first coronavirus lockdown of 2020 showed that people felt less socially connected.

Almost 1 in $4(23 \%)$ of

Victorians did not feel connected with others, up from 1 in 10 $(10 \%)$ in February 2020

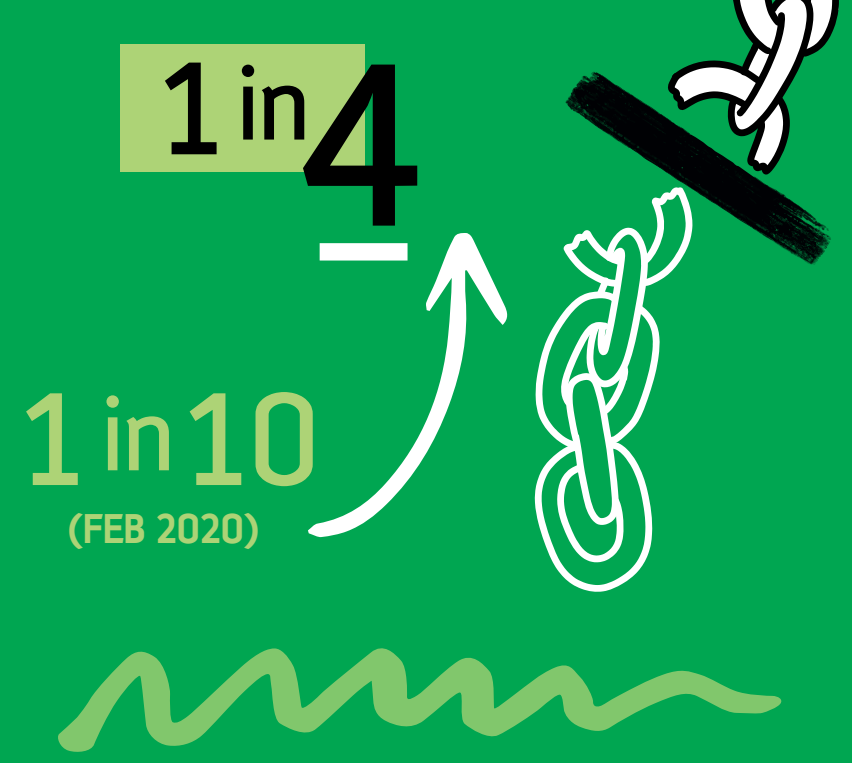

1 in 5 Victorians said the first lockdown put a strain on their relationships with the people they live with
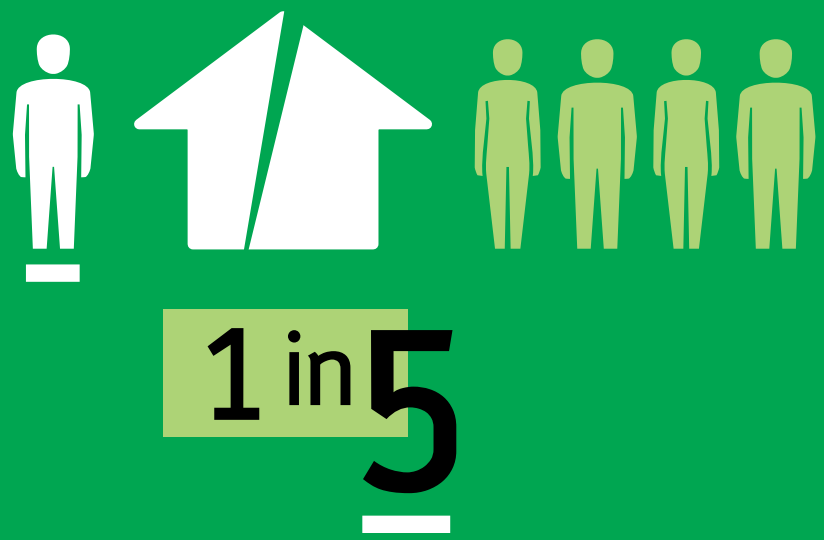

3 in 10 Victorians found it hard or very hard to stay connected to friends or family during lockdown

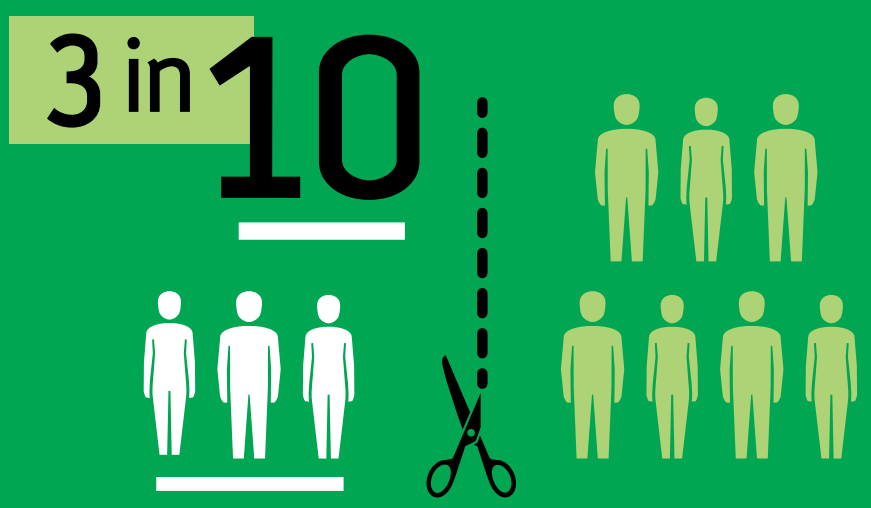

Staying connected to others during the first lockdown was most difficult for:

\section{Aboriginal \& Torres \\ Strait Islander Victorians

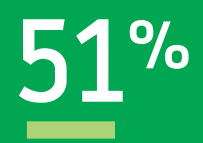

Young Victorians

aged 18-24

\section{$39 \%$}

Victorians who speak a language other than $39 \%$ English at home

Victorians eligible for JobKeeper (42\%) or JobSeeker (39\%)

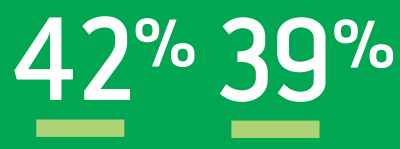




\section{Findings: Social connection}

Restrictions on movement due to the first coronavirus lockdown were expected to change the ways in which people interacted and connected with others. This presented a risk of disconnecting people from their friends, family and the wider community. To track this, we asked respondents to assess how connected they felt to others as well as using a subjective Index of social solidarity to provide an indicative measure of how a person is engaged with their community ${ }^{14}$. We also asked about people's sense of connection with family and friends outside the home and strength of relationships inside the home.

\section{Social Connection}

\section{Impact on social connection}

- Two in five (37\%) agreed they felt connected to others during lockdown restrictions, down from three in five (57\%) in February 2020. The proportion of those disagreeing with the statement that they felt connected with others increased from $10 \%$ to $23 \%$.

- The average social solidarity score for respondents was 21.2 out of a maximum of 30 , higher results being indicative of feeling more connected to the local community.

- Three in ten respondents (30\%) reported that they had found staying connected to friends and family hard or very hard. One in five (20\%) living in a household with other people reported to feeling that their relationship with the people they live with had become more strained due to the first lockdown restrictions.

\section{Factors influencing these changes}

- The aspects of social solidarity that most people agreed with was that their neighbourhood is a good place to live ( $71 \%$ agree). Many also agreed that they trust their neighbours $(58 \%)$, and that they are proud to be a member of their community $(50 \%)$. Fewer respondents agreed that people in their neighbourhood share the same values (39\%), and that they feel like a part of a community $(42 \%)$.

- The proportion of people using videoconferencing as a means of social connection has increased from $18 \%$ to $41 \%$. The use of the telephone ( $45 \%$ to $56 \%$ ) and group messaging (30\% to $38 \%)$ has also risen. Decreases are seen in the frequency of people staying connected while walking with others $(30 \%$ to $19 \%)$ and during exercise ( $23 \%$ to $13 \%)$.

\section{Variation by subgroups}

- Groups that were feeling less connected during the first lockdown restrictions include those with a self-reported disability (33\%), those who were unemployed during February 2020 $(36 \%)$, and those in a lower income bracket (30\%). Those unemployed during February 2020 also were more likely than Victorians overall to report that their relationships with other members of their household had been strained $(30 \%)$.

\footnotetext{
${ }^{14}$ Hawdon, J., Räsänen, P., Oksanen, A. and Ryan, J., 2012. Social solidarity and wellbeing after critical incidents: Three cases of mass shootings. Journal of critical incident analysis, 3(1), pp.2-25.
} 
- Lower social solidarity scores were recorded for those aged 45 to 54 (20.4), those living in a share house or other living arrangement (20.1), those based in outer metro Melbourne (20.1), and those unemployed in February 2020 (19.5). Higher results were recorded for those aged 65 to 74 (22.2) and 75 or older (23.4), couples living alone (22.1), those living in large shires (23.0), and people in bushfire affected communities (23.2).

- Younger people aged 18 to 24 were more likely to report that they have had difficulties staying connected with others (39\%). Those speaking a language other than English at home (39\%) and Aboriginal and Torres Strait Islanders (51\%) were also more likely to report difficulties maintaining connections.

\subsection{Social connection to others}

Respondents were asked whether they agreed that they felt connected to others during the coronavirus period as well as during February 2020. The proportion of those who agreed with this statement was lower for the lockdown period (37\%) than for the period of February 2020. The proportion who disagreed, indicating that they didn't feel connected to others, increased during the first lockdown compared to February 2020 (23\% vs $10 \%)$.

Figure 10 Agreement that respondents feel connected to others (disagree, mildly agree or disagree, agree)

During first lockdown

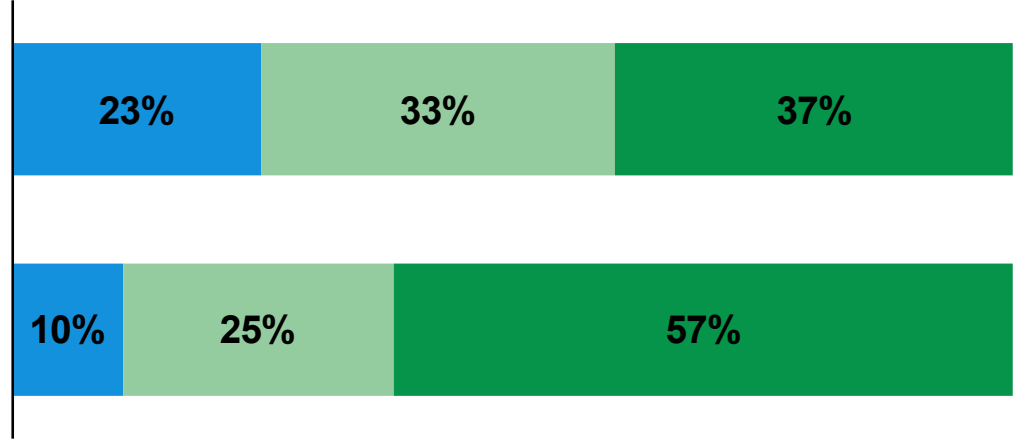

February 2020

$$
10 \%
$$

Disagree

Mildly

Agree

C1 Please rate the degree to which you agree or disagree (where 1 is strongly disagree and 6 is strongly agree), with the following statement: I feel connected with others

Base: $\quad$ All $(n=2,000)$

Note: $\quad$ Not shown; not sure $(2 \%, 2 \%)$, prefer not to say $(5 \%, 5 \%)$

Figure 11 shows the proportion of respondents who disagreed with the statement 'I feel connected to others' for Victoria overall and for sub-populations. 
Figure 11 Disagreement with the statement 'I feel connected to others' - Victorian and sub-population frequencies (\% disagree) during the first lockdown

Note: Responses that are significantly more favourable than the Victorian overall result are on the right, highlighted in green. Responses that are significantly less favourable than the Victorian overall result are on the left, highlighted in blue.

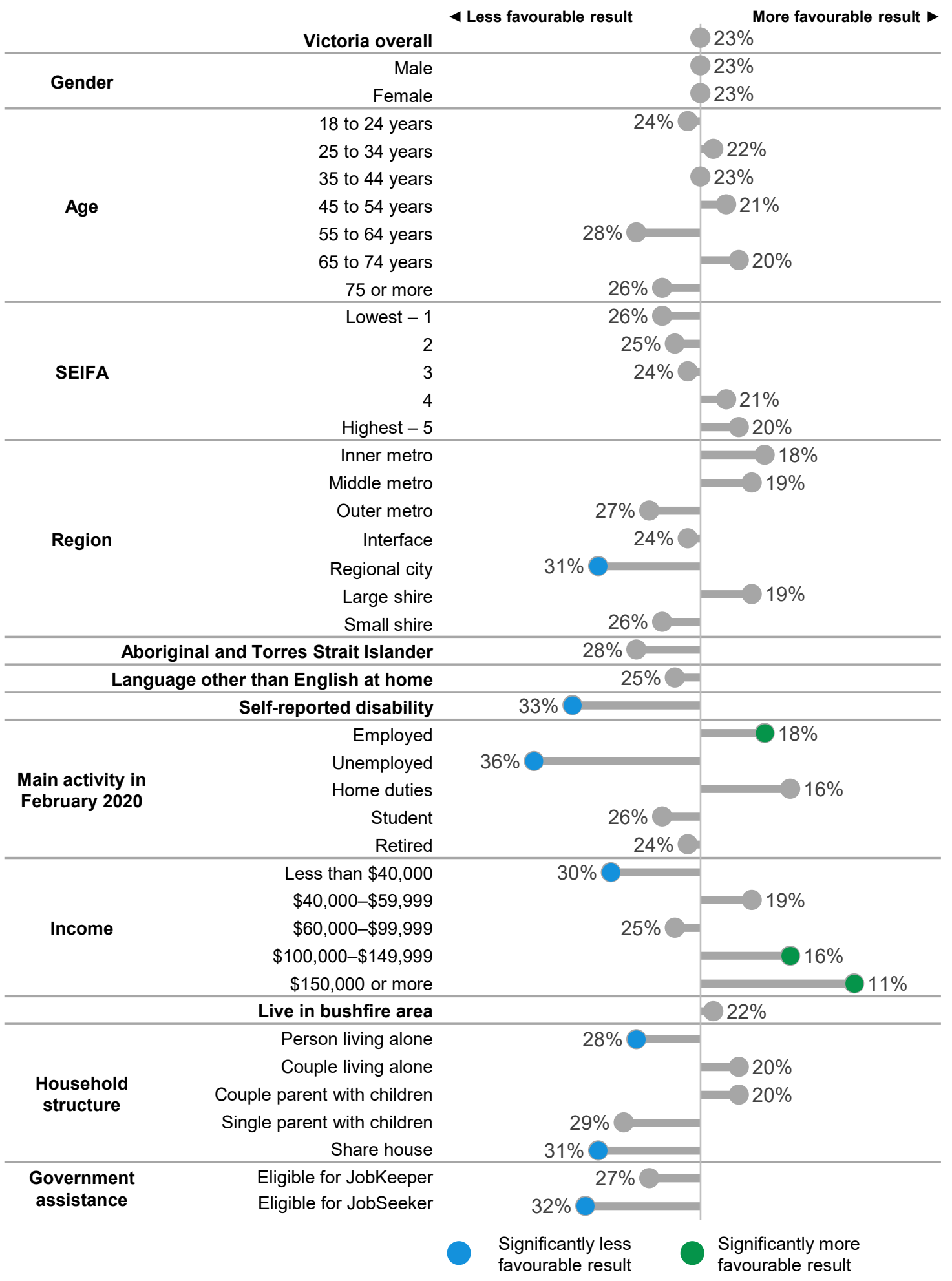

C1 Please rate the degree to which you agree or disagree (where 1 is strongly disagree and 6 is strongly agree), with the following statement: I feel connected with others

Base: $\quad$ All $(n=2,000)$

Note: $\quad$ Results for some subgroups are higher than others and not significantly different to the overall results due to small base sizes 
Figure 12 Disagreement with the statement 'I feel connected to others' - Victorian and sub-population frequencies (\% disagree) during February 2020

Note: Responses that are significantly more favourable than the Victorian overall result are on the right, highlighted in green. Responses that are significantly less favourable than the Victorian overall result are on the left, highlighted in blue.

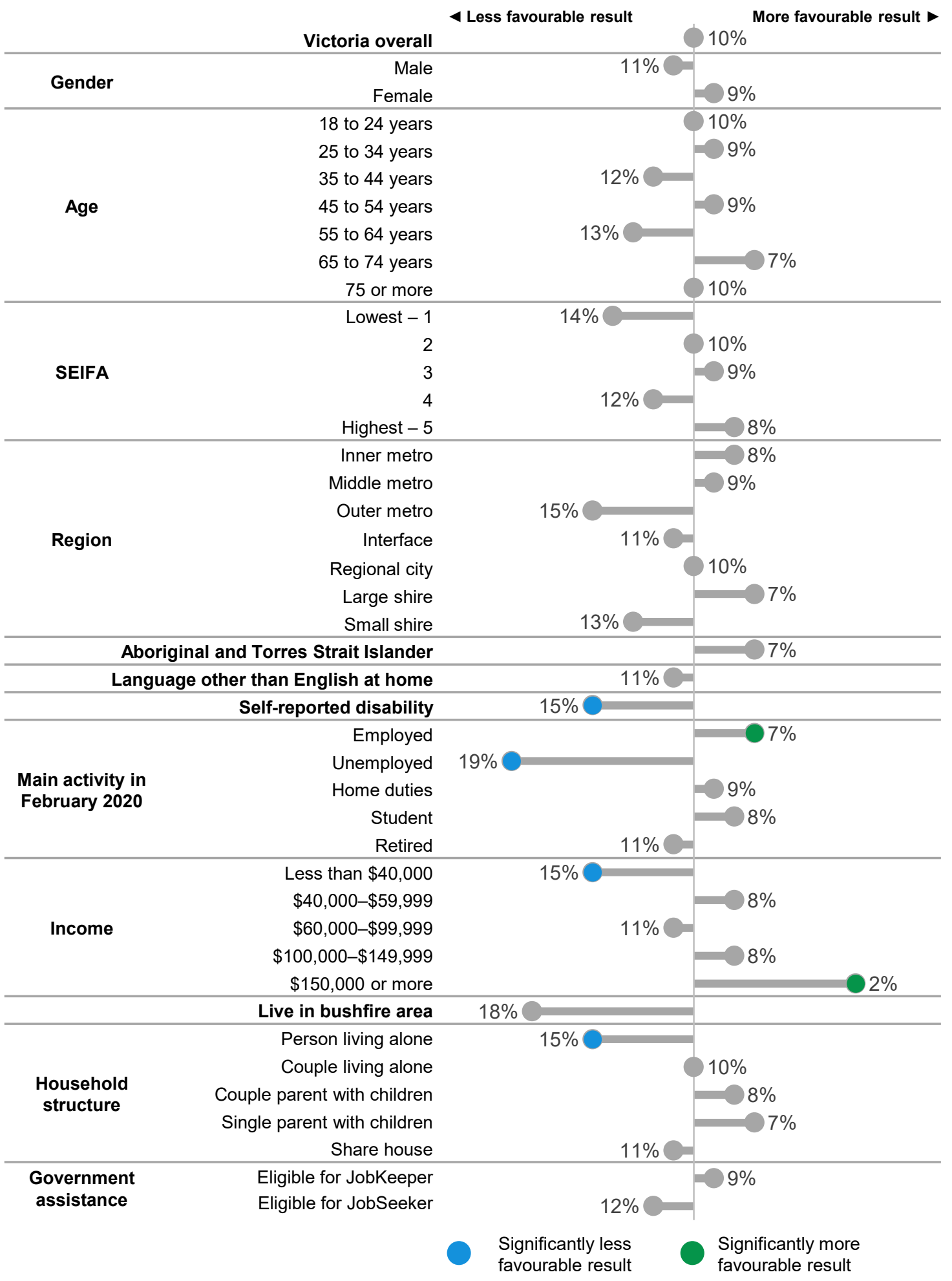

C1 Please rate the degree to which you agree or disagree (where 1 is strongly disagree and 6 is strongly agree), with the following statement: I feel connected with others

Base: $\quad$ All $(n=2,000)$

Note: $\quad$ Results for some subgroups are higher than others and not significantly different to the overall results due to small base sizes 
Figure 13 Disagreement with the statement 'I feel connected to others' - Victorian and sub-population frequencies (\% disagree) during the first lockdown compared to February 2020

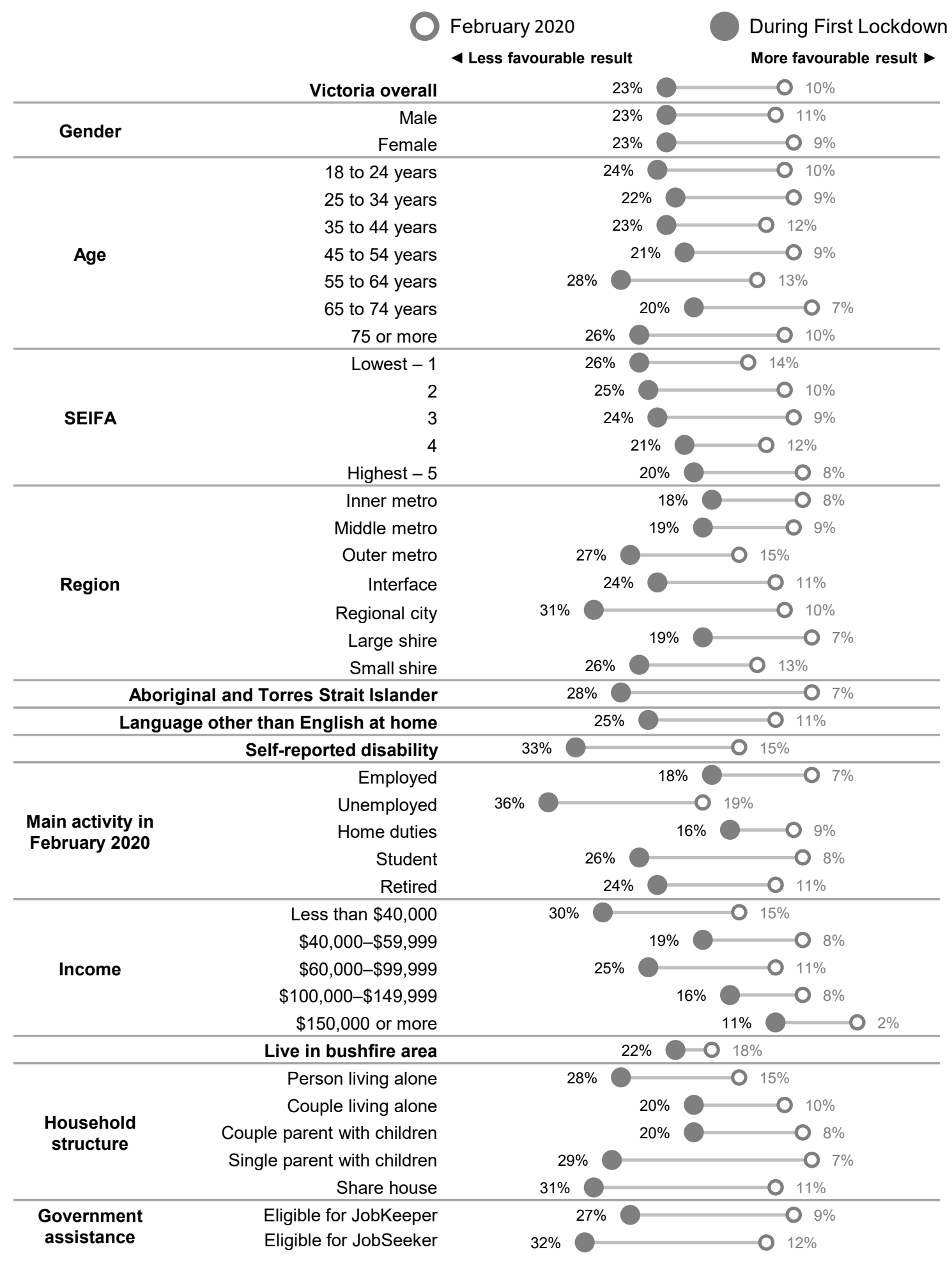

C1 Please rate the degree to which you agree or disagree (where 1 is strongly disagree and 6 is strongly agree), with the following statement: I feel connected with others

Base: $\quad$ All $(n=2,000)$ 
Figure 14 Agreement with social connectedness statements

To what extent do you currently agree with the following statements?

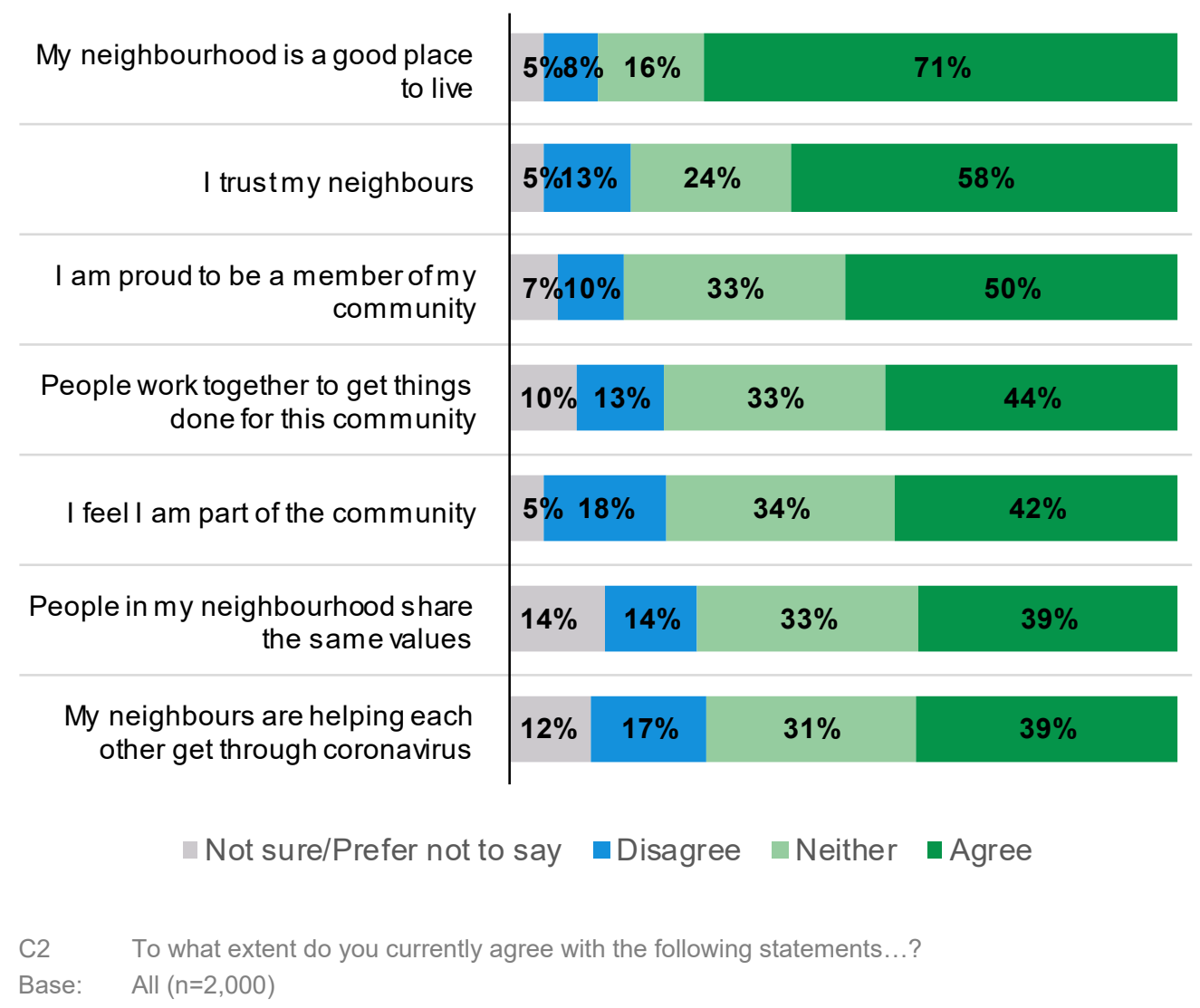

The figure above shows the agreement respondents had with several statements regarding their connection with the local community. The majority agree that their neighbourhood is a good place to live, that they trust their neighbours and that they are proud to be a member of their community. Responses to the remaining statements were more mixed, less than half agreeing that people work together in their community, that they fell like they are a part of the community and that their neighbourhood shares the same values.

Two in five respondents (39\%) agree that their neighbours are helping each other to get through coronavirus. One in five (17\%) disagree with this statement.

Responses to the above statements, excluding the item 'neighbours are helping each other to get through coronavirus' have been combined into an Index of social solidarity that indicates the level of local community social solidarity and support experienced by individuals (Hawdon et al. 2012) ${ }^{15}$. This social solidarity score has a range of 6 to 30, results for this are presented in Figure 15.

\footnotetext{
15 Hawdon, J., Räsänen, P., Oksanen, A. and Ryan, J., 2012. Social solidarity and wellbeing after critical incidents: Three cases of mass shootings. Journal of critical incident analysis, 3(1), pp.2-25.
} 
Figure 15 Social solidarity - Victorian and sub-population scores (max score of 30)

Note: Responses that are significantly more favourable than the Victorian overall result are on the right, highlighted in green. Responses that are significantly less favourable than the Victorian overall result are on the left, highlighted in blue.

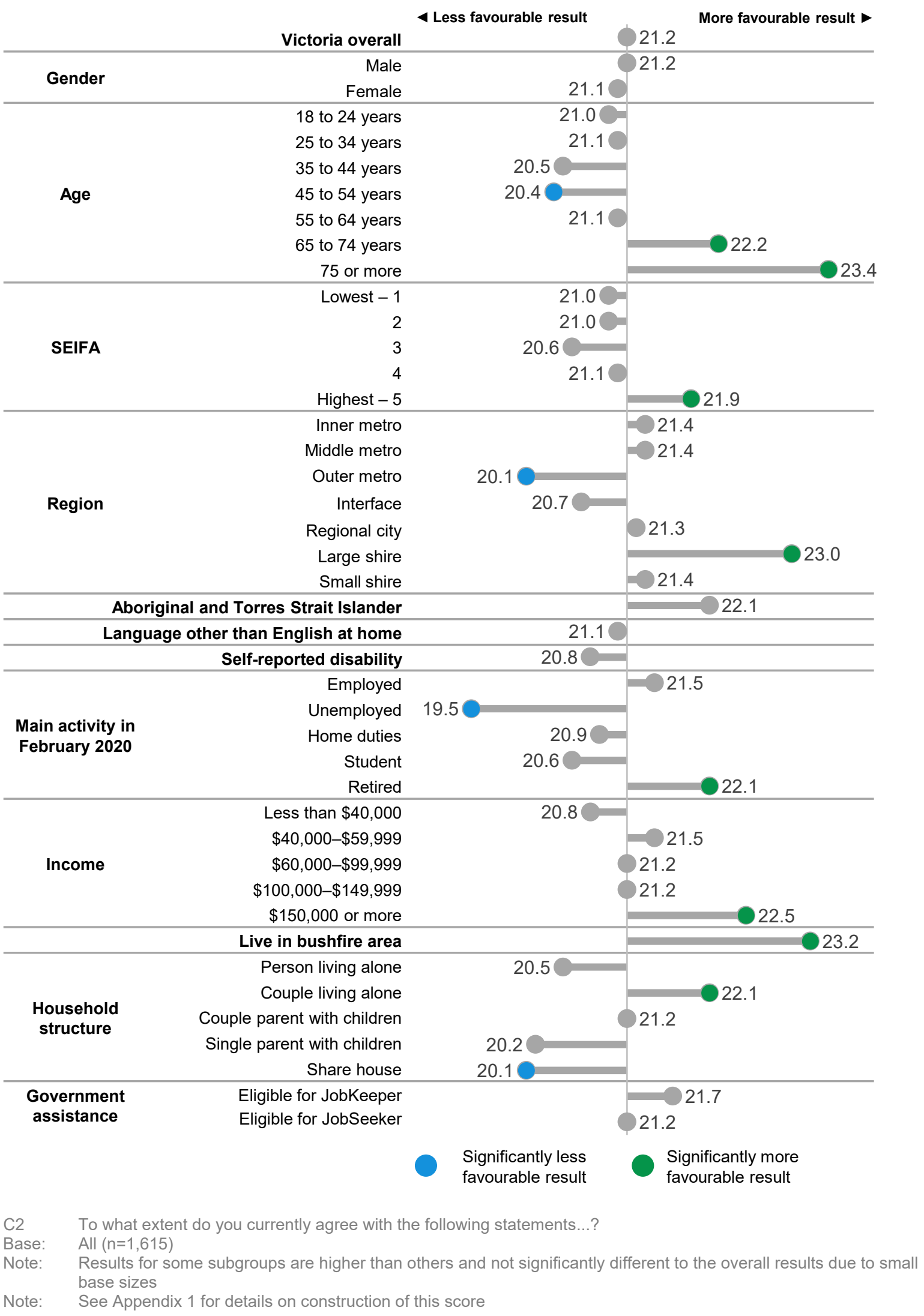


As shown in Table 3, some subgroups were more likely to disagree with certain aspects of social connection. Younger Victorians (aged 18 to 24 years) were more likely to disagree with the statements that they trust their neighbours $(20 \%)$ and that they are proud to be a member of their community $(16 \%)$.

Those who were unemployed during February 2020 were more likely to disagree that they were proud to be a part of their community $(17 \%)$, that people work together in their community $(21 \%)$, and that they feel like a part of their community (30\%).

People living in outer metro Melbourne were more likely to disagree that their neighbourhood shares the same values $(20 \%)$, and that their neighbours were helping each other to get through coronavirus restrictions $(26 \%)$.

Table 3 Individual social solidarity indicators - subgroups with significantly different frequencies compared to the overall Victorian frequency

\begin{tabular}{|c|c|c|c|c|c|}
\hline \multirow{4}{*}{$\begin{array}{c}\begin{array}{c}\text { Social solidarity } \\
\text { indicator }\end{array} \\
\text { My neighbourhood is } \\
\text { a good place to live }\end{array}$} & \multirow{4}{*}{$\begin{array}{c}\begin{array}{c}\text { Victoria } \\
\text { overall }\end{array} \\
8 \%\end{array}$} & \multicolumn{2}{|c|}{$\begin{array}{l}\text { Sub-groups who report this } \\
\text { more often }\end{array}$} & \multicolumn{2}{|c|}{$\begin{array}{l}\text { Sub-groups who report this } \\
\text { less often }\end{array}$} \\
\hline & & & & SEIFA 5 & $4 \%$ \\
\hline & & & & 65 to 74 years & $4 \%$ \\
\hline & & & & $\$ 150,000$ or more & $3 \%$ \\
\hline \multirow{4}{*}{ I trust my neighbours } & \multirow{4}{*}{$13 \%$} & 18 to 24 years & $20 \%$ & $\$ 150,000$ or more & $7 \%$ \\
\hline & & & & Retired & $7 \%$ \\
\hline & & & & 65 to 74 years & $7 \%$ \\
\hline & & & & SEIFA 5 & $6 \%$ \\
\hline \multirow{3}{*}{$\begin{array}{l}\text { I am proud to be a } \\
\text { member of my } \\
\text { community }\end{array}$} & \multirow{3}{*}{$10 \%$} & Unemployed & $17 \%$ & 65 to 74 years & $5 \%$ \\
\hline & & 18 to 24 years & $16 \%$ & $\$ 150,000$ or more & $4 \%$ \\
\hline & & & & Large shire & $3 \%$ \\
\hline \multirow{2}{*}{$\begin{array}{l}\text { People work together } \\
\text { to get things done for } \\
\text { this community }\end{array}$} & \multirow[t]{2}{*}{$13 \%$} & Unemployed & $21 \%$ & Retired & $8 \%$ \\
\hline & & & & 75 or more & $2 \%$ \\
\hline \multirow{3}{*}{$\begin{array}{l}\text { I feel I am part of the } \\
\text { community }\end{array}$} & \multirow{3}{*}{$18 \%$} & Unemployed & $30 \%$ & \multirow[t]{3}{*}{$\$ 150,000$ or more } & \multirow[t]{3}{*}{$10 \%$} \\
\hline & & Eligible for JobSeeker & $26 \%$ & & \\
\hline & & Has disability & $25 \%$ & & \\
\hline $\begin{array}{c}\text { People in my } \\
\text { neighbourhood share } \\
\text { the same values }\end{array}$ & $14 \%$ & Outer metro & $20 \%$ & $\$ 150,000$ or more & $8 \%$ \\
\hline \multirow{3}{*}{$\begin{array}{l}\text { My neighbours are } \\
\text { helping each other } \\
\text { get through the } \\
\text { COVID-19 } \\
\text { restrictions* }\end{array}$} & \multirow{3}{*}{$17 \%$} & \multirow[t]{3}{*}{ Outer metro } & \multirow[t]{3}{*}{$26 \%$} & SEIFA 5 & $11 \%$ \\
\hline & & & & Retired & $10 \%$ \\
\hline & & & & 75 or more & $5 \%$ \\
\hline
\end{tabular}

${ }^{*}$ Not included in overall social solidarity measure 


\subsubsection{Staying connected with friends and family}

The ways people were communicating and connecting with friends and family differed during the first Victorian coronavirus lockdown. Respondents were slightly more likely to use the telephone as a means of social connection during the first Victorian coronavirus lockdown than in February 2020 (56\% vs $45 \%)$.

A larger increase is observed in the use of videoconferencing technologies such as Facetime or Zoom. The usage of this means of social connection was almost double during the first Victorian coronavirus lockdown ( $41 \%$ vs $18 \%)$.

Access to social connection through walking with others and exercising outside with others was lower during the first Victorian coronavirus lockdown, this is likely due to the restrictions on exercising with those outside of household.

Figure 16 Means of social connection during the first Victorian coronavirus lockdown and February 2020

During First Lockdown February 2020

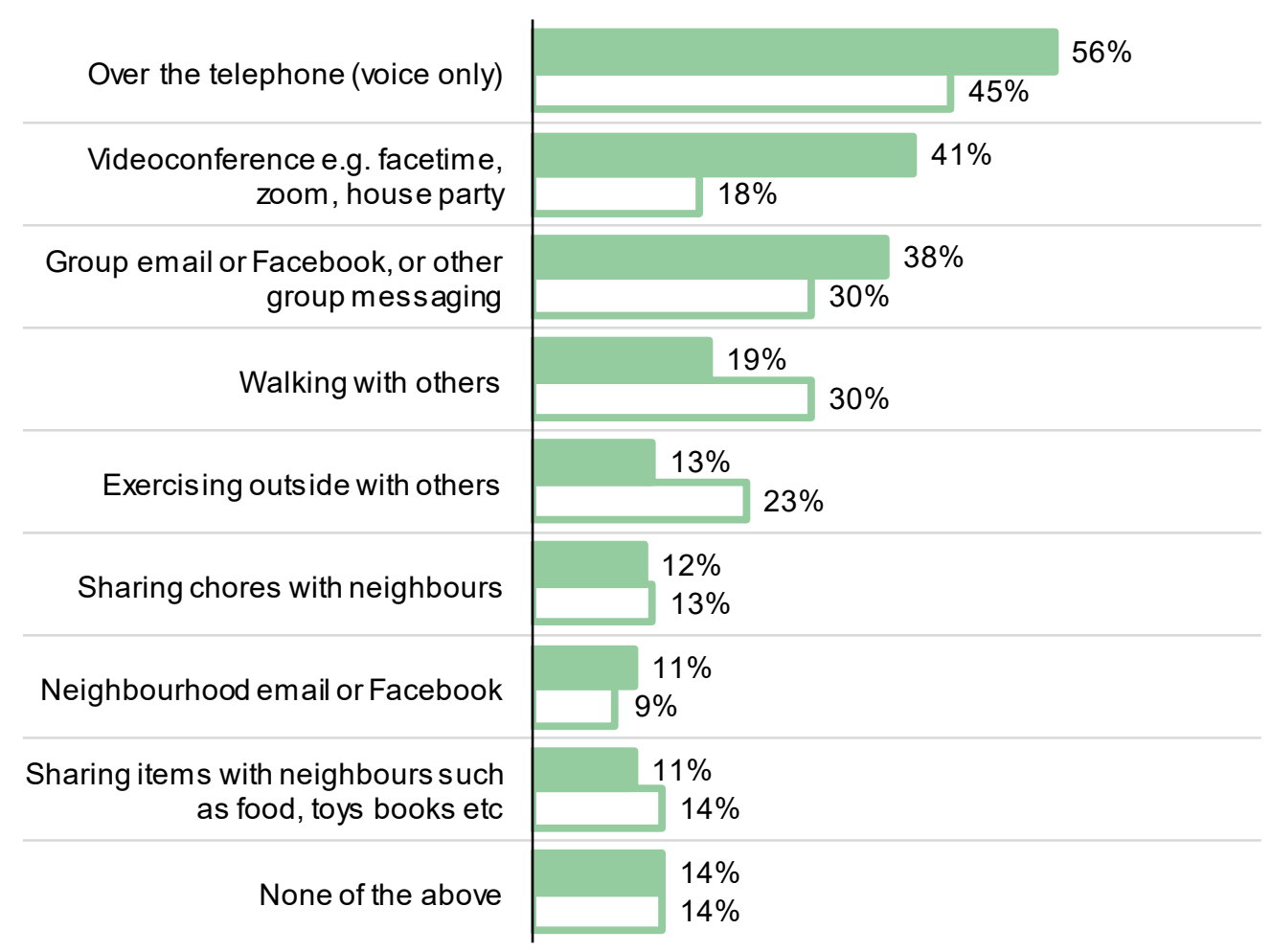

C3 People like to connect with each other in different ways. Excluding work, have you connected with others in any of the following ways?

Base: $\quad$ All $(n=2,000)$

Note: $\quad$ Not shown; not sure $(5 \%, 4 \%)$, prefer not to say $(2 \%, 2 \%)$ 
The figure below shows that three in ten (30\%) found that staying connected with friends and family outside their household had been hard or very hard.

Figure 17 Difficulty of staying connected with friends and family by subgroup (easy, hard, neither)

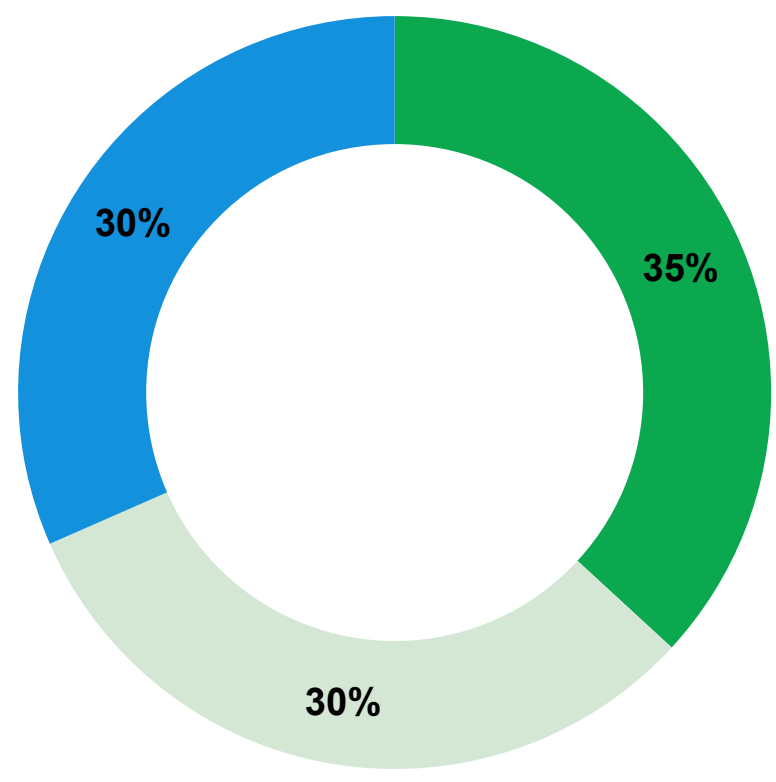

Easy/Very easy $\quad$ Neither easy nor hard $\quad$ Hard/Very hard

C4W Since the COVID-19 restrictions started, how easy has it been to stay connected with family and friends outside your household?

Base: $\quad$ All $(n=2,000)$

Note: $\quad$ Not shown; not sure (3\%), prefer not to say $(2 \%)$

Groups that were more likely to find it difficult to stay connected with family or friends outside the home include those who speak a language other than English at home (39\%) and respondents aged 18 to $24(39 \%)$. These results are presented in Figure 18. 
Figure 18 Difficulty (hard/very hard) staying connected with friends and family outside of the home - Victorian and sub-population frequencies

Note: Responses that are significantly more favourable than the Victorian overall result are on the right, highlighted in green. Responses that are significantly less favourable than the Victorian overall result are on the left, highlighted in blue.

\begin{tabular}{|c|c|c|c|}
\hline & Victoria overall & 4 Less favourable result & $\begin{array}{l}\text { More favourable result } \\
30 \%\end{array}$ \\
\hline \multirow{2}{*}{ Gender } & Male & & $29 \%$ \\
\hline & Female & $31 \%$ & \\
\hline \multirow{7}{*}{ Age } & 18 to 24 years & $39 \% \bigcirc$ & \\
\hline & 25 to 34 years & $33 \%$ & \\
\hline & 35 to 44 years & & $27 \%$ \\
\hline & 45 to 54 years & & $29 \%$ \\
\hline & 55 to 64 years & & $26 \%$ \\
\hline & 65 to 74 years & & $28 \%$ \\
\hline & 75 or more & & $27 \%$ \\
\hline \multirow{5}{*}{ SEIFA } & Lowest -1 & $33 \%$ & \\
\hline & 2 & $33 \%$ & \\
\hline & 3 & & $28 \%$ \\
\hline & 4 & & $29 \%$ \\
\hline & Highest -5 & & $28 \%$ \\
\hline \multirow{7}{*}{ Region } & Inner metro & $34 \%$ & \\
\hline & Middle metro & & $25 \%$ \\
\hline & Outer metro & $34 \%$ & \\
\hline & Interface & $35 \%$ & \\
\hline & Regional city & & $27 \%$ \\
\hline & Large shire & & $28 \%$ \\
\hline & Small shire & & $27 \%$ \\
\hline \multicolumn{2}{|c|}{ Aboriginal and Torres Strait Islander } & $51 \% \mathrm{C}$ & \\
\hline \multicolumn{2}{|c|}{ Language other than English at home } & $39 \% \bigcirc$ & \\
\hline & Self-reported disability & $33 \%$ & \\
\hline \multirow{5}{*}{$\begin{array}{c}\text { Main activity in } \\
\text { February } 2020\end{array}$} & Employed & & $29 \%$ \\
\hline & Unemployed & $35 \%$ & \\
\hline & Home duties & & $30 \%$ \\
\hline & Student & $41 \%$ & \\
\hline & Retired & & $26 \%$ \\
\hline \multirow{6}{*}{ Income } & Less than $\$ 40,000$ & & $30 \%$ \\
\hline & $\$ 40,000-\$ 59,999$ & $35 \%$ & \\
\hline & $\$ 60,000-\$ 99,999$ & $33 \%$ & \\
\hline & $\$ 100,000-\$ 149,999$ & $31 \%$ & \\
\hline & $\$ 150,000$ or more & & $21 \%$ \\
\hline & Live in bushfire area & $33 \%$ & \\
\hline \multirow{5}{*}{$\begin{array}{l}\text { Household } \\
\text { structure }\end{array}$} & Person living alone & & $29 \%$ \\
\hline & Couple living alone & & $26 \%$ \\
\hline & Couple parent with children & $31 \%$ & \\
\hline & Single parent with children & $37 \%$ & \\
\hline & Share house & $38 \%$ & \\
\hline \multirow{2}{*}{$\begin{array}{l}\text { Government } \\
\text { assistance }\end{array}$} & Eligible for JobKeeper & $42 \%$ & \\
\hline & Eligible for JobSeeker & $39 \%$ & \\
\hline
\end{tabular}

C4W Since the COVID-19 restrictions started, how easy has it been to stay connected with family and friends outside your household?

Base: $\quad$ All $(n=2,000)$

Note: Results for some subgroups are higher than others and not significantly different to the overall results due to small base sizes 


\subsubsection{Household connection}

Due to the physical distancing encouraged during the first Victorian coronavirus lockdown, many Victorians moved to working from home and by necessity were forced to interact with those in their household more often. The impact of this increased time spent with the household has been measured by asking respondents whether their relationships with members of their household has made them closer or more strained.

As shown in the figure below, one in two respondents reported that their relationships with other members of their household had remained unchanged during the first lockdown.

One in five respondents $(21 \%)$ found that the first lockdownhad brought them closer to those in their household. A similar proportion found that it had made their relationships more strained $(20 \%)$.

Figure 19 Quality of relationships with other people in household during the first lockdown (closer, no change, more strained)

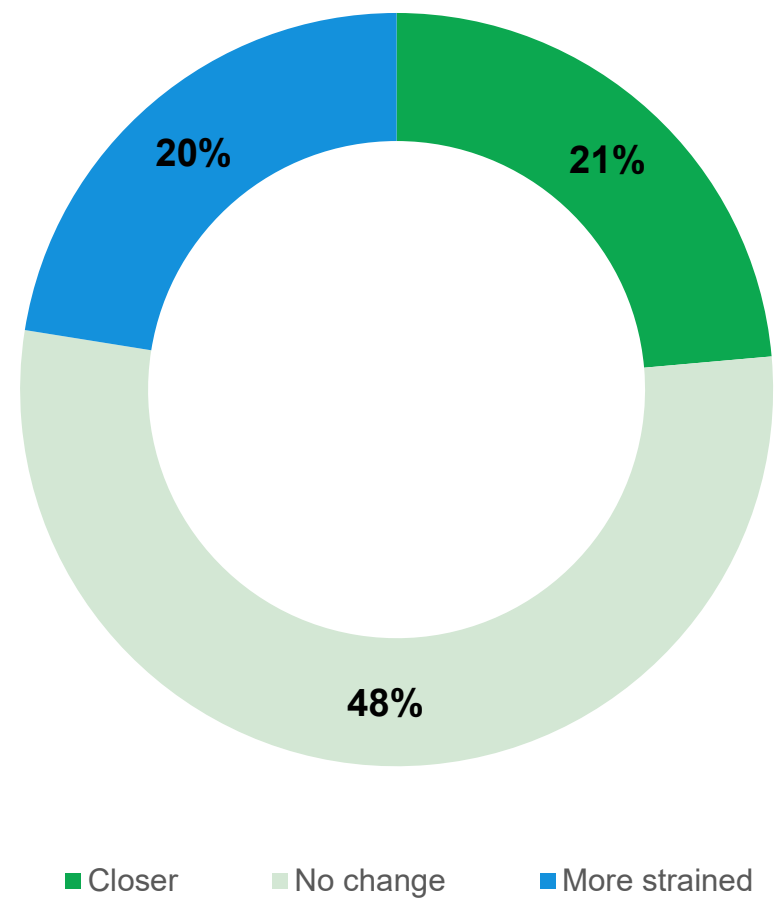

C5W How has the quality of your relationships with other people/family members in your household changed since the COVID-19 restrictions started?

Base: $\quad$ All $(n=2,000)$

Note: $\quad$ Not shown; not sure (3\%), prefer not to say (2\%), not applicable - single person household (6\%)

As presented in the following figure, those who were unemployed in February 2020 were more likely to have experienced household relationship strain during the first Victorian coronavirus lockdown. In contrast, as outlined in Figure 22, those aged 18 to 34, Aboriginal and Torres Strait Islanders and those from bushfire affected communities were amongst those where household connection had strengthened. 
Figure 20 Quality of relationships (more strained) with other people in household - Victorian and sub-population frequencies during the first lockdown

Note: Responses that are significantly more favourable than the Victorian overall result are on the right, highlighted in green. Responses that are significantly less favourable than the Victorian overall result are on the left, highlighted in blue.

\begin{tabular}{|c|c|c|c|}
\hline \multirow{2}{*}{\multicolumn{2}{|c|}{ Victoria overall }} & 4 Less favourable result & More favourable result \\
\hline & & & $20 \%$ \\
\hline \multirow{2}{*}{ Gender } & Male & & $20 \%$ \\
\hline & Female & & $19 \%$ \\
\hline \multirow{7}{*}{ Age } & 18 to 24 years & $24 \%$ & \\
\hline & 25 to 34 years & $26 \%$ & \\
\hline & 35 to 44 years & & $18 \%$ \\
\hline & 45 to 54 years & & $20 \%$ \\
\hline & 55 to 64 years & & $18 \%$ \\
\hline & 65 to 74 years & & $16 \%$ \\
\hline & 75 or more & & $7 \%$ \\
\hline \multirow{5}{*}{ SEIFA } & Lowest - 1 & & $17 \%$ \\
\hline & 2 & $21 \%$ & \\
\hline & 3 & & $20 \%$ \\
\hline & 4 & $22 \%$ & \\
\hline & Highest -5 & & $17 \%$ \\
\hline \multirow{7}{*}{ Region } & Inner metro & $25 \%$ & \\
\hline & Middle metro & $21 \%$ & \\
\hline & Outer metro & & $19 \%$ \\
\hline & Interface & & $20 \%$ \\
\hline & Regional city & & $16 \%$ \\
\hline & Large shire & & $17 \%$ \\
\hline & Small shire & & $14 \%$ \\
\hline \multicolumn{2}{|c|}{ Aboriginal and Torres Strait Islander } & $30 \% \mathrm{C}=$ & \\
\hline \multicolumn{2}{|c|}{ Language other than English at home } & $21 \%$ & \\
\hline & Self-reported disability & & $18 \%$ \\
\hline \multirow{5}{*}{$\begin{array}{c}\text { Main activity in } \\
\text { February } 2020\end{array}$} & Employed & $21 \%$ & \\
\hline & Unemployed & $30 \%$ & \\
\hline & Home duties & & $18 \%$ \\
\hline & Student & & $20 \%$ \\
\hline & Retired & & $14 \%$ \\
\hline \multirow{5}{*}{ Income } & Less than $\$ 40,000$ & & $17 \%$ \\
\hline & $\$ 40,000-\$ 59,999$ & $22 \%$ & \\
\hline & $\$ 60,000-\$ 99,999$ & $24 \%$ & \\
\hline & $\$ 100,000-\$ 149,999$ & $24 \%$ & \\
\hline & $\$ 150,000$ or more & & $18 \%$ \\
\hline & Live in bushfire area & & $13 \%$ \\
\hline \multirow{5}{*}{$\begin{array}{l}\text { Household } \\
\text { structure }\end{array}$} & Person living alone & & $12 \%$ \\
\hline & Couple living alone & & $17 \%$ \\
\hline & Couple parent with children & $23 \% \bigcirc$ & \\
\hline & Single parent with children & $22 \%$ & \\
\hline & Share house & $30 \% \bigcirc$ & \\
\hline \multirow{2}{*}{$\begin{array}{l}\text { Government } \\
\text { assistance }\end{array}$} & Eligible for JobKeeper & $30 \%$ & \\
\hline & Eligible for JobSeeker & $36 \%$ & \\
\hline
\end{tabular}

C5W How has the quality of your relationships with other people/family members in your household changed since the COVID-19 restrictions started?

Base: $\quad$ All $(n=2,000)$

Note: $\quad$ Results for some subgroups are higher than others and not significantly different to the overall results due to small base sizes

Note: 'Not applicable - living alone' was offered to respondents as part of the code frame, with most of those living alone selecting this option ( $6 \%$ overall selected this option). 
Figure 21 Quality of relationships (stronger) with other people in household - Victorian and sub-population frequencies during the first lockdown

Note: Responses that are significantly more favourable than the Victorian overall result are on the right, highlighted in green. Responses that are significantly less favourable than the Victorian overall result are on the left, highlighted in blue.

\begin{tabular}{|c|c|c|c|}
\hline & & \multirow{2}{*}{\multicolumn{2}{|c|}{ Less favourable result $21 \%$}} \\
\hline & Victoria overall & & \\
\hline \multirow{2}{*}{ Gender } & Male & & $22 \%$ \\
\hline & Female & & $21 \%$ \\
\hline \multirow{7}{*}{ Age } & 18 to 24 years & & $30 \%$ \\
\hline & 25 to 34 years & & $31 \%$ \\
\hline & 35 to 44 years & $17 \%$ & \\
\hline & 45 to 54 years & $18 \%$ & \\
\hline & 55 to 64 years & $19 \%$ & \\
\hline & 65 to 74 years & $11 \% \bigcirc$ & \\
\hline & 75 or more & $15 \%$ & \\
\hline \multirow{5}{*}{ SEIFA } & Lowest - 1 & $19 \%$ & \\
\hline & 2 & & $23 \%$ \\
\hline & 3 & $17 \%$ & \\
\hline & 4 & $18 \%$ & \\
\hline & Highest -5 & & $-28 \%$ \\
\hline \multirow{7}{*}{ Region } & Inner metro & & $26 \%$ \\
\hline & Middle metro & & $24 \%$ \\
\hline & Outer metro & & $22 \%$ \\
\hline & Interface & $20 \%$ & \\
\hline & Regional city & $13 \% \bigcirc$ & \\
\hline & Large shire & $20 \%$ & \\
\hline & Small shire & $20 \%$ & \\
\hline \multicolumn{2}{|c|}{ Aboriginal and Torres Strait Islander } & & $36 \%$ \\
\hline \multicolumn{2}{|c|}{ Language other than English at home } & & $30 \%$ \\
\hline & Self-reported disability & & $23 \%$ \\
\hline \multirow{5}{*}{$\begin{array}{l}\text { Main activity in } \\
\text { February } 2020\end{array}$} & Employed & & $25 \%$ \\
\hline & Unemployed & & $22 \%$ \\
\hline & Home duties & & $21 \%$ \\
\hline & Student & & $29 \%$ \\
\hline & Retired & $15 \% \bigcirc$ & \\
\hline \multirow{5}{*}{ Income } & Less than $\$ 40,000$ & $16 \%$ & \\
\hline & $\$ 40,000-\$ 59,999$ & $19 \%$ & \\
\hline & $\$ 60,000-\$ 99,999$ & & $24 \%$ \\
\hline & $\$ 100,000-\$ 149,999$ & & \begin{tabular}{|l|l} 
\\
\end{tabular} \\
\hline & $\$ 150,000$ or more & & \begin{tabular}{|l} 
\\
\end{tabular} \\
\hline \multirow{6}{*}{$\begin{array}{l}\text { Household } \\
\text { structure }\end{array}$} & Live in bushfire area & & $36 \%$ \\
\hline & Person living alone & $6 \%$ & \\
\hline & Couple living alone & $20 \%$ & \\
\hline & Couple parent with children & & $30 \%$ \\
\hline & Single parent with children & & $28 \%$ \\
\hline & Share house & $16 \%$ & \\
\hline \multirow{3}{*}{$\begin{array}{l}\text { Government } \\
\text { assistance }\end{array}$} & Eligible for JobKeeper & & $30 \%$ \\
\hline & Eligible for JobSeeker & & $26 \%$ \\
\hline & & $\begin{array}{l}\text { Significantly less } \\
\text { favourable result }\end{array}$ & $\begin{array}{l}\text { Significantly more } \\
\text { favourable result }\end{array}$ \\
\hline
\end{tabular}

C5W How has the quality of your relationships with other people/family members in your household changed since the COVID-19 restrictions started?

Base: $\quad$ All $(n=2,000)$

Note: $\quad$ Results for some subgroups are higher than others and not significantly different to the overall results due to small base sizes

Note: 'Not applicable - living alone' was offered to respondents as part of the code frame, with most of those living alone selecting this option ( $6 \%$ overall selected this option). 


\section{PHYSICAL ACTIVITY}

VicHealth Coronavirus Victorian Wellbeing Impact Study

A comprehensive survey of 2,000 Victorians in the first coronavirus lockdown of 2020 showed most of those able to continue being active did so, but there were some limiting factors.
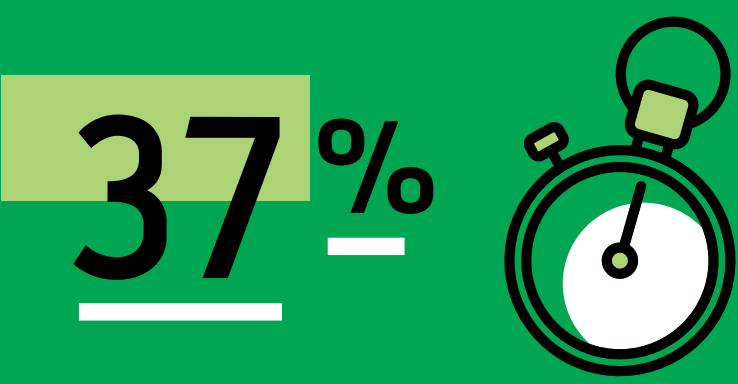

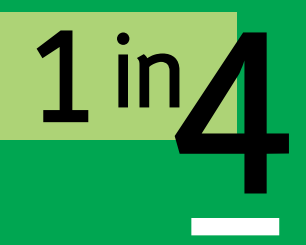

1 in $4(27 \%)$ people in Victoria were physically inactive during lockdown*

*Physically inactive: exercising 0-1 days per week

\section{2 in 5 Victorians (37\%)}

exercised less in the first lockdown compared to February 2020

1 in 3 Victorians who exercised less in lockdown didn't have regular access to a space to exercise at home

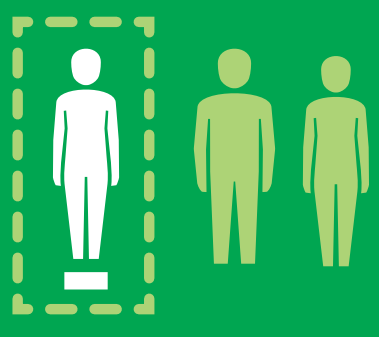

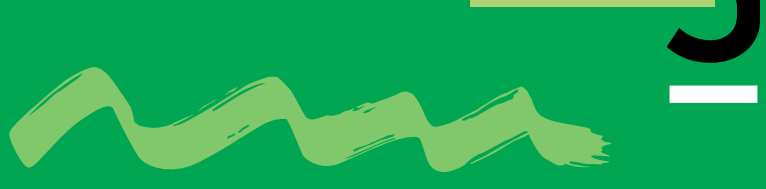

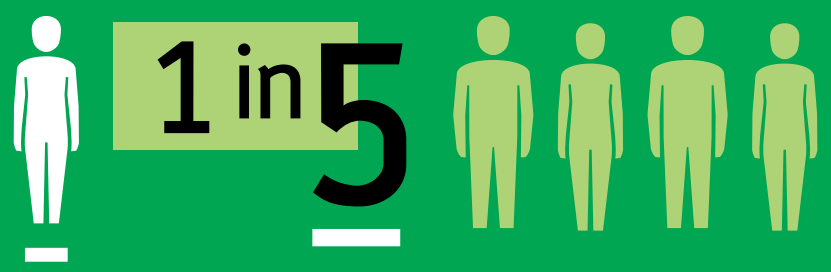

Almost 1 in 5 Victorians who exercised less in lockdown had no one to exercise with or didn't feel safe outside

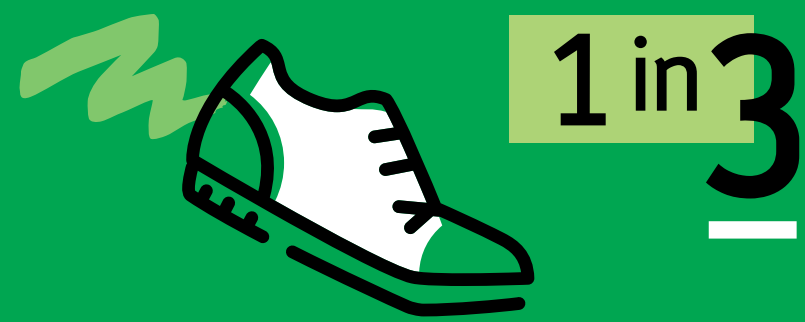

Around 1 in 3 Victorians who were more active during lockdown were motivated by:

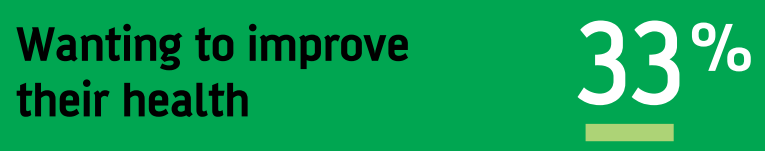

Wanting to get out

$31 \%$ of the house

$34 \%$

Having more free time

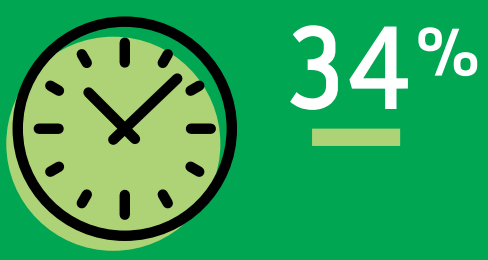




\section{Findings: Physical activity}

Frequent physical activity is an important part of maintaining a healthy lifestyle both in terms of physical health and emotional wellbeing. As many recreational facilities were closed due to coronavirus, access to people's preferred physical activity may have been limited. Closures impacted many forms of recreational activity, gyms and pools were closed, sporting clubs were restricted from meeting for training, and extended travel for physical activity was discouraged.

To measure changes in physical activity the survey asked respondents to provide a measure for frequency of physical activity ${ }^{16},{ }^{16}$ :

- during the first Victorian coronavirus lockdown

- $\quad$ for the period before the first coronavirus lockdown (February 2020).

Respondents were also asked whether they felt that this frequency had increased or decreased and were asked to provide reasons for any changes in frequency or in the types of activities they participated in.

Physical Activity

\section{Impact on physical activity}

- One in three respondents (32\%) were sufficiently active by participating in physical activity five or more days a week during lockdown. This is slightly less than in February 2020 (37\%), and similar to the 2015 comparison survey (30\%).

- About one in four (27\%) respondents reported they were inactive (0-1 day of physical activity per week) during lockdown. This is slightly higher than in February $2020(20 \%)$, but the same as the 2015 comparison survey $(27 \%)$.

- The types of physical activity undertaken during lockdown remained similar to the activity types undertaken in February 2020. Walking remained the most common form of physical activity (73\% during restrictions, $77 \%$ during February 2020$)$. Muscle strengthening exercises at home was the next most common form of physical activity $(29 \%$ during restrictions, 23\% during February 2020).

\section{Factors influencing these changes}

- Reasons for decreases in physical activity levels provided by respondents included:

- having restricted access to exercise spaces at home (29\%)

$\circ \quad$ having no one to exercise with (18\%)

- not feeling safe to exercise outside (17\%).

- $\quad$ Some also reported that they were doing less activity as they were concerned about catching coronavirus $(26 \%)$ or had low motivation $(39 \%)$.

\footnotetext{
${ }^{16}$ VHI 2015 - https://www.vichealth.vic.gov.au/media-and-resources/publications/vichealth-indicators-report-2015 16 O'Halloran P, Kingsley M, Nicholson M, Staley K, Randle E, Wright A, et al. Validity of the single item measure to assess change in physical activity. PloS one. 2020;15(6):e0234420.
} 
- Common reasons for increased levels of physical activity during the coronavirus lockdown included:

○ having more time $(34 \%)$

○ wanting to improve health (33\%)

$\circ$ to get out of the house $(31 \%)$.

\section{Variation by subgroups}

- The impact of the first lockdown on physical activity varied by gender. The proportion of men who did physical activity on five or more days a week dropped from $42 \%$ in February 2020 to $35 \%$ during lockdown. Women reported a slightly lower degree of change in activity (doing five or more days per week) between the two time periods, going from $33 \%$ in February 2020 to $29 \%$ during lockdown. However, women's level of insufficient physical activity ( $0-1$ day per week) increased more compared to men, 8 percentage points compared to 6 percentage points.

- Large changes are also seen among Aboriginal and Torres Strait Islanders (52\% in February 2020 and $38 \%$ during lockdown) and similarly among students (34\% and $22 \%$ respectively).

\section{Active}

(physically active for at least 30 minutes,

5 or more days each week)

\section{Inactive}

(physically active for at least 30 minutes, 0 or 1 days each week)

VHI 2015 - https://www.vichealth.vic.gov.au/media-and-resources/publications/vichealth-indicators-report-2015

Note: The VHI 2015 Inactive and Active results reported in the table above are based on new research ${ }^{16}$ and re-analysis of VHI 2015 data using different categories for physical activity levels of at least 30 minutes per day, where 0-1 days per week = inactive, 2-4 days per week = somewhat active and 5-7 days per week $=$ active . The VHI 2015 Selected Findings Report used the categories 0 days per week, $1-3$ days per week and $4-7$ days per week. 


\subsubsection{Frequency of physical activity}

Victorians were doing less physical activity during the first Victorian coronavirus lockdown than in February 2020. The proportion of those doing no physical activity or one day of at least 30 minutes of physical activity per week increased from $20 \%$ in February 2020 to $27 \%$ during the first Victorian coronavirus lockdown.

Figure 22 Frequency of physical activity

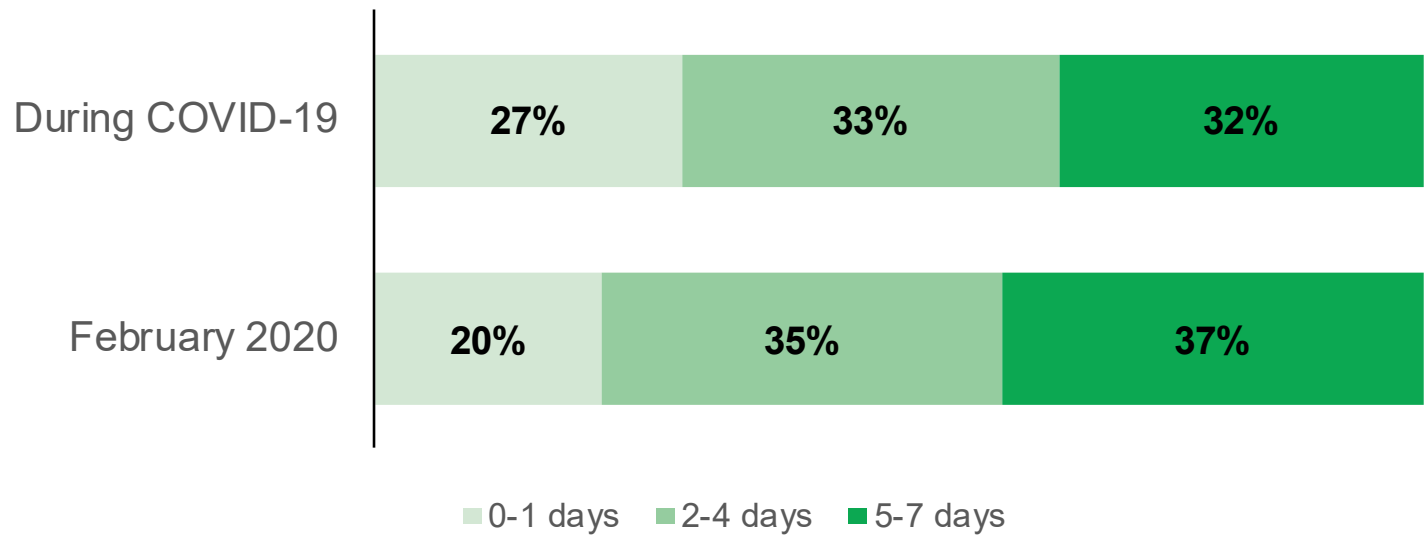

\footnotetext{
B4a. Days exercised during the first lockdown

B4b. Days exercised during February 2020

Base: $\quad$ All $(n=2,000)$

Note: Not shown; not sure $(6 \%, 6 \%)$, prefer not to say $(2 \%, 2 \%)$
}

The following figures break down changes in physical activity frequency by subgroups. Initially presenting the proportion participating in at least 30 minutes of physical activity five or more days per week and subsequently those participating in at least 30 minutes of physical activity $0-1$ day per week. 
Figure 2330 minutes of physical activity, five or more days per week - Victorian and sub-population frequencies during the first lockdown

Note: Responses that are significantly more favourable than the Victorian overall result are on the right, highlighted in green. Responses that are significantly less favourable than the Victorian overall result are on the left, highlighted in blue.

\begin{tabular}{|c|c|c|c|}
\hline & & 4 Less favourable result & More favourable result \\
\hline & Victoria overall & & $32 \%$ \\
\hline & Male & & $35 \%$ \\
\hline Gender & Female & $29 \%$ & \\
\hline & 18 to 24 years & $29 \%$ & \\
\hline & 25 to 34 years & & $41 \%$ \\
\hline & 35 to 44 years & $24 \%$ & \\
\hline Age & 45 to 54 years & $31 \%$ & \\
\hline & 55 to 64 years & $31 \%$ & \\
\hline & 65 to 74 years & & $34 \%$ \\
\hline & 75 or more & $30 \%$ & \\
\hline & Lowest - 1 & $25 \%$ & \\
\hline & 2 & & $35 \%$ \\
\hline SEIFA & 3 & $30 \%$ & \\
\hline & 4 & $31 \%$ & \\
\hline & Highest -5 & & $37 \%$ \\
\hline & Inner metro & & $43 \%$ \\
\hline & Middle metro & $31 \%$ & \\
\hline & Outer metro & & $33 \%$ \\
\hline Region & Interface & $29 \%$ & \\
\hline & Regional city & & $32 \%$ \\
\hline & Large shire & $31 \%$ & \\
\hline & Small shire & & $34 \%$ \\
\hline Abo & and Torres Strait Islander & & $38 \%$ \\
\hline Lang & ther than English at home & & $33 \%$ \\
\hline & Self-reported disability & $30 \%$ & \\
\hline & Employed & & $37 \%$ \\
\hline & Unemployed & $29 \%$ & \\
\hline $\begin{array}{l}\text { Main activity in } \\
\text { February } 2020\end{array}$ & Home duties & $26 \%$ & \\
\hline & Student & $22 \%$ & \\
\hline & Retired & & $34 \%$ \\
\hline & Less than $\$ 40,000$ & $30 \%$ & \\
\hline & $\$ 40,000-\$ 59,999$ & $31 \%$ & \\
\hline Income & $\$ 60,000-\$ 99,999$ & $30 \%$ & \\
\hline & $\$ 100,000-\$ 149,999$ & & $38 \%$ \\
\hline & $\$ 150,000$ or more & & $39 \%$ \\
\hline & Live in bushfire area & & $47 \%$ \\
\hline & Person living alone & $30 \%$ & \\
\hline & Couple living alone & & $36 \%$ \\
\hline $\begin{array}{l}\text { Household } \\
\text { structure }\end{array}$ & Couple parent with children & & $33 \%$ \\
\hline & Single parent with children & $26 \%$ & \\
\hline & Share house & $25 \% \mathrm{C}=$ & \\
\hline $\begin{array}{l}\text { Government } \\
\text { assistance }\end{array}$ & Eligible for JobKeeper & & $38 \%$ \\
\hline & & $\begin{array}{l}\text { Significantly less } \\
\text { favourable result }\end{array}$ & $\begin{array}{l}\text { Significantly more } \\
\text { favourable result }\end{array}$ \\
\hline
\end{tabular}

B4a. In a usual week, on how many days do you do a total of 30 minutes or more of physical activity, which was enough to raise your breathing rate? During the first lockdown

Base: $\quad$ All $(n=2,000)$

Note: $\quad$ Results for some subgroups are higher than others and not significantly different to the overall results due to small base sizes 
Figure 2430 minutes of physical activity five or more days per week - Victorian and sub-population frequencies during February 2020

Note: Responses that are significantly more favourable than the Victorian overall result are on the right, highlighted in green. Responses that are significantly less favourable than the Victorian overall result are on the left, highlighted in blue.

\begin{tabular}{|c|c|c|c|}
\hline \multicolumn{4}{|c|}{4 Less favourable result } \\
\hline & Victoria overall & & $37 \%$ \\
\hline \multirow{2}{*}{ Gender } & Male & & $42 \%$ \\
\hline & Female & $33 \% \bigcirc$ & \\
\hline \multirow{7}{*}{ Age } & 18 to 24 years & & $38 \%$ \\
\hline & 25 to 34 years & & $44 \%$ \\
\hline & 35 to 44 years & $30 \% \bigcirc$ & \\
\hline & 45 to 54 years & $35 \% \mathrm{C}$ & \\
\hline & 55 to 64 years & $33 \%$ & \\
\hline & 65 to 74 years & & $41 \%$ \\
\hline & 75 or more & & $42 \%$ \\
\hline \multirow{5}{*}{ SEIFA } & Lowest -1 & $36 \%$ & \\
\hline & 2 & & $38 \%$ \\
\hline & 3 & & $41 \%$ \\
\hline & 4 & $36 \%$ & \\
\hline & Highest -5 & & $37 \%$ \\
\hline \multirow{7}{*}{ Region } & Inner metro & & $46 \%$ \\
\hline & Middle metro & $33 \%$ & \\
\hline & Outer metro & & $39 \%$ \\
\hline & Interface & & $38 \%$ \\
\hline & Regional city & & $39 \%$ \\
\hline & Large shire & & $38 \%$ \\
\hline & Small shire & $31 \%$ & \\
\hline \multicolumn{2}{|c|}{ Aboriginal and Torres Strait Islander } & & $52 \%$ \\
\hline \multicolumn{2}{|c|}{ Language other than English at home } & & $40 \%$ \\
\hline & Self-reported disability & $36 \%$ & \\
\hline \multicolumn{3}{|c|}{ Employed } & $42 \%$ \\
\hline \multirow{4}{*}{$\begin{array}{c}\text { Main activity in } \\
\text { February } 2020\end{array}$} & Unemployed & $29 \%$ & \\
\hline & Home duties & $32 \%$ & \\
\hline & Student & $34 \%$ & \\
\hline & Retired & & $39 \%$ \\
\hline \multirow{5}{*}{ Income } & Less than $\$ 40,000$ & & $38 \%$ \\
\hline & $\$ 40,000-\$ 59,999$ & $35 \%$ & \\
\hline & $\$ 60,000-\$ 99,999$ & & $37 \%$ \\
\hline & $\$ 100,000-\$ 149,999$ & & $43 \%$ \\
\hline & $\$ 150,000$ or more & & $38 \%$ \\
\hline & Live in bushfire area & & $47 \%$ \\
\hline \multirow{5}{*}{$\begin{array}{l}\text { Household } \\
\text { structure }\end{array}$} & Person living alone & & $39 \%$ \\
\hline & Couple living alone & & $41 \%$ \\
\hline & Couple parent with children & $36 \%$ & \\
\hline & Single parent with children & & $37 \%$ \\
\hline & Share house & $32 \%$ & \\
\hline $\begin{array}{l}\text { Government } \\
\text { assistance }\end{array}$ & $\begin{array}{l}\text { Eligible for JobKeeper } \\
\text { Eligible for JobSeeker }\end{array}$ & & $41 \%$ \\
\hline
\end{tabular}

B4b. In a usual week, on how many days do you do a total of 30 minutes or more of physical activity, which was enough to raise your breathing rate? During February 2020

Base: $\quad$ All $(n=2,000)$

Note: $\quad$ Results for some subgroups are higher than others and not significantly different to the overall results due to small base sizes 
Figure 2530 minutes of physical activity, five or more days per week - Victorian and sub-population frequencies during the first lockdown compared to February 2020

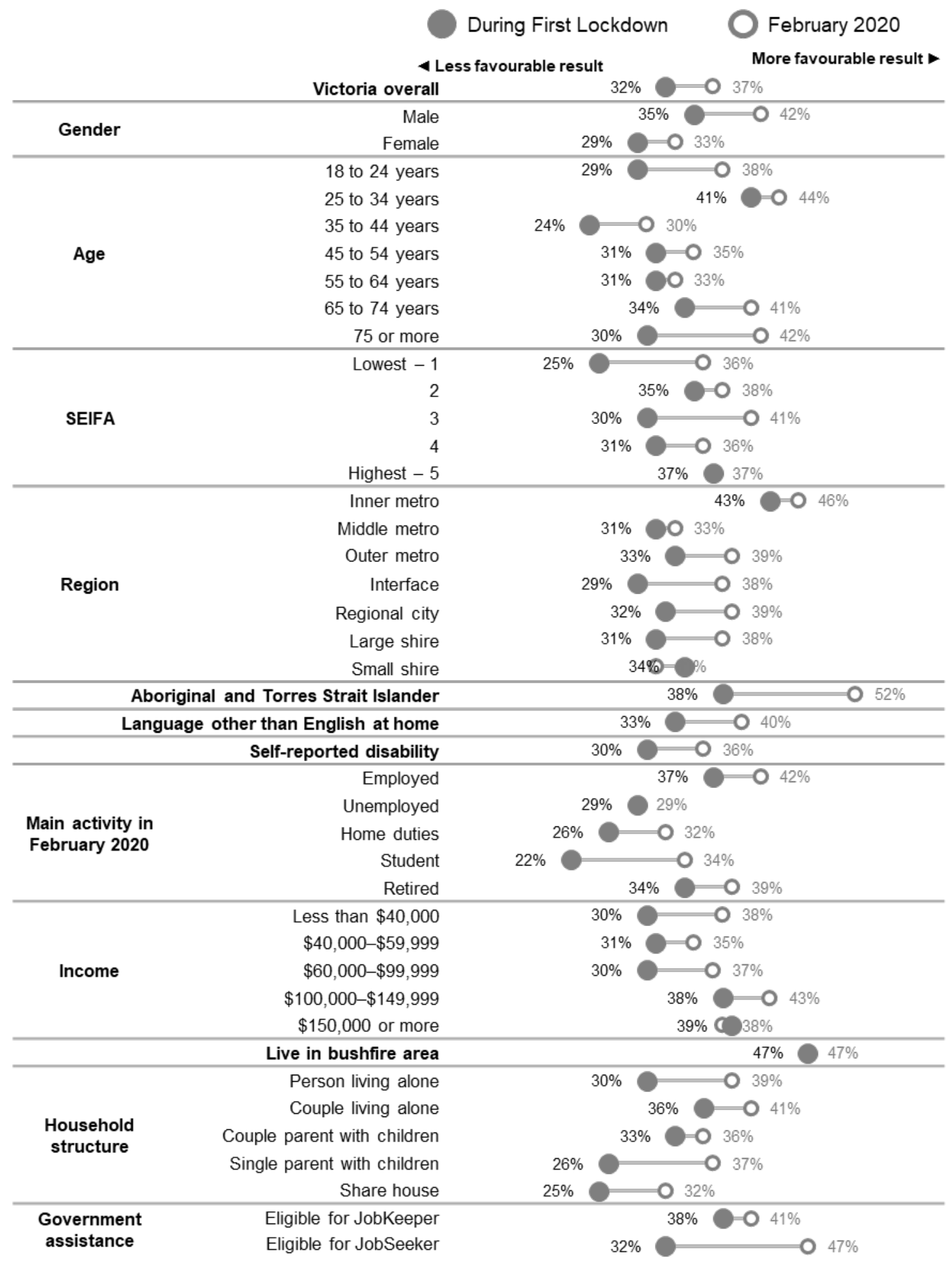

\footnotetext{
B4a. In a usual week, on how many days do you do a total of 30 minutes or more of physical activity, which was enough to raise your breathing rate? During the first lockdown

B4b. In a usual week, on how many days do you do a total of 30 minutes or more of physical activity, which was enough to raise your breathing rate? During February 2020

Base: $\quad$ All $(n=2,000)$
} 
Figure 2630 minutes of physical activity, 1 to 0 days per week - Victorian and sub-population frequencies during the first lockdown

Note: Responses that are significantly more favourable than the Victorian overall result are on the right, highlighted in green. Responses that are significantly less favourable than the Victorian overall result are on the left, highlighted in blue.

\begin{tabular}{|c|c|c|c|}
\hline & & 4 Less favourable result & More favourable result $\downarrow$ \\
\hline & Victoria overall & & $27 \%$ \\
\hline & Male & & $23 \%$ \\
\hline Gender & Female & $30 \%$ & \\
\hline & 18 to 24 years & & $19 \%$ \\
\hline & 25 to 34 years & & $17 \%$ \\
\hline & 35 to 44 years & $28 \%$ & \\
\hline Age & 45 to 54 years & $29 \%$ & \\
\hline & 55 to 64 years & $33 \%$ & \\
\hline & 65 to 74 years & $32 \%$ & \\
\hline & 75 or more & $37 \%$ & \\
\hline & Lowest - 1 & & $23 \%$ \\
\hline & 2 & & $25 \%$ \\
\hline SEIFA & 3 & $33 \%$ & \\
\hline & 4 & & $27 \%$ \\
\hline & Highest -5 & & $24 \%$ \\
\hline & Inner metro & & $17 \%$ \\
\hline & Middle metro & $29 \%$ & \\
\hline & Outer metro & & $19 \%$ \\
\hline Region & Interface & $29 \%$ & \\
\hline & Regional city & & $25 \%$ \\
\hline & Large shire & $33 \%$ & \\
\hline & Small shire & $34 \%$ & \\
\hline Abo & I and Torres Strait Islander & & $6 \%$ \\
\hline Lang & other than English at home & & $26 \%$ \\
\hline & Self-reported disability & $39 \% \bigcirc$ & \\
\hline & Employed & & $22 \%$ \\
\hline & Unemployed & & $27 \%$ \\
\hline $\begin{array}{l}\text { Main activity in } \\
\text { February } 2020\end{array}$ & Home duties & $28 \%$ & \\
\hline & Student & & $27 \%$ \\
\hline & Retired & $32 \%$ & \\
\hline & Less than $\$ 40,000$ & $31 \% \mathrm{C}$ & \\
\hline & $\$ 40,000-\$ 59,999$ & $30 \%$ & \\
\hline Income & $\$ 60,000-\$ 99,999$ & & $26 \%$ \\
\hline & $\$ 100,000-\$ 149,999$ & & $20 \%$ \\
\hline & $\$ 150,000$ or more & & $23 \%$ \\
\hline & Live in bushfire area & & $22 \%$ \\
\hline & Person living alone & $29 \%$ & \\
\hline & Couple living alone & & $27 \%$ \\
\hline $\begin{array}{l}\text { Household } \\
\text { structure }\end{array}$ & Couple parent with children & & $27 \%$ \\
\hline & Single parent with children & & $20 \%$ \\
\hline & Share house & $31 \%$ & \\
\hline $\begin{array}{l}\text { Government } \\
\text { assistance }\end{array}$ & $\begin{array}{l}\text { Eligible for JobKeeper } \\
\text { Eligible for JobSeeker }\end{array}$ & & $22 \%$ \\
\hline & & $\begin{array}{l}\text { Significantly less } \\
\text { favourable result }\end{array}$ & $\begin{array}{l}\text { Significantly more } \\
\text { favourable result }\end{array}$ \\
\hline
\end{tabular}

B4a. In a usual week, on how many days do you do a total of 30 minutes or more of physical activity, which was enough to raise your breathing rate? During the first lockdown

Base: $\quad$ All $(n=2,000)$

Note: Results for some subgroups are lower than other and not significantly different to the overall results due to small base sizes 
Figure 2730 minutes of physical activity, 0 to 1 days per week - Victorian and sub-population frequencies during February 2020

Note: Responses that are significantly more favourable than the Victorian overall result are on the right, highlighted in green. Responses that are significantly less favourable than the Victorian overall result are on the left, highlighted in blue.

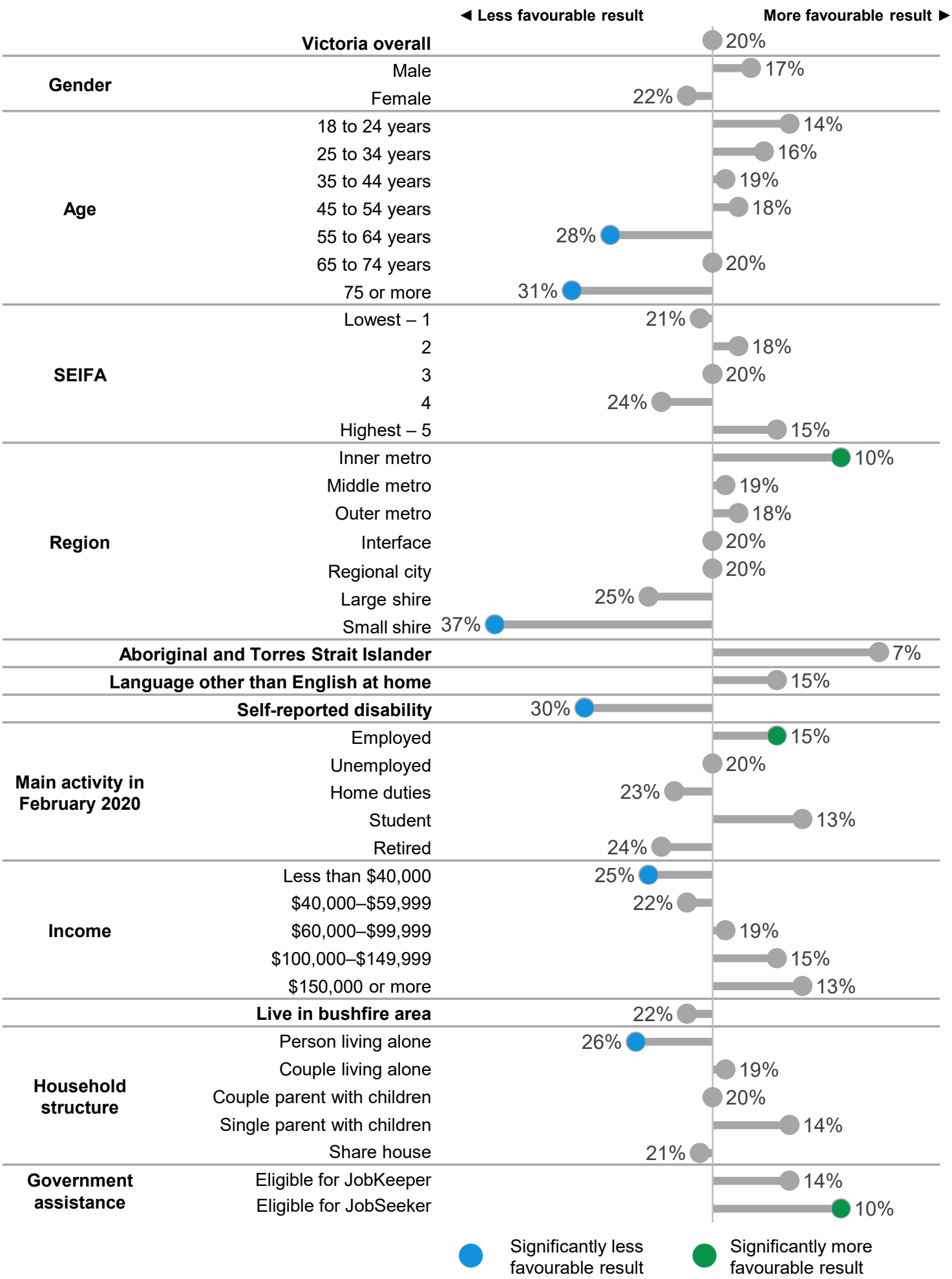

B4b. In a usual week, on how many days do you do a total of 30 minutes or more of physical activity, which was enough to raise your breathing rate? During February 2020

Base: $\quad$ All $(n=2,000)$

Note: $\quad$ Results for some subgroups are higher than others and not significantly different to the overall results due to small base sizes 
Figure 2830 minutes of physical activity, 1 to 0 days per week - Victorian and sub-population frequencies during the first lockdown compared to February 2020

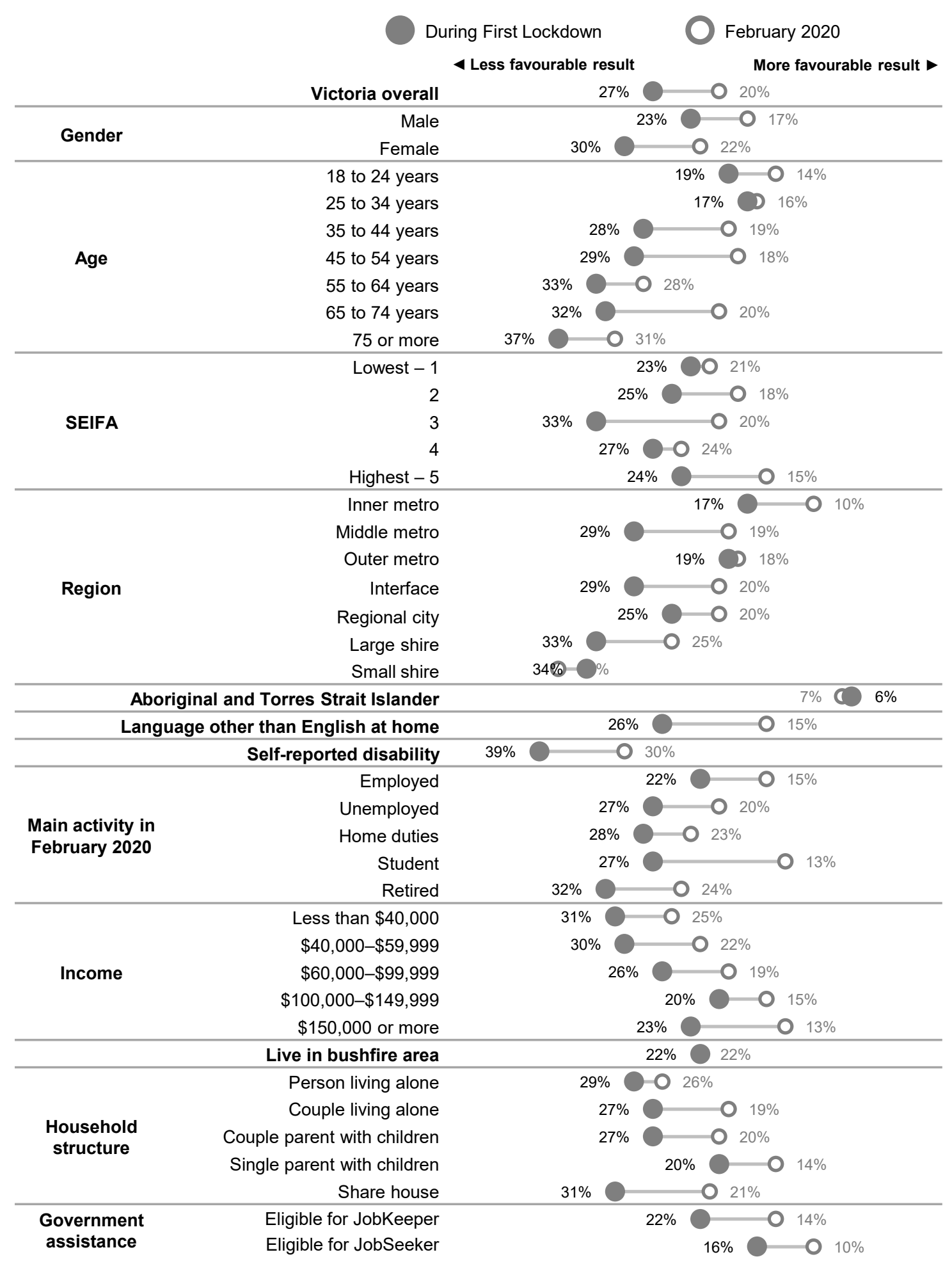

\footnotetext{
B4a. In a usual week, on how many days do you do a total of 30 minutes or more of physical activity, which was enough to raise your breathing rate? During the first lockdown

B4b. In a usual week, on how many days do you do a total of 30 minutes or more of physical activity, which was enough to raise your breathing rate? During February 2020

Base: $\quad$ All $(n=2,000)$
} 
The previous figures show that decreases in physical activity frequency had occurred for most subgroups during the first lockdown. Respondents were also asked to provide a subjective assessment of whether they were doing more or less physical activity during the first Victorian coronavirus lockdown.

One in five respondents $(21 \%)$ reported that they were doing more physical activity during the first lockdown in comparison to February 2020. Two in five (37\%) reported that they were doing less activity. This decrease in activity is fairly consistent with the findings earlier in this section indicating that the levels of activity of Victorians during the first lockdown restriction was lower than during the month before restrictions.

Figure 29 Levels of physical activities during the first lockdown compared to February 2020

(more, same, less)

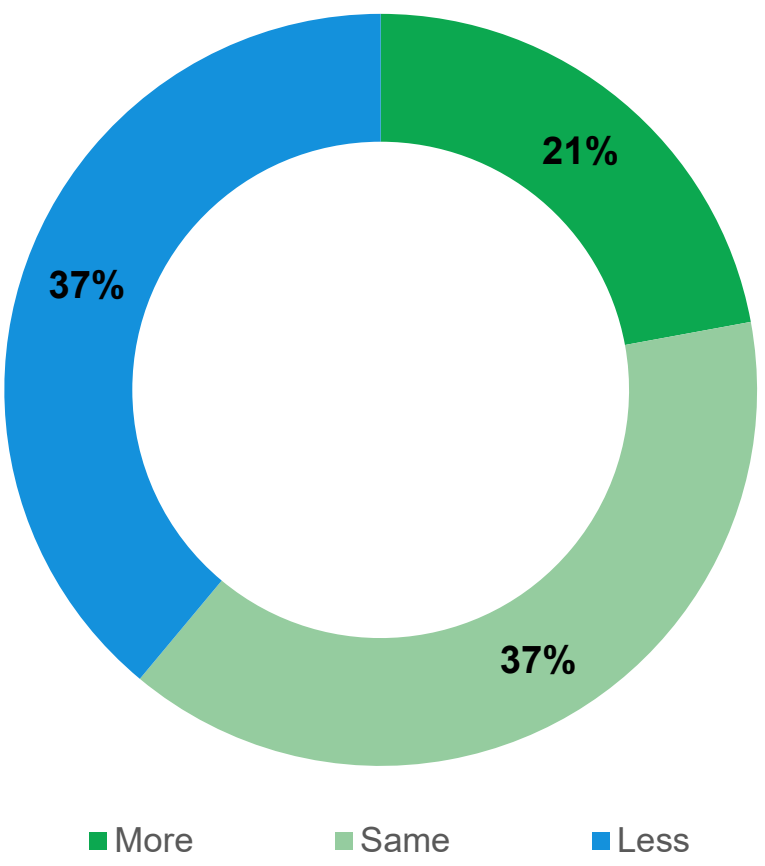

B1. Overall, do you feel you are doing more, less or about the same level of physical activity now - during COVID-19 restrictions, compared to February 2020?

Base: $\quad$ All $(n=2,000)$

Note: $\quad$ Not shown; not sure (3\%), prefer not to say (1\%) 


\subsection{Reasons for changes in physical activity levels}

To further understand why levels of activity may have changed during the first Victorian coronavirus lockdown, respondents who had indicated they were doing less physical activity were asked about the main reason this was occurring. Those who felt they were doing more, or the same level of physical activity, were asked for the main reason for the change or why they had not been impacted.

Responses to these questions may help identify the barriers to participation and how increased physical activity can be facilitated. Respondents were asked to provide the main reason for these changes; however, they were able to select multiple responses.

\subsubsection{Reasons for decreased physical activity levels}

Struggles with getting motivated (39\%) was the most commonly reported reason why respondents were participating in less physical activity during the first Victorian coronavirus lockdown.

Not having exercise space at home (29\%), not having people to exercise with (18\%), and not feeling safe to be physically active outside the home $(16 \%)$ were commonly reported barriers to physical activity. Limited access to parks or paths were more commonly reported by those from low socioeconomic status areas (SEIFA level 1,24\%).

One in four respondents $(26 \%)$ reported that their concerns about catching coronavirus had caused a decrease in the amount of physical activity they were doing. These concerns were higher among those in outer metro Melbourne (39\%).

Figure $\mathbf{3 0}$ Main reason for less physical activity during the first lockdown

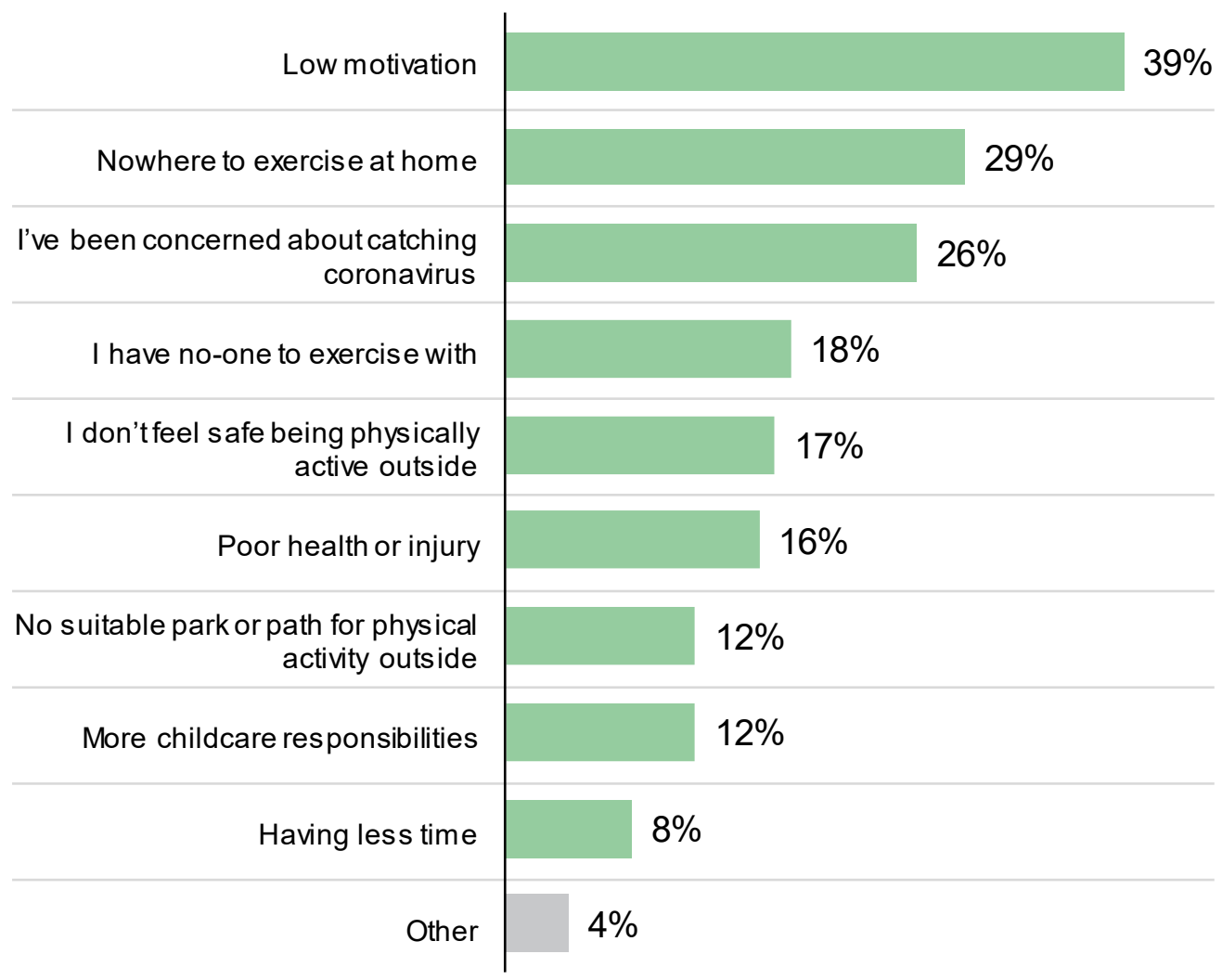

B2. What is the main reason your physical activity level has been less during the COVID-19 restrictions?

Note: Not shown; not sure (2\%), prefer not to say (1\%) 
Subgroups showing significantly different reasons for decreased physical activity are presented in the table below.

Table 4 Reasons for less physical activity during the first lockdown - subpopulation frequencies that are significantly different to the overall Victorian level

\begin{tabular}{|c|c|c|c|c|c|}
\hline \multirow[t]{2}{*}{$\begin{array}{l}\text { Reason for less } \\
\text { physical activity }\end{array}$} & \multirow[t]{2}{*}{$\begin{array}{l}\text { Victoria } \\
\text { overall }\end{array}$} & \multicolumn{2}{|c|}{$\begin{array}{l}\text { Sub-groups who report this } \\
\text { more often }\end{array}$} & \multicolumn{2}{|c|}{$\begin{array}{l}\text { Sub-groups who report this } \\
\text { less often }\end{array}$} \\
\hline & & Eligible for JobKeeper & $57 \%$ & Retired & $26 \%$ \\
\hline Low motivation & $39 \%$ & 25 to 34 years & $55 \%$ & Eligible for JobSeeker & $20 \%$ \\
\hline \multirow{3}{*}{$\begin{array}{l}\text { More childcare } \\
\text { responsibilities }\end{array}$} & \multirow{3}{*}{$12 \%$} & 35 to 44 years & $36 \%$ & 65 to 74 years & $3 \%$ \\
\hline & & Home duties & $26 \%$ & 55 to 64 years & $3 \%$ \\
\hline & & $\$ 100,000-\$ 149,999$ & $24 \%$ & Retired & $2 \%$ \\
\hline \multirow{3}{*}{$\begin{array}{l}\text { I have no one to } \\
\text { exercise with }\end{array}$} & \multirow{3}{*}{$18 \%$} & Unemployed & $33 \%$ & $\$ 150,000$ or more & $8 \%$ \\
\hline & & & & Eligible for JobKeeper & $8 \%$ \\
\hline & & & & SEIFA 1 & $5 \%$ \\
\hline \multirow{3}{*}{ Poor health or injury } & \multirow{3}{*}{$16 \%$} & Has disability & $47 \%$ & Employed & $8 \%$ \\
\hline & & Retired & $33 \%$ & 35 to 44 years & $8 \%$ \\
\hline & & 65 to 74 years & $28 \%$ & 18 to 24 years & $4 \%$ \\
\hline $\begin{array}{l}\text { I've been concerned } \\
\text { about catching } \\
\text { coronavirus }\end{array}$ & $26 \%$ & Outer metro & $39 \%$ & & \\
\hline \multirow[t]{2}{*}{$\begin{array}{c}\text { No suitable park or } \\
\text { path for physical } \\
\text { activity outside }\end{array}$} & $12 \%$ & SEIFA 1 & $24 \%$ & & \\
\hline & & 35 to 44 years & $19 \%$ & Has disability & $2 \%$ \\
\hline \multirow[t]{2}{*}{ Having less time } & $8 \%$ & $\$ 100,000-\$ 149,999$ & $16 \%$ & 55 to 64 years & $2 \%$ \\
\hline & & Employed & $13 \%$ & 65 to 74 years & $1 \%$ \\
\hline
\end{tabular}

\subsubsection{Reasons for increased or maintained physical activity levels}

Changes in lifestyles due to coronavirus restrictions have allowed many to increase or maintain their levels of physical activity. One in three $(34 \%)$ had more time in their lives allowing them to increase their participation in physical activity. One in eight (15\%) found that working from home arrangements facilitated an increased or maintained physical activity regime.

Another common reason for more or the same amount of physical activity was linked to the benefits of a healthy physical activity regime. One in three $(33 \%)$ of those doing more or the same amount physical activity reported that they were doing so to improve their health. For a similar proportion $(31 \%)$, physical activity was a way to get out of the house. 
Figure 31 Main reason for more or the same level of physical activity during the first Victorian coronavirus lockdown

\begin{tabular}{|c|c|c|}
\hline Having more time & & $34 \%$ \\
\hline $\begin{array}{r}\text { I wanted to improve my health in } \\
\text { general }\end{array}$ & & $33 \%$ \\
\hline To get out of the house & & $31 \%$ \\
\hline I like my local area & $22 \%$ & \\
\hline $\begin{array}{r}\text { I have more flexible work } \\
\text { arrangements }\end{array}$ & $15 \%$ & \\
\hline $\begin{array}{r}\text { I like catching up with others whilst } \\
\text { exercising }\end{array}$ & $7 \%$ & \\
\hline Less childcare responsibilities & $3 \%$ & \\
\hline Other & $7 \%$ & \\
\hline
\end{tabular}

B3 What is the main reason your physical activity level has been more (or same) during the COVID-19 restrictions? Base: Doing more or the same physical activity $(n=1,179)$

Note: $\quad$ Not shown; not sure $(11 \%)$, prefer not to say $(1 \%)$

Subgroups showing significantly different reasons for increased or maintained levels of physical activity are presented in the table below. 
Table 5 Subgroups with differing main reasons for more or maintained physical activity - subpopulation frequencies that are significantly different to the overall Victorian level

\begin{tabular}{|c|c|c|c|c|c|}
\hline \multirow[t]{2}{*}{$\begin{array}{l}\text { Reason for more } \\
\text { physical activity }\end{array}$} & \multirow[t]{2}{*}{$\begin{array}{l}\text { Victoria } \\
\text { overall }\end{array}$} & \multicolumn{2}{|c|}{$\begin{array}{l}\text { Sub-groups who report this } \\
\text { more often }\end{array}$} & \multicolumn{2}{|c|}{$\begin{array}{l}\text { Sub-groups who report this } \\
\text { less often }\end{array}$} \\
\hline & & 25 to 34 years & $49 \%$ & 55 to 64 years & $24 \%$ \\
\hline \multirow{5}{*}{ Having more time } & \multirow{5}{*}{$34 \%$} & $\$ 100,000-\$ 149,999$ & $43 \%$ & Less than $\$ 40,000$ & $25 \%$ \\
\hline & & \multirow[t]{4}{*}{ Employed } & \multirow[t]{4}{*}{$40 \%$} & SEIFA 1 & $21 \%$ \\
\hline & & & & Retired & $20 \%$ \\
\hline & & & & Has disability & $18 \%$ \\
\hline & & & & Large shire & $21 \%$ \\
\hline $\begin{array}{l}\text { I wanted to improve my } \\
\text { health in general }\end{array}$ & $33 \%$ & Retired & $43 \%$ & & \\
\hline \multirow{8}{*}{$\begin{array}{l}\text { I have more flexible } \\
\text { work arrangements }\end{array}$} & \multirow{8}{*}{$15 \%$} & 18 to 24 years & $33 \%$ & 55 to 64 years & $8 \%$ \\
\hline & & Inner metro & $31 \%$ & Regional city & $6 \%$ \\
\hline & & $\$ 150,000$ or more & $32 \%$ & Less than $\$ 40,000$ & $8 \%$ \\
\hline & & $\$ 100,000-\$ 149,999$ & $30 \%$ & Has disability & $7 \%$ \\
\hline & & Employed & $29 \%$ & Retired & $4 \%$ \\
\hline & & Eligible for JobKeeper & $26 \%$ & 65 to 74 years & $3 \%$ \\
\hline & & Eligible for JobSeeker & $25 \%$ & Home duties & $2 \%$ \\
\hline & & & & 75 or more & $2 \%$ \\
\hline $\begin{array}{l}\text { Less childcare } \\
\text { responsibilities }\end{array}$ & $3 \%$ & Home duties & $9 \%$ & & \\
\hline \multirow{3}{*}{ I like my local area } & \multirow{3}{*}{$22 \%$} & Live in bushfire area & $44 \%$ & Unemployed & $11 \%$ \\
\hline & & 18 to 24 years & $35 \%$ & & \\
\hline & & Retired & $30 \%$ & & \\
\hline \multirow{4}{*}{$\begin{array}{l}\text { I like catching up with } \\
\text { others while exercising }\end{array}$} & \multirow{4}{*}{$7 \%$} & Live in bushfire area & $29 \%$ & & \\
\hline & & Eligible for JobKeeper & $18 \%$ & & \\
\hline & & 18 to 24 years & $17 \%$ & & \\
\hline & & Employed & $10 \%$ & & \\
\hline \multirow{3}{*}{ To get out of the house } & \multirow{3}{*}{$31 \%$} & 65 to 74 years & $42 \%$ & LOTE & $21 \%$ \\
\hline & & Retired & $39 \%$ & 18 to 24 years & $19 \%$ \\
\hline & & & & Inner metro & $18 \%$ \\
\hline
\end{tabular}




\subsubsection{Participation in specific activities}

Examining changes in the types of physical activities that people are participating in may provide further insight into why some have been able to continue to regularly participate in physical activity while others have been limited.

The below figure shows that among those participating in physical activity at least once a week for 30 minutes the shifts in the types of activity have been minor. The largest change was an increase observed in those doing muscle strengthening exercises at home. It is important to note that while walking has declined slightly, overall it has stayed the same or increased in some sub-populations e.g. for women aged 45-54 it has remained steady at 93\%, and for women aged 55-64 it increased from $80 \%$ in February 2020 to $85 \%$ during the first lockdown.

Figure 32 Activities participated in during the first Victorian coronavirus lockdown and February 2020

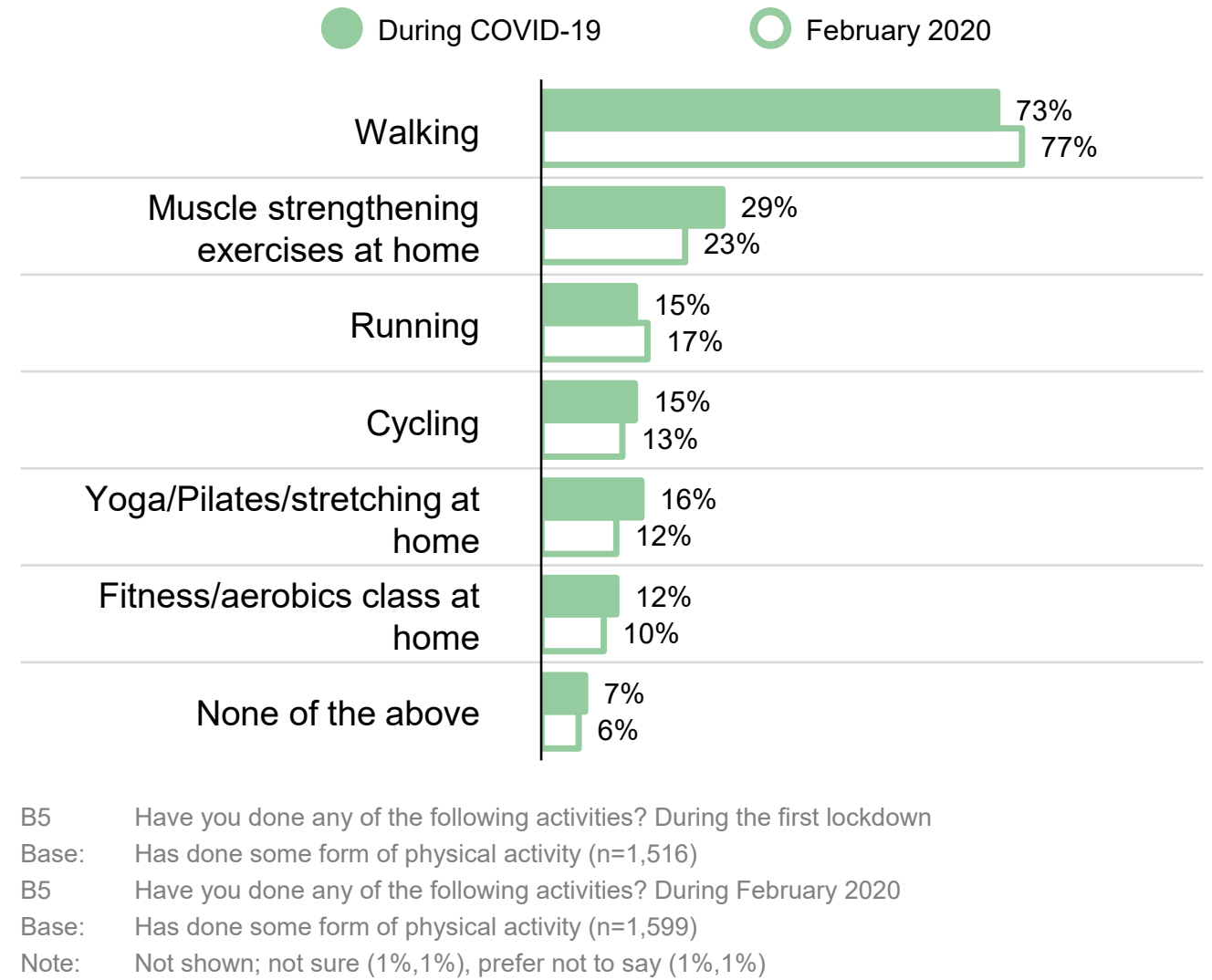




\section{HEALTHY EATING}

VicHealth Coronavirus Victorian Wellbeing Impact Study

A comprehensive survey of 2,000 Victorians in the first coronavirus lockdown of 2020 showed a rise in food insecurity and consumption of sugary drinks.

The number of Victorians drinking sugary drinks each day has tripled to $32 \%$

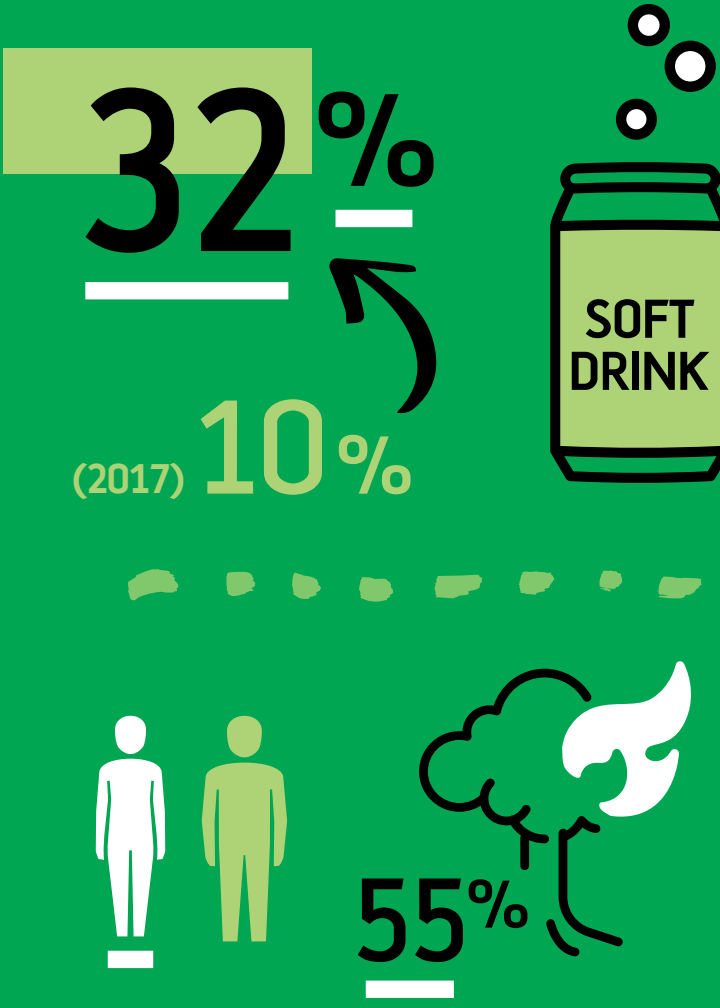

$55 \%$ of Victorians from bushfire affected communities drank sugary drinks daily, as did:

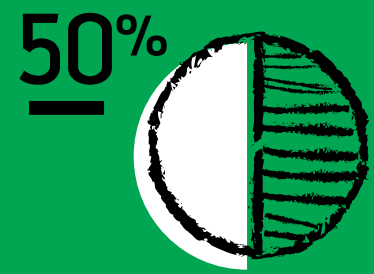

Young people aged 18-24

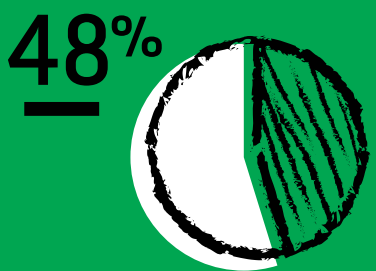

Men aged 45-54
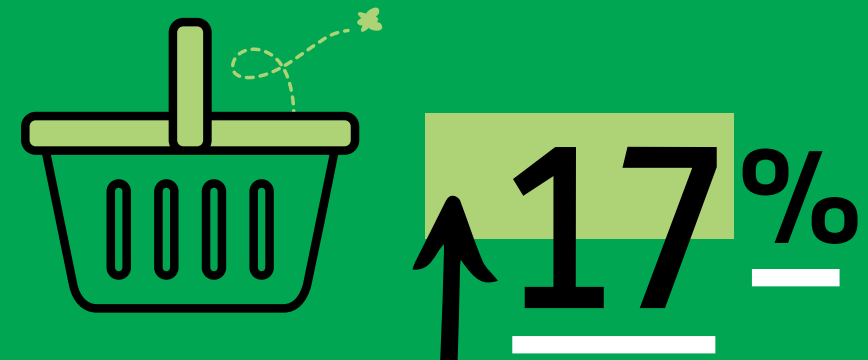

(सв:80202) $9 \%$

$17 \%$ of Victorians were worried about having enough money to buy food compared to $\mathbf{9} \%$ in Feb 2020

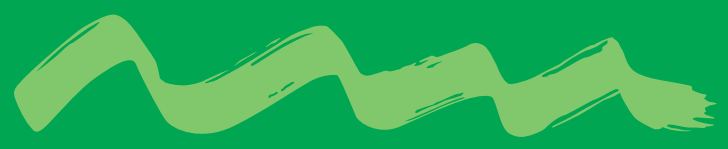

1 in 3 Victorians ate takeaway food less often, while a similar number cooked dinner more often
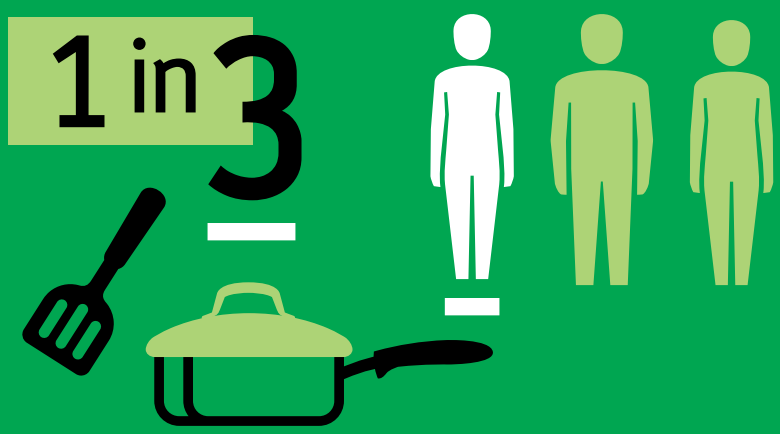

Of those cooking more, almost 1 in 2 (46\%) were doing so to save money

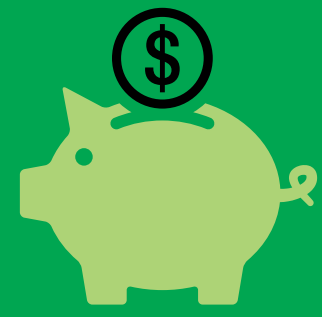




\section{Findings: Healthy eating}

\subsection{Food behaviours}

The first Victorian coronavirus lockdown had implications for Victoria's food system. Food supply issues, limits on the purchasing of certain food products, and restrictions on the services provided by cafes and restaurants to takeaway only, impacted Victorians food behaviours and food access in a variety of ways.

This section explores how these changes impacted Victorians' food behaviours and food access during the first coronavirus lockdown.

\section{Healthy eating}

\section{Impact on healthy eating}

- On average, respondents were eating more serves of vegetables -2.5 serves per day during lockdown compared to 2.2 serves per day in 2017.

- $32 \%$ of respondents reported drinking sugar sweetened beverages daily - this is substantially higher than the 2017 comparison survey result of $10.1 \%$.

- One in three respondents (34\%) reported eating takeaway foods less frequently during the lockdown. This is consistent with a lower proportion (4.3\%) reporting eating takeaway foods three or more times a week compared to 2015 (10.2\%)

- $28 \%$ of respondents reported cooking dinner more frequently during the lockdown when compared to February 2020.

- Food insecurity has affected survey respondents. $17 \%$ of respondents reported worrying about having enough money to buy food during the lockdown compared to $9 \%$ in February 2020.

- One in four respondents $(23 \%)$ reported relying on a restricted range of low-cost unhealthy food because of financial concerns during the lockdown.

- $7 \%$ of respondents ran out of food and couldn't afford to buy more - this is substantially higher than the 2014 comparison survey result of $4 \%$.

\section{Factors influencing food preparation}

- In this current survey, only factors related to food preparation as indicated by frequency of cooking dinner each week were examined. The risks of going out to shop was the most common reason for less cooking at home, with one in three $(31 \%)$ concerned about going to the supermarket. Three in five $(57 \%)$ reported that they were cooking more as they had more time to prepare and cook food. Other common reasons for cooking more were to save money (46\%) and preferring to stay home during lockdown $(43 \%)$ 


\section{Variation by subgroups}

- Groups eating significantly fewer serves of vegetables include those based in middle metro areas (average 2.2 serves per day), people who were unemployed in February 2020 ( 2.0 serves) and speak a language other than English at home (2.1 serves).

- Four in five (80\%) Aboriginal and Torres Strait Islander respondents reported drinking sugar sweetened beverages daily. Other groups with high intake included those aged 18 to 24 years $(50 \%)$, men aged 45 to 54 years $(48 \%)$, those eligible for JobKeeper $(43 \%)$ or JobSeeker (47\%), people living in inner metro areas $(42 \%)$, people earning between $\$ 40,000$ and $\$ 59,000(45 \%)$, one parent families $(49 \%)$, and those living in areas impacted by the 2019 bushfires (55\%).

- Subgroups with high levels of takeaway food consumption included those living in a bushfire impacted area (16\%), students $(11 \%)$, those with a disability $(8 \%)$, those who speak a language other than English at home (8\%), and Aboriginal and Torres Strait Islanders $(27 \%)$.

\begin{tabular}{|c|c|c|}
\hline $\begin{array}{l}\text { Daily Vegetable Serves } \\
\text { (average serves per day) }\end{array}$ & 2.5 & $2.2(2017)$ \\
\hline $\begin{array}{l}\text { Daily Vegetable Serves } \\
\text { (eating } 5 \text { or more serves per day) }\end{array}$ & $8 \%$ & $6.4 \%(2017)$ \\
\hline $\begin{array}{l}\text { Sugar Sweetened Beverages } \\
\text { Frequency } \\
\text { (consume daily) }\end{array}$ & $32 \%$ & $10.1 \%(2017)$ \\
\hline $\begin{array}{l}\text { Takeaway Foods Frequency } \\
\text { (more than twice a week) }\end{array}$ & $4 \%$ & $10 \%(2015)$ \\
\hline $\begin{array}{l}\text { Restricted range of low-cost } \\
\text { unhealthy food (\% yes) }\end{array}$ & $23 \%$ & $13 \%(2014)$ \\
\hline Ran out of food (\% yes) & $7 \%$ & $4 \%(2014)$ \\
\hline \multicolumn{3}{|c|}{$\begin{array}{l}\text { VPHS } 2017 \text { - https://www2.health.vic.gov.au/public-health/population-health-systems/health-status-of-victorians/survey-data-and- } \\
\text { reports/victorian-population-health-survey/victorian-population-health-survey-2017 }\end{array}$} \\
\hline \multicolumn{3}{|c|}{ VHI 2015 - https://www.vichealth.vic.gov.au/media-and-resources/publications/vichealth-indicators-report-2015 } \\
\hline
\end{tabular}




\subsubsection{Vegetable consumption}

Vegetable consumption is a proxy indicator for healthy food intake. The recommended daily serves of vegetables is at least five serves ${ }^{17}$. For our analysis, we have grouped those who are eating five or more serves of vegetables together. Less than one in ten respondents $(8 \%)$ were eating five or more serves of vegetables each day. One in five $(22 \%)$ were eating one or fewer serves of vegetables each day. On average, respondents were eating 2.5 serves of vegetables a day.

Figure 33 Frequency of vegetable serves consumed each day

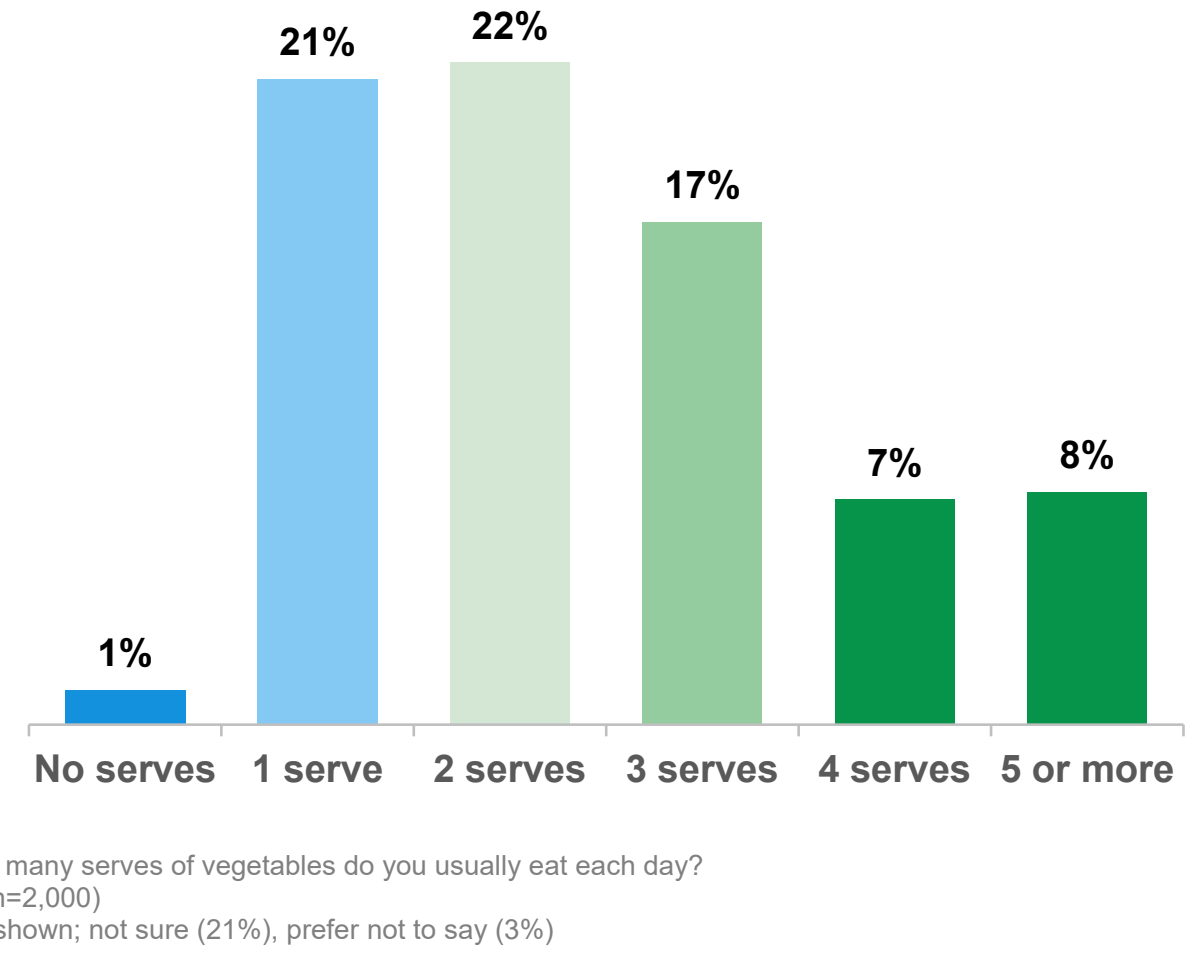

As shown in Figures 35 and 36, while a higher proportion of respondents aged 75 and over reported eating five or more serves of vegetables per day compared to other age groups, they showed no significantly higher average consumption of vegetables. Those who speak a language other than English at home (4\%) and those living in interface regions (4\%), those between metro and rural areas (e.g. Melton, Yarra Ranges) were significantly less likely to be consuming five or more serves of vegetables each day. People who speak a language other than English at home (2.1 serves) were also significantly more likely to consume less vegetables each day.

\footnotetext{
${ }^{17}$ National Health and Medical Research Council (NHMRC) 2013, Dietary guidelines for Australian adults, NHMRC, Canberra. 
Figure 34 Consumption of 5 or more serves of vegetables per day - Victorian and sub-population frequencies during the first lockdown

Note: Responses that are significantly more favourable than the Victorian overall result are on the right, highlighted in green. Responses that are significantly less favourable than the Victorian overall result are on the left, highlighted in blue.

\begin{tabular}{|c|c|c|c|}
\hline & & 4 Less favourable res & More favourable result \\
\hline & Victoria overall & & $8 \%$ \\
\hline Gander & Male & $6 \% \mathrm{C}$ & \\
\hline Genaer & Female & & $9 \%$ \\
\hline & 18 to 24 years & $7 \%$ & \\
\hline & 25 to 34 years & $6 \% \mathrm{C}=$ & \\
\hline & 35 to 44 years & $6 \%$ & \\
\hline Age & 45 to 54 years & $7 \%$ & \\
\hline & 55 to 64 years & $7 \%$ & \\
\hline & 65 to 74 years & & $11 \%$ \\
\hline & 75 or more & & $\bigcirc 17 \%$ \\
\hline & Lowest - 1 & $6 \%$ & \\
\hline & 2 & & $9 \%$ \\
\hline SEIFA & 3 & & $8 \%$ \\
\hline & 4 & & \\
\hline & Highest -5 & $7 \% \bigcirc$ & \\
\hline & Inner metro & & $9 \%$ \\
\hline & Middle metro & $6 \%$ & \\
\hline & Outer metro & & $12 \%$ \\
\hline Region & Interface & $4 \%$ & \\
\hline & Regional city & & $8 \%$ \\
\hline & Large shire & & $13 \%$ \\
\hline & Small shire & & $19 \%$ \\
\hline Abo & I and Torres Strait Islander & & $12 \%$ \\
\hline Lang & ther than English at home & $4 \% \bigcirc$ & \\
\hline & Self-reported disability & $7 \%$ & \\
\hline & Employed & $7 \% \mathrm{C}$ & \\
\hline & Unemployed & $4 \%$ & \\
\hline $\begin{array}{l}\text { Main activity in } \\
\text { February } 2020\end{array}$ & Home duties & & $9 \%$ \\
\hline & Student & & $9 \%$ \\
\hline & Retired & & $11 \%$ \\
\hline & Less than $\$ 40,000$ & & $9 \%$ \\
\hline & $\$ 40,000-\$ 59,999$ & & $9 \%$ \\
\hline Income & $\$ 60,000-\$ 99,999$ & & $8 \%$ \\
\hline & $\$ 100,000-\$ 149,999$ & & $8 \%$ \\
\hline & $\$ 150,000$ or more & $5 \%$ & \\
\hline & Live in bushfire area & & $11 \%$ \\
\hline & Person living alone & $7 \% \mathrm{O}$ & \\
\hline & Couple living alone & & $12 \%$ \\
\hline $\begin{array}{l}\text { Household } \\
\text { structure }\end{array}$ & Couple parent with children & $6 \%$ & \\
\hline & Single parent with children & $5 \%$ & \\
\hline & Share house & $7 \%$ & \\
\hline $\begin{array}{l}\text { Government } \\
\text { assistance }\end{array}$ & $\begin{array}{l}\text { Eligible for JobKeeper } \\
\text { Eligible for JobSeeker }\end{array}$ & $7 \%$ & \\
\hline & & $\begin{array}{l}\text { Significantly le } \\
\text { favourable res }\end{array}$ & $\begin{array}{l}\text { Significantly more } \\
\text { favourable result }\end{array}$ \\
\hline
\end{tabular}

D1. How many serves of vegetables do you usually eat each day?

Base: $\quad$ All $(n=2,000)$

Note: $\quad$ Not shown; not sure (21\%), prefer not to say (3\%)

Note: $\quad$ Results for some subgroups are lower than other and not significantly different to the overall results due to small base sizes 
Figure 35 Serves of vegetables per day - Victorian and sub-population average number of serves during the first lockdown

Note: Responses that are significantly more favourable than the Victorian overall result are on the right, highlighted in green. Responses that are significantly less favourable than the Victorian overall result are on the left, highlighted in blue.

\begin{tabular}{|c|c|c|c|}
\hline & Victoria overall & 4 Less favourable result & $\begin{array}{l}\text { More favourable result } \\
2.5\end{array}$ \\
\hline \multirow{2}{*}{ Gender } & Male & $2.3 \mathrm{C}=$ & \\
\hline & Female & & 2.6 \\
\hline \multirow{7}{*}{ Age } & 18 to 24 years & & 2.5 \\
\hline & 25 to 34 years & $2.4 \mathrm{C}$ & \\
\hline & 35 to 44 years & $2.4 \mathrm{C}=$ & \\
\hline & 45 to 54 years & $2.3 \mathrm{C}=$ & \\
\hline & 55 to 64 years & & 2.5 \\
\hline & 65 to 74 years & & 2.7 \\
\hline & 75 or more & & 2.7 \\
\hline \multirow{5}{*}{ SEIFA } & Lowest - 1 & $2.3 \mathrm{C}=$ & \\
\hline & 2 & & 2.7 \\
\hline & 3 & $2.4 \mathrm{O}$ & \\
\hline & 4 & $2.4 \mathrm{C}=$ & \\
\hline & Highest -5 & $2.4 \mathrm{C}$ & \\
\hline \multirow{7}{*}{ Region } & Inner metro & $2.4 \mathrm{C}$ & \\
\hline & Middle metro & $2.3 \mathrm{C}=$ & \\
\hline & Outer metro & & 2.5 \\
\hline & Interface & $2.4 \mathrm{O}=$ & \\
\hline & Regional city & & 2.7 \\
\hline & Large shire & & 2.8 \\
\hline & Small shire & & 3.1 \\
\hline \multicolumn{2}{|c|}{ Aboriginal and Torres Strait Islander } & & 3.0 \\
\hline \multicolumn{2}{|c|}{ Language other than English at home } & $2.1 \mathrm{O}^{-}$ & \\
\hline & Self-reported disability & $2.4 \mathrm{C}$ & \\
\hline \multirow{5}{*}{$\begin{array}{c}\text { Main activity in } \\
\text { February } 2020\end{array}$} & Employed & $2.4 \mathrm{C}=$ & \\
\hline & Unemployed & $2.0 \mathrm{C}$ & \\
\hline & Home duties & & 2.5 \\
\hline & Student & & 2.8 \\
\hline & Retired & & 2.7 \\
\hline \multirow{5}{*}{ Income } & Less than $\$ 40,000$ & & 2.5 \\
\hline & $\$ 40,000-\$ 59,999$ & & 2.5 \\
\hline & $\$ 60,000-\$ 99,999$ & $2.4 \mathrm{C}$ & \\
\hline & $\$ 100,000-\$ 149,999$ & & 2.5 \\
\hline & $\$ 150,000$ or more & & 2.5 \\
\hline \multirow{6}{*}{$\begin{array}{l}\text { Household } \\
\text { structure }\end{array}$} & Live in bushfire area & & 2.9 \\
\hline & Person living alone & $2.3 \mathrm{C}$ & \\
\hline & Couple living alone & & 2.6 \\
\hline & Couple parent with children & $2.4 \mathrm{C}$ & \\
\hline & Single parent with children & & 2.5 \\
\hline & Share house & $2.4 \bigcirc$ & \\
\hline \multirow{2}{*}{$\begin{array}{l}\text { Government } \\
\text { assistance }\end{array}$} & Eligible for JobKeeper & $2.3 \mathrm{C}=$ & \\
\hline & Eligible for JobSeeker & 2.3 & \\
\hline
\end{tabular}

D1. How many serves of vegetables do you usually eat each day?

Base: $\quad$ All $(n=1,560)$

Note: $\quad$ Excludes; not sure, prefer not to say

Note: $\quad$ Results for some subgroups are lower than other and not significantly different to the overall results due to small base sizes

Note: Results for some subgroups are higher than others but not significantly different to the overall results due to small base sizes 
Figure 36 Levels of vegetable consumption during the first lockdown compared to February 2020 (more, same, less)

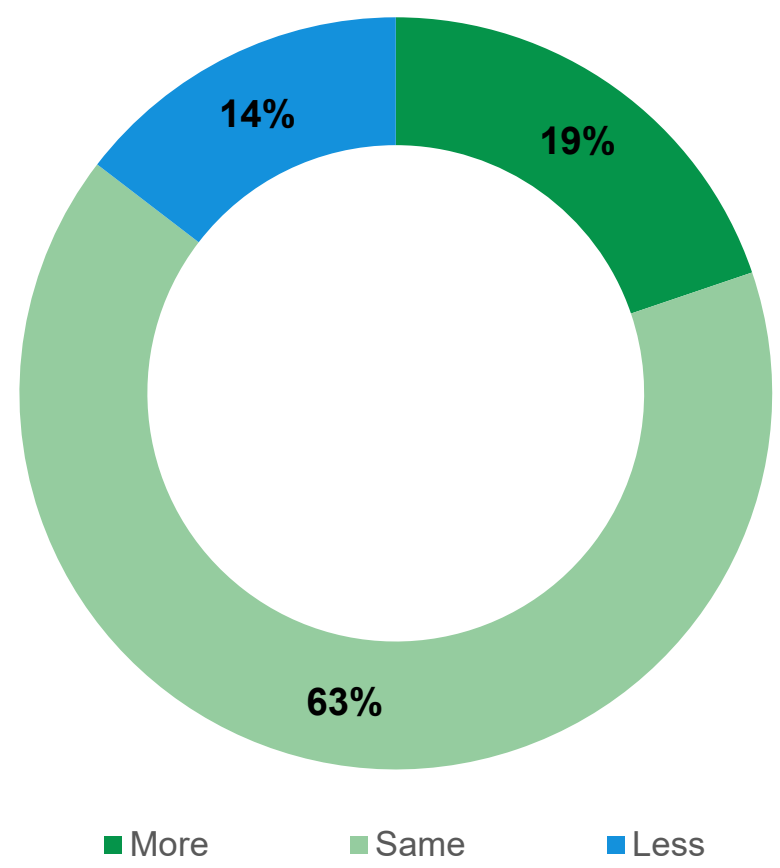

D2. Overall, do you feel you are eating more, less or about the same amount of vegetables now - during the first lockdown restrictions, compared to February 2020?

Base: $\quad$ All $(n=2,000)$

Note: $\quad$ Not shown; not sure $(2 \%)$, prefer not to say $(1 \%)$

Two in three respondents (63\%) felt that their vegetable consumption had not changed during the first lockdown in comparison to February 2020. A small proportion felt that they had consumed less vegetables $(14 \%)$ while a similarly small proportion felt that they had increased their vegetable consumption $(19 \%)$. 


\subsubsection{Sugar sweetened beverage consumption}

Sugar sweetened beverages are the largest source of free sugars in the Australian diet, and high intake of sugary drinks is a key driver of overweight and obesity and poor health ${ }^{18}$. In $2017,10.1 \%$ of Victorians consumed at least one sugar sweetened beverage daily, however, in the first lockdown, $32 \%$ of respondents reported consuming a sugar sweetened beverage at least once a day.

Consumption was significantly higher in respondents who were male (39\%), particularly men aged 45 $54(48 \%)$, young people aged 18 to 24 years (50\%), living in the inner metro region of Victoria $(42 \%)$, with a self-reported disability (38\%), living in a bushfire affected area (55\%), living in one parent families $(49 \%)$, and eligible for JobSeeker (47\%) or JobKeeper (43\%).

Although the sample size is too small to show significant differences to the rest of the population, four in five $(80 \%)$ Aboriginal and Torres Strait Islander respondents reported consuming sugar sweetened beverages daily during the first lockdown.

\footnotetext{
${ }^{18}$ NHMRC. Eat for Health: Australian Dietary Guidelines Summary. Canberra: NHMRC, Department of Health and Ageing; 2013. Contract No.: ISBN: 1864965789. 
Figure 37 Sugar sweetened beverage consumption - Victorian and sub-population frequencies of daily consumption during the first lockdown

Note: Responses that are significantly more favourable than the Victorian overall result are on the right, highlighted in green. Responses that are significantly less favourable than the Victorian overall result are on the left, highlighted in blue.

\begin{tabular}{|c|c|c|c|}
\hline \multicolumn{2}{|r|}{ Victoria overall } & More favo & $\begin{array}{l}\text { vourable result } \\
32 \%\end{array}$ \\
\hline \multirow{2}{*}{ Gender } & Male & $39 \%$ & \\
\hline & Female & & $26 \%$ \\
\hline \multirow{7}{*}{ Age } & 18 to 24 years & $50 \% \bigcirc$ & \\
\hline & 25 to 34 years & $37 \%$ & \\
\hline & 35 to 44 years & & $30 \%$ \\
\hline & 45 to 54 years & $34 \%$ & \\
\hline & 55 to 64 years & & $24 \%$ \\
\hline & 65 to 74 years & & $23 \%$ \\
\hline & 75 or more & & $20 \%$ \\
\hline \multirow{5}{*}{ SEIFA } & Lowest - 1 & & $31 \%$ \\
\hline & 2 & $35 \%$ & \\
\hline & 3 & $36 \%$ & \\
\hline & 4 & & $30 \%$ \\
\hline & Highest -5 & & $31 \%$ \\
\hline \multirow{7}{*}{ Region } & Inner metro & $42 \%$ & \\
\hline & Middle metro & & $30 \%$ \\
\hline & Outer metro & & $32 \%$ \\
\hline & Interface & & $32 \%$ \\
\hline & Regional city & $35 \%$ & \\
\hline & Large shire & & $23 \%$ \\
\hline & Small shire & $36 \%$ & \\
\hline \multicolumn{2}{|c|}{ Aboriginal and Torres Strait Islander } & $80 \% \mathrm{C}$ & \\
\hline \multicolumn{2}{|c|}{ Language other than English at home } & $37 \%$ & \\
\hline & Self-reported disability & $38 \% \bigcirc=$ & \\
\hline \multirow{5}{*}{$\begin{array}{l}\text { Main activity in } \\
\text { February } 2020\end{array}$} & Employed & $39 \% \bigcirc-$ & \\
\hline & Unemployed & $35 \%$ & \\
\hline & Home duties & & $21 \%$ \\
\hline & Student & $38 \%$ & \\
\hline & Retired & & $25 \%$ \\
\hline \multirow{6}{*}{ Income } & Less than $\$ 40,000$ & $33 \%$ & \\
\hline & $\$ 40,000-\$ 59,999$ & $45 \%$ & \\
\hline & $\$ 60,000-\$ 99,999$ & $33 \%$ & \\
\hline & $\$ 100,000-\$ 149,999$ & & $31 \%$ \\
\hline & $\$ 150,000$ or more & $36 \%$ & \\
\hline & Live in bushfire area & $55 \%$ & \\
\hline \multirow{5}{*}{$\begin{array}{l}\text { Household } \\
\text { structure }\end{array}$} & Person living alone & & $29 \%$ \\
\hline & Couple living alone & & $27 \%$ \\
\hline & Couple parent with children & $33 \%$ & \\
\hline & Single parent with children & $49 \% \bigcirc$ & \\
\hline & Share house & $41 \% \mathrm{O}$ & \\
\hline \multirow{2}{*}{$\begin{array}{l}\text { Government } \\
\text { assistance }\end{array}$} & Eligible for JobKeeper & $43 \%$ & \\
\hline & Eligible for JobSeeker & $47 \%$ & \\
\hline
\end{tabular}

N1. How many glasses of soft drink, cordial, flavoured mineral water, energy drink or sports drink do you consume every day? (exclude diet variety)

Base: $\quad$ All $(n=2,000)$

Note: $\quad$ Results for some subgroups are lower than other and not significantly different to the overall results due to small base sizes 
As shown in Figure 39, two in three respondents (65\%) felt that their intake of sugar sweetened beverages was unchanged during the first lockdown. One in five respondents $(18 \%)$ reported lower levels of consumption, while one in ten $(11 \%)$ reported increased consumption. Those who were drinking a sugar sweetened beverage daily during the lockdown were significantly more likely to report that they were drinking more than in February 2020 (23\%).

Figure 38 Sugar sweetened beverages consumption during the first Victorian coronavirus lockdown compared to February 2020 (more, same, less)

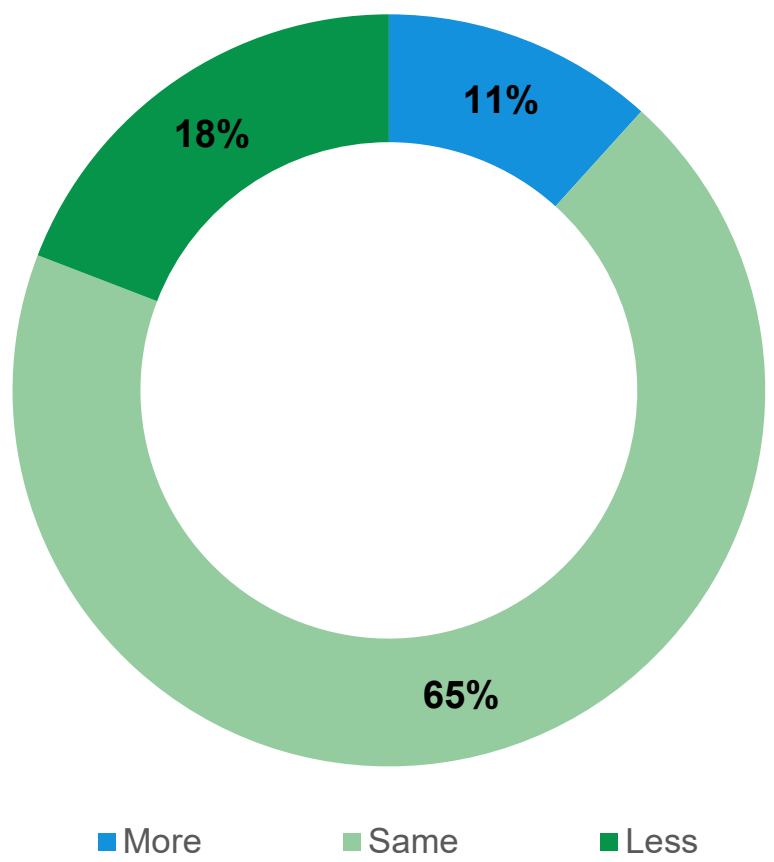

N2. Overall, do you feel you are drinking more, less or about the same amount of soft drink, cordial, flavoured mineral water, energy drink or sports now - during the first lockdown, compared to February 2020?

Base: $\quad$ All $(n=2,000)$

Note: $\quad$ Not shown; not sure (5\%), prefer not to say $(2 \%)$

\subsubsection{Takeaway food consumption}

The consumption of takeaway meals and snacks was measured as a proxy indicator for unhealthy, discretionary food intake.

During the first lockdown, $4 \%$ of respondents reported consuming takeaway food three or more times per week. As shown in Figure 40, this was significantly higher in respondents aged 25 to 34 years $(11 \%)$, those speaking a language other than English at home $(8 \%)$, with a self-reported disability $(8 \%)$, identifying as a student $(11 \%)$, living in bushfire affected areas $(16 \%)$, living in one parent families (11\%) and eligible for JobKeeper (10\%). 
Figure 39 Takeaway food consumption - Victorian and sub-population frequencies of consuming three or more times per week

Note: Responses that are significantly more favourable than the Victorian overall result are on the right, highlighted in green. Responses that are significantly less favourable than the Victorian overall result are on the left, highlighted in blue.

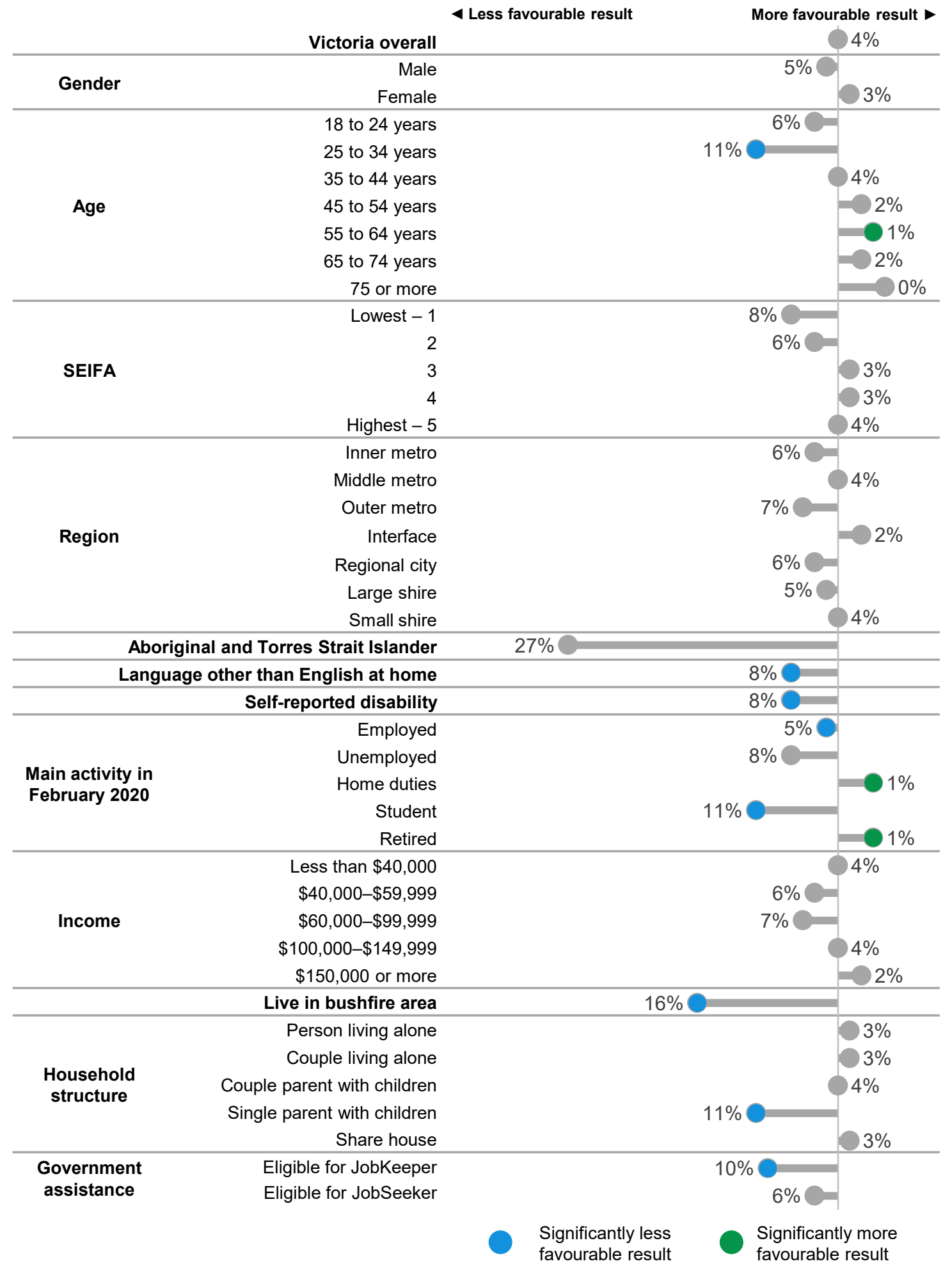

N3. How often do you have meals or snacks such as burgers, pizza, chicken or chips from places like McDonalds, Hungry Jacks, Pizza Hut, KFC, Red Rooster or local takeaway places?

Base: $\quad$ All $(n=2,000)$

Note: $\quad$ Results for some subgroups are lower than others but not significantly different to the overall results due to small base sizes 
Figure $\mathbf{4 0}$ Levels of takeaway food consumption during the first Victorian coronavirus lockdown compared to February 2020 (more, same, less)

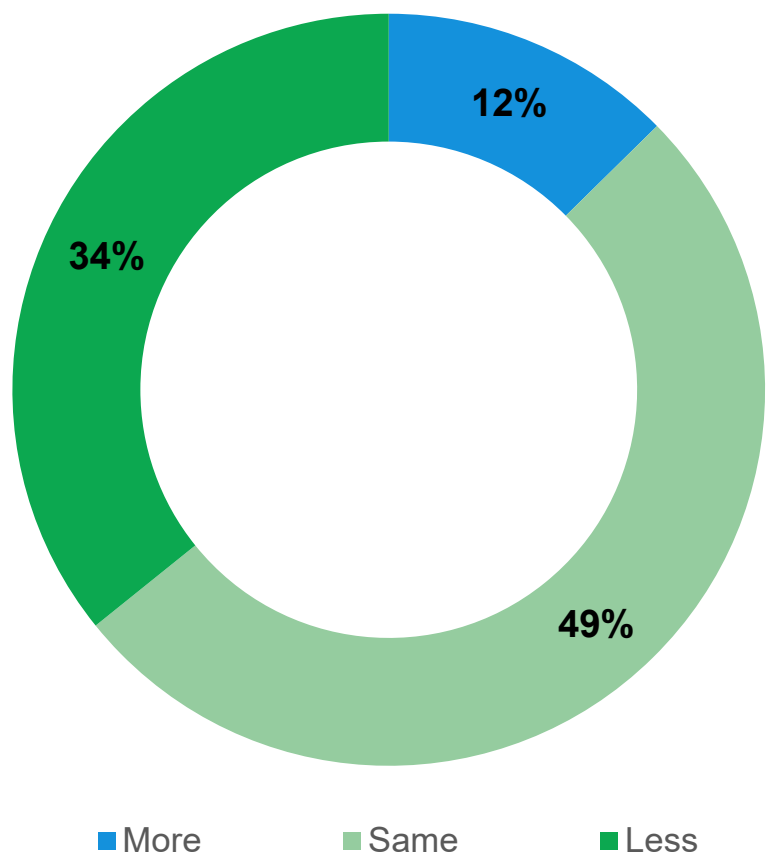

N4. Overall, do you feel you are having more, less or about the same number of meals or snacks such as burgers, pizza, chicken or chips from places like McDonalds, Hungry Jacks, Pizza Hut, KFC, Red Rooster or local takeaway places now - during the first lockdown, compared to February 2020?

Base: $\quad$ All $(n=2,000)$

Note: $\quad$ Not shown; not sure $(4 \%)$, prefer not to say $(1 \%)$

Changes in takeaway food consumption during the first lockdown predominantly indicates an overall reduction in consumption. One in three respondents $(34 \%)$ reported consuming less takeaway food than during February 2020. In comparison, one in ten respondents (12\%) reported consuming more takeaway food than during February 2020.

Respondents eating more takeaway food during the lockdown were significantly more likely to eat takeaway food three or more times per week (54\%) when compared with Victorians overall (12\%).

\subsubsection{Changes in household meals}

The average number of dinners households were cooking at home during the first lockdown restrictions was 5.9 times per week.

Approximately one in ten respondents $(12 \%)$ cooked dinner four or less times per week. As shown in the figure below, this was significantly higher in respondents aged 25 to 34 years (24\%), living alone $(17 \%)$ and eligible for JobSeeker (24\%). 
Figure 41 Cooking dinner four or less times per week - Victorian and subpopulation frequencies during the first lockdown

Note: Responses that are significantly more favourable than the Victorian overall result are on the right, highlighted in green. Responses that are significantly less favourable than the Victorian overall result are on the left, highlighted in blue.

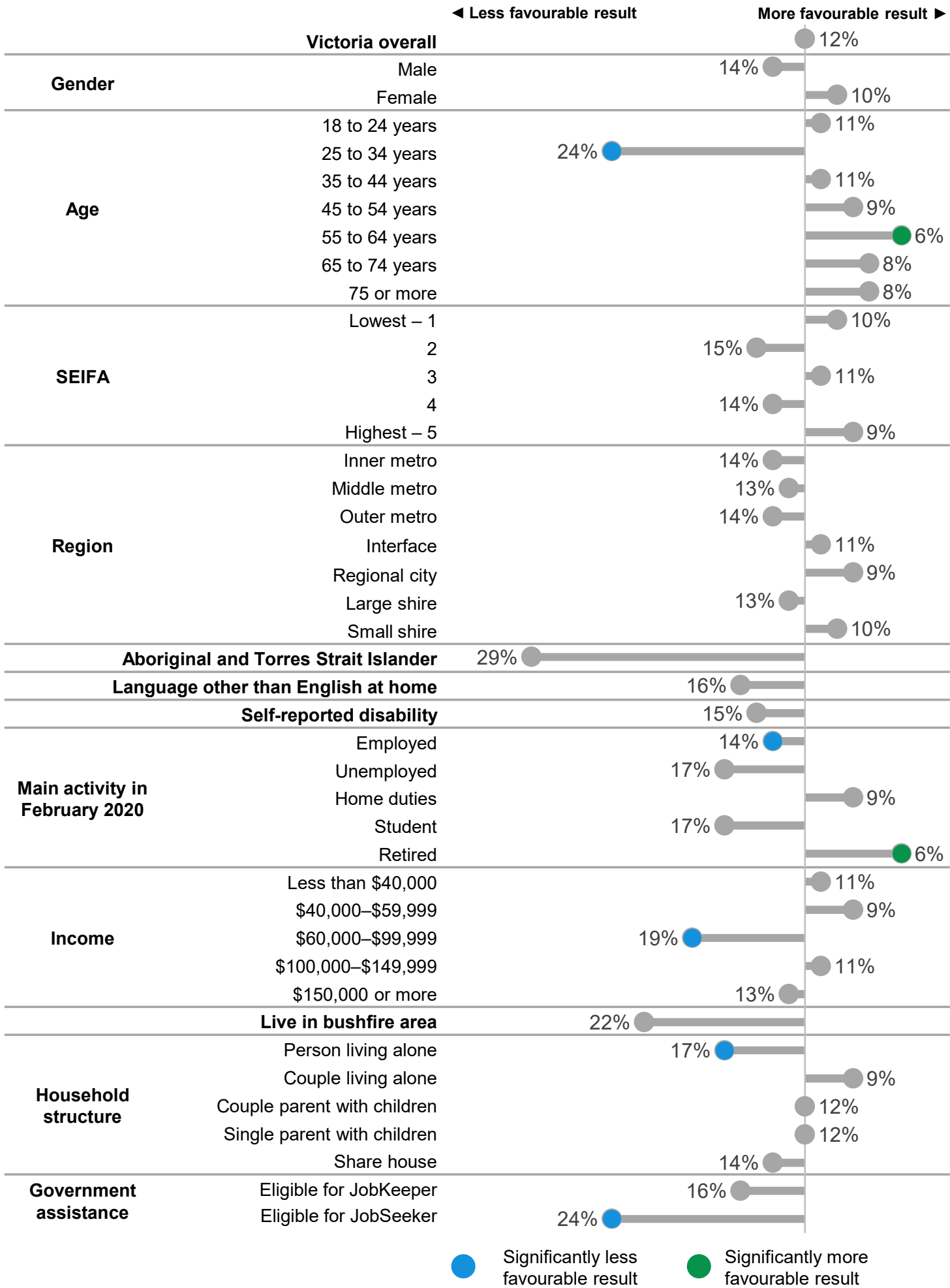

D4. On average, since the COVID-19 restrictions started, how many times do you and your household cook dinner each week?

Base: $\quad$ All $(n=2,000)$

Note: $\quad$ Results for some subgroups are lower than others but not significantly different to the overall results due to small base sizes 
Figure 42 Changes in frequency of cooking dinner during the first lockdown compared to February 2020 (more, same, less)

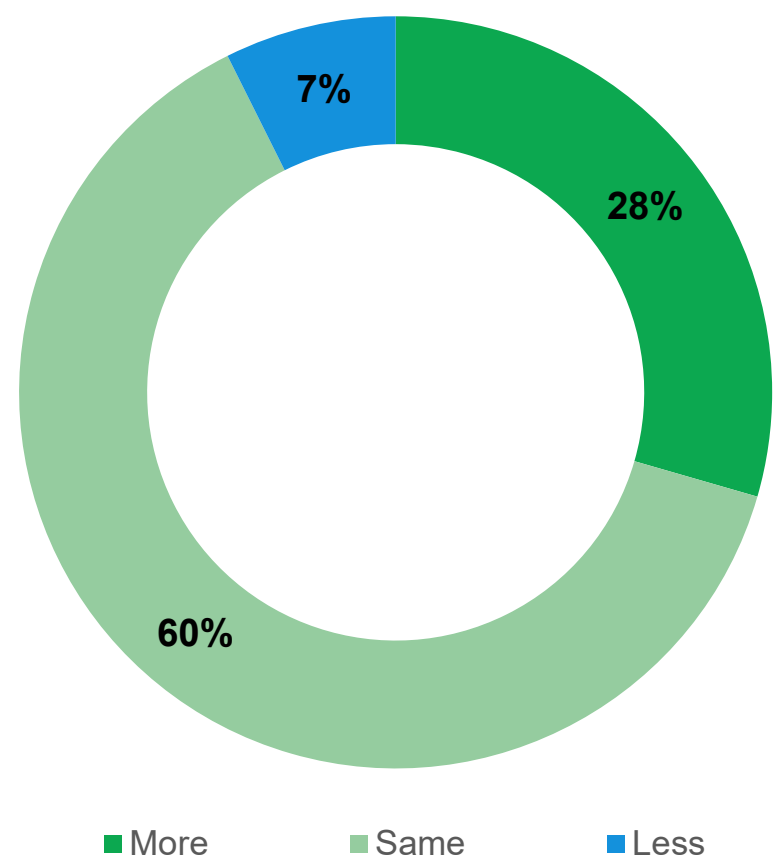

D5. Would you say this is more, less or about the same now - during the COVID-19 lockdown restrictions, compared to February 2020?

Base: $\quad$ All $(n=2,000)$

Note: Not shown; not sure (3\%), prefer not to say (1\%)

During the first lockdown, three in ten $(28 \%)$ respondents reported cooking dinner more often than during February 2020. As shown in Figure 43, the most common reason for the increase in home cooking frequency was having more time to prepare food $(57 \%)$. One in two $(46 \%)$ reported doing more home cooking as a cost saving measure.

In contrast, as shown in Figure 44, less than one in ten (7\%) reported cooking dinner less frequently during the first lockdown. Some of the reasons for doing less cooking were related to concerns about being in supermarkets $(31 \%)$, the cost of food $(28 \%)$ and concerns about food safety $(13 \%)$. A small proportion $(10 \%)$ reported limited supply at shops as the main reason for cooking less. 
Figure 43 Main reason for more cooking during the first lockdown

\begin{tabular}{|c|c|c|c|}
\hline More time to prepare and cook food & & & $57 \%$ \\
\hline Home cooked food costs less & & $46 \%$ & \\
\hline Prefer to stay home at this time & & $43 \%$ & \\
\hline Cooking dinner is important to me & & $30 \%$ & \\
\hline $\begin{array}{r}\text { Members of my household / familywant to } \\
\text { eat home cooked meals }\end{array}$ & & $30 \%$ & \\
\hline More time to shop for food & & & \\
\hline Less good quality take-away food available & $14 \%$ & & \\
\hline People I know are cooking more & $13 \%$ & & \\
\hline Other & $4 \%$ & & \\
\hline
\end{tabular}

D6. What do you think are the main reasons you've increased/maintained the number of times you cook dinner each week?

Base: $\quad$ Doing more cooking $(n=579)$

Note: $\quad$ Not shown; not sure $(1 \%)$, prefer not to say $(<1 \%)$

Table 6 Reasons for cooking more dinners during the first lockdown - subpopulation frequencies that are significantly different to the overall Victorian level

\begin{tabular}{|c|c|c|c|c|c|}
\hline \multirow{2}{*}{$\begin{array}{l}\text { Reason for cooking } \\
\text { more } \\
\text { More time to prepare } \\
\text { and cook food }\end{array}$} & \multirow{2}{*}{$\begin{array}{c}\begin{array}{c}\text { Victoria } \\
\text { overall }\end{array} \\
57 \%\end{array}$} & \multicolumn{2}{|l|}{$\begin{array}{l}\text { Sub-groups who report this } \\
\text { more often }\end{array}$} & \multicolumn{2}{|l|}{$\begin{array}{l}\text { Sub-groups who report this } \\
\text { less often }\end{array}$} \\
\hline & & Employed & $64 \%$ & & \\
\hline $\begin{array}{l}\text { Home cooked food } \\
\text { costs less }\end{array}$ & $46 \%$ & Share house & $67 \%$ & & \\
\hline \multirow{2}{*}{$\begin{array}{l}\text { Prefer to stay home at } \\
\text { this time }\end{array}$} & \multirow{2}{*}{$43 \%$} & 45 to 54 years & $59 \%$ & Inner metro & $25 \%$ \\
\hline & & & & 18 to 24 years & $24 \%$ \\
\hline $\begin{array}{l}\text { Cooking dinner is } \\
\text { important to me }\end{array}$ & $30 \%$ & Eligible for JobKeeper & $41 \%$ & & \\
\hline \multirow{2}{*}{$\begin{array}{l}\text { Members of my } \\
\text { household / family want } \\
\text { to eat home cooked } \\
\text { meals }\end{array}$} & \multirow[b]{2}{*}{$30 \%$} & 18 to 24 years & $46 \%$ & Employed & $27 \%$ \\
\hline & & & & Person living alone & \\
\hline \multirow{5}{*}{$\begin{array}{l}\text { More time to shop for } \\
\text { food }\end{array}$} & \multirow{5}{*}{$22 \%$} & 18 to 24 years & $37 \%$ & & \\
\hline & & Inner metro & $36 \%$ & & \\
\hline & & Eligible for JobSeeker & $35 \%$ & & \\
\hline & & Eligible for JobKeeper & $32 \%$ & & \\
\hline & & Employed & $28 \%$ & & \\
\hline $\begin{array}{l}\text { Less good quality } \\
\text { takeaway food } \\
\text { available }\end{array}$ & $14 \%$ & Employed & $17 \%$ & & \\
\hline \multirow{3}{*}{$\begin{array}{l}\text { People I know are } \\
\text { cooking more }\end{array}$} & \multirow{3}{*}{$13 \%$} & Eligible for JobSeeker & $29 \%$ & 45 to 54 years & $5 \%$ \\
\hline & & Eligible for JobKeeper & $28 \%$ & Person living alone & $3 \%$ \\
\hline & & Employed & $17 \%$ & & \\
\hline
\end{tabular}


Figure 44 Main reason for less cooking during the first lockdown

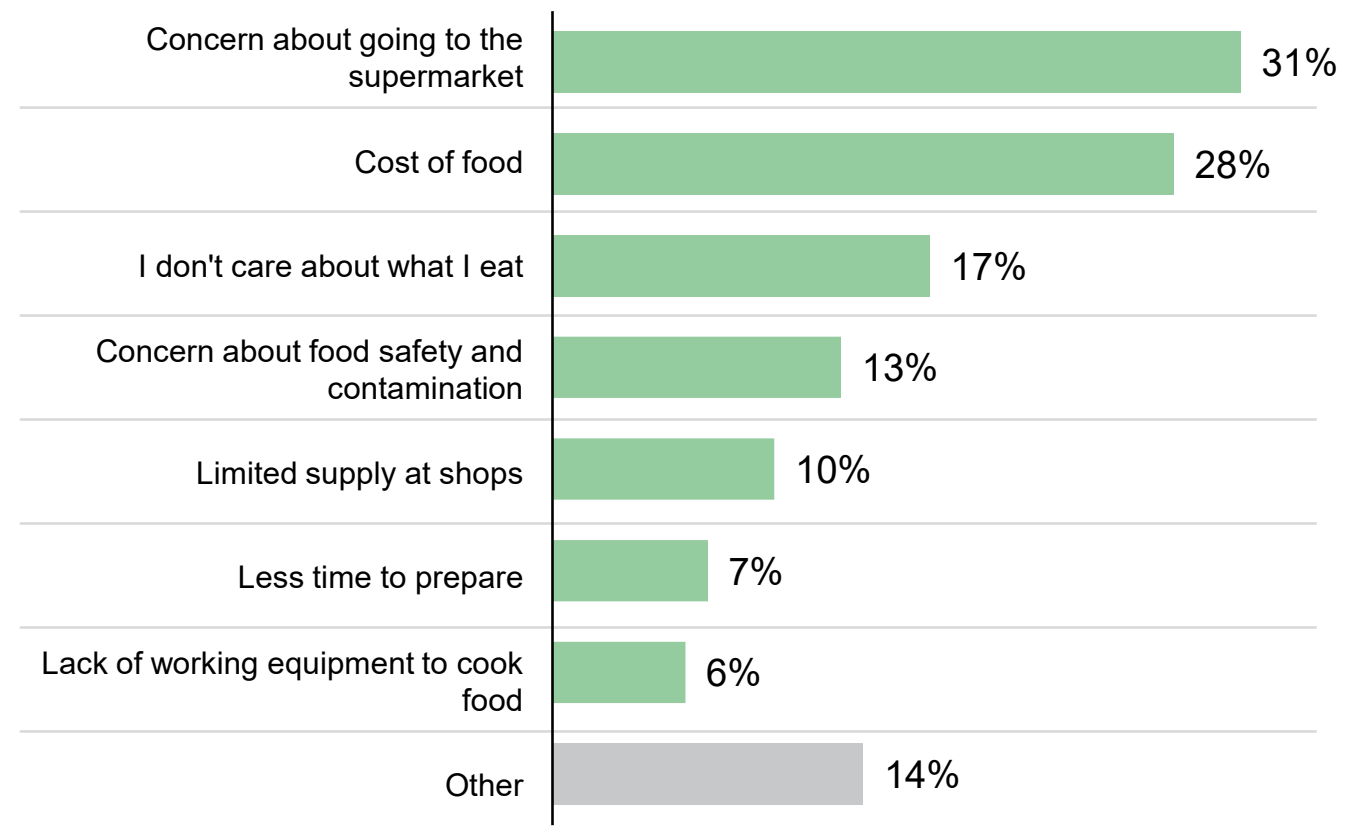

D7. What do you think are the main reasons you've decreased the number of times you cook dinner each week? Base: Doing less cooking $(n=136)$

Note: $\quad$ Not shown; not sure $(6 \%)$, prefer not to say $(1 \%)$

Table 7 Reasons for cooking less dinners during the first lockdown - subpopulation frequencies that are significantly different to the overall Victorian level

\begin{tabular}{|c|c|c|c|c|c|}
\hline \multirow{2}{*}{$\begin{array}{l}\text { Reason for cooking } \\
\text { less } \\
\text { Concern about going to } \\
\text { the supermarket }\end{array}$} & \multirow{2}{*}{$\begin{array}{c}\begin{array}{c}\text { Victoria } \\
\text { overall }\end{array} \\
31 \%\end{array}$} & \multicolumn{2}{|l|}{$\begin{array}{l}\text { Sub-groups who report this } \\
\text { more often }\end{array}$} & \multicolumn{2}{|c|}{$\begin{array}{c}\text { Sub-groups who report this } \\
\text { less often }\end{array}$} \\
\hline & & & & Employed & $26 \%$ \\
\hline Cost of food & $28 \%$ & Employed & $40 \%$ & & \\
\hline $\begin{array}{l}\text { I don't care about what } \\
\text { I eat }\end{array}$ & $17 \%$ & & & Employed & $8 \%$ \\
\hline $\begin{array}{l}\text { Concern about food } \\
\text { safety and } \\
\text { contamination }\end{array}$ & $13 \%$ & Employed & $18 \%$ & & \\
\hline Limited supply at shops & $10 \%$ & Employed & $24 \%$ & & \\
\hline Less time to prepare & $7 \%$ & Employed & $12 \%$ & & \\
\hline
\end{tabular}


Coronavirus restrictions have impacted people's food practices, including how they shop for and prepare foods. Some of these adaptions are shown in the following figure.

Approximately half of respondents $(53 \%)$ reported keeping more food at home during the first lockdown. Respondents also reported increased meal planning (50\%) and more local shopping at local grocers, butchers and fruit and vegetable suppliers (49\%).

Figure 45 Food related behaviours that commenced during the first lockdown

\begin{tabular}{|c|c|c|}
\hline $\begin{array}{r}\text { Kept more food and other } \\
\text { essentials at home }\end{array}$ & & $53 \%$ \\
\hline Planned meals for the week & & $50 \%$ \\
\hline Shopped locally & & $49 \%$ \\
\hline $\begin{array}{r}\text { Ordered food directly from a local } \\
\text { restaurant or cafe }\end{array}$ & $36 \%$ & \\
\hline $\begin{array}{r}\text { Planted vegetable seeds or } \\
\text { seedlings or grown food }\end{array}$ & $34 \%$ & \\
\hline $\begin{array}{r}\text { Ordered a takeaway from an } \\
\text { online delivery service (e.g. Uber Eats) }\end{array}$ & $28 \%$ & \\
\hline $\begin{array}{r}\text { Purchased food from a farmers' } \\
\text { market or local farm }\end{array}$ & $16 \%$ & \\
\hline
\end{tabular}

D3. Have you or anyone in your household started doing the following during the first lockdown? (\% responding yes) Base: $\quad$ All $(n=2,000)$ 


\subsection{Food insecurity}

Food insecurity occurs 'whenever the availability of nutritionally adequate and safe foods or the ability to acquire acceptable food in socially acceptable ways is limited or uncertain' (Radimer and Radimer $2002)^{19}$

As shown in Figure 46, approximately one in four respondents $(23 \%)$ reported that since the beginning of coronavirus restrictions, they have had to rely on a restricted range of low-cost unhealthy food due to running out of money to buy food.

Figure 46 Relied on a restricted range of low-cost unhealthy food during the first lockdown

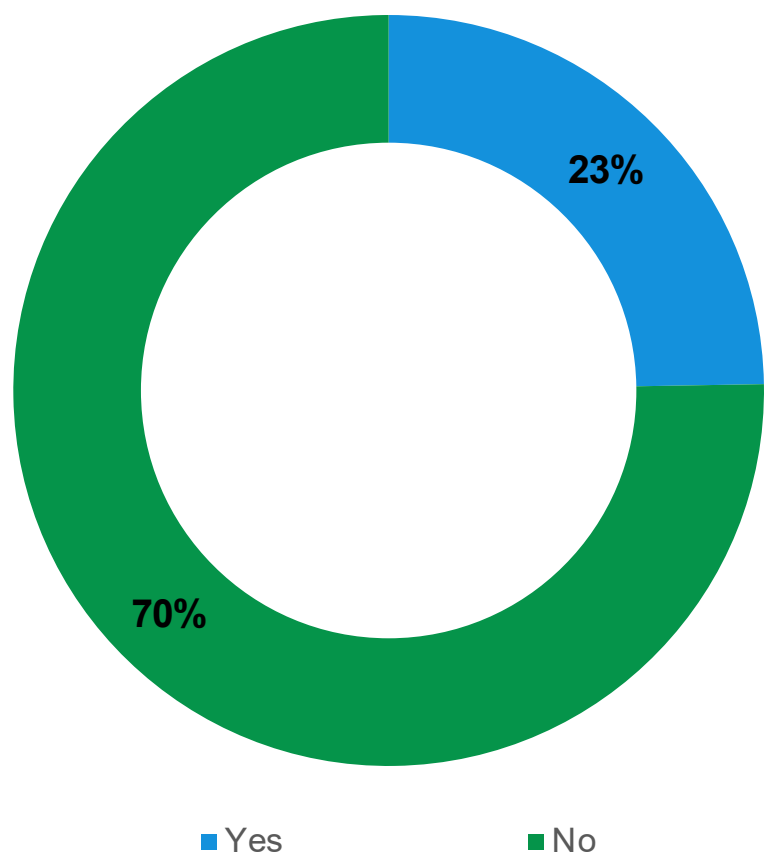

D7a. Since the COVID-19 restrictions began, did you have to rely on a restricted range of low-cost unhealthy food because you were running out of money to buy food?

Base: $\quad$ All $(n=2,000)$

Note: $\quad$ Not shown; not sure $(5 \%)$, prefer not to say $(2 \%)$

As shown in Figure 47, relying on low-cost unhealthy food was significantly more common for younger Victorians aged $18-24$ years (44\%) and 25-34 years (33\%), those living in inner metro Melbourne $(36 \%)$ and interface council areas (those between metro and rural areas e.g. Melton, Yarra Ranges), $(29 \%)$ those who were unemployed in February 2020 (40\%), those from bushfire affected communities $(45 \%)$ and those who speak a language other than English at home (36\%). Although the base size is too small for a significant difference to the overall figure, one in two Aboriginal and Torres Strait Islanders (54\%) reported having to purchase low-cost unhealthy food due to running out of money.

\footnotetext{
19 Radimer, K. L. and K. L. Radimer (2002). "Measurement of household food security in the USA and other industrialised countries." Public Health Nutr 5(6A): 859-864
} 
Figure 47 Relied on a restricted range of low-cost unhealthy food since - Victorian and sub-population frequencies (\% yes) during the first lockdown

Note: Responses that are significantly more favourable than the Victorian overall result are on the right, highlighted in green. Responses that are significantly less favourable than the Victorian overall result are on the left, highlighted in blue.

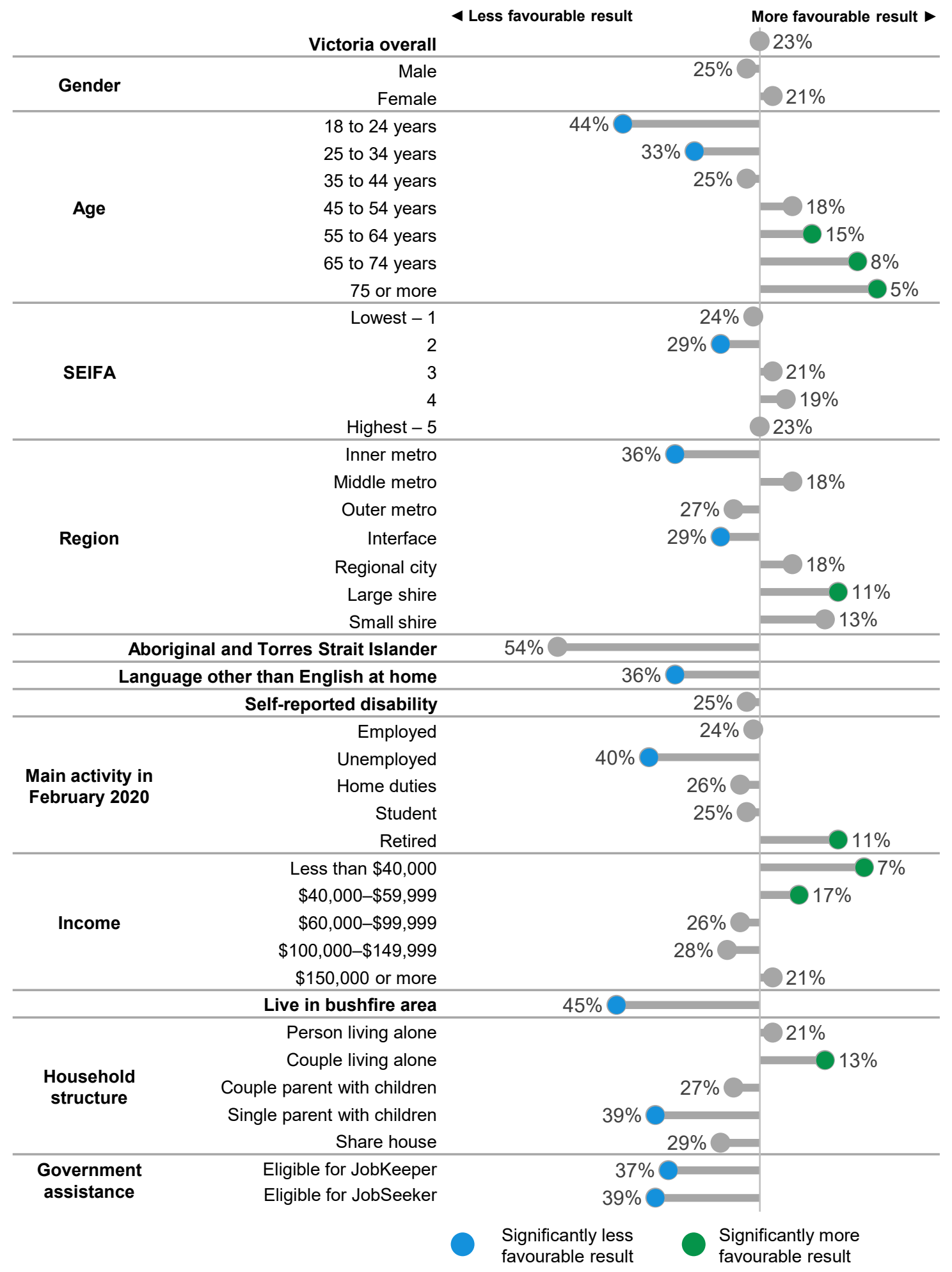

D7a. Since the COVID-19 restrictions began, did you have to rely on a restricted range of low-cost unhealthy food because you were running out of money to buy food?

Base: $\quad$ All $(n=2,000)$

Note: Results for some subgroups are lower than others but not significantly different to the overall results due to small base sizes 
As outlined in Figure 48, the impact of coronavirus restrictions on the employment and income of Victorians may have led to people not having enough money to buy food.

When asked if this had occurred, $7 \%$ indicated that they had run out of food and were unable to afford to buy more due to a shortage of money. This was similar to the proportion who had not been able to afford to buy food in February 2020 due to money shortages (6\%) (see Figure 49), however, for some population sub-groups, the percentage increase between time points is more pronounced (see Figure $50)$. 
Figure 48 Ran out of food and could not afford to buy more because of a shortage of money - Victorian and sub-population frequencies (\% yes) during the first lockdown

Note: Responses that are significantly more favourable than the Victorian overall result are on the right, highlighted in green. Responses that are significantly less favourable than the Victorian overall result are on the left, highlighted in blue.

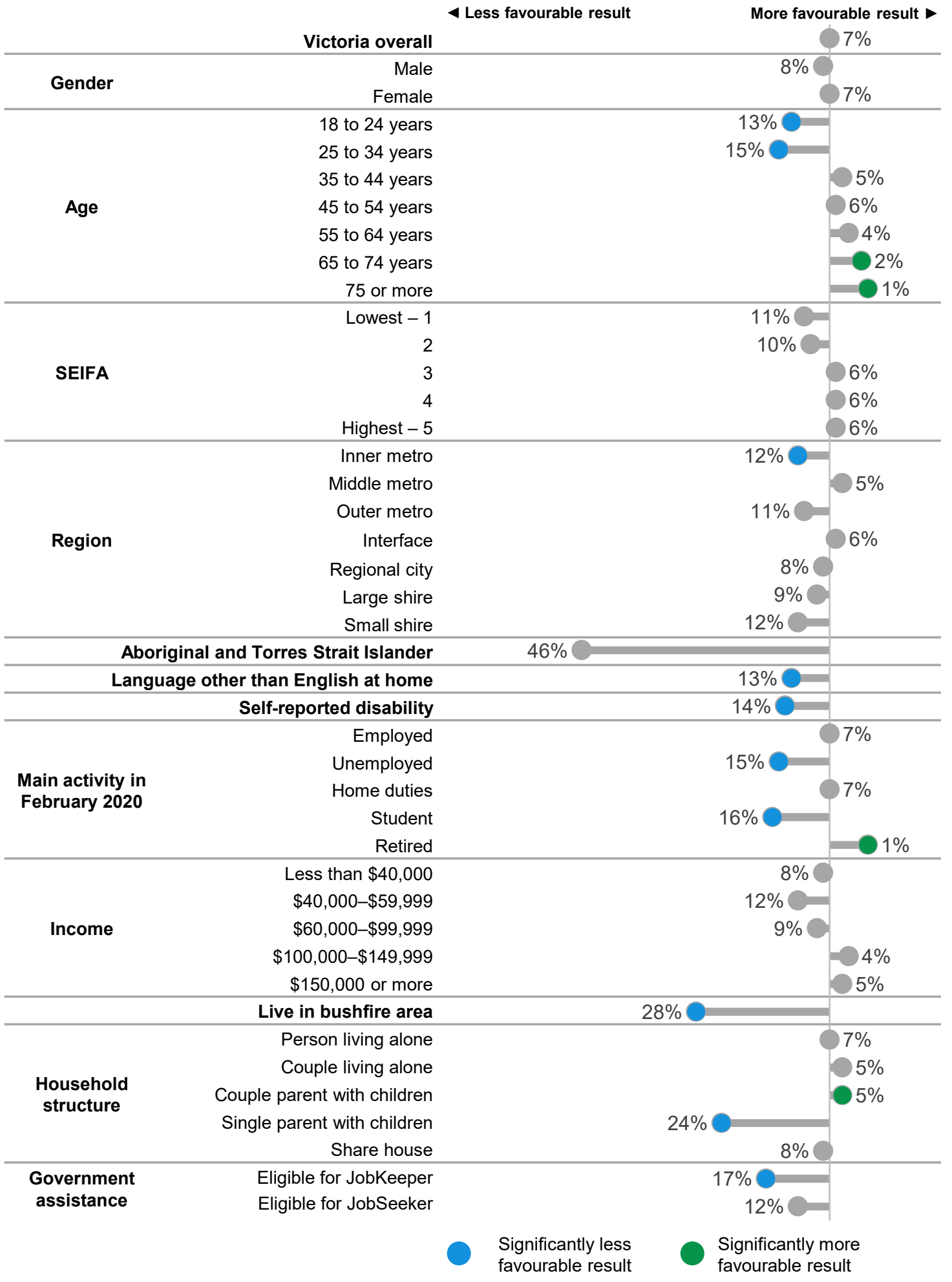

G12. Since COVID-19 restrictions began, did the of the following happen because of a shortage of money? Ran out of food and could not afford to buy more

Base: $\quad$ All $(n=2,000)$

Note: Results for some subgroups are lower than others but not significantly different to the overall results due to small base sizes 
Figure 49 Ran out of food and could not afford to buy more because of a shortage of money - Victorian and sub-population frequencies (\% yes) during February 2020

Note: Responses that are significantly more favourable than the Victorian overall result are on the right, highlighted in green. Responses that are significantly less favourable than the Victorian overall result are on the left, highlighted in blue.

\begin{tabular}{|c|c|c|c|}
\hline & Victoria overall & 4 Less favourable result & $\begin{array}{l}\text { rable result - } \\
6 \%\end{array}$ \\
\hline \multirow{2}{*}{ Gender } & Male & & $5 \%$ \\
\hline & Female & $7 \%$ & \\
\hline \multirow{7}{*}{ Age } & 18 to 24 years & $12 \%$ & \\
\hline & 25 to 34 years & $10 \%$ & \\
\hline & 35 to 44 years & & $\%$ \\
\hline & 45 to 54 years & & $-1 \%$ \\
\hline & 55 to 64 years & & $4 \%$ \\
\hline & 65 to 74 years & & $1 \%$ \\
\hline & 75 or more & & $1 \%$ \\
\hline \multirow{5}{*}{ SEIFA } & Lowest - 1 & $11 \% \bigcirc$ & \\
\hline & 2 & $8 \%$ & \\
\hline & 3 & & $3 \%$ \\
\hline & 4 & & $6 \%$ \\
\hline & Highest -5 & & $4 \%$ \\
\hline \multirow{7}{*}{ Region } & Inner metro & $9 \%$ & \\
\hline & Middle metro & & $3 \%$ \\
\hline & Outer metro & $10 \%$ & \\
\hline & Interface & $7 \%$ & \\
\hline & Regional city & & $4 \%$ \\
\hline & Large shire & & $5 \%$ \\
\hline & Small shire & $12 \%$ & \\
\hline \multicolumn{2}{|c|}{ Aboriginal and Torres Strait Islander } & $32 \% \mathrm{C}=$ & \\
\hline \multicolumn{2}{|c|}{ Language other than English at home } & $9 \%$ & \\
\hline \multicolumn{2}{|c|}{ Self-reported disability } & $11 \% \bigcirc$ & \\
\hline \multirow{5}{*}{$\begin{array}{l}\text { Main activity in } \\
\text { February } 2020\end{array}$} & Employed & & $6 \%$ \\
\hline & Unemployed & $12 \%$ & \\
\hline & Home duties & $7 \%$ & \\
\hline & Student & $9 \%$ & \\
\hline & Retired & & $2 \%$ \\
\hline \multirow{6}{*}{ Income } & Less than $\$ 40,000$ & $8 \% \mathrm{C}$ & \\
\hline & $\$ 40,000-\$ 59,999$ & $9 \%$ & \\
\hline & $\$ 60,000-\$ 99,999$ & & $6 \%$ \\
\hline & $\$ 100,000-\$ 149,999$ & & $3 \%$ \\
\hline & $\$ 150,000$ or more & & $3 \%$ \\
\hline & Live in bushfire area & $22 \%$ & \\
\hline \multirow{5}{*}{$\begin{array}{l}\text { Household } \\
\text { structure }\end{array}$} & Person living alone & & $5 \%$ \\
\hline & Couple living alone & & $3 \%$ \\
\hline & Couple parent with children & & $5 \%$ \\
\hline & Single parent with children & $21 \%$ & \\
\hline & Share house & $9 \%$ & \\
\hline \multirow{2}{*}{$\begin{array}{l}\text { Government } \\
\text { assistance }\end{array}$} & Eligible for JobKeeper & $12 \%$ & \\
\hline & Eligible for JobSeeker & $14 \%$ & \\
\hline
\end{tabular}

G12. And in February 2020, did any of these happen because of a shortage of money? Ran out of food and could not afford to buy more

Base: $\quad$ All $(n=2,000)$

Note: $\quad$ Results for some subgroups are lower than others but not significantly different to the overall results due to small base sizes 
Figure 50 Ran out of food and could not afford to buy more because of a shortage of money - Victorian and sub-population frequencies (\% yes) during the first lockdown compared to February 2020

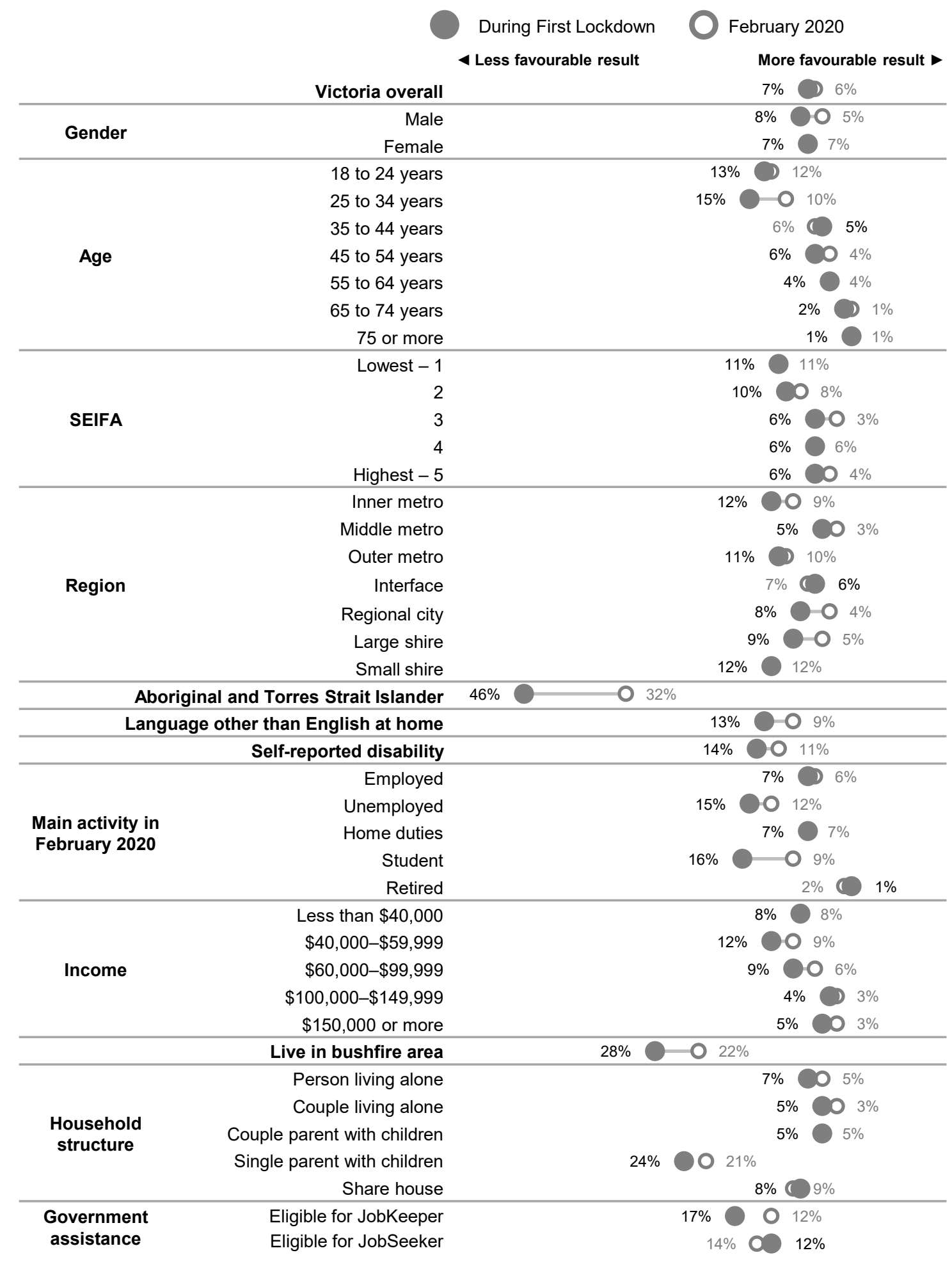

G12. Since COVID-19 restrictions began, did the of the following happen because of a shortage of money? And in February 2020, did any of these happen because of a shortage of money? Ran out of food and could not afford to buy more

Base: $\quad$ All $(n=2,000)$ 
In addition to running out of food and being unable to afford more, a series of other food consumption behaviours that were impacted upon due to a shortage of money related to financial difficulties (food insecurity) were explored in the survey (see Figure 51).

Significant increases were observed in the proportion of people who are:

- worrying about having enough money to buy food (up from 9\% in February 2020 to $17 \%$ )

- skipping meals to feed their household (up from 7\% in February 2020 to $10 \%$ )

- going without meals (up from 6\% in February 2020 to $8 \%$ ).

Figure 51 Food insecurity during the first lockdown and February 2020

During First Lockdown

February 2020

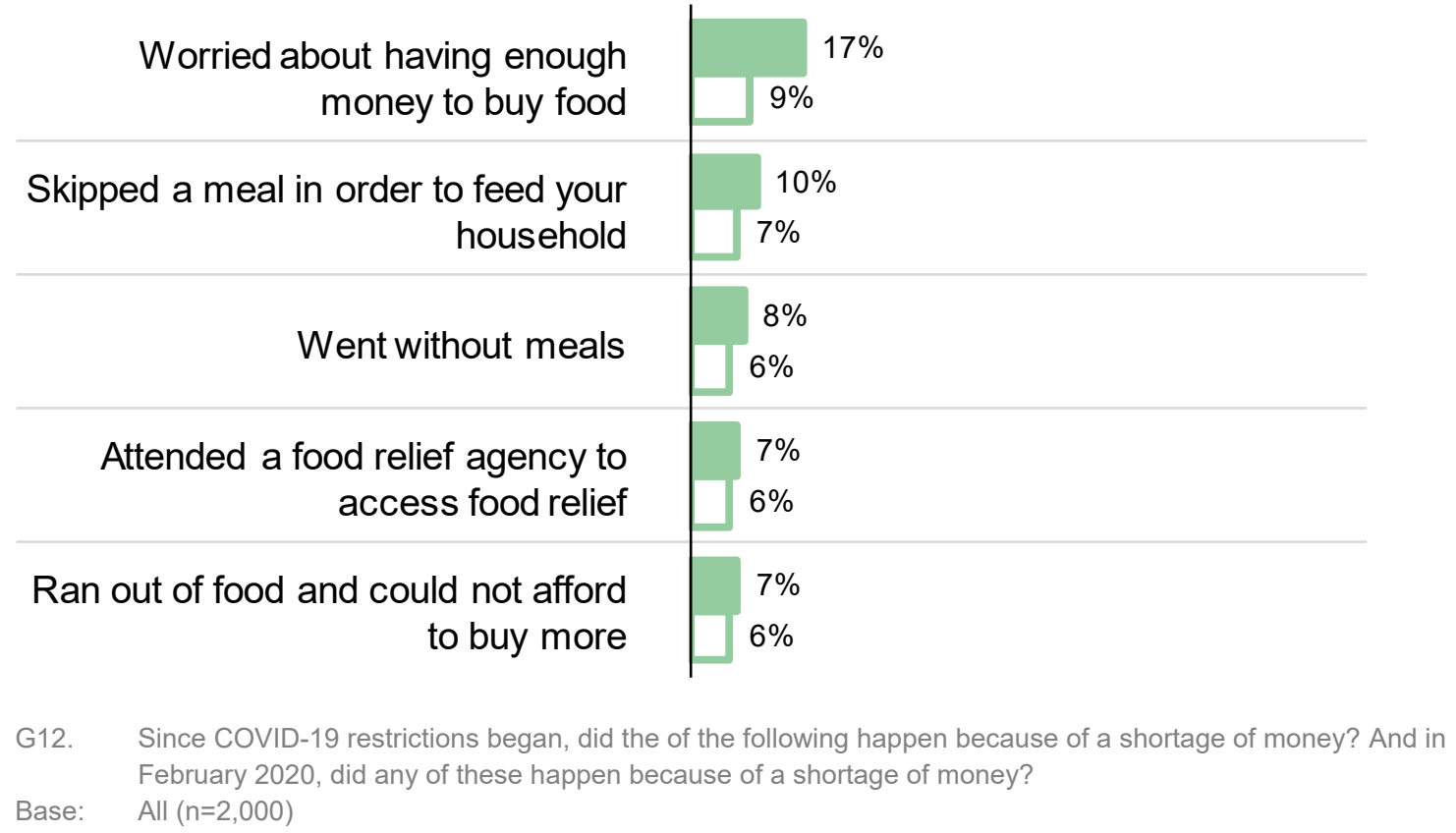

For those that had run out of food and couldn't to afford to buy more due to money shortage during the first lockdown, this had mostly occurred between one and five times (35\% once or twice, $40 \%$ three to five times). $5 \%$ ran out of food and couldn't afford to buy more due to money shortages more than 10 times since the restrictions started. 


\section{ALCOHOL CONSUMPTION}

VicHealth Coronavirus Victorian Wellbeing Impact Study

A comprehensive survey of 2,000 Victorians in the first coronavirus lockdown of 2020 showed that feeling anxious or stressed may have increased alcohol intake.

The risk of short term harm* from alcohol consumption across the state each week remains unchanged since 2017 at $11 \%$

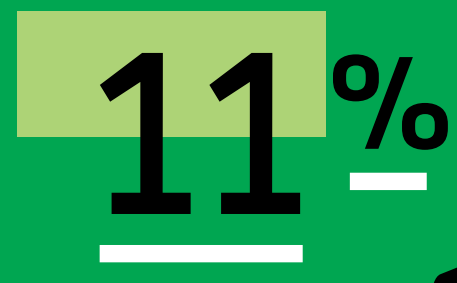

* People are at more risk of short term harm from alcohol, such as injury, if they consume 5 or more standard drinks in one session.

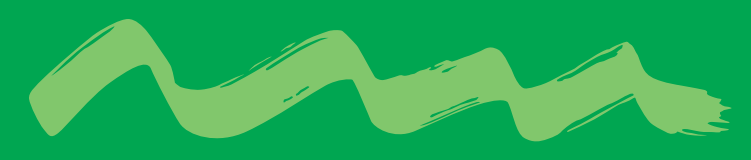

But the rate of short term harm from alcohol consumption each week is higher for some groups:

People from bushfire affected communities

$$
33 \%
$$

People on JobSeeker

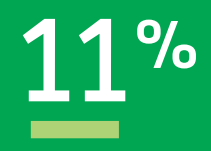

The risk of long term harm** from alcohol consumption is more likely for people from bushfire affected areas and those facing loss of income or employment

** Consuming more than 2 standard drinks most days of the week increases the risk of long term harm from alcohol, as it can cause chronic disease.

\section{This includes:}

People from bushfire affected communities

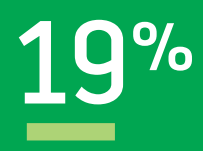

People on JobKeeper

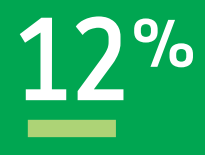

00000

People on JobSeeker

\section{$26 \%$}

Young people

aged 18-24

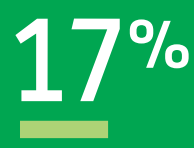

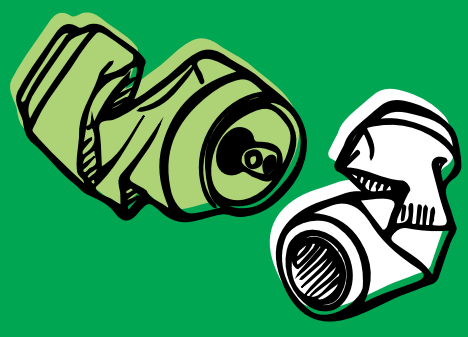

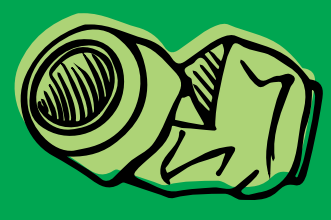




\section{Findings: Alcohol consumption}

The National Health and Medical Research Council's (NHMRC) 2009 Australian guidelines to reduce health risks from drinking alcohol ${ }^{20}$ recommend that people consume no more than:

- two standard drinks per day to reduce the risk of long term harms such as chronic disease

- four standard drinks on a single occasion to reduce the risk of short term harm such as injury.

Alcohol

Impact on alcohol consumption

- Consumption of alcohol consistent with levels defined as causing short term harm (more than four standard drinks in a session each week) was similar during coronavirus restrictions $(11 \%)$ and in a 2017 comparison survey (11.5\%).

- $\quad$ The proportion of those consuming more than two standard drinks of alcohol at least 5 days a week which is consistent with long term harm was $7 \%$.

\section{Factors influencing these changes}

- Boredom (43\%), increased stress and anxiety (42\%), and having more time (38\%) were the most commonly reported reason for increased consumption during coronavirus lockdown restrictions.

- Those who reported drinking less alcohol cite not being able to socialise with the people they usually drink with (37\%), and not being able to access usual places to drink (35\%) as reasons for reduced alcohol drinking. Another common reason was to improve personal health $(30 \%)$.

\section{Variation by subgroups}

- Consuming alcohol at levels linked to longer term harm was more commonly reported among those who were earning $\$ 40,000$ to $\$ 60,000(12 \%)$, those from bushfire affected areas $(19 \%)$, and those eligible for JobKeeper $(12 \%)$ or JobSeeker $(13 \%)$.

- Alcohol consumption behaviours consistent with short term harm were significantly more common among those aged 18 to $24(17 \%)$ single parents (31\%), parents of under $18 \mathrm{~s}$ with an income of more than $\$ 40,000(18 \%)$, males aged $45-54$ years $(18 \%)$ those with a disability (14\%), those earning $\$ 40,000$ to $\$ 60,000$ (18\%) those eligible for JobSeeker $(26 \%)$, and those from bushfire affected communities (33\%).

\footnotetext{
${ }^{20}$ National Health and Medical Research Council's 2009 Australian Guidelines to Reduce Health Risks from Drinking Alcohol
} 


\section{Short term harm}

(consumed more than 4 standard drinks

in a session at least weekly)

\subsection{Drinking frequency}

As shown in the figure below, during the first lockdown there have been a roughly equal proportion of people who were drinking on more days and those who were drinking on fewer days. Of the $7 \%$ who reported drinking daily, $35 \%$ reported this was more than pre-lockdown, significantly higher than the proportion among all respondents who drank alcohol. Likewise, a significantly higher proportion of those who drink monthly $(31 \%)$ or less often $(26 \%)$ were more likely to report drinking less during restrictions compared to pre-lockdown.

Figure 52 Frequency of alcohol consumption during the first lockdown compared to February 2020 (more, same or less number of days)

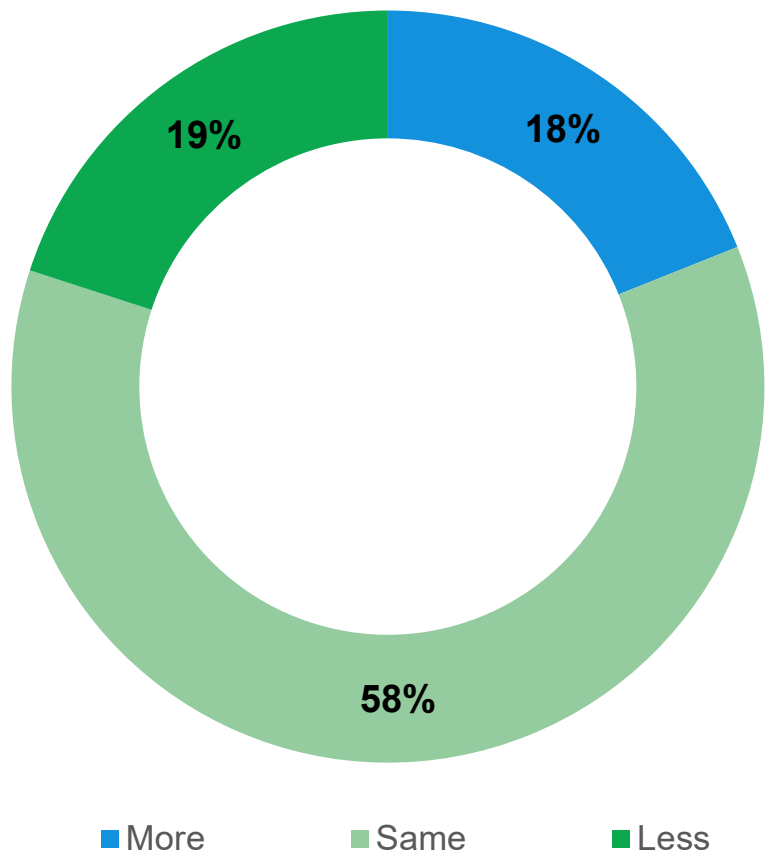

E2. Would you say this is more, less or about the same now - during COVID-19 restrictions, compared to February 2020?

Base: $\quad$ Had an alcoholic drink during the first lockdown $(n=1,492)$

Note: $\quad$ Not shown; not sure $(4 \%)$, prefer not to say $(2 \%)$ 
As shown in Figure 53, during the first lockdown there was a similar proportion of people who were drinking more standard drinks during each of their drinking sessions as those drinking fewer standard drinks. One in six (16\%) were drinking more in comparison to February 2020.

Figure 53 Levels of alcohol consumed in each drinking session during the first lockdown compared to February 2020 (more, same, less)

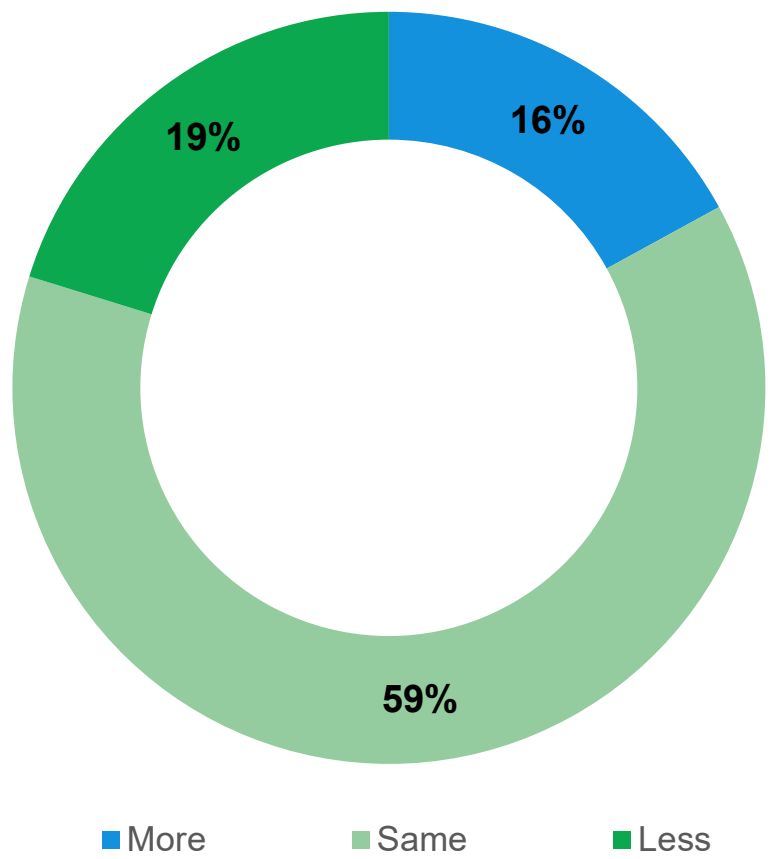

E4

Would you say this is more, less or about the same now - during COVID-19 restrictions, compared to February $2020 ?$

Base: $\quad$ Had an alcoholic drink during the first lockdown $(n=1,492)$

Note: $\quad$ Not shown; not sure (4\%), prefer not to say $(2 \%)$

Three in ten $(30 \%)$ of those who were drinking at a level that would put them at risk of short term harm (more than four standard drinks in a session each week) reported that they were drinking more drinks in a single session than they were before the first lockdown. This is significantly higher than the result for Victorians who had been drinking in general (16\%).

As shown in Figure 54, one in ten respondents (11\%) had consumed alcohol at a level that would put them at risk of short term harm (more than four standard drinks in a session each week). This behaviour was more common among those aged 18 to $24(17 \%)$ those with a disability (14\%), single parents $(31 \%)$, those earning $\$ 40,000$ to $\$ 60,000$ (18\%), those from a bushfire impacted area (33\%), and those eligible for JobSeeker $(26 \%)$. Male respondents were more likely to report this behaviour $(14 \%)$ than female respondents $(7 \%)$. 
Figure 54 Risk of short term harm (consumption of more than 4 standard drinks in a single session at least weekly) - Victorian and sub-population frequencies during the first lockdown

Note: Responses that are significantly more favourable than the Victorian overall result are on the right, highlighted in green. Responses that are significantly less favourable than the Victorian overall result are on the left, highlighted in blue.

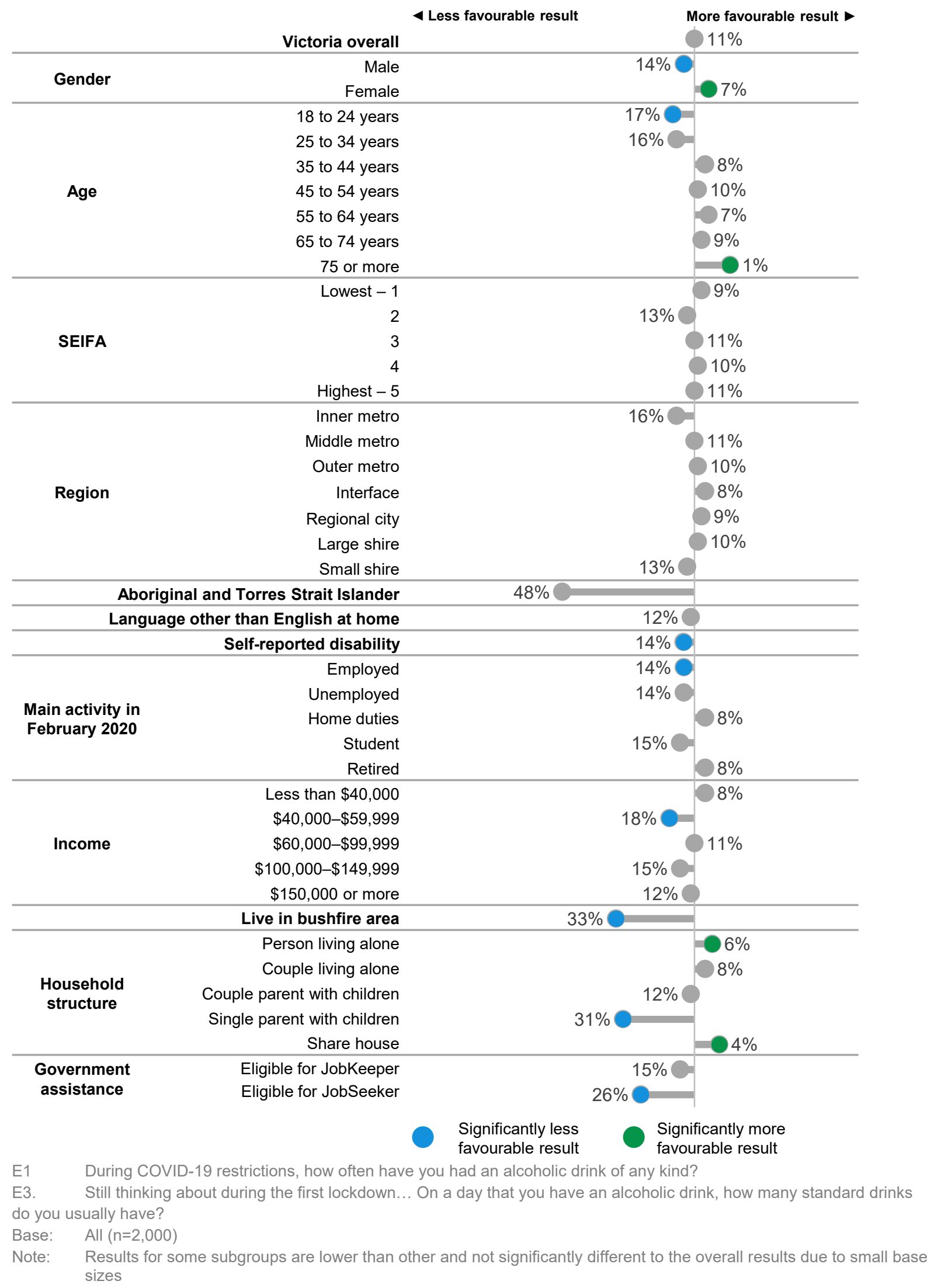


As shown in Figure 55, the proportion of those consuming more than two standard drinks of alcohol at least 5 days a week which is consistent with long term harm was $7 \%$ and was significantly higher amongst those earning $\$ 40,000$ to $\$ 60,000(12 \%)$, those from bushfire affected areas (19\%), and those eligible for JobKeeper (12\%) or JobSeeker (13\%). 
Figure 55 Risk of long term harm (consumption of more than two standard drinks in a single session, 5 to 7 days a week) - Victorian and sub-population frequencies during the first lockdown

Note: Responses that are significantly more favourable than the Victorian overall result are on the right, highlighted in green. Responses that are significantly less favourable than the Victorian overall result are on the left, highlighted in blue

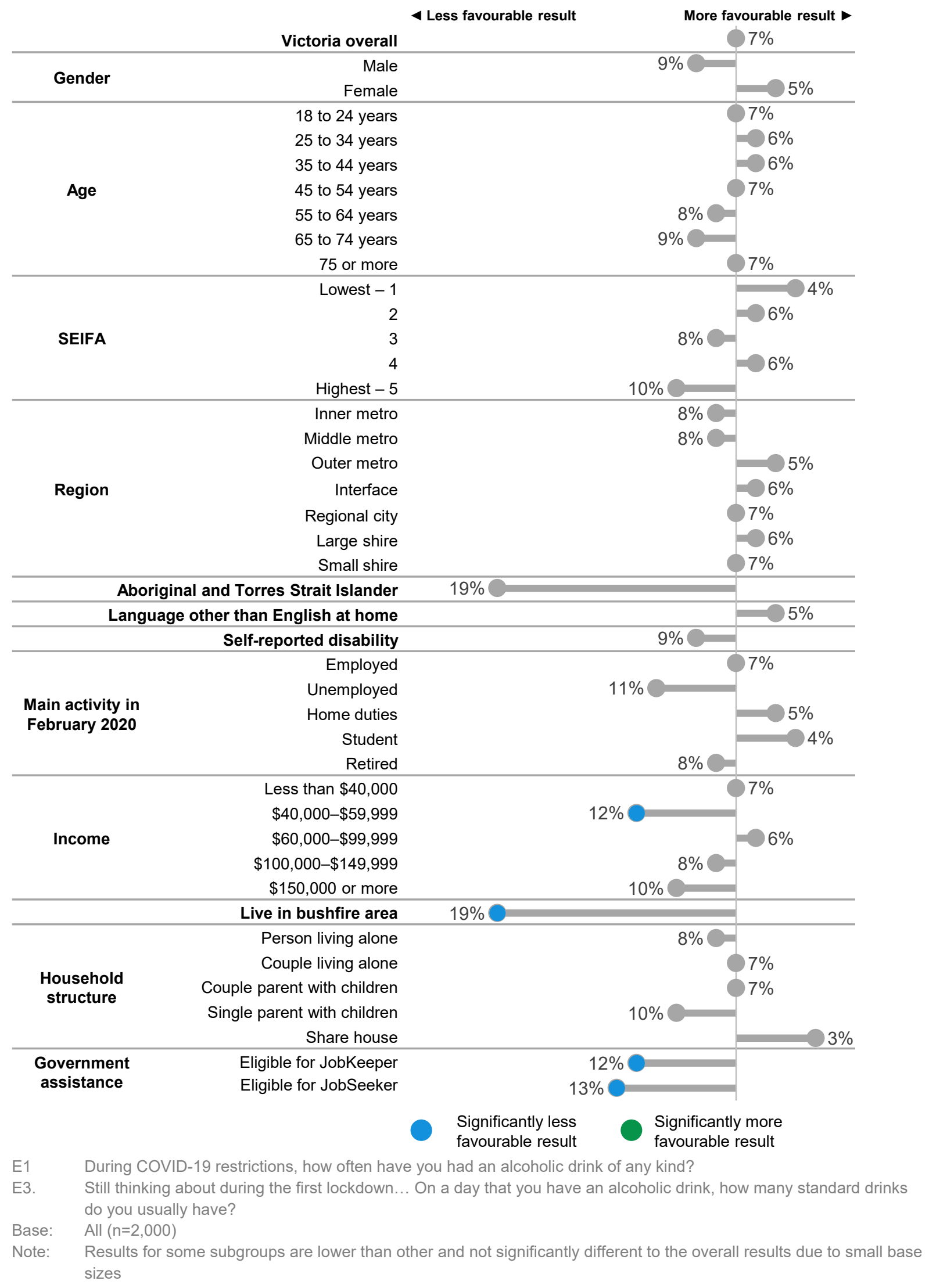




\subsection{Drinking behaviour change}

Respondents were asked for the reasons that they were drinking more alcohol during the first lockdown and could select multiple reasons. Responses to these questions may help identify the causes of increased alcohol consumption and how future safer drinking behaviour can be encouraged. Common reasons for increased drinking behaviour among respondents included boredom (43\%), dealing with anxiety or stress (42\%), or having more time (38\%), see Figure 56.

Drinking more due to anxiety or stress was more commonly cited as a reason for increased alcohol consumption for those aged 45 to $54(64 \%)$.

Figure 56 Main reason for drinking more alcohol during the first lockdown

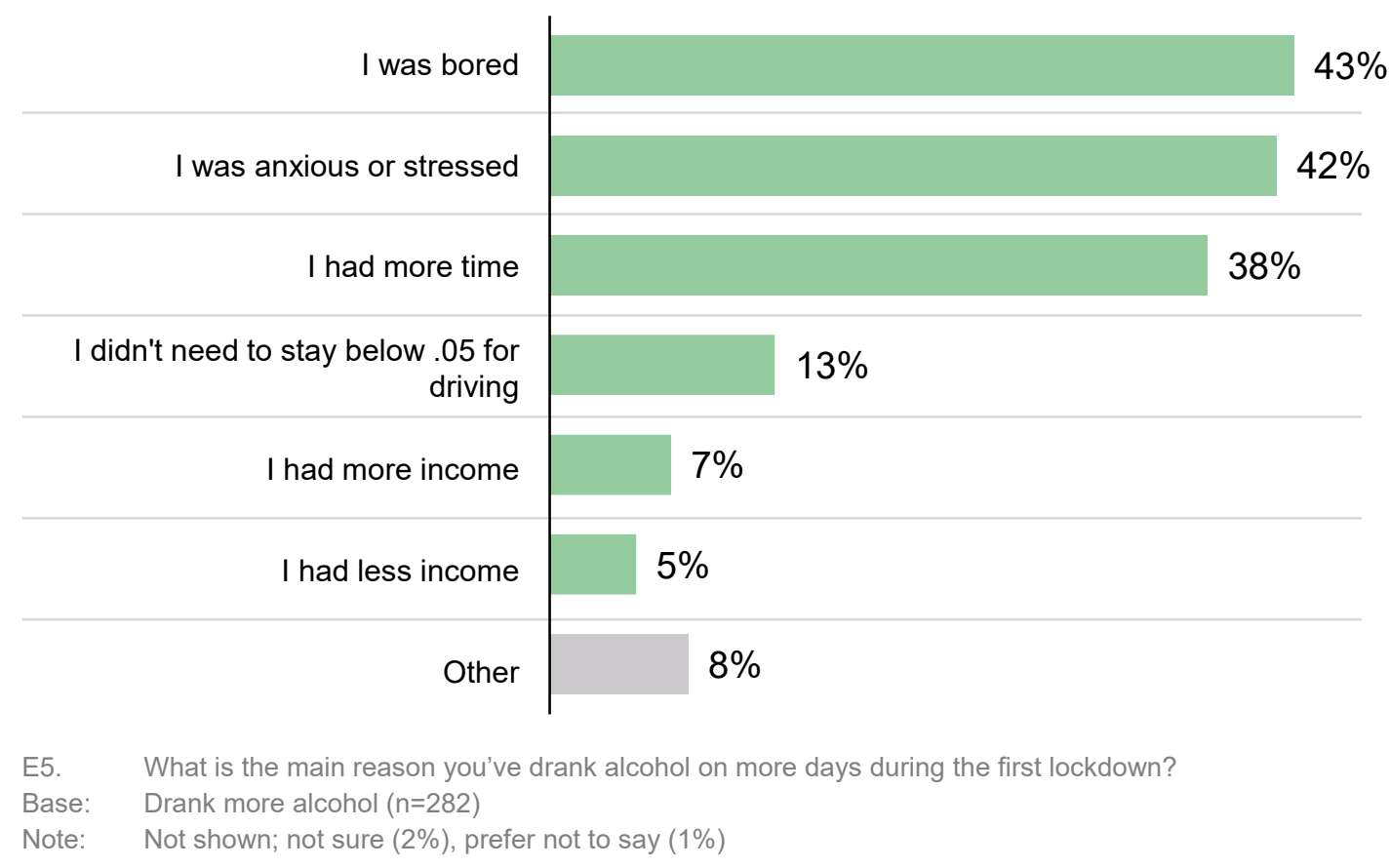

The reasons for drinking less alcohol are shown in Figure 57. Respondents could select multiple reasons. Reasons for drinking less alcohol included not being in social situations that encourage drinking (37\%) and the enforced closure of drinking establishments (35\%).

People living alone were indicatively more likely to cite not having access to places they usually drink as a reason for consuming less alcohol $(53 \%)$. 
Figure 57 Main reason for drinking less alcohol during the first lockdown

\begin{tabular}{|c|c|c|}
\hline $\begin{array}{r}\text { I can't socialise with the people } \\
\text { I usuallydrink with }\end{array}$ & & $37 \%$ \\
\hline $\begin{array}{r}\text { The places where I usuallydrink } \\
\text { are closed }\end{array}$ & & $35 \%$ \\
\hline $\begin{array}{l}\text { I wanted to improve my health in } \\
\text { general }\end{array}$ & & $30 \%$ \\
\hline I had less income & $14 \%$ & \\
\hline $\begin{array}{r}\text { Had fewer opportunities to } \\
\text { drink at home }\end{array}$ & $13 \%$ & \\
\hline $\begin{array}{l}\text { Concerned that drinking alcohol could } \\
\text { increase the risk or severity of coronavirus }\end{array}$ & $8 \%$ & \\
\hline I had more income & $2 \%$ & \\
\hline Other & $4 \%$ & \\
\hline
\end{tabular}

E6. What is the main reason you've drank alcohol on less days during the first lockdown?

Base: Drank less alcohol $(n=287)$

Note: $\quad$ Not shown; not sure $(5 \%)$, prefer not to say $(2 \%)$

Figure 58 Situations preferred for alcohol consumption during the first lockdown

\begin{tabular}{r|r}
$\begin{array}{r}\text { At home with } \\
\text { family/partner/housemates }\end{array}$ & $54 \%$ \\
\hline At home on your own & $41 \%$ \\
\hline $\begin{array}{r}\text { At home on a video call with } \\
\text { friends/family }\end{array}$ & $11 \%$ \\
\hline $\begin{array}{r}\text { None of the above } \\
\text { nat }\end{array}$ & $10 \%$
\end{tabular}

E7. There are a number of situations that people prefer to drink alcohol. Which of the following have applied to you during restrictions?

Base: $\quad$ Had an alcoholic drink during the first lockdown $(n=1,492)$

Note: $\quad$ Not shown; not sure $(4 \%)$, prefer not to say $(2 \%)$

Among those who had a drink of alcohol during the first lockdown, the most commonly preferred situations to drink was with others at home (54\%), see Figure 58 above. Two in five report that they prefer to drink at home alone (41\%).

Those aged 45 to 54 were more likely to report that they preferred drinking at home alone during the first coronavirus lockdown (55\%). Those living alone were also commonly drinking in this manner (72\%).

Drinking at home on a video call was more common for those living in inner metro Melbourne $(21 \%)$, among those earning $\$ 150,000$ or more $(24 \%)$, and among those living in share houses $(18 \%)$. 


\section{SMOKING}

VicHealth Coronavirus Victorian Wellbeing Impact Study

A comprehensive survey of 2,000 Victorians in the first coronavirus lockdown of 2020 showed mixed results for smokers.

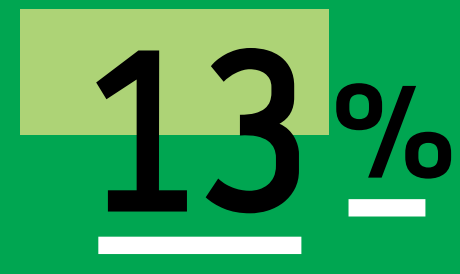

of Victorians who smoke attempted
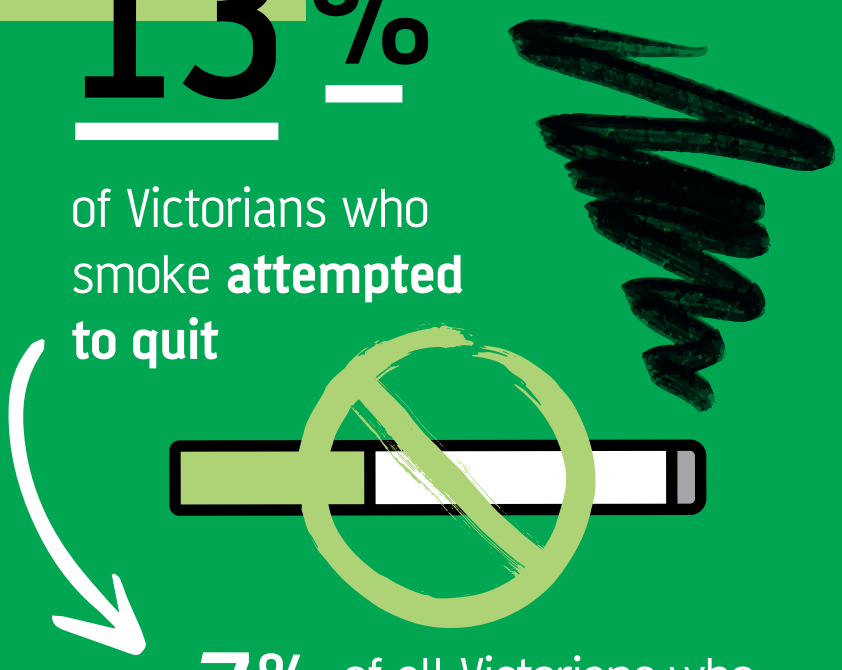

$7 \%$ of all Victorians who
smoke successfully quit

1 in 4 of Victorians who smoke who attempted to quit did so to save money
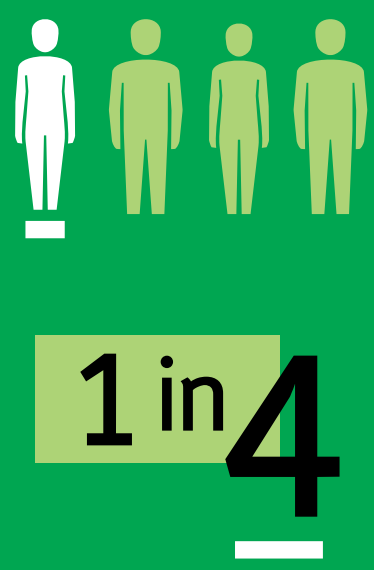
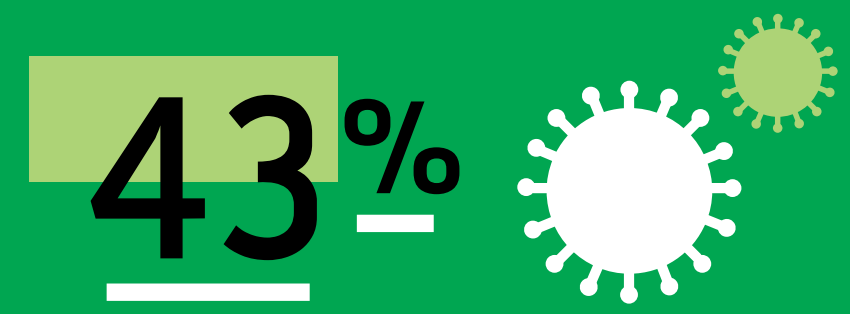

who attempted to quit smoking did so because they were worried it could increase the risk/severity of coronavirus
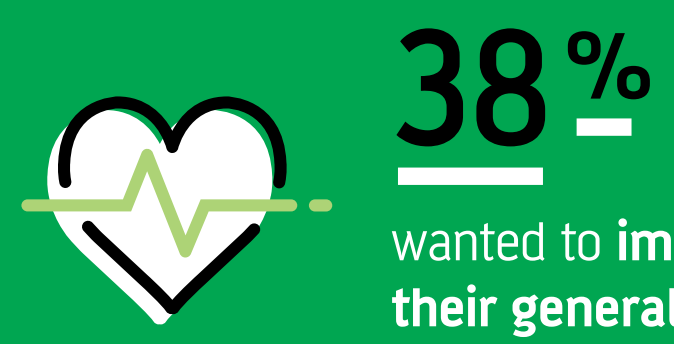

wanted to improve their general health

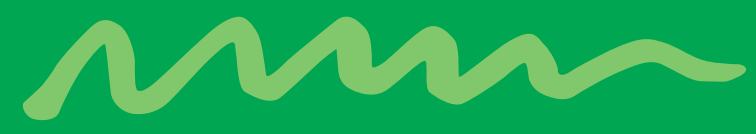

For Victorians who smoked more, over half said this was due to:

Anxiety or stress
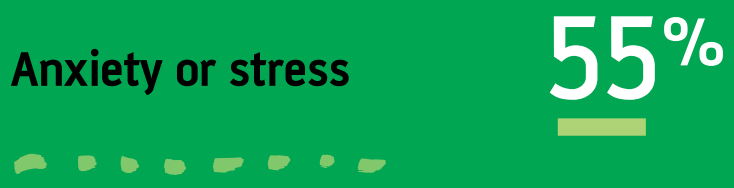

\section{Boredom}

$$
51^{\%}
$$

Having more free time

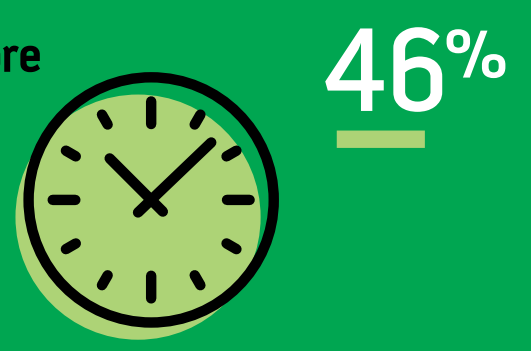




\section{Findings: Smoking}

Tobacco smoking is one of the leading causes of preventable death and disease in Australia ${ }^{21}$. A measure of smoking frequency was included in the survey to monitor any changes in smoking behaviours.

\section{Smoking}

\section{Impact on smoking}

- The proportion of respondents who reported they smoke daily $(12 \%)$ is consistent with the 2017 comparison survey (12.4\%). However, a recent survey of smoking behaviour in Victoria ${ }^{22}$ revealed the rate of daily smoking was $10 \%$, therefore the current result of $12 \%$ may indicate an increase in daily smoking rates.

- One in four respondents that smoke $(23 \%)$ reported that they had smoked more than usual during the first lockdown. A similar proportion of people who smoke reported smoking less than usual (19\%).

- The restrictions may have been a catalyst to stop smoking for some, with $13 \%$ attempting to quit and $7 \%$ successful in quitting.

\section{Factors influencing these changes}

- $\quad$ Factors leading to more frequent smoking include stress or anxiety $(55 \%)$, boredom $(51 \%)$, and more free time $(46 \%)$.

- Improving respondents' general health was the most common driver of smoking less (63\%).

- The most common reason for attempting to quit smoking during the first coronavirus lockdown was due to concern that smoking could increase the risk or severity of coronavirus $(43 \%)$. Other reasons included to improve their general health $(38 \%)$, and to save money $(27 \%)$.

- For the small proportion of people who had successfully quit during the first lockdown, the most common reason to do so was to improve their general health (46\%).

\section{Variation by subgroups}

- People who smoke daily were more likely to be aged 55 to 64 years, and to be living alone.

\footnotetext{
21 1. AlHW (Australian Institute of Health and Welfare) 2019. Australian Burden of Disease Study: impact and causes of illness and death in Australia 2015. Australian Burden of Disease Study series no.19. Cat. no. BOD 22. Canberra: AlHW. Viewed 13 June 2019

${ }^{22}$ Australian Institute of Health and Welfare 2020. National Drug Strategy Household Survey 2019. Drug Statistics series no. 32. PHE 270. Canberra AIHW, https://www.aihw.gov.au/getmedia/4a26ccf6-4934-4dcc-8052-c6ee705ebb0f/aihw-phe-270-factsheet-Vic.pdf.aspx
} 


\section{Smoking frequency}

(smoke daily)

$12 \%$

$12.4 \%(2017)$

VPHS 2017 - https://www2.health.vic.gov.au/public-health/population-health-systems/health-status-of-victorians/survey-data-andreports/victorian-population-health-survey/victorian-population-health-survey-2017

\subsection{Smoking frequency}

Respondents were asked how frequently they smoked cigarettes, cigars, pipes or any other tobacco products. $12 \%$ of respondents were smoking at least daily at the time of the survey. Figure 59 shows the daily smoking rate for Victorians overall as well as daily smoking rates in sub-populations. 
Figure 59 Daily smoking of cigarettes, cigars, pipes or any other tobacco products - Victorian and subpopulation frequencies (\% daily smoking) during the first lockdown

Note: Responses that are significantly more favourable than the Victorian overall result are on the right, highlighted in green. Responses that are significantly less favourable than the Victorian overall result are on the left, highlighted in blue.

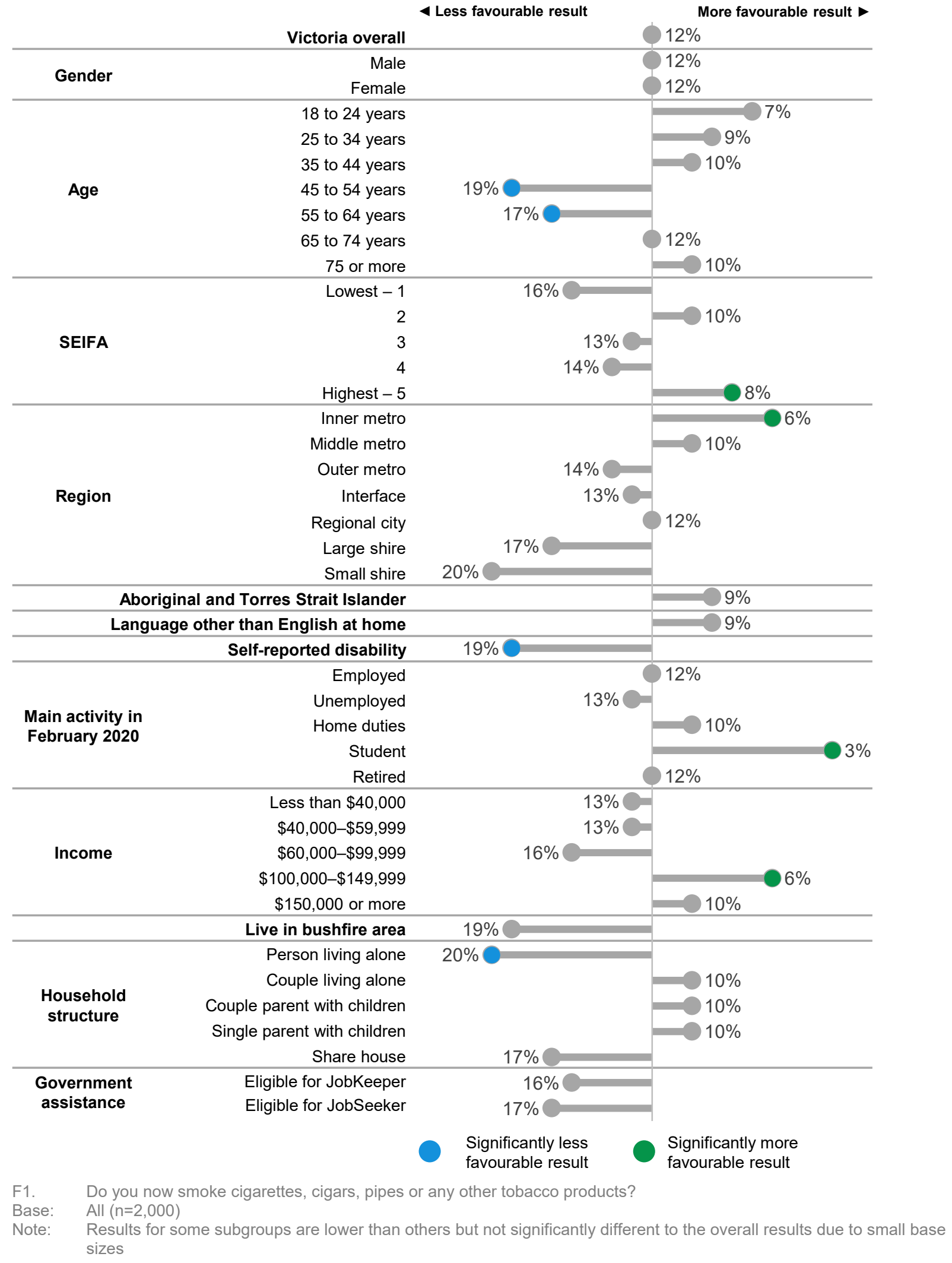




\subsection{Smoking behaviour change}

People who smoke daily were significantly more likely than smokers in general to report they were smoking more than usual (32\% compared to $23 \%$ ) and that they had not changed their smoking behaviour ( $45 \%$ compared to $31 \%$ ).

Three in ten people who smoke (31\%) reported that they had not changed their smoking behaviour during the first lockdown.

One in five people who smoke (13\%) had tried to quit during the restrictions with a further $7 \%$ doing so successfully (Figure 60).

Figure 60 Smoking behaviour changes during the first lockdown

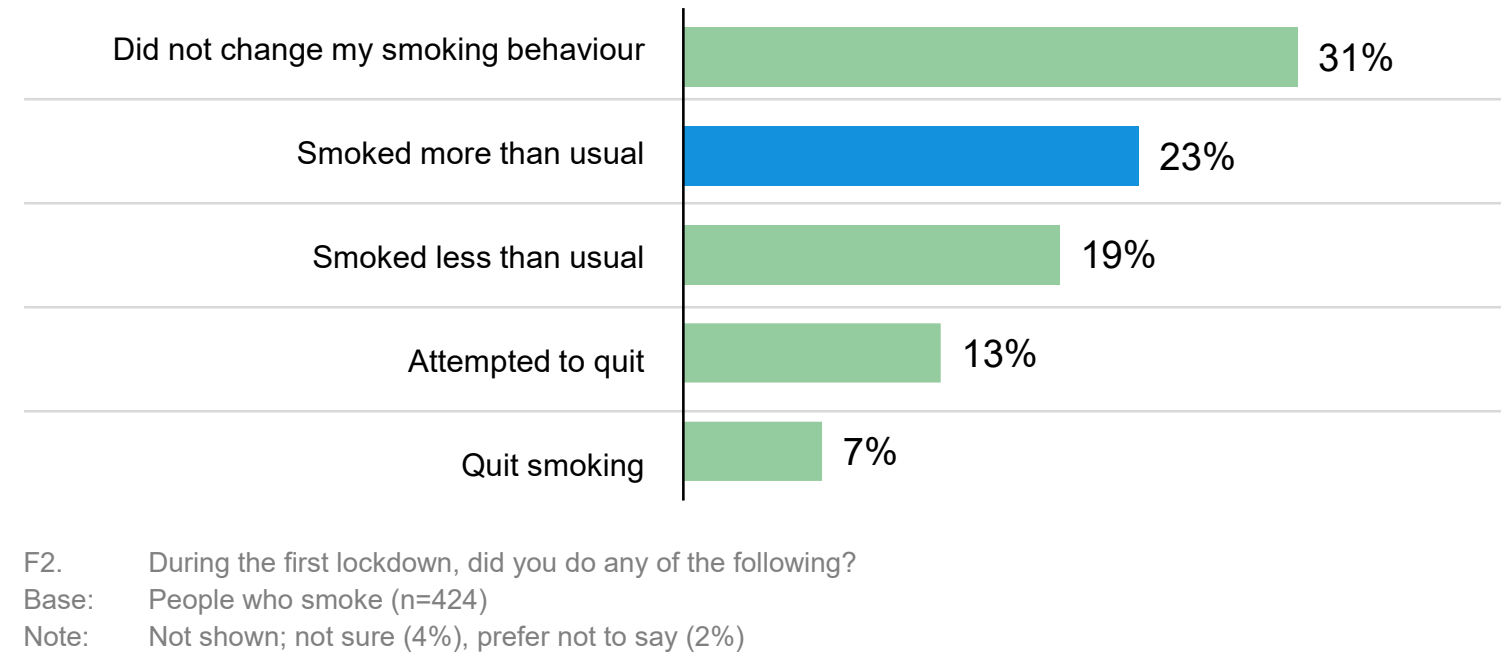

Those living in share housing were more likely to be smoking more than usual $(42 \%)$. Other groups reporting increased smoking included those with a self-reported disability $(35 \%)$ and those eligible for JobKeeper (49\%) Those who were eligible for JobSeeker payments were more likely to report that they had attempted to quit smoking (28\%). Respondents aged 25 to $34(28 \%)$, and those with a university level education (22\%) were also more likely to have attempted to quit smoking

Figure 61 Main reason for smoking more often during the first lockdown

\begin{tabular}{|c|c|}
\hline I was anxious or stressed & $55 \%$ \\
\hline I was bored & $51 \%$ \\
\hline I had more time & $46 \%$ \\
\hline Other & $1 \%$ \\
\hline
\end{tabular}

F3. What is the main reason you smoked more than usual during the first lockdown?

Base: $\quad$ Smoked more than usual $(n=107)$

Note: $\quad$ Not shown; not sure $(2 \%)$, prefer not to say $(0 \%)$ 
Among the $23 \%$ of people who smoke who reported smoking more during the first lockdown, common reasons for increased smoking included increased anxiety or stress $(55 \%)$, boredom (51\%), and more free time (46\%) (Figure 61).

For the $19 \%$ that were smoking less the most common driver to change their habit was to improve their health (63\%) (Figure 62).

Figure 62 Main reason for smoking less often during the first lockdown

\begin{tabular}{r|c} 
I wanted to improve my health in general & \\
\hline $\begin{array}{r}\text { Had fewer opportunities to smoke athome } \\
\text { the risk or severity of coronavirus }\end{array}$ & $16 \%$ \\
\hline $\begin{array}{r}\text { Concerned that smoking could increase } \\
\text { Reduced income }\end{array}$ & $13 \%$ \\
\hline Other & $9 \%$
\end{tabular}

F4. What is the main reason you smoked less than usual during the first lockdown?

Base: $\quad$ Smoked less than usual $(n=70)$

Note: $\quad$ Not shown; not sure $(1 \%)$, prefer not to say $(<1 \%)$ 
Figure 63 Main reason for attempting to quit smoking during the first lockdown

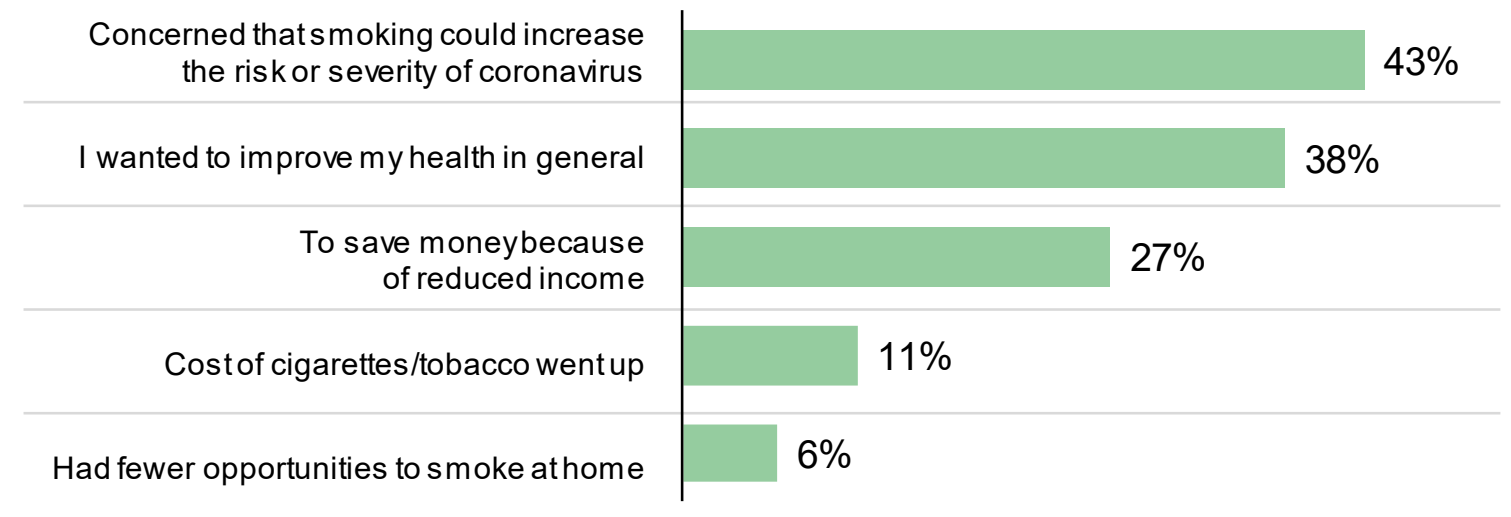

F5. What is the main reason you attempted to quit during the first lockdown?

Base: $\quad$ Attempted to quit $(n=51)$

Note: $\quad$ Not shown; not sure $(<1 \%)$, prefer not to say $(2 \%)$

Common reasons for attempting to quit smoking during the first lockdown were the perceived increased risks for people who smoke of coronavirus infections (43\%) and to improve general health (Figure 63).

Similar reasons for quitting were observed among those who quit (Figure 64).

Figure 64 Main reason for quitting smoking during the first lockdown*

\begin{tabular}{|c|c|}
\hline I wanted to improve my health in general & $46 \%$ \\
\hline $\begin{array}{r}\text { Concerned that smoking could increase } \\
\text { the risk or severity of coronavirus }\end{array}$ & $26 \%$ \\
\hline $\begin{array}{r}\text { To save moneybecause } \\
\text { of reduced income }\end{array}$ & $19 \%$ \\
\hline Cost of cigarettes/tobacco went up & $10 \%$ \\
\hline Other & $2 \%$ \\
\hline
\end{tabular}

F6. What is the main reason you've quit during the first lockdown?

Base: $\quad$ Quit smoking $(n=26)$

Note: $\quad$ Small base size $(n<30)$ interpret results with caution. Not shown; not sure $(7 \%)$, prefer not to say $(<1 \%)$ 


\section{FINANCIAL HARDSHIP}

VicHealth Coronavirus Victorian Wellbeing Impact Study

A comprehensive survey of 2,000 Victorians in the first coronavirus lockdown of 2020 showed a large number experienced financial hardships and increasing uncertainty.

1 in 4 Victorians experienced financial hardship during the first lockdown, compared to 1 in 6 before it started
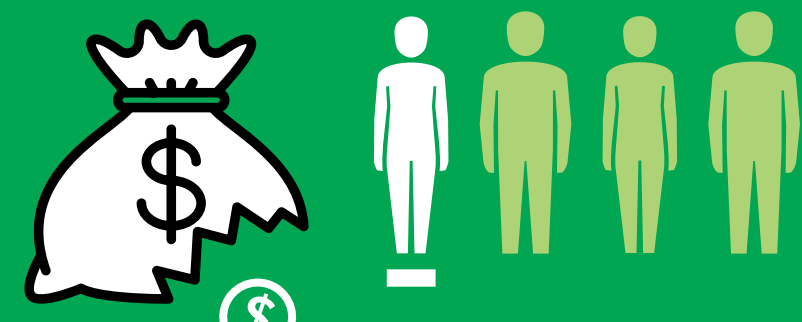

The first lockdown affected the jobs and finances of Victorians:

4 in 10 Hours cut tasck

1 in 6 rook a pay aut

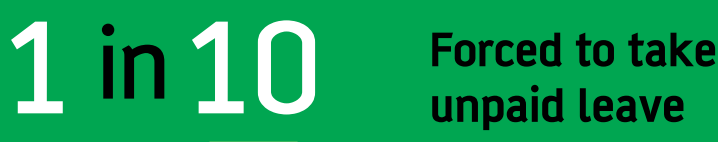
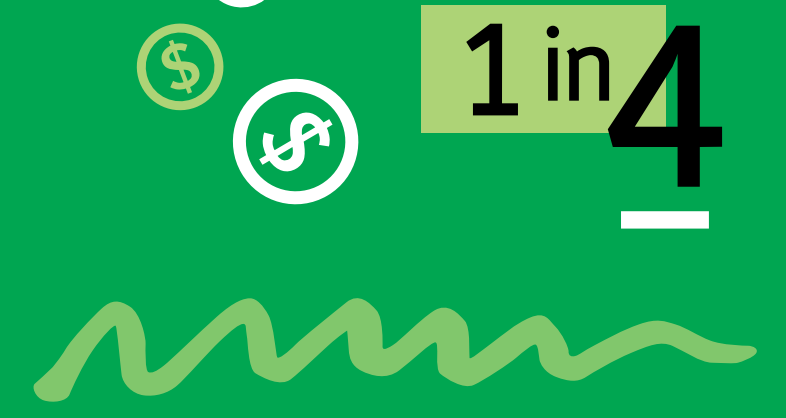

1 in 10

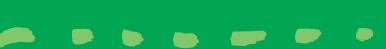

3 in 10 Victorians (29\%) were worried about their job prospects
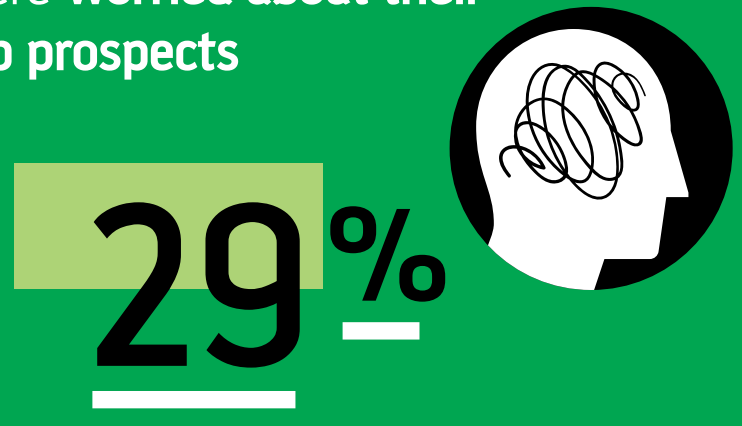

VicHealth
Those with a disability

Victorians doing it tough before coronavirus were more likely to lose their job during the first lockdown:

\section{Young women aged 18-24}

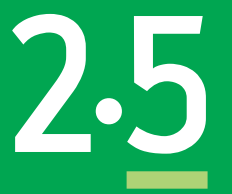

$\mathrm{X}$ more likely 


\section{Financial hardship}

The first lockdown caused many Victorians to have their hours of work and pay reduced, and many lost their jobs. The impact on these large-scale workforce reductions have been felt by many, with job insecurity leading to financial concerns as well as financial hardships.

Financial Hardship and Employment Impacts

\section{Impact on financial hardship and employment}

- One in four respondents (24\%) reported experiencing some form of hardship during the first lockdown. This is higher than the proportion who reported experiencing hardship during February 2020 (16\%).

- The most common forms of financial hardship during the first lockdown were having to ask friends or family for financial help (12\%).

- Concerns for the future were also common, three in ten respondents $(29 \%)$ were concerned about the stability of their future employment.

\section{Factors influencing these changes}

- Four in ten respondents reported a reduction in their hours worked (40\%). Other impacts on respondents' employment include having hourly rates of pay cut $(17 \%)$ and forced paid leave $(16 \%)$.

- One in ten of those employed in February 2020 reported that they had lost their job during the first lockdown.

\section{Variation by subgroups}

- Increases in the frequency of experiencing some form of financial hardship were largely consistent between subgroups. Those experiencing significantly higher levels of hardship in February 2020 were also more likely to be experiencing hardship during coronavirus lockdown restrictions.

- Young people aged 18-24 were more likely to report they had lost their job (17\%) compared to $10 \%$ of Victorians overall. However, it is young women who were most impacted with $26 \%$ losing their job, compared to $11 \%$ of young men of the same age group. People with a disability $(22 \%)$ were also more likely to report that they had lost their job since the coronavirus restrictions started.

\subsection{Hardship}

Respondents were asked if they had experienced one of the listed forms of financial hardships during the first lockdown due to a shortage of money. They were also asked if they had experienced any of these in February 2020. Those who reported experiencing any of 6 forms of financial hardship were combined into a single measure for the proportion of respondents that had experienced financial hardship (see Appendix 1 for scoring method). 
Coronavirus restrictions increased the proportion of respondents experiencing hardship in several areas. One in four respondents (24\%) had experienced some form of hardship during the first lockdown, an increase from the 16\% that had experienced hardship in February 2020.

Having to ask for financial help from friends or family was the most common hardship behaviour reported, growing from $8 \%$ having to do this in February 2020 to $12 \%$ during the first lockdown. Smaller increases are seen in those struggling to pay bills on time (up from $8 \%$ to $11 \%$ ).

Figure 65 Financial hardship experienced during the first lockdown and February 2020

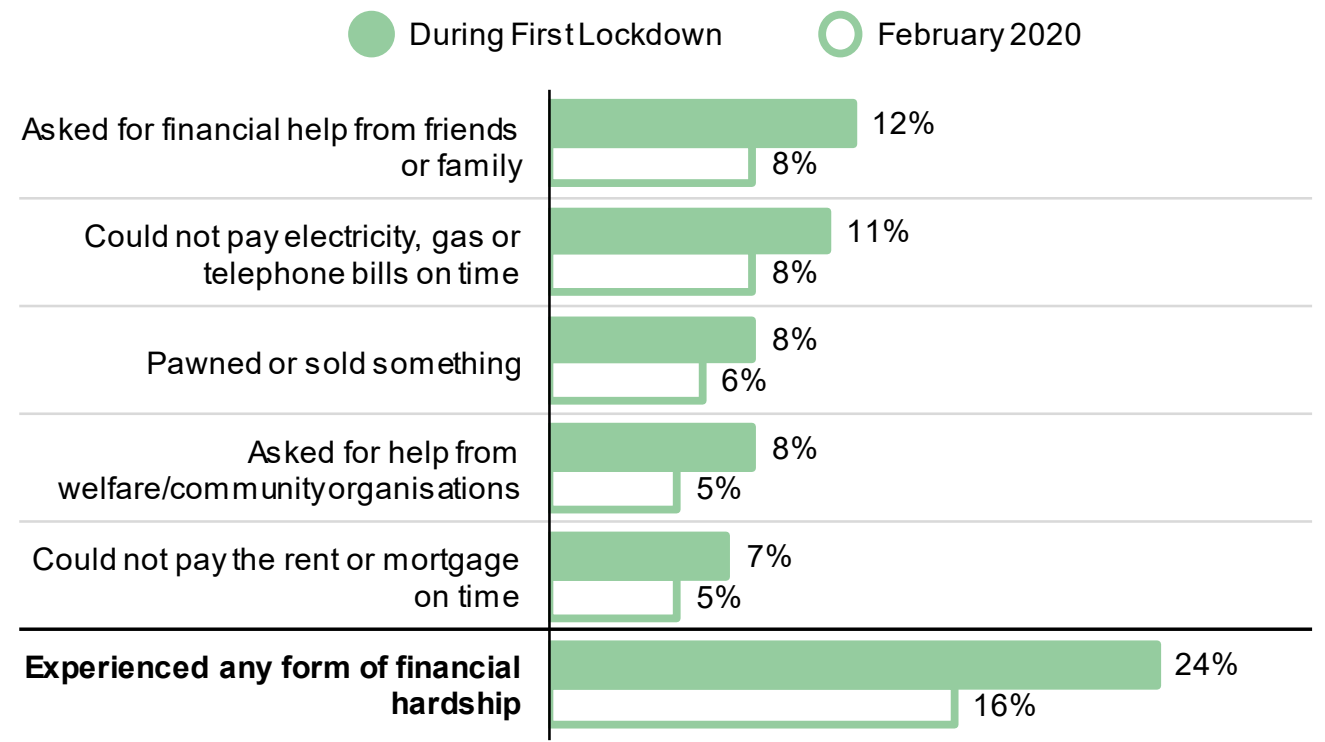

G12 Since COVID-19 restrictions began, did the of the following happen because of a shortage of money? (\% responding yes), items a-f.

Base: $\quad$ All $(n=2,000)$

Note: 'Any form of financial hardship' measure includes items in the figure above and 'Went without meals' (\% reported in Figure 51 under food insecurity), see Appendix 1 for details.

The following figures show how different subgroups were encountering any form of financial hardship during the first lockdown and during February 2020. 
Figure 66 Experience of financial hardship - Victorian and sub-population frequencies during the first lockdown Note: Responses that are significantly more favourable than the Victorian overall result are on the right, highlighted in green. Responses that are significantly less favourable than the Victorian overall result are on the left, highlighted in blue.




Figure 67 Experience of financial hardship - Victorian and sub-population frequencies during February 2020 Note: Responses that are significantly more favourable than the Victorian overall result are on the right, highlighted in green. Responses that are significantly less favourable than the Victorian overall result are on the left, highlighted in blue.

\begin{tabular}{|c|c|c|c|}
\hline & Victoria overall & 4 Less favourable result & $\begin{array}{l}\text { ore favourable result } \\
16 \%\end{array}$ \\
\hline \multirow{2}{*}{ Gender } & Male & & $16 \%$ \\
\hline & Female & & $15 \%$ \\
\hline \multirow{7}{*}{ Age } & 18 to 24 years & $30 \%$ & \\
\hline & 25 to 34 years & $31 \% \bigcirc$ & \\
\hline & 35 to 44 years & & $11 \%$ \\
\hline & 45 to 54 years & & $12 \%$ \\
\hline & 55 to 64 years & & $12 \%$ \\
\hline & 65 to 74 years & & $4 \%$ \\
\hline & 75 or more & & $\bigcirc 1 \%$ \\
\hline \multirow{5}{*}{ SEIFA } & Lowest -1 & $22 \%$ & \\
\hline & 2 & $20 \%$ & \\
\hline & 3 & & $13 \%$ \\
\hline & 4 & & $12 \%$ \\
\hline & Highest -5 & & $16 \%$ \\
\hline \multirow{7}{*}{ Region } & Inner metro & $26 \%$ & \\
\hline & Middle metro & & $10 \%$ \\
\hline & Outer metro & $19 \%$ & \\
\hline & Interface & $17 \%$ & \\
\hline & Regional city & & $14 \%$ \\
\hline & Large shire & $17^{\circ}$ & \\
\hline & Small shire & $24 \%$ & \\
\hline \multicolumn{2}{|c|}{ Aboriginal and Torres Strait Islander } & $63 \% \mathrm{C}=$ & \\
\hline \multicolumn{2}{|c|}{ Language other than English at home } & $23 \% \bigcirc$ & \\
\hline & Self-reported disability & $26 \%$ & \\
\hline \multirow{5}{*}{$\begin{array}{c}\text { Main activity in } \\
\text { February } 2020\end{array}$} & Employed & $28 \%$ & \\
\hline & Unemployed & & $3 \%$ \\
\hline & Home duties & & $13 \%$ \\
\hline & Student & & $15 \%$ \\
\hline & Retired & $29 \%$ & \\
\hline \multirow{6}{*}{ Income } & Less than $\$ 40,000$ & $19 \%$ & \\
\hline & $\$ 40,000-\$ 59,999$ & $22 \% \bigcirc$ & \\
\hline & $\$ 60,000-\$ 99,999$ & & $16 \%$ \\
\hline & $\$ 100,000-\$ 149,999$ & & $12 \%$ \\
\hline & $\$ 150,000$ or more & & $8 \%$ \\
\hline & Live in bushfire area & $44 \% \bigcirc$ & \\
\hline \multirow{5}{*}{$\begin{array}{l}\text { Household } \\
\text { structure }\end{array}$} & Person living alone & & $14 \%$ \\
\hline & Couple living alone & & $10 \%$ \\
\hline & Couple parent with children & & $16 \%$ \\
\hline & Single parent with children & $36 \%$ & \\
\hline & Share house & $20 \%$ & \\
\hline \multirow{3}{*}{$\begin{array}{l}\text { Government } \\
\text { assistance }\end{array}$} & Eligible for JobKeeper & $23 \%$ & \\
\hline & Eligible for JobSeeker & $38 \%$ & \\
\hline & & $\begin{array}{l}\text { Significantly less } \\
\text { favourable result }\end{array}$ & $\begin{array}{l}\text { icantly more } \\
\text { rable result }\end{array}$ \\
\hline
\end{tabular}

G12 Since COVID-19 restrictions began, did the of the following happen because of a shortage of money?

Base: $\quad$ All $(n=2,000)$

Note: Results for some subgroups are lower than other and not significantly different to the overall results due to small base sizes 
Figure 68 Experience of financial hardship - Victorian and sub-population frequencies during the first lockdown compared to February 2020

\begin{tabular}{|c|c|c|}
\hline & \multirow[b]{2}{*}{ Victoria overall } & $\begin{array}{l}\text { February } 2020 \\
\text { More favourable result }\end{array}$ \\
\hline & & \\
\hline \multirow{2}{*}{ Gender } & Male & \multirow{2}{*}{$\begin{array}{rrr}24 \% & 0 & 16 \% \\
26 \% & 0 & 16 \% \\
21 \% & -0 & 15 \% \\
\end{array}$} \\
\hline & Female & \\
\hline \multirow{7}{*}{ Age } & 18 to 24 years & $\begin{array}{ll} & 21 \% \\
39 \% & \bigcirc 30 \%\end{array}$ \\
\hline & 25 to 34 years & \multirow{2}{*}{ 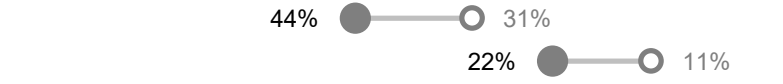 } \\
\hline & 35 to 44 years & \\
\hline & 45 to 54 years & $21 \% \bigcirc 12 \%$ \\
\hline & 55 to 64 years & $14 \% \bigcirc 12 \%$ \\
\hline & 65 to 74 years & $9 \% \bigcirc-\bigcirc 4 \%$ \\
\hline & 75 or more & $1 \% \bigcirc 1 \%$ \\
\hline \multirow{5}{*}{ SEIFA } & Lowest - 1 & $29 \% \bigcirc-22 \%$ \\
\hline & 2 & \multirow{3}{*}{$\begin{array}{ccc}28 \% & & 20 \% \\
22 \% & \bigcirc & 13 \% \\
20 \% & 0 & 12 \%\end{array}$} \\
\hline & 3 & \\
\hline & 4 & \\
\hline & Highest -5 & $25 \% \bigcirc-16 \%$ \\
\hline \multirow{7}{*}{ Region } & Inner metro & $36 \% \bigcirc 26 \%$ \\
\hline & Middle metro & $22 \% \bigcirc-\bigcirc 10 \%$ \\
\hline & Outer metro & $26 \% \bigcirc 19 \%$ \\
\hline & Interface & $23 \% \bigcirc 17 \%$ \\
\hline & Regional city & $21 \% \bigcirc \bigcirc 14 \%$ \\
\hline & Large shire & $21 \% \bigcirc 17 \%$ \\
\hline & Small shire & $27 \% \bigcirc 24 \%$ \\
\hline
\end{tabular}

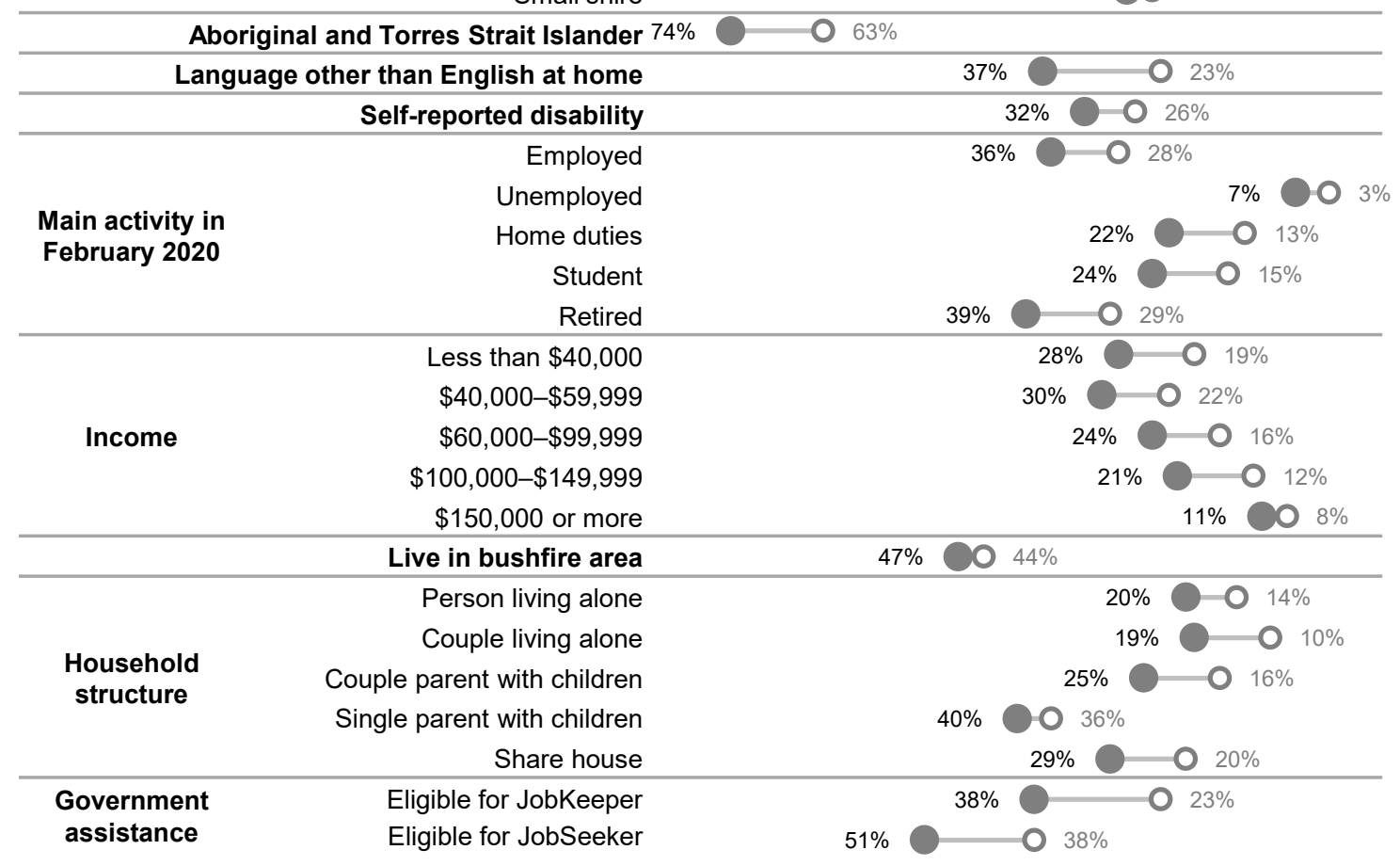

G12 Since COVID-19 restrictions began, did the of the following happen because of a shortage of money?
Base: $\quad$ All $(n=2,000)$ 


\subsubsection{Concerns around housing security}

Concerns about financial security may also play into concerns about how secure people are in their housing situation. At the time of the survey, one in five respondents $(19 \%)$ were concerned about the stability of their housing as highlighted in Figure 69. Figure 70 illustrates how this varies according to population sub-group.

Figure 69 Concerned about stability of housing (concerned, not concerned, neither)

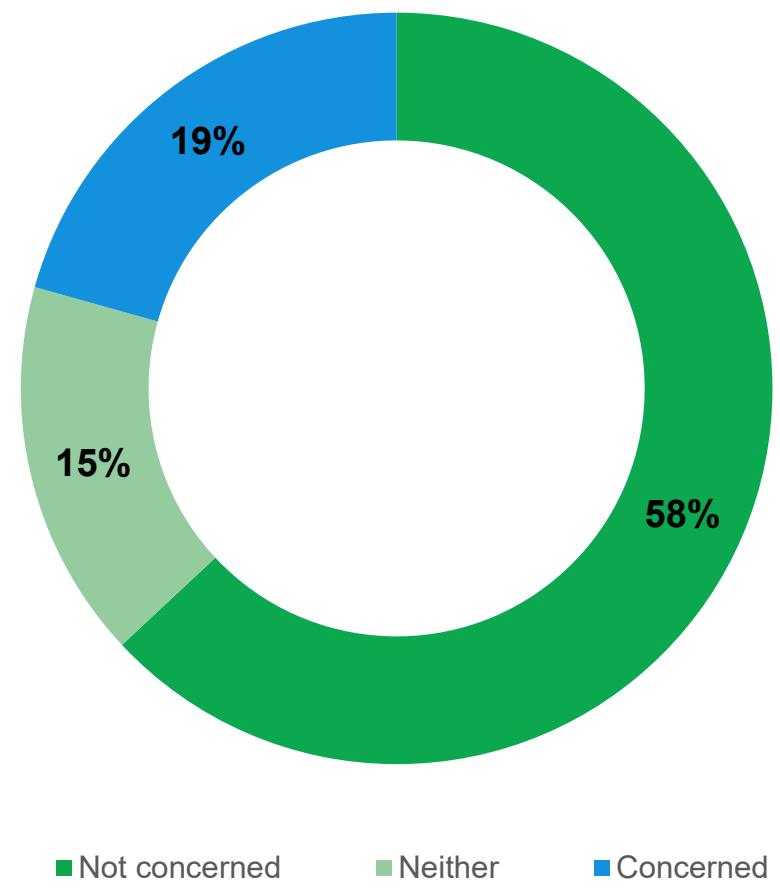

Thinking about how you feel right now, on a scale of 1 to 5 , where 1 is very concerned and 5 is not at all concerned would you say...? I feel concerned about stability of housing

Base: $\quad$ All $(n=2,000)$

Note: $\quad$ Concerned responses (1 or 2), Not concerned (4 or 5), Neither (3)

Note: $\quad$ Not shown; not sure $(5 \%)$, prefer not to say $(3 \%)$ 
Figure $\mathbf{7 0}$ Concern about stability of housing - Victorian and subpopulation frequencies (\% concerned) during the first lockdown

\begin{tabular}{|c|c|c|c|}
\hline \multirow{2}{*}{\multicolumn{2}{|c|}{ Victoria overall }} & 4 Less favourable result & More favourable result \\
\hline & & & $19 \%$ \\
\hline \multirow{2}{*}{ Gender } & Male & $23 \%$ & \\
\hline & Female & & $16 \%$ \\
\hline \multirow{7}{*}{ Age } & 18 to 24 years & $32 \% \bigcirc-$ & \\
\hline & 25 to 34 years & $31 \% \bigcirc$ & \\
\hline & 35 to 44 years & $23 \%$ & \\
\hline & 45 to 54 years & & $18 \%$ \\
\hline & 55 to 64 years & & $11 \%$ \\
\hline & 65 to 74 years & & $7 \%$ \\
\hline & 75 or more & & $\bigcirc 1 \%$ \\
\hline \multirow{5}{*}{ SEIFA } & Lowest -1 & $22 \%$ & \\
\hline & 2 & $23 \% \mathrm{C}=$ & \\
\hline & 3 & & $17 \%$ \\
\hline & 4 & & $19 \%$ \\
\hline & Highest -5 & & $18 \%$ \\
\hline \multirow{7}{*}{ Region } & Inner metro & $34 \%$ & \\
\hline & Middle metro & & $18 \%$ \\
\hline & Outer metro & $25 \%$ & \\
\hline & Interface & $20 \%$ & \\
\hline & Regional city & & $11 \%$ \\
\hline & Large shire & & $11 \%$ \\
\hline & Small shire & & $18 \%$ \\
\hline \multicolumn{2}{|c|}{ Aboriginal and Torres Strait Islander } & $31 \% \mathrm{C}=$ & \\
\hline \multicolumn{2}{|c|}{ Language other than English at home } & $33 \% \bigcirc$ & \\
\hline \multirow{6}{*}{$\begin{array}{l}\text { Main activity in } \\
\text { February } 2020\end{array}$} & Self-reported disability & & $18 \%$ \\
\hline & Employed & $21 \%$ & \\
\hline & Unemployed & $33 \%$ & \\
\hline & Home duties & & $18 \%$ \\
\hline & Student & $31 \%$ & \\
\hline & Retired & & $8 \%$ \\
\hline \multirow{6}{*}{ Income } & Less than $\$ 40,000$ & $23 \%$ & \\
\hline & $\$ 40,000-\$ 59,999$ & $22 \%$ & \\
\hline & $\$ 60,000-\$ 99,999$ & $20 \%$ & \\
\hline & $\$ 100,000-\$ 149,999$ & & $15 \%$ \\
\hline & $\$ 150,000$ or more & & $11 \%$ \\
\hline & Live in bushfire area & $32 \%$ & \\
\hline \multirow{5}{*}{$\begin{array}{l}\text { Household } \\
\text { structure }\end{array}$} & Person living alone & & $17 \%$ \\
\hline & Couple living alone & & $16 \%$ \\
\hline & Couple parent with children & $24 \% \bigcirc$ & \\
\hline & Single parent with children & & $16 \%$ \\
\hline & Share house & $26 \% \bigcirc$ & \\
\hline \multirow{2}{*}{$\begin{array}{l}\text { Government } \\
\text { assistance }\end{array}$} & Eligible for JobKeeper & 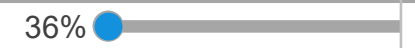 & \\
\hline & Eligible for JobSeeker & $36 \%$ & \\
\hline
\end{tabular}

G13 Thinking about how you feel right now, on a scale of 1 to 5 , where 1 is very concerned and 5 is not at all concerned, would you say...? I feel concerned about my future employment/job prospects

Base: $\quad$ All $(n=2,000)$

Note: $\quad$ Showing (1) - Very concerned and (2) Concerned responses

Note: $\quad$ Results for some subgroups are lower than others but not significantly different to the overall results due to small base sizes 
VicHealth Coronavirus Victorian Wellbeing Impact Study

A comprehensive survey of 2,000 Victorians in the first coronavirus lockdown of 2020 showed many were concerned about their job prospects, and mothers were bearing a greater burden.

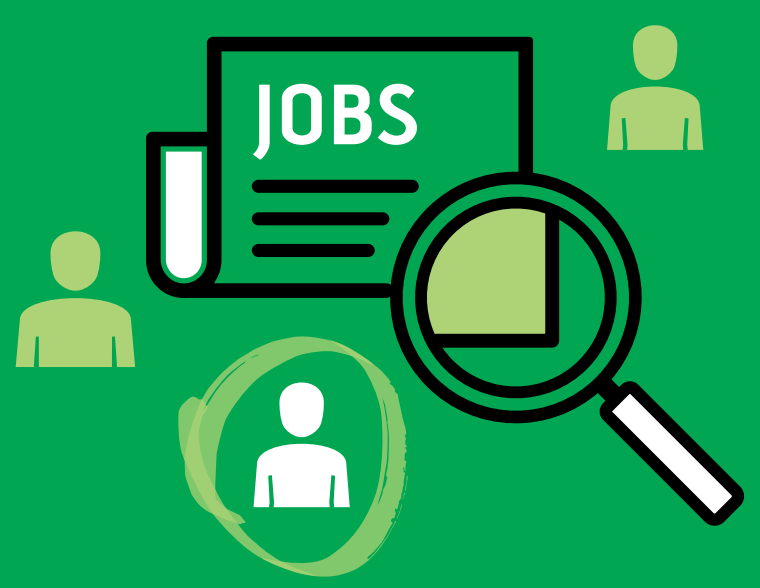

Some Victorians were more concerned about their job prospects than others:

Victorians who were already unemployed

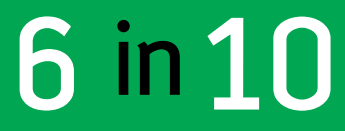

Victorians

aged 25-34

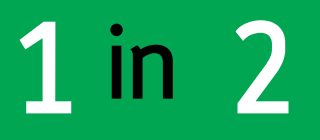

$0.0-0$.

Young Victorians aged 18-24 and Victorians who speak a language other than English at home
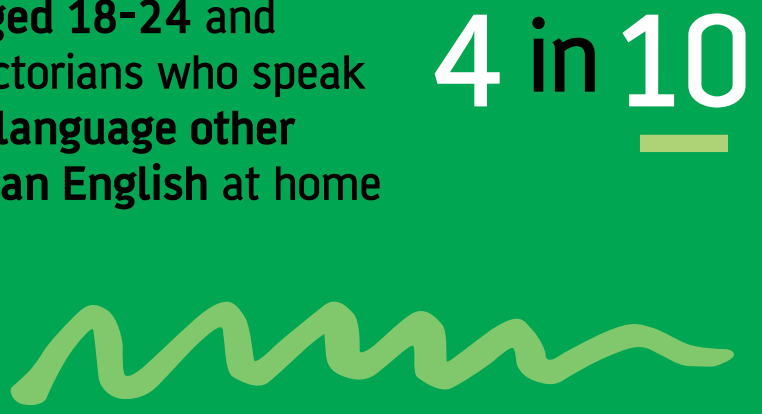

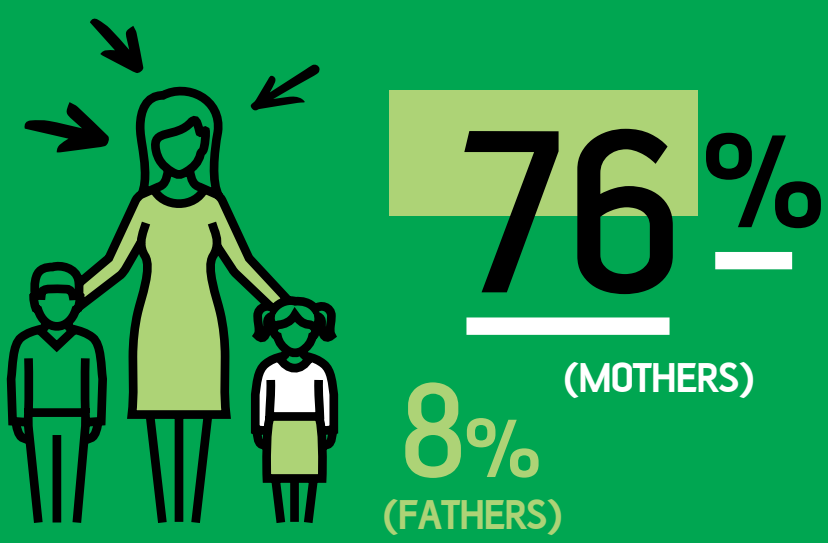

$76 \%$ of Victorian mothers were primarily responsible for looking after their pre-school aged kids, compared with only $8 \%$ of fathers

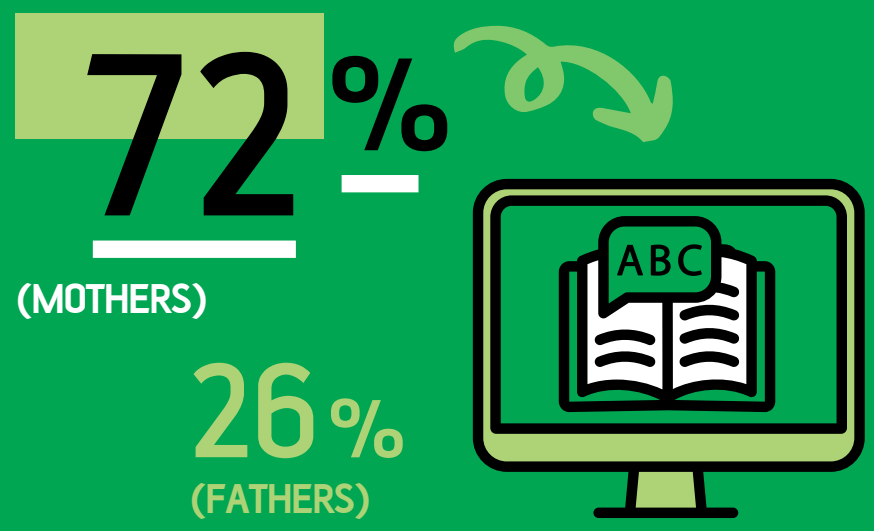

3 in 4 (72\%) Victorian mothers spent the most time helping their kids with remote learning, compared with just 1 in 4 of fathers (26\%) 


\section{Findings: Working and home life}

\subsection{Working status}

The figure below shows some of the ways respondents' employment status has been impacted by coronavirus.

The most commonly reported impact of coronavirus was a reduction in the number of hours people were working, four in ten respondents $(40 \%)$ had had their hours of work reduced. Many had to take paid $(16 \%)$ or unpaid leave $(10 \%)$ during this time.

One in ten respondents (10\%) had lost their job during the first lockdown. As shown in Table 6 respondents aged 18 to $24(17 \%)$ and those with a disability (22\%) were more likely to report that they had lost their job since the restrictions started.

Figure 71 Impacts of first lockdown on employment

\begin{tabular}{l|r}
$\begin{array}{r}\text { Had your hours of work reduced } \\
\text { Your hourly rate of pay / salary been } \\
\text { reduced not related to the number of } \\
\text { hours you work }\end{array}$ & $17 \%$ \\
\hline $\begin{array}{r}\text { Required to take paid leave } \\
\text { entitled }\end{array}$ & $16 \%$ \\
\hline Lot received a bonus that you job & $15 \%$ \\
\hline $\begin{array}{r}\text { Required to take unpaid leave } \\
\text { The company you worked for ceased } \\
\text { operating / had to close my business }\end{array}$ & $10 \%$ \\
G6 $\quad$ Thinking now about since the CoVID-19 restrictions started, have you experienced any of the following? (\% \\
responding yes) \\
Base: Had job in February 2020 (n=1,154)
\end{tabular}


Table 8 Types of employment impact due to first lockdown - subpopulation frequencies that are significantly different to the overall Victorian level

\begin{tabular}{|c|c|c|c|c|c|}
\hline \multirow{7}{*}{$\begin{array}{c}\text { Employment impact } \\
\begin{array}{c}\text { Had your hours of work } \\
\text { reduced }\end{array}\end{array}$} & \multirow{2}{*}{$\begin{array}{l}\text { Victoria } \\
\text { overall }\end{array}$} & \multicolumn{2}{|c|}{$\begin{array}{l}\text { Sub-groups who report this } \\
\text { more often }\end{array}$} & \multicolumn{2}{|c|}{$\begin{array}{l}\text { Sub-groups who report this } \\
\text { less often }\end{array}$} \\
\hline & & Eligible for JobKeeper & $69 \%$ & $\$ 100,000-\$ 149,999$ & $33 \%$ \\
\hline & \multirow{5}{*}{$40 \%$} & Eligible for JobSeeker & $68 \%$ & Middle metro & $32 \%$ \\
\hline & & $\$ 40,000-\$ 59,999$ & $59 \%$ & $\$ 150,000$ or more & $26 \%$ \\
\hline & & Large shire & $54 \%$ & & \\
\hline & & Has disability & $54 \%$ & & \\
\hline & & LOTE & $49 \%$ & & \\
\hline \multirow{5}{*}{$\begin{array}{l}\text { Your hourly rate of pay I } \\
\text { salary been reduced not } \\
\text { related to the number of } \\
\text { hours you work }\end{array}$} & \multirow{5}{*}{$17 \%$} & Eligible for JobSeeker & $47 \%$ & SEIFA 5 & $12 \%$ \\
\hline & & Inner metro & $29 \%$ & & \\
\hline & & Eligible for JobKeeper & $32 \%$ & & \\
\hline & & Has disability & $29 \%$ & & \\
\hline & & LOTE & $25 \%$ & & \\
\hline \multirow{3}{*}{ Lost your job } & \multirow{3}{*}{$10 \%$} & Eligible for JobSeeker & $31 \%$ & 45 to 54 years & $4 \%$ \\
\hline & & Has disability & $22 \%$ & & \\
\hline & & 18 to 24 years & $17 \%$ & & \\
\hline \multirow{4}{*}{$\begin{array}{l}\text { Required to take unpaid } \\
\text { leave }\end{array}$} & \multirow{4}{*}{$10 \%$} & Eligible for JobSeeker & $25 \%$ & $\$ 100,000-\$ 149,999$ & $6 \%$ \\
\hline & & Has disability & $24 \%$ & & \\
\hline & & Eligible for JobKeeper & $23 \%$ & & \\
\hline & & SEIFA 2 & $17 \%$ & & \\
\hline \multirow{7}{*}{$\begin{array}{l}\text { Not received a bonus } \\
\text { that you were entitled to }\end{array}$} & \multirow{7}{*}{$15 \%$} & Eligible for JobSeeker & $33 \%$ & 45 to 54 years & $7 \%$ \\
\hline & & LOTE & $29 \%$ & $\$ 150,000$ or more & $6 \%$ \\
\hline & & Inner metro & $20 \%$ & 55 to 64 years & $5 \%$ \\
\hline & & Eligible for JobKeeper & $23 \%$ & & \\
\hline & & Has disability & $23 \%$ & & \\
\hline & & 18 to 24 years & $22 \%$ & & \\
\hline & & 25 to 34 years & $21 \%$ & & \\
\hline \multirow{2}{*}{$\begin{array}{l}\text { Required to take paid } \\
\text { leave }\end{array}$} & \multirow{2}{*}{$16 \%$} & Eligible for JobKeeper & $31 \%$ & & \\
\hline & & LOTE & $23 \%$ & & \\
\hline \multirow{3}{*}{$\begin{array}{c}\text { The company you } \\
\text { worked for ceased } \\
\text { operating / had to close } \\
\text { my business }\end{array}$} & \multirow{3}{*}{$8 \%$} & Eligible for JobSeeker & $26 \%$ & & \\
\hline & & Has disability & $18 \%$ & & \\
\hline & & Eligible for JobKeeper & $17 \%$ & & \\
\hline
\end{tabular}


Impacts on the employment of respondents' partners were consistent with impacts on respondents themselves. The most common impact being a reduction in hours worked.

Figure 72 Impacts of first lockdown on partners' employment

\begin{tabular}{|c|c|}
\hline Had their hours of work reduced & $31 \%$ \\
\hline $\begin{array}{r}\text { Their hourly rate of pay / salary been } \\
\text { reduced not related to the number of } \\
\text { hours they work }\end{array}$ & $13 \%$ \\
\hline $\begin{array}{r}\text { Not received a bonus that they were } \\
\text { entitled }\end{array}$ & $13 \%$ \\
\hline Required to take paid leave & $12 \%$ \\
\hline Lost their job & $8 \%$ \\
\hline Required to take unpaid leave & $9 \%$ \\
\hline $\begin{array}{l}\text { The company they worked for ceased } \\
\text { operating / had to close their business }\end{array}$ & $7 \%$ \\
\hline \multicolumn{2}{|c|}{ And how about your partner? (\% responding yes) } \\
\hline Partner had job in February 202 & \\
\hline
\end{tabular}


Since the first lockdown many people have switched from working from the office or another location to working from home (Figure 73). The proportion working from home with standard hours increased from $20 \%$ during February 2020 to $29 \%$ during the first lockdown. A similar increase is seen in those working from home with flexible start and finish times (up from $12 \%$ to $20 \%$ ).

Figure 73 Usual place of work during the first lockdown and in February 2020

\begin{tabular}{c|c} 
During First Lockdown & February 2020 \\
$\begin{array}{c}\text { Worked mainly from another location } \\
\text { with standard hours }\end{array}$ & $32 \%$ \\
\hline $\begin{array}{c}\text { Worked mainly from home with standard } \\
\text { hours }\end{array}$ & $20 \%$ \\
\hline $\begin{array}{c}\text { Worked mainly from another location } \\
\text { office with flexible start and finish times }\end{array}$ & $11 \%$ \\
\hline $\begin{array}{c}\text { Worked mainly from home with flexible } \\
\text { start and finish times }\end{array}$ & $15 \%$ \\
\hline
\end{tabular}

\footnotetext{
G7a Thinking now about since the COVID-19 restrictions started, where is your usual place of work?

Base: $\quad$ Had job in February and still has it $(n=1,065)$

Note: $\quad$ Not shown; not sure (3\%), prefer not to say (5\%)

G5a And in February 2020, where was your usual place of work?

Base: $\quad$ Had job in February $(n=1,154)$

Note: Not shown; not sure (3\%), prefer not to say (3\%)
}

As shown in Figure 74, increased working from home was also commonly reported for respondents' partners. 
As shown in the following figure, younger people, parents, people in share houses, those who are unemployed, people who speak a language other than English at home and those in inner metro areas were most concerned. 
Figure 76 Concern about future job prospects - Victorian and subpopulations frequencies (\% concerned) during first lockdown

\begin{tabular}{|c|c|c|c|}
\hline & & 4 Less favourable result & More favourable result \\
\hline & Victoria overall & & $29 \%$ \\
\hline \multirow{2}{*}{ Gender } & Male & $32 \%$ & \\
\hline & Female & & $25 \%$ \\
\hline \multirow{7}{*}{ Age } & 18 to 24 years & $41 \%$ & \\
\hline & 25 to 34 years & $48 \%$ & \\
\hline & 35 to 44 years & $30 \%$ & \\
\hline & 45 to 54 years & & $27 \%$ \\
\hline & 55 to 64 years & & $20 \%$ \\
\hline & 65 to 74 years & & $8 \%$ \\
\hline & 75 or more & & $3 \%$ \\
\hline \multirow{5}{*}{ SEIFA } & Lowest - 1 & & $24 \%$ \\
\hline & 2 & $32 \%$ & \\
\hline & 3 & & $26 \%$ \\
\hline & 4 & & $28 \%$ \\
\hline & Highest -5 & $31 \%$ & \\
\hline \multirow{7}{*}{ Region } & Inner metro & $42 \%$ & \\
\hline & Middle metro & $33 \%$ & \\
\hline & Outer metro & & $26 \%$ \\
\hline & Interface & & $29 \%$ \\
\hline & Regional city & & $17 \%$ \\
\hline & Large shire & & $21 \%$ \\
\hline & Small shire & & $24 \%$ \\
\hline \multicolumn{2}{|c|}{ Aboriginal and Torres Strait Islander } & $31 \%$ & \\
\hline \multicolumn{2}{|c|}{ Language other than English at home } & $40 \% \bigcirc$ & \\
\hline \multirow{6}{*}{$\begin{array}{c}\text { Main activity in } \\
\text { February } 2020\end{array}$} & Self-reported disability & & $23 \%$ \\
\hline & Employed & $33 \%$ & \\
\hline & Unemployed & $60 \%$ & \\
\hline & Home duties & & $22 \%$ \\
\hline & Student & $33 \%$ & \\
\hline & Retired & & $8 \%$ \\
\hline \multirow{6}{*}{ Income } & Less than $\$ 40,000$ & $32 \%$ & \\
\hline & $\$ 40,000-\$ 59,999$ & & $24 \%$ \\
\hline & $\$ 60,000-\$ 99,999$ & $32 \%$ & \\
\hline & $\$ 100,000-\$ 149,999$ & & $25 \%$ \\
\hline & $\$ 150,000$ or more & & $23 \%$ \\
\hline & Live in bushfire area & $33 \%$ & \\
\hline \multirow{5}{*}{$\begin{array}{l}\text { Household } \\
\text { structure }\end{array}$} & Person living alone & & $23 \%$ \\
\hline & Couple living alone & & $19 \%$ \\
\hline & Couple parent with children & $36 \%$ & \\
\hline & Single parent with children & $32 \%$ & \\
\hline & Share house & $40 \% \bigcirc$ & \\
\hline \multirow{2}{*}{$\begin{array}{l}\text { Government } \\
\text { assistance }\end{array}$} & Eligible for JobKeeper & $52 \%$ & \\
\hline & Eligible for JobSeeker & $56 \%$ & \\
\hline
\end{tabular}

G13 Thinking about how you feel right now, on a scale of 1 to 5 , where 1 is very concerned and 5 is not at all concerned, would you say...? I feel concerned about the stability of my future employment/job prospects

Base: $\quad$ All $(n=2,000)$

Note: $\quad$ Showing (1) - Very concerned and (2) -Concerned responses

Note: $\quad$ Results for some subgroups are lower than others but not significantly different to the overall results due to small base sizes 


\section{Gender equity during coronavirus}

During the first coronavirus lockdown, schools moved to a remote learning model. This necessitated that parents to be at home to supervise their child's learning wherever possible. The survey asked questions to determine who provided the majority of child care to monitor the division of these responsibilities between men and women.

\subsection{Childcare responsibilities between parents}

As outlined in Figure 77, among respondents who were female, the majority indicated they were the spending the most time helping their child with school at home (72\%), a further $16 \%$ indicated it was a shared responsibility. One in ten female respondents reported that their partner was primarily providing child supervision during the first lockdown.

By contrast only one in four male respondents $(26 \%)$ reported that they were providing the most care for their child during the first lockdown. This finding suggests there is a gender disparity in how the burden of having children schooling at home is impacting on parents. It is important to note this includes employed and non-employed parents.

Figure 77 Responsibility for caring for school age children during the first lockdown in two parent families

\section{Women}

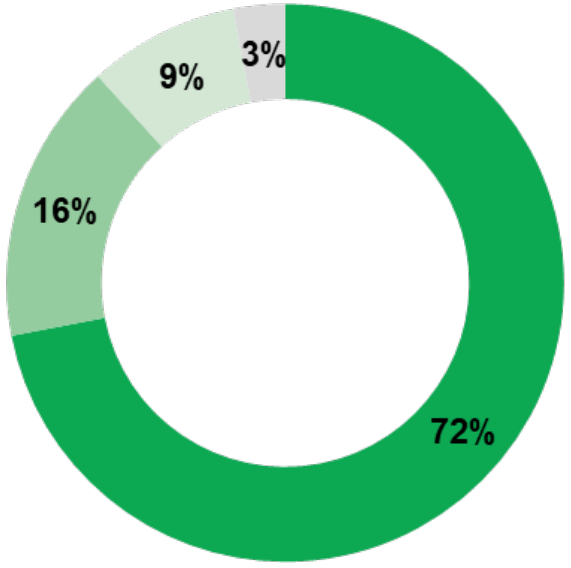

I am
Shared equally
Men

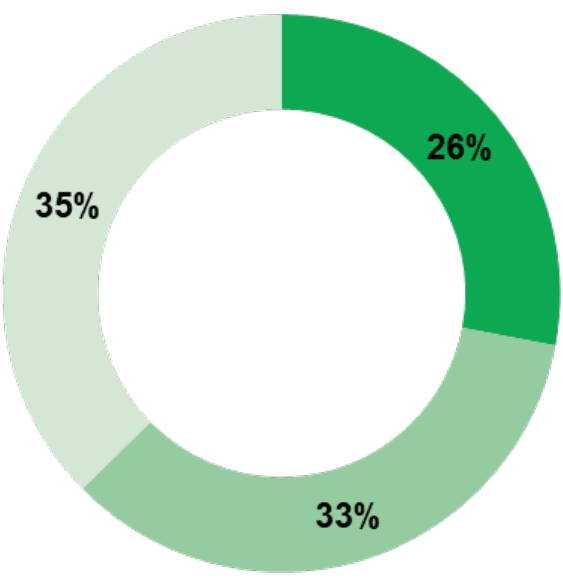

Other parent
Someone else

G11 Who would you say is spending, or has spent, the most time helping your child(ren) with school at home during the COVID-19 restrictions?

Base: Families (couple or single with other parent involved) doing school remotely $(n=291)$

Note: $\quad$ No distinction was made for same sex couples, some of the partners of respondents may be of the same sex

Note: Not shown; not sure [women $(<1 \%)$, men $(6 \%)]$ 
Although only a small number of respondents were caring for preschool children, the following figure shows that the disparities in childcare responsibilities are also higher for women caring for preschoolers.

Figure 78 Responsibility for caring for preschool aged children during the first lockdown in two parent families*

Women

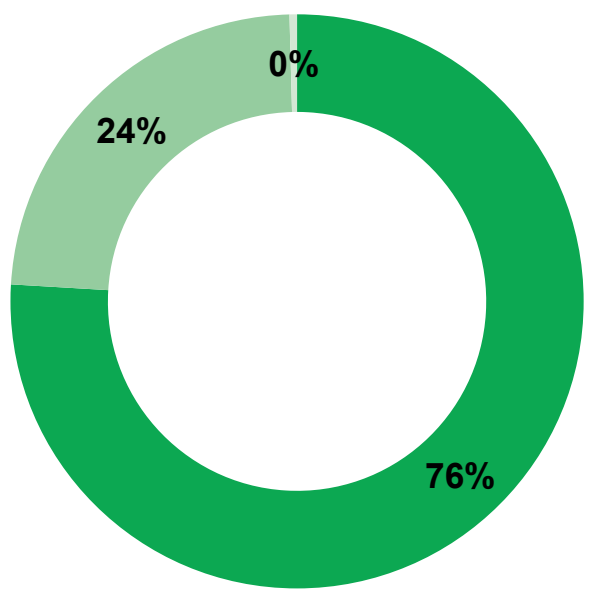

I am
Men

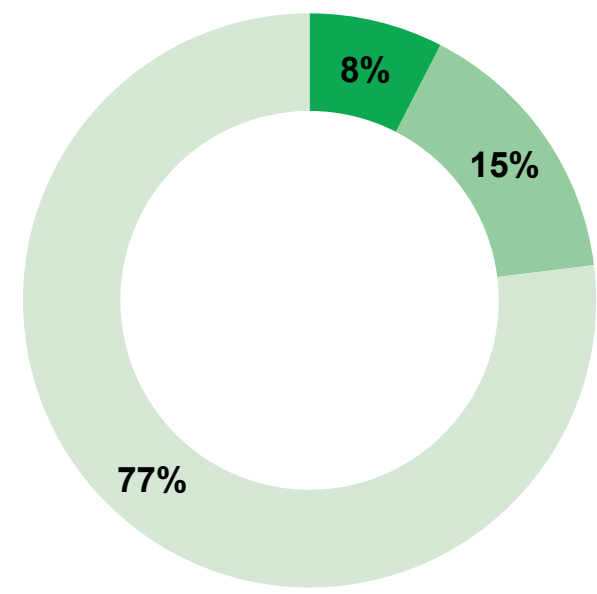

Other parent

G10 Who would you say is spending, or has spent, the most time looking after your preschool child(ren) during the COVID19 restrictions?

Base: $\quad$ Families (couple or single with other parent involved) who discontinued kindergarten or childcare $(n=48)$

Note: $\quad$ No distinction was made for same sex couples, some of the partners of respondents may be of the same sex

*Note: $\quad$ Small base size $(n<100)$ 


\section{POSITIVE IMPACTS}

VicHealth Coronavirus Victorian Wellbeing Impact Study

A comprehensive survey of 2,000 Victorians in the first coronavirus lockdown of 2020 showed there were some silver linings.
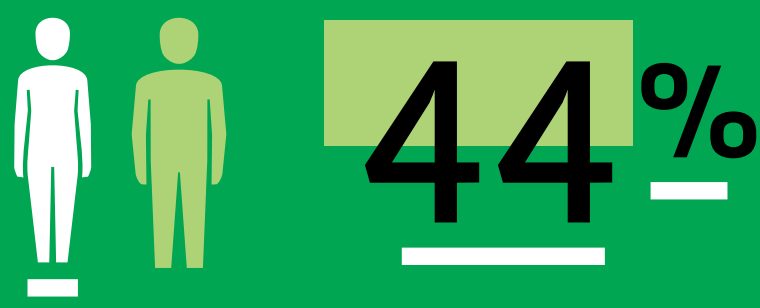

Almost 1 in $2(44 \%)$ Victorians said there were some aspects of life in lockdown they want to keep

\section{OF THAT $44 \%$ :}

\section{Home life}

1 in $4(26 \%)$ want to spend more time with friends and family

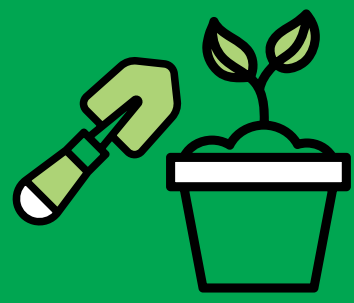

More than 1 in 10 $(12 \%)$ want to continue gardening

\section{Work life}

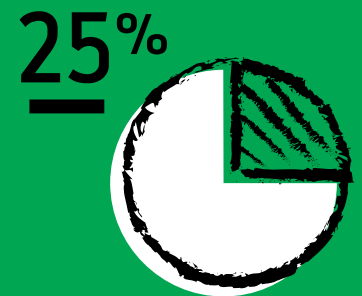

1 in 4 want to work from home

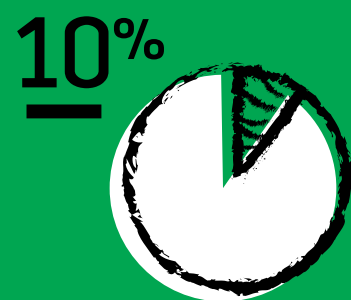

1 in 10 want
Social life

$17 \%$ want to stay in touch with people through technology
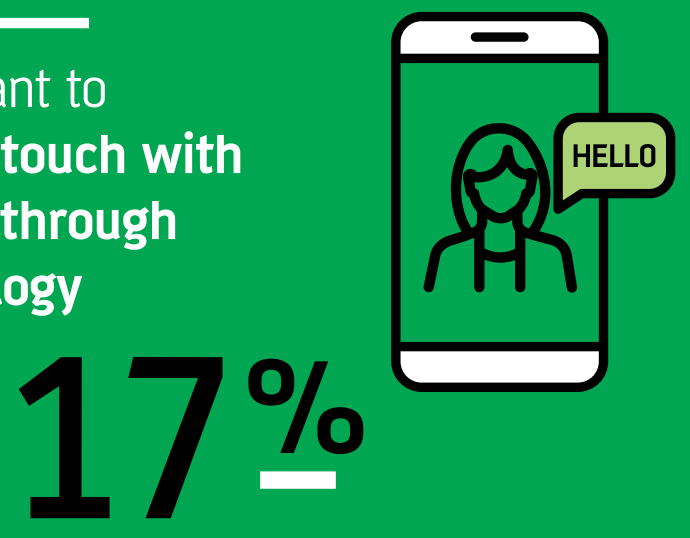

$11 \%$ want to socialise more and have more contact with people

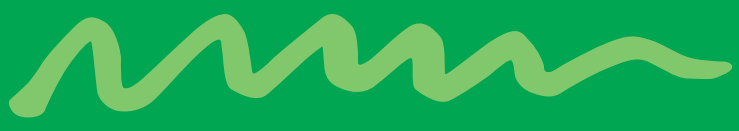

\section{Personal wellbeing}

$25 \%$ want to keep exercising
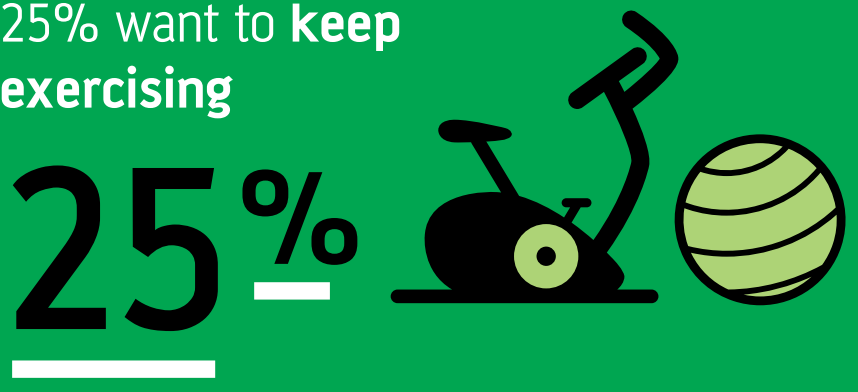


\section{Positive impacts of the first coronavirus lockdown}

To explore any positive impacts the first lockdown may have had, respondents were asked if there were any aspects from the coronavirus restriction period that they would like to maintain after restrictions were lifted. Almost half (44\%) stated there was something that they would like to maintain, one in three $(30 \%)$ said there was nothing they'd like to retain, the remainder were unsure $(21 \%)$ or did not want to respond (5\%). Respondents stating there was something they would like to retain were prompted to provide detailed verbatim responses across the domains of work life, social life, home life and personal wellbeing. Respondents could provide as much detail as they liked.

\subsection{Work life}

The shift to working from home is the most common aspect of the first lockdown relating to working life that respondents would like to maintain. Of those providing comment on the aspects of lockdown that they would like retained, one in four (25\%) would maintain the working from home aspect.

Another common aspect of working life to retain was the move to more flexible working hours $(10 \%)$. A small percentage $(6 \%)$ indicated that there were aspects of working life that they'd like to retain without further information (e.g. "Yes, has been better").

Figure 79 Positive aspects of working life to retain from the first lockdown

\begin{tabular}{|c|c|c|}
\hline Working from home & & $25 \%$ \\
\hline Flexible working hours & $10 \%$ & \\
\hline Retired / Unemployed & $7 \%$ & \\
\hline Generally positive NFI & $6 \%$ & \\
\hline Work fewer hours & $3 \%$ & \\
\hline $\begin{array}{r}\text { Change my job / get a new job / } \\
\text { seek new employment }\end{array}$ & $2 \%$ & \\
\hline Spending more time with family & $2 \%$ & \\
\hline Continuing as normal & $1 \%$ & \\
\hline Other & $9 \%$ & \\
\hline
\end{tabular}

Thinking about your work life, social life, home life and your wellbeing, are there any aspects from the COVID-19 period that you would like to maintain after restrictions are over? Work life (e.g. work from home, change my job, ask for flexible hours)

Base: Provided a response $(n=927)$

Note: $\quad$ Not shown; none $(13 \%)$, not applicable $(6 \%)$, prefer not to say $(<1 \%)$, not sure $(<1 \%)$ 


\subsection{Social life}

The ways people are interacting with others through technology is the form of social life that people would most commonly like to retain from the first lockdown (17\%). Some also reported to having more contact with people during the lockdown (11\%). Some also mentioned that walking was an aspect of their coronavirus social life they would like to retain $(9 \%)$.

Figure $\mathbf{8 0}$ Positive aspects of social life to retain from the first lockdown

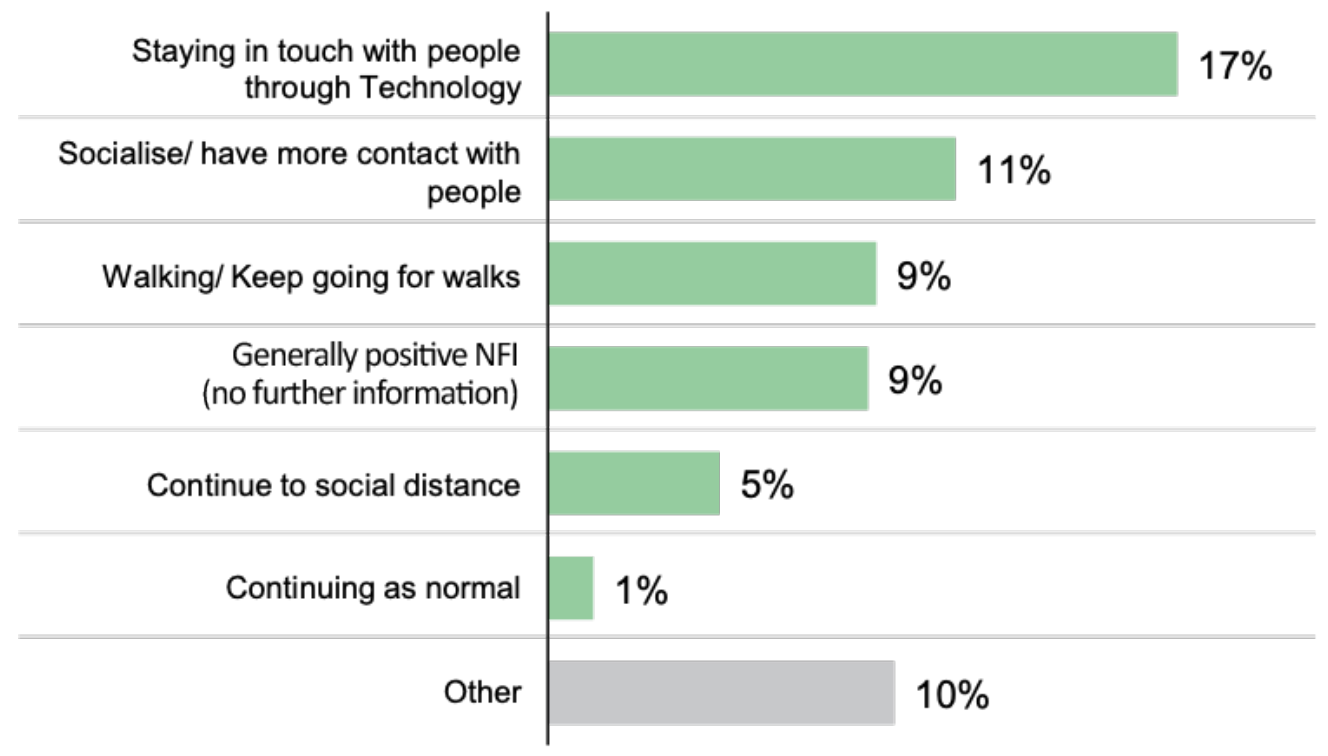

Thinking about your work life, social life, home life and your wellbeing, are there any aspects from the COVID-19 period that you would like to maintain after restrictions are over? Social life (e.g. walking with friends, using zoom or facetime to talk to friends, see more of my neighbours)

Base: $\quad$ Provided a response $(n=927)$

Note: $\quad$ Not shown; none $(13 \%)$, not applicable $(1 \%)$, prefer not to say $(<1 \%)$, entertain more from home $(<1 \%)$, not sure $(<1 \%)$ 


\subsection{Home life}

The ability to spend more time with family and friends during the first lockdown is an aspect of home life that many would like to retain. An increase in the amount of gardening was also a common activity people would like to maintain.

Figure 81 Positive aspects of home life to retain from the first lockdown

\begin{tabular}{|c|c|c|}
\hline $\begin{array}{r}\text { Spending time with family and } \\
\text { friends }\end{array}$ & & $26 \%$ \\
\hline Generally positive NFI & $13 \%$ & \\
\hline Gardening & $12 \%$ & \\
\hline Home maintenance & $6 \%$ & \\
\hline Relaxing / recreational activities & $4 \%$ & \\
\hline Cooking & $2 \%$ & \\
\hline Continuing as normal & $1 \%$ & \\
\hline Creative pursuits / hobbies & $1 \%$ & \\
\hline Other & $11 \%$ & \\
\hline
\end{tabular}

Thinking about your work life, social life, home life and your wellbeing, are there any aspects from the COVID-19 period that you would like to maintain after restrictions are over? Home life (e.g. spend more time with my children, do more with my household/family, keep doing gardening)

Base: $\quad$ Provided a response $(n=927)$

Note: $\quad$ Not shown; none $(10 \%)$, not applicable $(2 \%)$, prefer not to say $(1 \%)$, not sure $(<1 \%)$ 


\subsection{Personal wellbeing}

Aspects of personal wellbeing that respondents would commonly like to retain from the first lockdown are commonly related to physical activity. Many would like to keep exercising at the levels they were during the lockdown (25\%). Others reported they would like to maintain the healthy lifestyle they established during the first lockdown period $(8 \%)$. Similarly, some would like to continue walking or running like they were during the lockdown $(8 \%)$.

Figure 82 Positive aspects of personal wellbeing to retain from the first lockdown

\begin{tabular}{|c|c|c|}
\hline Keep exercising / Exercise more & & $25 \%$ \\
\hline Generally positive NFI & & $14 \%$ \\
\hline Maintain healthy lifestyle & $8 \%$ & \\
\hline Continue Walking / Running & $8 \%$ & \\
\hline Improvements to personal wellbeing & $3 \%$ & \\
\hline Meditation & $2 \%$ & \\
\hline Eat healthy & $2 \%$ & \\
\hline Take care of mental health & $1 \%$ & \\
\hline Other & & $12 \%$ \\
\hline
\end{tabular}

Thinking about your work life, social life, home life and your wellbeing, are there any aspects from the COVID-19 period that you would like to maintain after restrictions are over? Personal wellbeing (e.g. keep exercising, look after my health, meditate)

Base: $\quad$ Provided a response $(n=927)$

Note: $\quad$ Not shown; none $(10 \%)$, not applicable $(1 \%)$, prefer not to say $(<1 \%)$, not sure $(<1 \%)$ 


\section{PEOPLE FACING HARDSHIP VicHealth}

VicHealth Coronavirus Victorian Wellbeing Impact Study

A comprehensive survey of 2000 Victorians in the first coronavirus lockdown of 2020 highlighted stark differences between the experiences of some people and communities facing hardship, and the whole population.

Young people aged 18-24

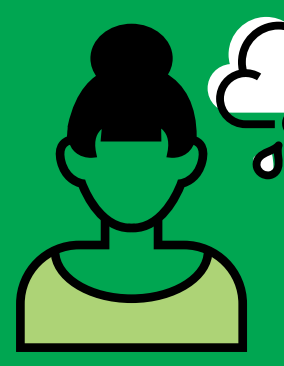

$23 \%$ experienced high psychological distress compared to $16 \%$ in the rest of the state

Young people aged 25-34

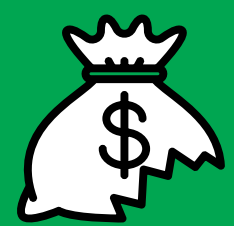

$44 \%$ experienced financial hardship compared to $24 \%$ in the rest of the state

\section{Young people aged 18-34}

Each week, around 1 in 6 were drinking alcohol at levels consistent with short term harm compared to 1 in 10 in the rest of the state

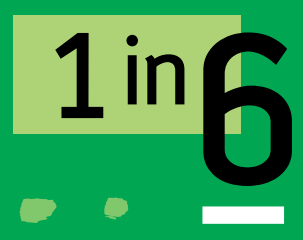

Low income: less than $\$ 40 \mathrm{k} /$ year

\section{Bushfire} affected communities

\section{$41 \%$}

$41 \%$ experienced high psychological distress compared to $16 \%$ in the

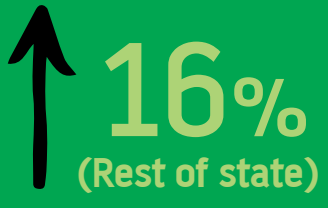
rest of the state

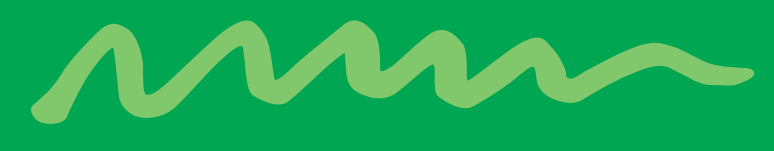

\section{Living in inner Melbourne}

Victorians living in the inner metro area were more likely to:

Experience high

psychological distress

0.000 .0

Consume sugary drinks daily

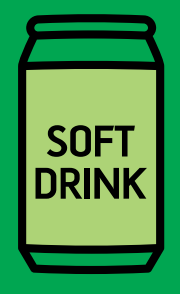

Eat low cost, unhealthy food due to shortage of money
$24 \%$

vs $16 \%$

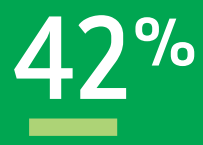

vs $32 \%$

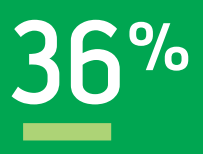

vs $23 \%$ 


\section{Key indicators: Bushfire affected area}

\section{Wellbeing}

- Those in living in areas impacted by the 2019/2020 Victorian bushfires showed similar results for life satisfaction and subjective wellbeing during the first lockdown as others in the state.

- Four in ten of those living in a bushfire impacted area were scored as having high levels of psychological distress $(41 \%)$, significantly higher than the rest of Victoria and the highest of all sub-populations examined in this study.

\section{Physical activity}

- Unlike those in other parts of the state, residents of bushfire impacted areas showed consistent levels of physical activity during February 2020 and during the first lockdown

\section{Social connection}

- Those living in bushfire impacted areas show similar levels of social connection to the rest of the state during the coronavirus restrictions.

- The social solidarity score for those in bushfire impacted areas was significantly higher than the results for the rest of the state (23.2 compared to 21.2 ). The only group to have a higher social solidarity score were Victorians aged 75 years or more (23.4).

\section{Healthy eating}

- Residents from bushfire impacted areas reported higher levels of unhealthy food consumption and food hardship than the rest of the state. Significantly less favourable results were seen for:

- Frequency of daily soft drink consumption (55\% compared to $32 \%$ )

- Frequency of takeaway food consumption at least 3 times a week ( $16 \%$ compared to $4 \%)$

\section{Alcohol consumption}

- All measures of food related financial hardship.

- $\quad$ Although not significantly higher than the rest of the state, the proportion of bushfire impacted Victorians reporting drinking at harmful levels was high. Two in ten (19\%) were drinking at levels consistent with long term harm. One in three (33\%) were drinking at levels consistent with short term harm.

\section{Smoking}

- $\quad$ Although smoking frequency was slightly above state levels, no significant differences were observed in the frequency of smoking for those living in bushfire impacted areas.

\section{Financial hardship}

- One in two (47\%) of those in living in areas impacted by the $2019 / 2020$ Victorian bushfires were experiencing some form of financial hardship during the first lockdown. The level of financial hardship for this group was also higher than the rest of the state in February 2020 (44\%). 
Table 9 Indicator results for bushfire affected areas compared to Victorian result

\begin{tabular}{|c|c|c|c|}
\hline Indicator & Measure & Victoria & $\begin{array}{c}\text { Bushfire } \\
\text { affected areas }\end{array}$ \\
\hline \multicolumn{4}{|l|}{ General wellbeing } \\
\hline Life satisfaction - during coronavirus restrictions (A1) & 0 to 6 & $49 \%$ & $47 \%$ \\
\hline Life satisfaction - during February 2020 (A1) & 0 to 6 & $33 \%$ & $39 \%$ \\
\hline Subjective wellbeing indicator (A2) & Mean score & 65.0 & 63.3 \\
\hline Psychological distress (A4) & $\%$ high & $16 \%$ & $41 \%$ \\
\hline \multicolumn{4}{|l|}{ Physical activity } \\
\hline Physical activity - during coronavirus (B4a) & $\% 5$ or more & $32 \%$ & $47 \%$ \\
\hline Physical activity - during February 2020 (B4b) & $\% 5$ or more & $37 \%$ & $47 \%$ \\
\hline Physical activity - during coronavirus (B4a) & $\% 0-1$ & $27 \%$ & $22 \%$ \\
\hline Physical activity - during February 2020 (B4b) & $\% 0-1$ & $20 \%$ & $22 \%$ \\
\hline \multicolumn{4}{|l|}{ Social connectedness } \\
\hline I feel connected with others - during COVID-19 (C1a) & $\%$ disagree & $23 \%$ & $22 \%$ \\
\hline I feel connected with others - during February $2020(\mathrm{C} 1 \mathrm{~b})$ & $\%$ disagree & $10 \%$ & $18 \%$ \\
\hline Social solidarity & Mean score & 21.2 & 23.2 \\
\hline Ease of staying connected with family and friends (C4W) & $\%$ hard / very hard & $30 \%$ & $33 \%$ \\
\hline \multirow{2}{*}{ Relationships other people in your household (C5W) } & $\%$ difficult/strained & $20 \%$ & $13 \%$ \\
\hline & $\%$ closer/stronger & $21 \%$ & $36 \%$ \\
\hline \multicolumn{4}{|l|}{ Healthy eating } \\
\hline \multirow{2}{*}{ Vegetable serves per week (D1) } & $\% 5$ or more & $8 \%$ & $11 \%$ \\
\hline & Average & 2.5 & 2.9 \\
\hline Frequency sugary drink consumption (N1) & $\%$ everyday & $32 \%$ & $55 \%$ \\
\hline Takeaway food frequency (N3) & $\% 3$ or more & $4 \%$ & $16 \%$ \\
\hline Times dinners cooked each week (D4) & $\% 4$ times or fewer & $12 \%$ & $22 \%$ \\
\hline Restricted range of low-cost food (D7a) & $\%$ yes & $23 \%$ & $51 \%$ \\
\hline Went without meals (G12d) & $\%$ yes & $8 \%$ & $22 \%$ \\
\hline Attended a food relief agency to access food relief (G12g) & $\%$ yes & $7 \%$ & $22 \%$ \\
\hline Worried about having enough money to buy food (G12h) & $\%$ yes & $17 \%$ & $36 \%$ \\
\hline Skipped a meal in order to feed your household (G12i) & $\%$ yes & $10 \%$ & $36 \%$ \\
\hline Ran out of food and could not afford to buy more (G12j) & $\%$ yes & $7 \%$ & $28 \%$ \\
\hline \multicolumn{4}{|l|}{ Alcohol } \\
\hline Long term harm - 3 or more drinks 5 or more times a week & $\%$ & $7 \%$ & $19 \%$ \\
\hline Short term harm - more than 4 drinks at least once a week & $\%$ & $11 \%$ & $33 \%$ \\
\hline \multicolumn{4}{|l|}{ Smoking } \\
\hline Smoke cigarettes, cigars, pipes or other products (F1) & $\%$ smoke daily & $12 \%$ & $19 \%$ \\
\hline \multicolumn{4}{|l|}{ Financial hardship } \\
\hline Could not pay bills on time (G12a) & $\%$ yes & $11 \%$ & $41 \%$ \\
\hline Could not pay the rent or mortgage on time (G12b) & $\%$ yes & $7 \%$ & $17 \%$ \\
\hline Pawned or sold something (G12c) & $\%$ yes & $8 \%$ & $33 \%$ \\
\hline Asked for financial help from friends or family (G12e) & $\%$ yes & $12 \%$ & $33 \%$ \\
\hline Asked for help from community organisations (G12f) & $\%$ yes & $8 \%$ & $33 \%$ \\
\hline Any form of financial hardship - during COVID-19 & $\%$ yes & $24 \%$ & $47 \%$ \\
\hline Any form of financial hardship - during February 2020 & $\%$ yes & $16 \%$ & $44 \%$ \\
\hline
\end{tabular}

Base: From bushfire affected area $(n=68)$

Significantly different more favourable result

Significantly different less favourable result 


\section{Key indicators: Young people (aged 18 to 24)}

\section{Wellbeing}

- One in four (23\%) young people aged 18 to 24 were experiencing high psychological distress compared with $16 \%$ of Victorians overall.

- Results for this group for subjective wellbeing and life satisfaction were on par with Victoria overall.

\section{Physical activity}

- Those aged 18 to 24 were as likely as other age groups to be getting the recommended levels of physical activity. They were also inactive at rates on par with the rest of the state.

\section{Social connection}

- Those aged 18 to 24 showed no significant differences in their level of social connection with others both during the first lockdown and in February 2020.

- $\quad$ Although their overall social solidarity score was on par with the rest of the state, younger Victorians (aged 18 to 24 years) were more likely to disagree with the statements that they trust their neighbours $(20 \%)$ and that they are proud to be a member of their community $(16 \%)$.

- Those aged 18 to 24 were more likely to report that they were having difficulties staying in contact with friends and family (39\% compared to $30 \%$ ). However, the result for young women was significantly higher than the state level for difficulty staying in contact outside of home (females $41 \%$, males $38 \%$ ) as well as reporting that relationships were strained at home (females $30 \%$, males $19 \%$ ).

\section{Healthy eating}

- Drinking sugar sweetened beverages was more common for younger Victorians than the rest of the state (50\% compared to $32 \%)$.

- $\quad$ They were also more likely to be experiencing food insecurity.

\section{Alcohol consumption}

- Victorians aged 18 to 24 were more likely to be drinking alcohol at levels consistent with short term harm ( $17 \%$ compared to $11 \%)$.

\section{Smoking}

- $\quad$ Although smoking frequency among younger Victorians was slightly below state levels, no significant differences were observed in the proportion of those in this age group who smoke daily.

\section{Financial hardship}

- Four in ten of those aged 18 to 24 had experienced hardship during the first lockdown (39\% compared to $24 \%$ of Victorians overall). Three in ten reported some form of financial hardship in February 2020 (30\% compared to 16\%). They were also more likely to report they had lost their job (17\%) compared to $10 \%$ of Victorians overall. Young women were most impacted with $26 \%$ losing their job, compared to $11 \%$ of young men of the same age group. 
Table 10 Indicator results for young people aged 18 to 24 years compared to Victorian result

\begin{tabular}{|c|c|c|c|}
\hline Indicator & Measure & Victoria & $\begin{array}{l}\text { Young people } \\
\text { (aged } 18 \text { to } 24 \text { ) }\end{array}$ \\
\hline \multicolumn{4}{|l|}{ General wellbeing } \\
\hline Life satisfaction - during COVID-19 restrictions (A1) & 0 to 6 & $49 \%$ & $57 \%$ \\
\hline Life satisfaction - during February 2020 (A1) & 0 to 6 & $33 \%$ & $35 \%$ \\
\hline Subjective wellbeing indicator (A2) & Mean score & 65.0 & 64.7 \\
\hline Psychological distress (K6) (A4) & $\%$ high & $16 \%$ & $23 \%$ \\
\hline \multicolumn{4}{|l|}{ Physical activity } \\
\hline Physical activity - during COVID-19 (B4a) & $\% 5$ or more & $32 \%$ & $29 \%$ \\
\hline Physical activity - during February 2020 (B4b) & $\% 5$ or more & $37 \%$ & $38 \%$ \\
\hline Physical activity - during COVID-19 (B4a) & $\% 0-1$ & $27 \%$ & $19 \%$ \\
\hline Physical activity - during February 2020 (B4b) & $\% 0-1$ & $20 \%$ & $14 \%$ \\
\hline \multicolumn{4}{|l|}{ Social connectedness } \\
\hline I feel connected with others - during COVID-19 (C1a) & $\%$ disagree & $23 \%$ & $24 \%$ \\
\hline I feel connected with others - during February 2020 (C1b) & $\%$ disagree & $10 \%$ & $10 \%$ \\
\hline Social solidarity & Mean score & 21.2 & 21.0 \\
\hline Ease of staying connected with family and friends (C4W) & $\%$ hard / very hard & $30 \%$ & $39 \%$ \\
\hline \multirow{2}{*}{ Relationships other people in your household (C5W) } & $\%$ difficult/strained & $20 \%$ & $24 \%$ \\
\hline & $\%$ closer/stronger & $21 \%$ & $30 \%$ \\
\hline \multicolumn{4}{|l|}{ Healthy eating } \\
\hline \multirow{2}{*}{ Vegetable serves per week (D1) } & $\% 5$ or more & $8 \%$ & $7 \%$ \\
\hline & Average & 2.5 & 2.5 \\
\hline Frequency sugary drink consumption (N1) & $\%$ everyday & $32 \%$ & $50 \%$ \\
\hline Takeaway food frequency (N3) & $\% 3$ or more & $4 \%$ & $6 \%$ \\
\hline Times dinners cooked each week (D4) & $\% 4$ times or fewer & $12 \%$ & $11 \%$ \\
\hline Restricted range of low-cost food (D7a) & $\%$ yes & $23 \%$ & $44 \%$ \\
\hline Went without meals (G12d) & $\%$ yes & $8 \%$ & $17 \%$ \\
\hline Attended a food relief agency to access food relief (G12g) & $\%$ yes & $7 \%$ & $16 \%$ \\
\hline Worried about having enough money to buy food (G12h) & $\%$ yes & $17 \%$ & $23 \%$ \\
\hline Skipped a meal in order to feed your household (G12i) & $\%$ yes & $10 \%$ & $16 \%$ \\
\hline Ran out of food and could not afford to buy more (G12j) & $\%$ yes & $7 \%$ & $13 \%$ \\
\hline \multicolumn{4}{|l|}{ Alcohol } \\
\hline Long term harm -3 or more drinks 5 or more times a week & $\%$ & $7 \%$ & $7 \%$ \\
\hline Short term harm - more than 4 drinks at least once a week & $\%$ & $11 \%$ & $17 \%$ \\
\hline \multicolumn{4}{|l|}{ Smoking } \\
\hline Smoke cigarettes, cigars, pipes or other products (F1) & $\%$ smoke daily & $12 \%$ & $7 \%$ \\
\hline \multicolumn{4}{|l|}{ Financial hardship } \\
\hline Could not pay bills on time (G12a) & $\%$ yes & $11 \%$ & $16 \%$ \\
\hline Could not pay the rent or mortgage on time (G12b) & $\%$ yes & $7 \%$ & $14 \%$ \\
\hline Pawned or sold something (G12c) & $\%$ yes & $8 \%$ & $19 \%$ \\
\hline Asked for financial help from friends or family (G12e) & $\%$ yes & $12 \%$ & $22 \%$ \\
\hline Asked for help from community organisations (G12f) & $\%$ yes & $8 \%$ & $15 \%$ \\
\hline Any form of financial hardship - during COVID-19 & $\%$ yes & $24 \%$ & $39 \%$ \\
\hline Any form of financial hardship - during February 2020 & $\%$ yes & $16 \%$ & $30 \%$ \\
\hline
\end{tabular}

Base: $\quad$ Aged 18 to $24(n=256)$

Significantly different more favourable result

Significantly different less favourable result 


\section{Key indicators: Young people (aged 25 to 34)}

\section{Wellbeing}

- One in five Victorians aged 25 to 34 were experiencing high psychological distress during the first lockdown $(22 \%)$, these levels are high but not significantly different to the rest of the state.

- Results for this group for subjective wellbeing and life satisfaction were on par with the rest of the state.

\section{Physical activity}

- Those aged 25 to 34 were more likely than other age groups to be getting the recommended levels of physical activity during the first lockdown ( $41 \%$ compared to $32 \%)$. They were also less likely to be inactive than the rest of the state ( $17 \%$ compared to $27 \%$ ).

- These significantly different levels of physical activity were not observed during the comparator period of February 2020 suggesting that the lockdown has not overly impacted the physical activity frequency of this group.

\section{Social connection}

- Those aged 25 to 34 showed no significant differences in their level of social connection with others both during the first lockdown and in February 2020. Their levels of social solidarity were also consistent with other age groups.

- Those aged 25 to 34 were more likely to report that their relationships with the others in their household had improved during the first lockdown (31\% compared to $21 \%$ ).

\section{Healthy eating}

- Eating takeaway or fast food more than 3 times a week was more common Victorians aged 25 to 34 than the rest of the state (11\% compared to $4 \%$ ) They were also more likely to be cooking at home four or fewer times a week ( $24 \%$ compared to $12 \%)$.

- Those aged 25 to 34 were more likely than others to be experiencing a variety of food related financial hardships.

\section{Alcohol consumption}

- $16 \%$ of Victorians aged 25 to 34 were drinking alcohol at levels consistent with short term harm although not significantly more than the rate for all Victorians.

\section{Smoking}

- $\quad$ Although smoking frequency among younger Victorians was slightly below state levels, no significant differences were observed in the proportion of those in this age group who smoke daily.

\section{Financial hardship}

- Younger Victorians were more likely to be experiencing hardship before and during the first coronavirus lockdown. More than four in ten of those aged 25 to 34 had experienced hardship during the first lockdown (44\% compared to $24 \%$ ). Three in ten reported some form of financial hardship in February 2020 (31\% compared to 16\%). 
Table 11 Indicator results for people aged 25-34 compared to the Victorian result

\begin{tabular}{|c|c|c|c|}
\hline Indicator & Measure & VIC result & $\begin{array}{l}\text { Young people } \\
\text { (aged } 25 \text { to } 34 \text { ) }\end{array}$ \\
\hline \multicolumn{4}{|l|}{ General wellbeing } \\
\hline Life satisfaction - during COVID-19 restrictions (A1) & 0 to 6 & $49 \%$ & $57 \%$ \\
\hline Life satisfaction - during February 2020 (A1) & 0 to 6 & $33 \%$ & $35 \%$ \\
\hline Subjective wellbeing indicator (A2) & Mean score & 65.0 & 61.8 \\
\hline Psychological distress (K6) (A4) & $\%$ high & $16 \%$ & $22 \%$ \\
\hline \multicolumn{4}{|l|}{ Physical activity } \\
\hline Physical activity - during COVID-19 (B4a) & $\% 5$ or more & $32 \%$ & $41 \%$ \\
\hline Physical activity - during February 2020 (B4b) & $\% 5$ or more & $37 \%$ & $44 \%$ \\
\hline Physical activity - during COVID-19 (B4a) & $\% 0-1$ & $27 \%$ & $17 \%$ \\
\hline Physical activity - during February 2020 (B4b) & $\% 0-1$ & $20 \%$ & $16 \%$ \\
\hline \multicolumn{4}{|l|}{ Social connectedness } \\
\hline I feel connected with others - during COVID-19 (C1a) & $\%$ disagree & $23 \%$ & $22 \%$ \\
\hline I feel connected with others - during February 2020 (C1b) & $\%$ disagree & $10 \%$ & $9 \%$ \\
\hline Social solidarity & Mean score & 21.2 & 21.1 \\
\hline Ease of staying connected with family and friends (C4W) & $\%$ hard / very hard & $30 \%$ & $33 \%$ \\
\hline \multirow{2}{*}{ Relationships other people in your household (C5W) } & $\%$ difficult/strained & $20 \%$ & $26 \%$ \\
\hline & $\%$ closer/stronger & $21 \%$ & $31 \%$ \\
\hline \multicolumn{4}{|l|}{ Healthy eating } \\
\hline \multirow{2}{*}{ Vegetable serves per week (D1) } & $\% 5$ or more & $8 \%$ & $6 \%$ \\
\hline & Average & 2.5 & 2.4 \\
\hline Frequency sugary drink consumption (N1) & $\%$ everyday & $32 \%$ & $37 \%$ \\
\hline Takeaway food frequency (N3) & $\% 3$ or more & $4 \%$ & $11 \%$ \\
\hline Times dinners cooked each week (D4) & $\% 4$ times or fewer & $12 \%$ & $24 \%$ \\
\hline Restricted range of low-cost food (D7a) & $\%$ yes & $23 \%$ & $33 \%$ \\
\hline Went without meals (G12d) & $\%$ yes & $8 \%$ & $14 \%$ \\
\hline Attended a food relief agency to access food relief (G12g) & $\%$ yes & $7 \%$ & $13 \%$ \\
\hline Worried about having enough money to buy food (G12h) & $\%$ yes & $17 \%$ & $25 \%$ \\
\hline Skipped a meal in order to feed your household (G12i) & $\%$ yes & $10 \%$ & $20 \%$ \\
\hline Ran out of food and could not afford to buy more (G12j) & $\%$ yes & $7 \%$ & $15 \%$ \\
\hline \multicolumn{4}{|l|}{ Alcohol } \\
\hline Long term harm -3 or more drinks 5 or more times a week & $\%$ & $7 \%$ & $6 \%$ \\
\hline Short term harm - more than 4 at least once a week & $\%$ & $11 \%$ & $16 \%$ \\
\hline \multicolumn{4}{|l|}{ Smoking } \\
\hline Smoke cigarettes, cigars, pipes or other products (F1) & $\%$ smoke daily & $12 \%$ & $9 \%$ \\
\hline \multicolumn{4}{|l|}{ Financial hardship } \\
\hline Could not pay bills on time (G12a) & $\%$ yes & $11 \%$ & $21 \%$ \\
\hline Could not pay the rent or mortgage on time (G12b) & $\%$ yes & $7 \%$ & $11 \%$ \\
\hline Pawned or sold something (G12c) & $\%$ yes & $8 \%$ & $16 \%$ \\
\hline Asked for financial help from friends or family (G12e) & $\%$ yes & $12 \%$ & $24 \%$ \\
\hline Asked for help from community organisations (G12f) & $\%$ yes & $8 \%$ & $16 \%$ \\
\hline Any form of financial hardship - during COVID-19 & $\%$ yes & $24 \%$ & $44 \%$ \\
\hline Any form of financial hardship - during February 2020 & $\%$ yes & $16 \%$ & $31 \%$ \\
\hline
\end{tabular}

Base: $\quad$ Aged 25 to $34(n=295)$

Significantly different more favourable result Significantly different less favourable result 


\section{Key indicators: Aboriginal and Torres Strait Islander people}

Although the number of respondents who were Aboriginal and Torres Strait Islanders was too small to show any significant differences from the results for Victoria overall, the results for this sub-group are indicative of less favourable outcomes across a variety of measures.

\section{Wellbeing}

- The proportion of Aboriginal and Torres Strait Islanders reporting low levels of life satisfaction increased from 47\% during February 2020 to $70 \%$ during the first lockdown.

- One in four (28\%) Aboriginal and Torres Strait Islanders had results indicative of high psychological distress.

- Subjective wellbeing for this group was on par with the rest of Victoria.

\section{Physical activity}

- Levels of physical activity for Aboriginal and Torres Strait Islanders dropped from $52 \%$ exercising 5 days or more a week during February 2020 to $38 \%$ exercising at this level during the first lockdown.

\section{Social connection}

- Levels of connection to others and social solidarity were similar for Aboriginal and Torres Strait Islander respondents and the rest of the state.

- One in two $(51 \%)$ reported finding it hard to stay connected with family and friends outside their household.

\section{Healthy eating}

- The average number of serves of vegetables eaten daily by Aboriginal and Torres Strait Islander respondents was indicatively higher than the rest of the state ( 3 serves compared to 2.5 serves).

- A large proportion of these respondents were:
- drinking soft drinks daily (80\%)
- eating takeaway food 3 times or more a week $(27 \%)$
$\circ$ experiencing high levels of food insecurity.

\section{Alcohol consumption}

- Many Aboriginal and Torres Strait Islanders were drinking alcohol at levels consistent with short term harm $(48 \%)$.

\section{Smoking}

- Less than one in ten (9\%) Aboriginal and Torres Strait Islander respondents reported smoking daily compared to the overall Victorian level of $12 \%$.

\section{Financial hardship}

- Many Aboriginal and Torres Strait Islanders reported experiencing financial hardship during lockdown restrictions (74\%) and during February 2020 (63\%). 
Table 12 Indicator results for Aboriginal and Torres Strait Islanders compared to the Victorian result

\begin{tabular}{|c|c|c|c|}
\hline Indicator & Measure & VIC result & $\begin{array}{l}\text { Aboriginal, } \\
\text { Torres Strait } \\
\text { Islander }\end{array}$ \\
\hline \multicolumn{4}{|l|}{ General wellbeing } \\
\hline Life satisfaction - during COVID-19 restrictions (A1) & 0 to 6 & $49 \%$ & $70 \%$ \\
\hline Life satisfaction - during February 2020 (A1) & 0 to 6 & $33 \%$ & $47 \%$ \\
\hline Subjective wellbeing indicator (A2) & Mean score & 65.0 & 60.9 \\
\hline Psychological distress (K6) (A4) & $\%$ high & $16 \%$ & $28 \%$ \\
\hline \multicolumn{4}{|l|}{ Physical activity } \\
\hline Physical activity - during COVID-19 (B4a) & $\% 5$ or more & $32 \%$ & $38 \%$ \\
\hline Physical activity - during February 2020 (B4b) & $\% 5$ or more & $37 \%$ & $52 \%$ \\
\hline Physical activity - during COVID-19 (B4a) & $\% 0-1$ & $27 \%$ & $6 \%$ \\
\hline Physical activity - during February 2020 (B4b) & $\% 0-1$ & $20 \%$ & $7 \%$ \\
\hline \multicolumn{4}{|l|}{ Social connectedness } \\
\hline I feel connected with others - during COVID-19 (C1a) & $\%$ disagree & $23 \%$ & $28 \%$ \\
\hline I feel connected with others - during February 2020 (C1b) & $\%$ disagree & $10 \%$ & $7 \%$ \\
\hline Social solidarity & Mean score & 21.2 & 22.1 \\
\hline Ease of staying connected with family and friends (C4W) & $\%$ hard / very hard & $30 \%$ & $51 \%$ \\
\hline \multirow{2}{*}{ Relationships other people in your household (C5W) } & $\%$ difficult/strained & $20 \%$ & $30 \%$ \\
\hline & $\%$ closer/stronger & $21 \%$ & $36 \%$ \\
\hline \multicolumn{4}{|l|}{ Healthy eating } \\
\hline \multirow{2}{*}{ Vegetable serves per week (D1) } & $\% 5$ or more & $8 \%$ & $12 \%$ \\
\hline & Average & 2.5 & 3.0 \\
\hline Frequency sugary drink consumption (N1) & $\%$ everyday & $32 \%$ & $80 \%$ \\
\hline Takeaway food frequency (N3) & $\% 3$ or more & $4 \%$ & $27 \%$ \\
\hline Times dinners cooked each week (D4) & $\% 4$ times or fewer & $12 \%$ & $29 \%$ \\
\hline Restricted range of low-cost food (D7a) & $\%$ yes & $23 \%$ & $54 \%$ \\
\hline Went without meals (G12d) & $\%$ yes & $8 \%$ & $42 \%$ \\
\hline Attended a food relief agency to access food relief (G12g) & $\%$ yes & $7 \%$ & $35 \%$ \\
\hline Worried about having enough money to buy food (G12h) & $\%$ yes & $17 \%$ & $35 \%$ \\
\hline Skipped a meal in order to feed your household (G12i) & $\%$ yes & $10 \%$ & $49 \%$ \\
\hline Ran out of food and could not afford to buy more (G12j) & $\%$ yes & $7 \%$ & $46 \%$ \\
\hline \multicolumn{4}{|l|}{ Alcohol } \\
\hline Long term harm -3 or more drinks 5 or more times a week & $\%$ & $7 \%$ & $19 \%$ \\
\hline Short term harm - more than 4 drinks at least once a week & $\%$ & $11 \%$ & $48 \%$ \\
\hline \multicolumn{4}{|l|}{ Smoking } \\
\hline Smoke cigarettes, cigars, pipes or other products (F1) & $\%$ smoke daily & $12 \%$ & $9 \%$ \\
\hline \multicolumn{4}{|l|}{ Financial hardship } \\
\hline Could not pay bills on time (G12a) & $\%$ yes & $11 \%$ & $31 \%$ \\
\hline Could not pay the rent or mortgage on time (G12b) & $\%$ yes & $7 \%$ & $25 \%$ \\
\hline Pawned or sold something (G12c) & $\%$ yes & $8 \%$ & $33 \%$ \\
\hline Asked for financial help from friends or family (G12e) & $\%$ yes & $12 \%$ & $31 \%$ \\
\hline Asked for help from community organisations (G12f) & $\%$ yes & $8 \%$ & $39 \%$ \\
\hline Any form of financial hardship - during COVID-19 & $\%$ yes & $24 \%$ & $74 \%$ \\
\hline Any form of financial hardship - during February 2020 & $\%$ yes & $16 \%$ & $63 \%$ \\
\hline
\end{tabular}

Significantly different more favourable result Significantly different less favourable result 


\section{Key indicators by geographic region}

\section{Wellbeing}

- Frequency of high psychological distress for those based in inner metro Melbourne were significantly higher (24\%) than Victoria overall $(16 \%)$, whereas for regional cities it was significantly lower $(10 \%)$.

\section{Physical activity}

- More favourable physical activity habits were observed for those based in inner metro areas (43\% compared to $32 \%$ for Victoria overall).

\section{Social connection}

- Higher levels of social solidarity were recorded for those living in large shires of Victoria (23.0 compared to 21.2). Significantly lower scores were recorded for those based in outer metro Melbourne (20.1).

\section{Healthy eating}

- Interface council areas (those between metro and rural areas e.g. Melton, Yarra Ranges), had the lowest rates of meeting vegetable guidelines (4\%) and were more likely to rely on a low-cost unhealthy food due to money shortage (29\%) compared to the Victorians overall (23\%).

- Less favourable healthy eating habits were also reported by those based in inner metro Melbourne. Significantly less favourable results were seen among this group for:

- frequency of daily soft drink consumption ( $42 \%$ compared to $32 \%$ )

- eating a restricted range of low-cost unhealthy food (36\% compared to $23 \%$ )

$\circ \quad$ all measures of food insecurity.

\section{Alcohol consumption}

- No areas of Victoria showed significantly higher or lower levels of risk of short- or long term harm due to alcohol consumption.

\section{Smoking}

- The highest proportion of people who smoke daily was found among Victorians living in large shires although levels were not significantly higher than the rest of Victoria ( $20 \%$ compared to $12 \%)$.

\section{Financial hardship}

- Victorians based in inner metro Melbourne were more likely than those in other areas to be experiencing hardship before and during first lockdown. During the first lockdown one in three inner metro Victorians (36\%) experienced financial hardship of some form. 
Table 13 Indicator results for metropolitan geographic regions compared to the Victorian result

\begin{tabular}{|c|c|c|c|c|c|c|}
\hline Indicator & Measure & $\begin{array}{l}\text { VIC } \\
\text { result }\end{array}$ & $\begin{array}{l}\text { Inner } \\
\text { metro }\end{array}$ & $\begin{array}{l}\text { Middle } \\
\text { metro }\end{array}$ & $\begin{array}{l}\text { Outer } \\
\text { metro }\end{array}$ & Interface \\
\hline \multicolumn{7}{|l|}{ General wellbeing } \\
\hline Life satisfaction - during COVID-19 restrictions (A1) & 0 to 6 & $49 \%$ & $53 \%$ & $50 \%$ & $54 \%$ & $46 \%$ \\
\hline Life satisfaction - during February 2020 (A1) & 0 to 6 & $33 \%$ & $36 \%$ & $32 \%$ & $38 \%$ & $30 \%$ \\
\hline Subjective wellbeing indicator (A2) & Mean score & 65.0 & 63.3 & 64.6 & 63.1 & 63.9 \\
\hline Psychological distress (K6) (A4) & $\%$ high & $16 \%$ & $24 \%$ & $17 \%$ & $20 \%$ & $15 \%$ \\
\hline \multicolumn{7}{|l|}{ Physical Activity } \\
\hline Physical activity - during COVID-19 (B4a) & $\% 5$ or more & $32 \%$ & $43 \%$ & $31 \%$ & $33 \%$ & $29 \%$ \\
\hline Physical activity - during February 2020 (B4b) & $\% 5$ or more & $37 \%$ & $46 \%$ & $33 \%$ & $39 \%$ & $38 \%$ \\
\hline Physical activity - during COVID-19 (B4a) & $\% 0-1$ & $27 \%$ & $17 \%$ & $29 \%$ & $19 \%$ & $29 \%$ \\
\hline Physical activity - during February 2020 (B4b) & $\% 0-1$ & $20 \%$ & $10 \%$ & $19 \%$ & $18 \%$ & $20 \%$ \\
\hline \multicolumn{7}{|l|}{ Social Connectedness } \\
\hline I feel connected with others - during COVID-19 (C1a) & $\%$ disagree & $23 \%$ & $18 \%$ & $19 \%$ & $27 \%$ & $24 \%$ \\
\hline I feel connected with others - during February 2020 (C1b) & $\%$ disagree & $10 \%$ & $8 \%$ & $9 \%$ & $15 \%$ & $11 \%$ \\
\hline Social solidarity & Mean score & 21.2 & 21.4 & 21.4 & 20.1 & 20.7 \\
\hline Ease of staying connected with family and friends (C4W) & $\%$ hard / very hard & $30 \%$ & $34 \%$ & $25 \%$ & $34 \%$ & $35 \%$ \\
\hline \multirow{2}{*}{ Relationships other people in your household (C5W) } & $\%$ difficult/strained & $20 \%$ & $25 \%$ & $21 \%$ & $19 \%$ & $20 \%$ \\
\hline & $\%$ closer/stronger & $21 \%$ & $26 \%$ & $24 \%$ & $22 \%$ & $20 \%$ \\
\hline \multicolumn{7}{|l|}{ Healthy Eating } \\
\hline \multirow{2}{*}{ Vegetable serves per week (D1) } & $\% 5$ or more & $8 \%$ & $9 \%$ & $6 \%$ & $12 \%$ & $4 \%$ \\
\hline & Average & 2.5 & 2.4 & 2.3 & 2.5 & 2.4 \\
\hline Frequency sugary drink consumption (N1) & $\%$ everyday & $32 \%$ & $42 \%$ & $30 \%$ & $32 \%$ & $32 \%$ \\
\hline Takeaway food frequency (N3) & $\% 3$ or more & $4 \%$ & $6 \%$ & $4 \%$ & $7 \%$ & $2 \%$ \\
\hline Times dinners cooked each week (D4) & $\% 4$ times or fewer & $12 \%$ & $14 \%$ & $13 \%$ & $14 \%$ & $11 \%$ \\
\hline Restricted range of low-cost food (D7a) & $\%$ yes & $23 \%$ & $36 \%$ & $18 \%$ & $27 \%$ & $29 \%$ \\
\hline Went without meals (G12d) & $\%$ yes & $8 \%$ & $11 \%$ & $6 \%$ & $11 \%$ & $7 \%$ \\
\hline Attended a food relief agency to access food relief (G12g) & $\%$ yes & $7 \%$ & $15 \%$ & $5 \%$ & $9 \%$ & $9 \%$ \\
\hline Worried about having enough money to buy food (G12h) & $\%$ yes & $17 \%$ & $25 \%$ & $14 \%$ & $22 \%$ & $17 \%$ \\
\hline Skipped a meal in order to feed your household (G12i) & $\%$ yes & $10 \%$ & $16 \%$ & $6 \%$ & $14 \%$ & $11 \%$ \\
\hline Ran out of food and could not afford to buy more (G12j) & $\%$ yes & $7 \%$ & $12 \%$ & $5 \%$ & $11 \%$ & $6 \%$ \\
\hline \multicolumn{7}{|l|}{ Alcohol } \\
\hline Long term harm -3 or more drinks 5 or more times a week & $\%$ & $7 \%$ & $7 \%$ & $8 \%$ & $5 \%$ & $7 \%$ \\
\hline Short term harm - more than 4 drinks at least once a week & $\%$ & $11 \%$ & $17 \%$ & $11 \%$ & $10 \%$ & $9 \%$ \\
\hline \multicolumn{7}{|l|}{ Smoking } \\
\hline Smoke cigarettes, cigars, pipes or other products (F1) & $\%$ smoke daily & $12 \%$ & $6 \%$ & $10 \%$ & $14 \%$ & $13 \%$ \\
\hline \multicolumn{7}{|l|}{ Financial hardship } \\
\hline Could not pay bills on time (G12a) & $\%$ yes & $11 \%$ & $17 \%$ & $9 \%$ & $15 \%$ & $11 \%$ \\
\hline Could not pay the rent or mortgage on time (G12b) & $\%$ yes & $7 \%$ & $8 \%$ & $4 \%$ & $10 \%$ & $10 \%$ \\
\hline Pawned or sold something (G12c) & $\%$ yes & $8 \%$ & $15 \%$ & $7 \%$ & $13 \%$ & $8 \%$ \\
\hline Asked for financial help from friends or family (G12e) & $\%$ yes & $12 \%$ & $21 \%$ & $11 \%$ & $16 \%$ & $12 \%$ \\
\hline Asked for help from community organisations (G12f) & $\%$ yes & $8 \%$ & $14 \%$ & $5 \%$ & $10 \%$ & $8 \%$ \\
\hline Any form of financial hardship - during COVID-19 & $\%$ yes & $24 \%$ & $36 \%$ & $22 \%$ & $26 \%$ & $23 \%$ \\
\hline $\begin{array}{l}\text { Any form of financial hardship - during February } 2020 \\
\text { ase: } \quad \text { Inner Metro }(n=950) \text {, Middle Metro }(n=231) \text {, Oute }\end{array}$ & $\begin{array}{l}\% \text { yes } \\
\text { etro }(n=57) \text {, Interf }\end{array}$ & $\begin{array}{r}16 \% \\
=160)\end{array}$ & $26 \%$ & $10 \%$ & $19 \%$ & $17 \%$ \\
\hline
\end{tabular}

Significantly different more favourable result

Significantly different less favourable result 
Table 14 Indicator results for rural geographic regions compared to the Victorian result

\begin{tabular}{|c|c|c|c|c|c|}
\hline Indicator & Measure & $\begin{array}{l}\text { VIC } \\
\text { result }\end{array}$ & $\begin{array}{l}\text { Regional } \\
\text { city }\end{array}$ & $\begin{array}{l}\text { Large } \\
\text { shire }\end{array}$ & $\begin{array}{l}\text { Small } \\
\text { shire }\end{array}$ \\
\hline \multicolumn{6}{|l|}{ General wellbeing } \\
\hline Life satisfaction - during COVID-19 restrictions (A1) & 0 to 6 & $49 \%$ & $52 \%$ & $45 \%$ & $31 \%$ \\
\hline Life satisfaction - during February 2020 (A1) & 0 to 6 & $33 \%$ & $32 \%$ & $29 \%$ & $35 \%$ \\
\hline Subjective wellbeing indicator (A2) & Mean score & 65.0 & 66.5 & 70.9 & 68.8 \\
\hline Psychological distress (K6) (A4) & $\%$ high & $16 \%$ & $10 \%$ & $14 \%$ & $7 \%$ \\
\hline \multicolumn{6}{|l|}{ Physical activity } \\
\hline Physical activity - during COVID-19 (B4a) & $\% 5$ or more & $32 \%$ & $32 \%$ & $31 \%$ & $34 \%$ \\
\hline Physical activity - during February 2020 (B4b) & $\% 5$ or more & $37 \%$ & $39 \%$ & $38 \%$ & $31 \%$ \\
\hline Physical activity - during COVID-19 (B4a) & $\% 0-1$ & $27 \%$ & $25 \%$ & $33 \%$ & $34 \%$ \\
\hline Physical activity - during February 2020 (B4b) & $\% 0-1$ & $20 \%$ & $20 \%$ & $25 \%$ & $37 \%$ \\
\hline \multicolumn{6}{|l|}{ Social connectedness } \\
\hline I feel connected with others - during COVID-19 (C1a) & $\%$ disagree & $23 \%$ & $31 \%$ & $19 \%$ & $26 \%$ \\
\hline I feel connected with others - during February $2020(\mathrm{C} 1 \mathrm{~b})$ & $\%$ disagree & $10 \%$ & $10 \%$ & $7 \%$ & $13 \%$ \\
\hline Social solidarity & Mean score & 21.2 & 21.3 & 23.0 & 21.4 \\
\hline Ease of staying connected with family and friends (C4W) & $\begin{array}{l}\% \text { hard / very } \\
\text { hard }\end{array}$ & $30 \%$ & $27 \%$ & $28 \%$ & $27 \%$ \\
\hline \multirow{2}{*}{ Relationships other people in your household (C5W) } & $\begin{array}{l}\% \\
\text { difficult/strained }\end{array}$ & $20 \%$ & $16 \%$ & $17 \%$ & $14 \%$ \\
\hline & $\%$ closer/stronger & $21 \%$ & $13 \%$ & $20 \%$ & $20 \%$ \\
\hline \multicolumn{6}{|l|}{ Healthy eating } \\
\hline \multirow{2}{*}{ Vegetable serves per week (D1) } & $\% 5$ or more & $8 \%$ & $8 \%$ & $13 \%$ & $19 \%$ \\
\hline & Average & 2.5 & 2.7 & 2.8 & 3.1 \\
\hline Frequency sugary drink consumption (N1) & $\%$ everyday & $32 \%$ & $35 \%$ & $23 \%$ & $36 \%$ \\
\hline Takeaway food frequency (N3) & $\% 3$ or more & $4 \%$ & $6 \%$ & $5 \%$ & $4 \%$ \\
\hline Times dinners cooked each week (D4) & $\begin{array}{l}\% 4 \text { times or } \\
\text { fewer }\end{array}$ & $12 \%$ & $9 \%$ & $13 \%$ & $10 \%$ \\
\hline Restricted range of low-cost food (D7a) & $\%$ yes & $23 \%$ & $18 \%$ & $11 \%$ & $13 \%$ \\
\hline Went without meals (G12d) & $\%$ yes & $8 \%$ & $6 \%$ & $10 \%$ & $14 \%$ \\
\hline Attended a food relief agency to access food relief (G12g) & $\%$ yes & $7 \%$ & $5 \%$ & $4 \%$ & $1 \%$ \\
\hline Worried about having enough money to buy food (G12h) & $\%$ yes & $17 \%$ & $14 \%$ & $14 \%$ & $15 \%$ \\
\hline Skipped a meal in order to feed your household (G12i) & $\%$ yes & $10 \%$ & $8 \%$ & $6 \%$ & $14 \%$ \\
\hline Ran out of food and could not afford to buy more (G12j) & $\%$ yes & $7 \%$ & $8 \%$ & $9 \%$ & $12 \%$ \\
\hline \multicolumn{6}{|l|}{ Alcohol } \\
\hline Long term harm -3 or more drinks 5 or more times a week & $\%$ & $7 \%$ & $7 \%$ & $7 \%$ & $6 \%$ \\
\hline Short term harm - more than 4 drinks at least once a week & $\%$ & $11 \%$ & $11 \%$ & $10 \%$ & $4 \%$ \\
\hline \multicolumn{6}{|l|}{ Smoking } \\
\hline Smoke cigarettes, cigars, pipes or other products (F1) & $\%$ smoke daily & $12 \%$ & $12 \%$ & $17 \%$ & $20 \%$ \\
\hline \multicolumn{6}{|l|}{ Financial hardship } \\
\hline Could not pay bills on time (G12a) & $\%$ yes & $11 \%$ & $8 \%$ & $11 \%$ & $17 \%$ \\
\hline Could not pay the rent or mortgage on time (G12b) & $\%$ yes & $7 \%$ & $7 \%$ & $7 \%$ & $7 \%$ \\
\hline Pawned or sold something (G12c) & $\%$ yes & $8 \%$ & $4 \%$ & $6 \%$ & $5 \%$ \\
\hline Asked for financial help from friends or family (G12e) & $\%$ yes & $12 \%$ & $7 \%$ & $8 \%$ & $3 \%$ \\
\hline Asked for help from community organisations (G12f) & $\%$ yes & $8 \%$ & $7 \%$ & $7 \%$ & $4 \%$ \\
\hline Any form of financial hardship - during COVID-19 & $\%$ yes & $24 \%$ & $21 \%$ & $21 \%$ & $27 \%$ \\
\hline $\begin{array}{l}\text { Any form of financial hardship - during February } 2020 \\
\text { Base: }\end{array}$ & $\%$ yes & $16 \%$ & $14 \%$ & $17 \%$ & $24 \%$ \\
\hline
\end{tabular}

Significantly different more favourable result

Significantly different less favourable result 


\section{Key indicators: Lower income (less than $\$ 40,000)$}

\section{Wellbeing}

- Those earning less than $\$ 40,000$ were more likely to report lower levels of life satisfaction both during February 2020 (44\% compared to 33\%) and during the first lockdown (58\% compared to $49 \%$ ).

\section{Physical activity}

- Reported levels of physical inactivity were higher for those earning less than $\$ 40,000$ during February 2020 than other groups (25\% compared to $20 \%$ ). Frequency of physical inactivity for this group during the first lockdown were on par with the rest of the state.

\section{Social connection}

- Victorians earning less than $\$ 40,000$ were more likely to disagree that they felt connected to others in February 2020 (15\% compared to 10\%) and during the first lockdown (30\% compared to $23 \%$ ).

- Their levels of social solidarity and connection to friends and family were on par with the rest of the state.

\section{Healthy eating}

- The eating habits of those earning $\$ 40,000$ or less were similar to the rest of the state.

\section{Alcohol consumption}

- No significant differences were observed in the levels of alcohol consumption for this group.

\section{Smoking}

- No significant differences were observed in smoking frequency for this group.

\section{Financial hardship}

- Being in a low-income bracket did not significantly impact on the levels of financial hardship reported by this group during the first lockdown when compared to Victoria overall. 
Table 15 Indicators results for low-income earners compared to the Victorian result

\begin{tabular}{|c|c|c|c|}
\hline Indicator & Measure & VIC result & $\begin{array}{l}\text { Earn less than } \\
\quad \$ 40,000\end{array}$ \\
\hline \multicolumn{4}{|l|}{ General wellbeing } \\
\hline Life satisfaction - during COVID-19 restrictions (A1) & 0 to 6 & $49 \%$ & $58 \%$ \\
\hline Life satisfaction - during February 2020 (A1) & 0 to 6 & $33 \%$ & $44 \%$ \\
\hline Subjective wellbeing indicator (A2) & Mean score & 65.0 & 61.4 \\
\hline Psychological distress (K6) (A4) & $\%$ high & $16 \%$ & $19 \%$ \\
\hline \multicolumn{4}{|l|}{ Physical activity } \\
\hline Physical activity - during COVID-19 (B4a) & $\% 5$ or more & $32 \%$ & $30 \%$ \\
\hline Physical activity - during February 2020 (B4b) & $\% 5$ or more & $37 \%$ & $38 \%$ \\
\hline Physical activity - during COVID-19 (B4a) & $\% 0-1$ & $27 \%$ & $31 \%$ \\
\hline Physical activity - during February 2020 (B4b) & $\% 0-1$ & $20 \%$ & $25 \%$ \\
\hline \multicolumn{4}{|l|}{ Social connectedness } \\
\hline I feel connected with others - during COVID-19 (C1a) & $\%$ disagree & $23 \%$ & $30 \%$ \\
\hline I feel connected with others - during February 2020 (C1b) & $\%$ disagree & $10 \%$ & $15 \%$ \\
\hline Social solidarity & Mean score & 21.2 & 20.8 \\
\hline Ease of staying connected with family and friends (C4W) & $\%$ hard / very hard & $30 \%$ & $30 \%$ \\
\hline \multirow{2}{*}{ Relationships other people in your household (C5W) } & $\%$ difficult/strained & $20 \%$ & $17 \%$ \\
\hline & $\%$ closer/stronger & $21 \%$ & $16 \%$ \\
\hline \multicolumn{4}{|l|}{ Healthy eating } \\
\hline \multirow{2}{*}{ Vegetable serves per week (D1) } & $\% 5$ or more & $8 \%$ & $9 \%$ \\
\hline & Average & 2.5 & 2.5 \\
\hline Frequency sugary drink consumption (N1) & $\%$ everyday & $32 \%$ & $33 \%$ \\
\hline Takeaway food frequency (N3) & $\% 3$ or more & $4 \%$ & $4 \%$ \\
\hline Times dinners cooked each week (D4) & $\% 4$ times or fewer & $12 \%$ & $11 \%$ \\
\hline Restricted range of low-cost food (D7a) & $\%$ yes & $23 \%$ & $68 \%$ \\
\hline Went without meals (G12d) & $\%$ yes & $8 \%$ & $9 \%$ \\
\hline Attended a food relief agency to access food relief (G12g) & $\%$ yes & $7 \%$ & $9 \%$ \\
\hline Worried about having enough money to buy food (G12h) & $\%$ yes & $17 \%$ & $20 \%$ \\
\hline Skipped a meal in order to feed your household (G12i) & $\%$ yes & $10 \%$ & $11 \%$ \\
\hline Ran out of food and could not afford to buy more (G12j) & $\%$ yes & $7 \%$ & $8 \%$ \\
\hline \multicolumn{4}{|l|}{ Alcohol } \\
\hline Long term harm -3 or more drinks 5 or more times a week & $\%$ & $7 \%$ & $7 \%$ \\
\hline Short term harm - more than 4 drinks at least once a week & $\%$ & $11 \%$ & $8 \%$ \\
\hline \multicolumn{4}{|l|}{ Smoking } \\
\hline Smoke cigarettes, cigars, pipes or other products (F1) & $\%$ smoke daily & $12 \%$ & $13 \%$ \\
\hline \multicolumn{4}{|l|}{ Financial hardship } \\
\hline Could not pay bills on time (G12a) & $\%$ yes & $11 \%$ & $13 \%$ \\
\hline Could not pay the rent or mortgage on time (G12b) & $\%$ yes & $7 \%$ & $8 \%$ \\
\hline Pawned or sold something (G12c) & $\%$ yes & $8 \%$ & $8 \%$ \\
\hline Asked for financial help from friends or family (G12e) & $\%$ yes & $12 \%$ & $14 \%$ \\
\hline Asked for help from community organisations (G12f) & $\%$ yes & $8 \%$ & $9 \%$ \\
\hline Any form of financial hardship - during COVID-19 & $\%$ yes & $24 \%$ & $28 \%$ \\
\hline Any form of financial hardship - during February 2020 & $\%$ yes & $16 \%$ & $19 \%$ \\
\hline $\begin{array}{l}\text { Any form of financial hardship - during February } 2020 \\
\text { Base: } \quad \text { Annual income of less than } \$ 40,000(n=182)\end{array}$ & & & \\
\hline Significantly different more favourable result & & & \\
\hline Significantly different less favourable result & & & \\
\hline
\end{tabular}




\section{Appendix 1}

\section{List of key indicators}

\begin{tabular}{|c|c|c|c|c|}
\hline Indicator and question & Score processing & Measure & Base & $\begin{array}{l}\text { Comparison } \\
\text { survey }\end{array}$ \\
\hline $\begin{array}{l}\text { Subjective wellbeing } \\
\text { [range 0-100] } \\
\text { Question A2 }\end{array}$ & $\begin{array}{l}\text { Average score of } 7 \text { domains is } \\
\text { combined into a Personal } \\
\text { Wellbeing Index score and } \\
\text { converted into a scale } \\
\text { maximum score with a range of } \\
0 \text { (completely dissatisfied) to } \\
100 \text { (completely satisfied). } \\
\text { Null responses excluded from } \\
\text { mean calculation }\end{array}$ & average & $\begin{array}{l}\text { All } \\
\text { respondents } \\
\text { (exclude } \\
\text { DKs and } \\
\text { Refs) }\end{array}$ & $\begin{array}{l}\text { VicHealth } \\
\text { Indicators, } 2015\end{array}$ \\
\hline $\begin{array}{l}\text { Satisfaction with life as a } \\
\text { whole } \\
\text { Question A1W }\end{array}$ & $\begin{array}{l}\text { Rating of general satisfaction } \\
\text { with life on a scale of } 0 \text { to } 10 \\
\text { where } 0 \text { is completely } \\
\text { dissatisfied and } 10 \text { is } \\
\text { completely satisfied. Low to } \\
\text { medium life satisfaction is a } \\
\text { score between } 0 \text { and } 6 \text { out of } \\
10 \text {. } \\
\text { Null responses excluded from } \\
\text { mean calculation }\end{array}$ & $\%$ & $\begin{array}{l}\text { All } \\
\text { respondents }\end{array}$ & $\begin{array}{l}\text { Victorian } \\
\text { Population Health } \\
\text { Survey, } 2017\end{array}$ \\
\hline $\begin{array}{l}\text { Psychological distress / K6 } \\
\text { Question A4 }\end{array}$ & $\begin{array}{l}\text { The Kessler } 6 \text { is a combined } \\
\text { score across } 6 \text { areas of } \\
\text { psychological distress. Each } \\
\text { person can score a minimum of } \\
6 \text { and maximum of } 30 \text {. Scores } \\
\text { of } 19 \text { or more are classified as } \\
\text { probable serious mental illness } \\
\text { and those with a score of } 6 \text { to } \\
18 \text { are classified as no } \\
\text { probable serious mental illness. } \\
\text { Null responses to } 2 \text { or more of } \\
\text { the } 6 \text { statements are excluded } \\
\text { from the mean calculation, with } \\
\text { adjustments made for those } \\
\text { who gave a null response to } 1 \\
\text { statement. }\end{array}$ & sum & $\begin{array}{l}\text { All } \\
\text { respondents } \\
\text { (exclude } \\
\text { DKs and } \\
\text { Refs for } 2 \text { or } \\
\text { more } \\
\text { statements) }\end{array}$ & $\begin{array}{l}\text { Victorian Public } \\
\text { Health Survey } \\
\text { (K10) } 2017\end{array}$ \\
\hline
\end{tabular}

\begin{tabular}{|c|c|c|c|c|}
\hline $\begin{array}{l}\text { Social Solidarity } \\
\text { Question C2 }\end{array}$ & $\begin{array}{l}\text { Responses for all six questions } \\
\text { were assigned the following } \\
\text { values: Strongly disagree }=1 \text {, } \\
\text { Disagree }=2 \text {, Neither agree nor } \\
\text { disagree }=3 \text {, Agree }=4 \text {, } \\
\text { Strongly agree }=5 \text {. Any } \\
\text { respondents providing a 'don't } \\
\text { know' or 'prefer not to answer' } \\
\text { response to any of the six } \\
\text { questions was excluded from } \\
\text { the analysis. The final score out } \\
\text { of a maximum of } 30 \text { and } \\
\text { minimum of six was used by } \\
\text { summing the values of the six } \\
\text { categories. }\end{array}$ & sum & $\begin{array}{l}\text { All } \\
\text { respondents } \\
\text { (exclude } \\
\text { DKs and } \\
\text { Refs) }\end{array}$ & Not applicable \\
\hline $\begin{array}{l}\text { Exercise } 0-1 \text { days per } \\
\text { week } \\
\text { Question B4 }\end{array}$ & $\begin{array}{l}\% \text { of people who do } 0 \text { to } 1 \text { days } \\
\text { of physical activity each week }\end{array}$ & $\%$ & $\begin{array}{l}\text { All } \\
\text { respondents }\end{array}$ & $\begin{array}{l}\text { VicHealth } \\
\text { Indicators, } 2015\end{array}$ \\
\hline $\begin{array}{l}\text { Exercise } 5 \text { or more days per } \\
\text { week } \\
\text { Question B4 }\end{array}$ & $\begin{array}{l}\% \text { of people who do } 5 \text { or more } \\
\text { days of physical activity each } \\
\text { week }\end{array}$ & $\%$ & $\begin{array}{l}\text { All } \\
\text { respondents }\end{array}$ & $\begin{array}{l}\text { VicHealth } \\
\text { Indicators, } 2015\end{array}$ \\
\hline
\end{tabular}




\begin{tabular}{|c|c|c|c|c|}
\hline Indicator and question & Score processing & Measure & Base & $\begin{array}{l}\text { Comparison } \\
\text { survey }\end{array}$ \\
\hline $\begin{array}{l}\text { Vegetable consumption (1) } \\
\text { Question D1 }\end{array}$ & $\begin{array}{l}\text { Average number of vegetables } \\
\text { serves consumed in a day }\end{array}$ & average & $\begin{array}{l}\text { All } \\
\text { respondents } \\
\text { (exclude } \\
\text { DKs and } \\
\text { Refs) }\end{array}$ & $\begin{array}{l}\text { Victorian } \\
\text { Population Health } \\
\text { Survey, } 2017\end{array}$ \\
\hline $\begin{array}{l}\text { Vegetable consumption (2) } \\
\text { Question D1 }\end{array}$ & $\begin{array}{l}\% \text { of people who consume } 5 \text { or } \\
\text { more serves of vegetables } \\
\text { each day }\end{array}$ & $\%$ & $\begin{array}{l}\text { All } \\
\text { respondents }\end{array}$ & $\begin{array}{l}\text { Victorian } \\
\text { Population Health } \\
\text { Survey, } 2017\end{array}$ \\
\hline $\begin{array}{l}\text { Sugar sweetened beverage } \\
\text { consumption } \\
\text { Question N1 }\end{array}$ & $\begin{array}{l}\% \text { of people who consume } \\
\text { sugar sweetened beverages } \\
\text { daily }\end{array}$ & $\%$ & $\begin{array}{l}\text { All } \\
\text { respondents }\end{array}$ & $\begin{array}{l}\text { Victorian } \\
\text { Population Health } \\
\text { Survey, } 2017\end{array}$ \\
\hline $\begin{array}{l}\text { Takeaway meals } \\
\text { Question N3 }\end{array}$ & $\begin{array}{l}\text { Percentage of people } \\
\text { consuming takeaway food at } \\
\text { least twice a week }\end{array}$ & $\%$ & $\begin{array}{l}\text { All } \\
\text { respondents }\end{array}$ & $\begin{array}{l}\text { VicHealth } \\
\text { Indicators, } 2015\end{array}$ \\
\hline $\begin{array}{l}\text { Home cooked dinners } \\
\text { Question D4 }\end{array}$ & $\begin{array}{l}\% \text { of people who cook dinner } \\
\text { less than } 5 \text { times a week }\end{array}$ & $\%$ & $\begin{array}{l}\text { All } \\
\text { respondents }\end{array}$ & Not applicable \\
\hline $\begin{array}{l}\text { Food insecurity (1) } \\
\text { Question D7 }\end{array}$ & $\begin{array}{l}\% \text { of people who relied on a } \\
\text { restricted range of low-cost } \\
\text { unhealthy food }\end{array}$ & $\%$ & $\begin{array}{l}\text { All } \\
\text { respondents }\end{array}$ & $\begin{array}{l}\text { Victorian } \\
\text { Population Health } \\
\text { Survey, } 2014\end{array}$ \\
\hline $\begin{array}{l}\text { Food insecurity (2) } \\
\text { Question G12j }\end{array}$ & $\begin{array}{l}\% \text { of people who ran out of } \\
\text { money to buy food }\end{array}$ & $\%$ & $\begin{array}{l}\text { All } \\
\text { respondents }\end{array}$ & $\begin{array}{l}\text { Victorian } \\
\text { Population Health } \\
\text { Survey, } 2014\end{array}$ \\
\hline $\begin{array}{l}\text { Short term harm from } \\
\text { alcohol } \\
\text { Questions E1 and E3 }\end{array}$ & $\begin{array}{l}\% \text { of people having } 5 \text { or more } \\
\text { standard drinks in a session at } \\
\text { least weekly }\end{array}$ & $\%$ & $\begin{array}{l}\text { All } \\
\text { respondents }\end{array}$ & $\begin{array}{l}\text { Victorian } \\
\text { Population Health } \\
\text { Survey, } 2017\end{array}$ \\
\hline $\begin{array}{l}\text { Long term harm from } \\
\text { alcohol } \\
\text { Questions E1 and E3 }\end{array}$ & $\begin{array}{l}\% \text { of people having } 3 \text { or more } \\
\text { drinks in a session, drinking } 5 \\
\text { to } 7 \text { days }\end{array}$ & $\%$ & $\begin{array}{l}\text { All } \\
\text { respondents }\end{array}$ & Not applicable \\
\hline $\begin{array}{l}\text { Tobacco } \\
\text { Question F1 }\end{array}$ & $\%$ of those smoking daily & $\%$ & $\begin{array}{l}\text { All } \\
\text { respondents }\end{array}$ & $\begin{array}{l}\text { Victorian } \\
\text { Population Health } \\
\text { Survey, } 2017\end{array}$ \\
\hline $\begin{array}{l}\text { Financial hardship } \\
\text { Question G12 a-f }\end{array}$ & $\begin{array}{l}\text { Answered yes to any of six } \\
\text { responses about a shortage of } \\
\text { money }\end{array}$ & $\%$ & $\begin{array}{l}\text { All } \\
\text { respondents }\end{array}$ & Not applicable \\
\hline
\end{tabular}

SEIFA or Socio-Economic Indexes for Areas is used in this report as an Index of socioeconomic status. Developed by the $\mathrm{ABS}^{23}$, it ranks areas in Australia according to relative socioeconomic advantage and disadvantage using postcodes. The indexes are based on information from the fiveyearly Census. The Index used in this report is the Index of Relative Socioeconomic Disadvantage (IRSD). It is presented in quintiles with the value of 1 indicating most disadvantaged and 5 indicating least disadvantaged.

\footnotetext{
${ }^{23}$ Australian Bureau of Statistics. Census of Population and Housing: Socio-Economic Indexes for Areas (SEIFA), Australia, 2016. Canberra: ABS; 2018.
} 


\section{Appendix 2 Questionnaire}

\section{VicHealth Coronavirus Victorian Wellbeing Impact Study questionnaire}

\section{MODULE A: GENERAL WELLBEING}

*(ALL)

A1W Thinking about your own life and your personal circumstances, how satisfied are you with your life as a whole? Please use a scale from $0-10$, where 0 is completely dissatisfied and 10 is completely satisfied.

Please provide a response for the time during COVID-19 restrictions and in February 2020.

Please select one answer for each column

\begin{tabular}{|l|l|l|}
\hline & $\begin{array}{c}\text { During COVID-19 } \\
\text { restrictions }\end{array}$ & In February 2020 \\
\hline $0-$ Completely dissatisfied & & \\
\hline 1 & & \\
\hline 2 & & \\
\hline 3 & & \\
\hline 4 & & \\
\hline 5 & & \\
\hline 6 & & \\
\hline 7 & & \\
\hline 8 & & \\
\hline 9 & & \\
\hline $10-$ Completely satisfied & & \\
\hline 98 Not sure & & \\
\hline 99 Prefer not to say & & \\
\hline
\end{tabular}

*(ALL)

*(PROGRAMMER NOTE - PLEASE LOOP A2 AND A3)

A2 Turning now to various areas of your life. How satisfied are you with...? Record number (Allowable range $=0$ to 10 )

Please provide a response for each statement.

\begin{tabular}{|l|l|}
\hline & $\begin{array}{c}\text { During COVID-19 } \\
\text { restrictions }\end{array}$ \\
\hline your standard of living & \\
\hline your health & \\
\hline $\begin{array}{c}\text { what you are currently } \\
\text { achieving in life }\end{array}$ & \\
\hline your personal relationships & \\
\hline how safe you feel & \\
\hline feeling part of your community & \\
\hline your future security & \\
\hline
\end{tabular}

98. Not sure

99. Prefer not to say

*(ALL)

A3 And would you say you were more or less satisfied, or feel about the same, now - during COVID -19 restrictions, compared to February 2020?

Please select an option for each statement 


\begin{tabular}{|c|c|c|c|c|c|}
\hline & $\begin{array}{c}\text { A lot } \\
\text { more } \\
\text { satisfied } \\
\text { now } \\
\end{array}$ & $\begin{array}{c}\text { A little } \\
\text { more } \\
\text { satisfied } \\
\text { now }\end{array}$ & $\begin{array}{c}\text { Feel } \\
\text { about the } \\
\text { same }\end{array}$ & $\begin{array}{c}\text { A little } \\
\text { less } \\
\text { satisfied } \\
\text { now }\end{array}$ & $\begin{array}{c}\text { A lot } \\
\text { less } \\
\text { satisfied } \\
\text { now } \\
\end{array}$ \\
\hline your standard of living & & & & & \\
\hline b. your health & & & & & \\
\hline $\begin{array}{l}\text { c. what you are currently } \\
\text { achieving in life }\end{array}$ & & & & & \\
\hline $\begin{array}{ll}\text { d. } & \begin{array}{l}\text { your personal } \\
\text { relationships }\end{array} \\
\end{array}$ & & & & & \\
\hline e. how safe you feel & & & & & \\
\hline $\begin{array}{l}\text { f. feeling part of your } \\
\text { community }\end{array}$ & & & & & \\
\hline g. your future security & & & & & \\
\hline
\end{tabular}

98. Not sure

99. Prefer not to say

\section{*(CLOSE LOOP)}

*(ALL)

*(PROGRAMMER NOTE - PLEASE LOOP A4 AND A5)

A4(W2) Now a question about your wellbeing, during the last month, how often did you feel...

(STATEMENTS)

1. Nervous?

2. Hopeless?

3. Restless or fidgety?

4. So depressed that nothing could cheer you up?

5. That everything was an effort?

6. Worthless?

\section{(RESPONSES)}

1. All of the time

1. Most

2. Some

3. A little

4. None of the time

98. Not sure

99. Prefer not to say

*(ALL)

A5 And would you say you feel more or less <insert statement from A4>, or about the same, now - during COVID -19 restrictions, compared to February 2020?

Please select an option for each statement

\begin{tabular}{|l|l|l|l|l|l|}
\hline & $\begin{array}{c}\text { A lot } \\
\text { more } \\
\text { now }\end{array}$ & $\begin{array}{c}\text { A little } \\
\text { more } \\
\text { now }\end{array}$ & $\begin{array}{c}\text { Feel } \\
\text { about the } \\
\text { same }\end{array}$ & $\begin{array}{c}\text { A little } \\
\text { less now }\end{array}$ & $\begin{array}{c}\text { A lot } \\
\text { less now }\end{array}$ \\
\hline a. Nervous & & & & & \\
\hline b. Hopeless & & & & & \\
\hline c. Restless or fidgety & & & & & \\
\hline d. $\quad \begin{array}{l}\text { So depressed that } \\
\text { nothing could cheer you } \\
\text { up }\end{array}$ & & & & & \\
\hline e. $\quad \begin{array}{l}\text { That everything was an } \\
\text { effort }\end{array}$ & & & & & \\
\hline
\end{tabular}




\begin{tabular}{|l|l|l|l|l|l|}
\hline f. Worthless & & & & & \\
\hline
\end{tabular}

98. Not sure

99. Prefer not to say

\section{*(CLOSE LOOP)}

\section{MODULE B: PHYSICAL ACTIVITY}

*(ALL)

B1 Now some questions about physical activity. Overall, do you feel you are doing more, less or about the same level of physical activity now - during COVID -19 restrictions, compared to February 2020 ?

Please select an option

1. A lot more now

2. A little more now

3. About the same

4. A little less now

5. A lot less now

98. Not sure

99. Prefer not to say

*(B1=4 OR 5, DOING LESS PHYSICAL ACTIVITY)

B2 What is the main reason your physical activity level has been less during the COVID-19 restrictions?

Please select all that apply

1. Low motivation

2. Poor health or injury

3. Having less time

4. I have no one to exercise with

5. Nowhere to exercise at home

6. More childcare responsibilities

7. No suitable park or path for physical activity outside

8. I've been concerned about catching COVID-19

9. I don't feel safe being physically active outside

10. Other - please specify

98. Not sure

99. Prefer not to say

*(B1=1, 2 OR 3, DOING MORE OR SAME PHYSICAL ACTIVITY)

B3 What is the main reason your physical activity level has been more (or same) during the COVID-19 restrictions?

Please select all that apply

1. Having more time

2. I like catching up with others while exercising

3. I like my local area

4. I have more flexible work arrangements

5. Less childcare responsibilities

6. To get out of the house

7. I wanted to improve my health in general

8. Other -please specify 
98. Not sure

99. Prefer not to say

*(ALL)

B4 In a usual week, on how many days do you do a total of 30 minutes or more of physical activity, which was enough to raise your breathing rate?

Please provide a response for the time during COVID-19 restrictions and in February 2020.

\begin{tabular}{|l|l|l|}
\hline & $\begin{array}{c}\text { During COVID-19 } \\
\text { restrictions }\end{array}$ & In February 2020 \\
\hline 0 & & \\
\hline 1 & & \\
\hline 2 & & \\
\hline 3 & & \\
\hline 5 & & \\
\hline 6 & & \\
\hline 7 & & \\
\hline
\end{tabular}

98. Not sure

99. Prefer not to say

*(B4=1-7, DOES SOME KIND OF PHYSICAL ACTIVITY)

B5 Have you done any of the following activities?

Please provide a response for the time during COVID-19 restrictions and in February 2020.

\begin{tabular}{|l|l|l|}
\hline & \multicolumn{1}{|c|}{$\begin{array}{c}\text { During COVID-19 } \\
\text { restrictions }\end{array}$} & In February 2020 \\
\hline Walking & & \\
\hline Cycling & & \\
\hline Running & & \\
\hline $\begin{array}{l}\text { Muscle strengthening } \\
\text { exercises at home }\end{array}$ & & \\
\hline $\begin{array}{l}\text { Yoga/Pilates/stretching at } \\
\text { home }\end{array}$ & & \\
\hline $\begin{array}{l}\text { Fitness/aerobics class at } \\
\text { home }\end{array}$ & & \\
\hline None of the above & & \\
\hline Other (please describe) & & \\
\hline 98 Not sure & & \\
\hline 99 Prefer not to say & & \\
\hline
\end{tabular}

\section{MODULE C: CONNECTING WITH OTHERS}

*(ALL)

C1 Please rate the degree to which you agree or disagree (where 1 is strongly disagree and 6 is strongly agree), with the following statement:

I feel connected with others

Please provide a response for the time during COVID-19 restrictions and in February 2020.

\begin{tabular}{|l|c|c|}
\hline & $\begin{array}{c}\text { During COVID-19 } \\
\text { restrictions }\end{array}$ & In February 2020 \\
\hline Strongly disagree & & \\
\hline Disagree & & \\
\hline Mildly disagree & & \\
\hline
\end{tabular}




\begin{tabular}{|l|l|l|}
\hline Mildly agree & & \\
\hline Agree & & \\
\hline Strongly agree & & \\
\hline 98 Not sure & & \\
\hline 99 Prefer not to say & & \\
\hline
\end{tabular}

*(ALL)

To what extent do you currently agree with the following statements

Please provide a response for each statement.

(STATEMENTS)

a) I am proud to be a member of my community

b) I feel I am part of the community

c) People in my neighbourhood share the same values

d) My neighbourhood is a good place to live

e) I trust my neighbours

f) People work together to get things done for this community

g) My neighbours are helping each other get through the COVID-19 restrictions

(RESPONSE FRAME)
1. Strongly agree
2. Agree
3. Neither agree nor disagree
4. Disagree
5. Strongly disagree

98. Not sure

99. Prefer not to say

*(ALL)

C3 People like to connect with each other in different ways. Excluding work, have you connected with others in any of the following ways?

Please provide a response for the time during COVID-19 restrictions and in February 2020.

\begin{tabular}{|l|l|l|}
\hline Exercising outside with others & $\begin{array}{c}\text { During COVID-19 } \\
\text { restrictions }\end{array}$ & In February 2020 \\
\hline $\begin{array}{l}\text { Over the telephone (voice } \\
\text { only) }\end{array}$ & & \\
\hline $\begin{array}{l}\text { Videoconference, e.g. } \\
\text { FaceTime, Zoom, House Party }\end{array}$ & & \\
\hline Walking with others & & \\
\hline $\begin{array}{l}\text { Group email or Facebook, or } \\
\text { other group messaging }\end{array}$ & & \\
\hline $\begin{array}{l}\text { Neighbourhood email or } \\
\text { Facebook }\end{array}$ & & \\
\hline $\begin{array}{l}\text { Sharing items with neighbours } \\
\text { such as food, toys books etc. }\end{array}$ & & \\
\hline $\begin{array}{l}\text { Sharing chores with } \\
\text { neighbours, e.g. bringing in } \\
\text { bins, grocery shopping, } \\
\text { mowing lawn }\end{array}$ & & \\
\hline Other, please specify & & \\
\hline None of the above & & \\
\hline Not sure & & \\
\hline Prefer not to say & & \\
\hline
\end{tabular}

*(ALL)

VicHealth Coronavirus Victorian Wellbeing Impact Study 
C4W Since the COVID-19 restrictions started, how easy has it been to stay connected with family and friends outside your household?

1. Very easy

2. Easy

3. Neither easy nor hard

4. Hard

5. Very hard

98. Not sure

99. Prefer not to say

${ }^{*}(\mathrm{ALL})$

C5W How has the quality of your relationships with other people/family members in your household changed since the COVID-19 restrictions started?

1. A lot closer/stronger

2. A little closer/stronger

3. No change

4. A little more difficult/strained

5. A lot more difficult/strained

97. Not applicable - single person household

98. Not sure

99. Prefer not to say

\section{MODULE D: HEALTHY EATING}

*(ALL)

D1 How many serves of vegetables do you usually eat each day?

A 'serve' is $1 / 2$ cup of cooked vegetables or 1 cup of salad vegetables.

'Vegetables' includes potatoes, hot potato chips, but excludes potato crisps and vegetable juice.

Please enter a response

1. Record number of serves *(RECORD NUMBER BETWEEN 0 AND 50)

98. Not sure

99. Prefer not to say

*(ALL)

D2

Overall, do you feel you are eating more, less or about the same amount of vegetables now - during COVID-19 restrictions, compared to February 2020?

Please select an option

1. A lot more now

2. A little more now

3. About the same

4. A little less now

5. A lot less now

98. Not sure

99. Prefer not to say

${ }^{*}(\mathrm{ALL})$ 
N1 How many glasses of soft drink, cordial, flavoured mineral water, energy drink or sports drink do you consume every day? (exclude diet variety)
1. None
2. Less than 1 per day
2. $\quad 1-2$ per day
3. 3-4 per day
4. $5+$ per day
98. Not sure
99. Prefer not to say

*(ALL)

N2

Overall, do you feel you are drinking more, less or about the same amount of soft drink, cordial, flavoured mineral water, energy drink or sports now - during COVID-19 restrictions, compared to February 2020?

Please select an option

1. A lot more now

2. A little more now

3. About the same

4. A little less now

5. A lot less now

98. Not sure

99. Prefer not to say

*(ALL)

N3 How often do you have meals or snacks such as burgers, pizza, chicken or chips from places like McDonalds, Hungry Jacks, Pizza Hut, KFC, Red Rooster or local takeaway places?

Please do not include sushi, takeaway Asian foods, salads, sandwiches or rolls

1. Most days (6-7 times per week)

2. 3-5 times per week

3. 1-2 times per week

4. 2-3 times per month

5. Once per month

6. Less than once per month

7. Never

98. Not sure

99. Prefer not to say

*(ALL)

Overall, do you feel you are having more, less or about the same number of meals or snacks such as burgers, pizza, chicken or chips from places like McDonalds, Hungry Jacks, Pizza Hut, KFC, Red Rooster or local takeaway places now - during COVID-19 restrictions, compared to February 2020?

Please do not include sushi, takeaway Asian foods, salads, sandwiches or rolls

Please select an option

1. A lot more now

2. A little more now

3. About the same

4. A little less now 
5. A lot less now

98. Not sure

99. Prefer not to say

*(ALL)

D3 Have you or anyone in your household started doing the following during COVID-19 restrictions?

Please provide a response for each statement.

\section{(STATEMENTS)}

a) Planted vegetable seeds or seedlings or grown food.

b) Purchased food from a farmers' market, vegetable box scheme or local farm.

c) Ordered a takeaway from an online delivery service (e.g. Deliveroo, Uber Eats, etc.).

d) Ordered food directly from a local restaurant or café.

e) Planned meals for the week.

f) Kept more food and other essentials at home.

g) Shopped locally, for example started going to local grocer, fruit and veg supply, butcher.

(RESPONSE FRAME)
1. Yes
2. No

98. Not sure

99. Prefer not to say

${ }^{*}(\mathrm{ALL})$

D4 On average, since the COVID-19 restrictions started, how many times do you and your household cook dinner each week?

Please enter a response

1. Record number of meals * (RECORD NUMBER BETWEEN 0 AND 7)

98. Not sure

99. Prefer not to say

${ }^{*}(\mathrm{ALL})$

D5 Would you say this is more, less or about the same now - during COVID-19 restrictions, compared to February 2020?

Please select an option

1. A lot more now

2. A little more now

3. About the same

4. A little less now

5. A lot less now

98. Not sure

99. Prefer not to say

*(D5=1 OR 2, COOKING MORE)

D6 What do you think are the main reasons you've increased/maintained the number of times you cook dinner each week?

Please select ALL that apply 
1. More time to prepare and cook food

2. More time to shop for food

3. People I know are cooking more

4. Members of my household / family want to eat home cooked meals

5. Less good quality takeaway food available

6. Cooking dinner is important to me

7. Home cooked food costs less

8. Prefer to stay home at this time

9. Other (please specify)

98. Not sure

99. Prefer not to say

*(D6=4 OR 5, COOKING LESS)

D7 What do you think are the main reasons you've decreased the number of times you cook dinner each week?

Please select ALL that apply

1. Less time to prepare

2. Limited supply at shops

3. Concern about food safety and contamination

4. Concern about going to the supermarket

5. Cost of food

6. Lack of working equipment to cook food

7. I don't care about what I eat

8. Other (please specify)

98. Not sure

99. Prefer not to say

*(ALL)

D7 Since the COVID-19 restrictions began, did you have to rely on a restricted range of lowcost unhealthy food because you were running out of money to buy food?
1. No, not at all
2. Not often
3. Sometimes, or
4. Yes, definitely

98. Not sure

99. Prefer not to say

\section{MODULE E: ALCOHOL}

*(ALL)

E1 During COVID-19 restrictions, how often have you had an alcoholic drink of any kind?

Please select an option.

1. Every day

2. 5 to 6 days a week

3. 3 to 4 days a week

4. 1 to 2 days a week

5. 2 to 3 days a month

6. About 1 day a month

7. Less often

8. I never drink alcohol 
98. Not sure

99. Prefer not to say

*(DRINKS ALCOHOL, E1=1-7, 98, 99)

E2 Would you say this is more, less or about the same now - during COVID -19 restrictions, compared to February 2020?

Please select an option

1. A lot more now

2. A little more now

3. About the same

4. A little less now

5. A lot less now

98. Not sure

99. Prefer not to say

*(E2=1 OR 2, DRINKING ALCOHOL ON MORE DAYS)

E5 What is the main reason you've drank alcohol on more days during COVID-19 restrictions?

Please select ALL that apply

1. I had more time

2. I was bored

3. I was anxious or stressed

4. I had more income

5. I had less income

6. I didn't need to stay below .05 for driving

7. Other (please specify)

98. Not sure

99. Prefer not to say

*(E2=4 OR 5, DRINKING ALCOHOL ON LESS DAYS)

E6 What is the main reason you've drank alcohol on less days during COVID-19 restrictions?

Please select ALL that apply

1. I had fewer opportunities to drink at home

2. I wanted to improve my health in general

3. The places where I usually drink are closed e.g. bars, clubs, restaurants

4. I was specifically concerned that drinking alcohol could increase the risk or severity of COVID-19

5. I can't socialise with the people I usually drink with

6. I had more income

7. I had less income

8. Other (please specify)

98. Not sure (EXCLUSIVE)

99. Prefer not to say (EXCLUSIVE)

*(DRINKS ALCOHOL, E1=1-7, 98, 99)

E3 Still thinking about during COVID-19 restrictions... On a day that you have an alcoholic drink, how many standard drinks do you usually have?

A standard drink is equal to 1 pot of full-strength beer, 1 small glass of wine or 1 pubsized nip of spirits. 
Please select an option.

1. 20 or more standard drinks

2. $16-19$ standard drinks

3. $13-15$ standard drinks

4. $11-12$ standard drinks

5. $9-10$ standard drinks

6. $7-8$ standard drinks

7. $5-6$ standard drinks

8. 3-4 standard drinks

9. 2 standard drinks

10. 1 standard drink

11. Half a standard drink

98. Not sure

99. Prefer not to say

*(DRINKS ALCOHOL, E1=1-7, 98, 99)

E4 Would you say this is more, less or about the same now - during COVID -19 restrictions, compared to February 2020?

Please select an option

1. A lot more now

2. A little more now

3. About the same

4. A little less now

5. A lot less now

98. Not sure

99. Prefer not to say

*(DRINKS ALCOHOL, E1=1-7, 98, 99)

E7 There are a number of situations that people prefer to drink alcohol. Which of the following have applied to you during COVID-19 restrictions?

Please select ALL that apply

1. At home on your own

2. At home with family/partner/housemates

3. At home on a video call with friends/family

4. None of the above

98. Not sure (EXCLUSIVE)

99. Prefer not to say (EXCLUSIVE)

\section{MODULE F: SMOKING}

*(ALL)

F1 Now l'd like to ask you some questions about smoking. Do you now smoke cigarettes, cigars, pipes or any other tobacco products?

1. Daily

2. At least weekly (not daily)

3. Less often than weekly, or

4. Not at all

98. Not sure (EXCLUSIVE)

99. Prefer not to say (EXCLUSIVE) 
F2 During COVID-19 restrictions, did you do any of the following?

1. Smoked more than usual $\rightarrow$ Go to QF3

2. Smoked less than usual $\rightarrow$ Go to F4

3. Attempted to quit Go to $\mathrm{F5}$

4. Quit smoking $\rightarrow$ Go to QF6

5. Did not change my smoking behaviour $\rightarrow$ Go to $\mathrm{G} 1$

98. Not sure (EXCLUSIVE)

99. Prefer not to say (EXCLUSIVE)

\section{*(F2=1, SMOKING MORE)}

F3 What is the main reason you smoked more than usual during COVID-19 restrictions?

Please select ALL that apply

1. I had more time

2. I was bored

3. I was anxious or stressed

4. I had more disposable income

5. Other - please specify

98. Not sure (EXCLUSIVE)

99. Prefer not to say (EXCLUSIVE)

\section{${ }^{*}(\mathrm{~F} 2=2, \mathrm{SMOKING} \mathrm{LESS})$}

F4 What is the main reason you smoked less than usual during COVID-19 restrictions?

Please select ALL that apply

1. I had fewer opportunities to smoke at home

2. I wanted to improve my health in general

3. I was specifically concerned that smoking could increase the risk or severity of COVID-19

4. My income was reduced

5. Other - please specify

98. Not sure (EXCLUSIVE)

99. Prefer not to say (EXCLUSIVE)

\section{*(F2=3, TRIED TO QUIT)}

F5 What is the main reason you attempted to quit during COVID-19 restrictions?

Please select ALL that apply

1. I had fewer opportunities to smoke at home

2. I tried to quit smoking to improve my health in general

3. I was specifically concerned that smoking could increase the risk or severity of COVID-19

4. I tried to quit smoking to save money, as my income was reduced

5. I tried to quit smoking because the cost of cigarettes/tobacco went up

6. Other please specify

98. Not sure (EXCLUSIVE)

99. Prefer not to say (EXCLUSIVE)

${ }^{*}(\mathrm{~F} 2=4, \mathrm{QUIT})$

F6 What is the main reason you've quit during COVID-19 restrictions? 
Please select ALL that apply

1. I had fewer opportunities to smoke at home

2. I quit smoking to improve my health in general

3. I was specifically concerned that smoking could increase the risk or severity of COVID-19

4. I quit smoking to save money, as my income was reduced

5. I quit smoking because the cost of cigarettes/tobacco went up

6. Other (please specify)

98. Not sure (EXCLUSIVE)

99. Prefer not to say (EXCLUSIVE)

\section{MODULE G: WORKING AND HOME LIFE DURING COVID}

${ }^{*}(\mathrm{ALL})$

G1 Now we are going to ask some questions about your home life. Which of these best describes your household...?

1. Person living alone

2. Couple living alone

3. Couple with child / children

$4 \quad$ One parent family with child / children, co-parenting with other parent living elsewhere

5 One parent family with child / children

6. Adults sharing house /apartment / flat

96. Something else (please specify)

98. Not sure (EXCLUSIVE)

99. Prefer not to say (EXCLUSIVE)

*(ALL)

G2 Which of these best describes your main activity in February 2020? Were you...? / And how about your partner?

\begin{tabular}{|l|l|l|}
\hline & ${ }^{*}($ ALL $)$ & $\begin{array}{l}{ }^{*}(\text { G1=CODES 2 OR 3, } \\
\text { HAS PARTNER AT } \\
\text { HOME) }\end{array}$ \\
\hline & $\begin{array}{l}\text { a) Which of these best } \\
\text { describes your main } \\
\text { activity in February } \\
\text { 2020? Were you...? }\end{array}$ & $\begin{array}{l}\text { b) And how about your } \\
\text { partner? }\end{array}$ \\
\hline Self-employed & & \\
\hline $\begin{array}{l}\text { Employed for wages, salary or } \\
\text { payment in-kind }\end{array}$ & & \\
\hline Unemployed & & \\
\hline Engaged in home duties & & \\
\hline A student & & \\
\hline Retired & & \\
\hline Unable to work & & \\
\hline $\begin{array}{l}\text { Something else (please } \\
\text { specify) }\end{array}$ & & \\
\hline Not sure & & \\
\hline Prefer not to say & & \\
\hline
\end{tabular}

*(G2a=1-2, HAD JOB IN FEBRUARY 2020) / *(G2b=1-2, PARTNER HAD JOB IN FEBRUARY 2020)

G3 And in February 2020, how many hours did you do in your job? / And how about your partner? 


\begin{tabular}{|l|l|l|}
\hline & $\begin{array}{l}\text { *(G2a=1 OR 2, HAD JOB } \\
\text { IN FEBRUARY 2020) }\end{array}$ & $\begin{array}{l}\text { *(G2b=1 OR 2, PARTNER } \\
\text { HAD JOB IN FEBRUARY } \\
2020)\end{array}$ \\
\hline & $\begin{array}{c}\text { a) And in February 2020, } \\
\text { how many hours did } \\
\text { you do in your job? } \\
\text { If you had more than one } \\
\text { job, please enter the } \\
\text { number of hours for ALL } \\
\text { your jobs }\end{array}$ & $\begin{array}{l}\text { bartner? } \\
\text { If your partner had more } \\
\text { than one job, please enter } \\
\text { the number of hours for } \\
\text { ALL their jobs }\end{array}$ \\
\hline $\begin{array}{l}\text { Enter number of hours } \\
\text { (ALLOWABLE RANGE: 1- } \\
\text { 100) }\end{array}$ & & \\
\hline Not sure & & \\
\hline Prefer not to say & & \\
\hline
\end{tabular}

*(G2a=1-2, HAD JOB IN FEBRUARY 2020) / * (G2b=1-2, PARTNER HAD JOB IN FEBRUARY 2020)

G4 What industry did you work in for your main job in February 2020? / And how about your partner?

\begin{tabular}{|c|c|c|}
\hline & $\begin{array}{l}\text { *(G2a=1-2, HAD JOB IN } \\
\text { FEBRUARY 2020) }\end{array}$ & $\begin{array}{l}\text { *(G2b=1-2, PARTNER } \\
\text { HAD JOB IN FEBRUARY } \\
\end{array}$ \\
\hline & $\begin{array}{l}\text { a) What industry did you } \\
\text { work in for your main } \\
\text { job in February } 2020 ? \\
\text { If you had more than one } \\
\text { job, please enter the usual } \\
\text { place of work for your } \\
\text { MAIN job }\end{array}$ & $\begin{array}{l}\text { b) And how about your } \\
\text { partner? } \\
1 . \quad \text { If your partner had } \\
\text { more than one job, } \\
\text { please enter the usual } \\
\text { place of work for their } \\
\text { MAIN job }\end{array}$ \\
\hline $\begin{array}{l}\text { 1. Agriculture, forestry and } \\
\text { fishing }\end{array}$ & & \\
\hline 2. Mining & & \\
\hline 3. Manufacturing & & \\
\hline $\begin{array}{l}\text { 4. Electricity, gas, water and } \\
\text { waste services }\end{array}$ & & \\
\hline 5. Construction & & \\
\hline 6. Wholesale trade & & \\
\hline 7. Retail trade & & \\
\hline $\begin{array}{l}\text { 8. Accommodation and food } \\
\text { services (e.g., hotels, cafes, } \\
\text { restaurants, pubs, takeaway) }\end{array}$ & & \\
\hline $\begin{array}{l}\text { 9. Transport, postal and } \\
\text { warehousing }\end{array}$ & & \\
\hline $\begin{array}{l}\text { 10. Information media and } \\
\text { telecommunications }\end{array}$ & & \\
\hline $\begin{array}{l}\text { 11. Financial and insurance } \\
\text { services }\end{array}$ & & \\
\hline $\begin{array}{l}\text { 12. Rental, hiring and real } \\
\text { estate services }\end{array}$ & & \\
\hline $\begin{array}{l}\text { 13. Professional, scientific and } \\
\text { technical services }\end{array}$ & & \\
\hline $\begin{array}{l}\text { 14. Administrative and support } \\
\text { services }\end{array}$ & & \\
\hline $\begin{array}{l}\text { 15. Public administration and } \\
\text { safety }\end{array}$ & & \\
\hline 16. Education and training & & \\
\hline $\begin{array}{l}\text { 17. Health care and social } \\
\text { assistance }\end{array}$ & & \\
\hline
\end{tabular}




\begin{tabular}{|l|l|l|}
\hline 18. Arts services & & \\
\hline $\begin{array}{l}\text { 19. Sports and recreation } \\
\text { services }\end{array}$ & & \\
\hline $\begin{array}{l}\text { 20. Something else (please } \\
\text { specify) }\end{array}$ & & \\
\hline Not sure & & \\
\hline Prefer not to say & & \\
\hline
\end{tabular}

*(G2a=1-2, HAD JOB IN FEBRUARY 2020) / *(G2b=1-2, PARTNER HAD JOB IN FEBRUARY 2020)

G5 And in February 2020, where was your usual place of work? / And how about your partner?

\begin{tabular}{|l|l|l|}
\hline & $\begin{array}{c}\text { *(G2a=1 OR 2, HAD JOB } \\
\text { IN FEBRUARY 2020) }\end{array}$ & $\begin{array}{l}{ }^{*}(\mathrm{G} 2 \mathrm{~b}=1 \text { OR 2, PARTNER } \\
\text { HAD JOB IN FEBRUARY } \\
\text { 2020) }\end{array}$ \\
\hline & $\begin{array}{l}\text { a) And in February 2020, } \\
\text { where was your usual } \\
\text { place of work? } \\
\text { If you had more than one } \\
\text { job, please enter the usual } \\
\text { place of work for your } \\
\text { MAIN job }\end{array}$ & $\begin{array}{l}\text { b) And how about your } \\
\text { partner? } \\
\text { If your partner had more } \\
\text { than one job, please enter } \\
\text { the usual place of work for } \\
\text { their MAIN job }\end{array}$ \\
\hline $\begin{array}{l}\text { Worked mainly from home with } \\
\text { standard hours }\end{array}$ & & \\
\hline $\begin{array}{l}\text { Worked mainly from home with } \\
\text { flexible start and finish times }\end{array}$ & & \\
\hline $\begin{array}{l}\text { Worked mainly from another } \\
\text { location e.g. office with } \\
\text { standard hours }\end{array}$ & & \\
\hline $\begin{array}{l}\text { Worked mainly from another } \\
\text { location e.g. office with flexible } \\
\text { start and finish times }\end{array}$ & & \\
\hline Not sure & & \\
\hline Prefer not to say & & \\
\hline
\end{tabular}

*(G2a=1-2, HAD JOB IN FEBRUARY 2020) / *(G2b=1-2, PARTNER HAD JOB IN FEBRUARY 2020)

G6 Thinking now about since the COVID-19 restrictions started, have you experienced any of the following? / And how about your partner?

\begin{tabular}{|c|c|c|}
\hline & $\begin{array}{l}\text { *(G2a=1, HAD JOB IN } \\
\text { FEBRUARY 2020) }\end{array}$ & $\begin{array}{l}\text { *(G2b=1, PARTNER HAD } \\
\text { JOB IN FEBRUARY 2020) }\end{array}$ \\
\hline $\begin{array}{l}\text { 1. Had your hours of work } \\
\text { reduced / had their hours of } \\
\text { work reduced }\end{array}$ & & \\
\hline $\begin{array}{l}\text { 2. Your hourly rate of pay / } \\
\text { salary been reduced not } \\
\text { related to the number of hours } \\
\text { you work / their hourly rate of } \\
\text { pay / salary reduced not } \\
\text { related to the number of hours } \\
\text { they work }\end{array}$ & & \\
\hline $\begin{array}{l}\text { 3. Not received a bonus that } \\
\text { you were entitled / not } \\
\text { received a bonus that they } \\
\text { were entitled }\end{array}$ & & \\
\hline 4. Lost your job / lost their job & & \\
\hline 5. Required to take paid leave & & \\
\hline $\begin{array}{l}\text { 6. Required to take unpaid } \\
\text { leave }\end{array}$ & & \\
\hline
\end{tabular}




\begin{tabular}{|l|l|l|}
\hline 7. The company you worked & & \\
for ceased operating / had to & & \\
close my business / the & & \\
company they worked for & & \\
ceased operating / had to & & \\
close their business & & \\
\hline
\end{tabular}

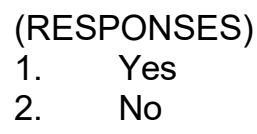

98. Not sure (EXCLUSIVE)

99. Prefer not to say (EXCLUSIVE)

*(G2a=1-2 AND G6a NOT 4 OR 7, HAD JOB IN FEBRUARY 2020 AND STILL HAS IT) / *(G2b=1-2 G6b NOT 4 OR 7, PARTNER HAD JOB IN FEBRUARY 2020 AND STILL HAS IT)

G7 Thinking now about since the COVID-19 restrictions started, where is your usual place of work? / And how about your partner?

\begin{tabular}{|l|l|l|}
\hline & \multicolumn{1}{|c|}{${ }^{*}($ G5 NOT 4 OR 7) } & *(G5 NOT 4 OR 7) \\
\hline & $\begin{array}{l}\text { a) And in February 2020, } \\
\text { where was your usual } \\
\text { place of work? } \\
\text { If you had more than one } \\
\text { job, please enter the usual } \\
\text { place of work for your } \\
\text { MAIN job }\end{array}$ & $\begin{array}{l}\text { b) And how about your } \\
\text { partner? } \\
\text { If your partner had more } \\
\text { than one job, please enter } \\
\text { the usual place of work for } \\
\text { their MAIN job }\end{array}$ \\
\hline $\begin{array}{l}\text { Worked mainly from home with } \\
\text { standard hours }\end{array}$ & & \\
\hline $\begin{array}{l}\text { Worked mainly from home with } \\
\text { flexible start and finish times }\end{array}$ & & \\
\hline $\begin{array}{l}\text { Worked mainly from another } \\
\text { location, e.g. office with } \\
\text { standard hours }\end{array}$ & & \\
\hline $\begin{array}{l}\text { Worked mainly from another } \\
\text { location, e.g. office with } \\
\text { flexible start and finish times }\end{array}$ & & \\
\hline Not sure & & \\
\hline Prefer not to say & & \\
\hline
\end{tabular}

*(ALL)

G7a Since COVID-19 restrictions started which of the following apply to you, if any?

Please select ALL that apply

1. Received, or have been notified that you will receive JobKeeper

2. Received, or have been notified that you will receive JobSeeker

3. Received, or have been notified that you will receive government rent assistance

4. Received, or have been notified that you will receive financial support from my University

5. Received, or have been notified that you will receive some other government income support (please specify)

97 None of these (EXCLUSIVE)

98. Not sure (EXCLUSIVE)

99. Prefer not to say (EXCLUSIVE)

*(G1=3, 4 OR 5, HOUSEHOLD STRUCTURE HAS CHILDREN)

G8 Thinking about your household, how many children aged under 18, if any, live in your household (at least $50 \%$ of the time)? 
1. Number of children given (please specify) *(ALLOWABLE RANGE 1-20)

2. None

98. Not sure (EXCLUSIVE)

99. Prefer not to say (EXCLUSIVE)

*(G8=1, HAS DEPENDENT CHIDLREN IN HOUSEHOLD)

G9 Which of the following applied to you during most of COVID-19 restrictions?

Please select ALL that apply

1. I have kept my child/children in childcare or kindergarten

2. I have started my child/children in childcare or kindergarten

3. I have discontinued my child/children going to childcare or kindergarten

4. I have child/children at school

5. I have child/children doing school at home

6. None of these

98. Not sure (EXCLUSIVE)

99. Prefer not to say (EXCLUSIVE)

*(CHILDREN DISCONTINUED CHILDCARE, G9=3 AND G1=3 OR 4, ANOTHER PARENT INVOLVED)

G10 Who would you say is spending, or has spent, the most time looking after your preschool child(ren) during the COVID-19 restrictions?

1. I am

2. My partner or other parent

3. Shared equally between my partner / the other parent and myself

4. Someone else in the household (please specify)

98. Not sure (EXCLUSIVE)

99. Prefer not to say (EXCLUSIVE)

*(CHILDREN DOING HOME SCHOOLING, G9=5 AND G1=3 OR 4, ANOTHER PARENT INVOLVED)

G11 Who would you say is spending, or has spent, the most time helping your child(ren) with school at home during the COVID-19 restrictions?

1. I am

2. My partner or other parent

3. Shared equally between my partner / the other parent and myself

4. Someone else in the household (please specify)

98. Not sure (EXCLUSIVE)

99. Prefer not to say (EXCLUSIVE)

${ }^{*}(\mathrm{ALL})$

G12 Since COVID-19 restrictions began, did the of the following happen because of a shortage of money?

And in February 2020, did any of these happen because of a shortage of money?

Please provide a response for the time during COVID-19 restrictions and in February 2020.

\begin{tabular}{|l|c|c|}
\hline & $\begin{array}{c}\text { During COVID-19 } \\
\text { restrictions }\end{array}$ & In February 2020 \\
\hline
\end{tabular}




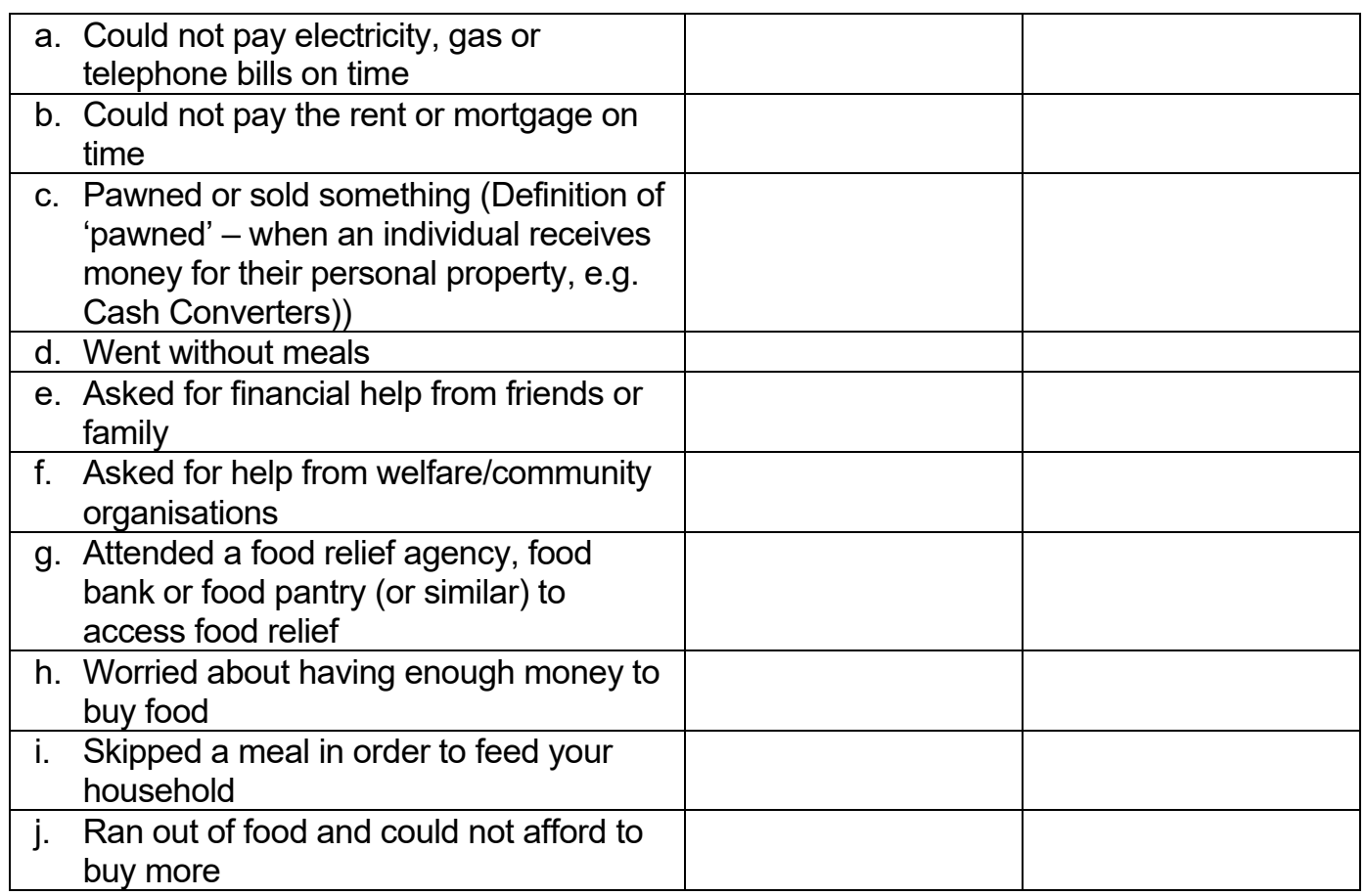

(RESPONSES)

1. Yes

2. No

98. Not sure (EXCLUSIVE)

99. Prefer not to say (EXCLUSIVE)

*(ALL)

G13 Thinking about how you feel right now, on a scale of 1 to 5 , where 1 is very concerned and 5 is not at all concerned, would you say...?

\section{(STATEMENTS)}

a) I feel concerned about my future employment/job prospects

b) I feel concerned about the stability of my housing

\section{(RESPONSE FRAME)}

1. Very concerned

2.

3.

4.

5. Not at all concerned

98. Not sure (EXCLUSIVE)

99. Prefer not to say (EXCLUSIVE)

${ }^{*}(\mathrm{ALL})$

G14 Please identify if you or those you know have been diagnosed with COVID-19?
1. Self
2. Close family member
3. Family member
4. Close friend
5. Friend
6. Household member
7. Work colleague
8. Recent acquaintance
9. I don't know anyone who has been diagnosed with COVID-19 
98. Not sure (EXCLUSIVE)

99. Prefer not to say (EXCLUSIVE)

*(ALL)

G15 Some people have found that some of the changes made during the COVID-19 pandemic have been positive.

* New line] Thinking about your work life, social life, home life and your wellbeing, are there any aspects from the COVID-19 period that you would like to maintain after restrictions are over?

Please write in your response to each of the following:

\begin{tabular}{|l|l|l|l|l|}
\hline Life area & $\begin{array}{l}\text { Yes, please tell us what changes } \\
\text { you would like to keep }\end{array}$ & No & $\begin{array}{l}\text { Not } \\
\text { sure }\end{array}$ & $\begin{array}{l}\text { Prefer } \\
\text { not to } \\
\text { say }\end{array}$ \\
\hline $\begin{array}{l}\text { Work life (e.g. work from home, } \\
\text { change my job, ask for flexible } \\
\text { hours) }\end{array}$ & & & & \\
\hline $\begin{array}{l}\text { Social life (e.g. walking with } \\
\text { friends, using Zoom or }\end{array}$ & & & & \\
$\begin{array}{l}\text { FaceTime to talk to friends, see } \\
\text { more of my neighbours) }\end{array}$ & & & & \\
\hline $\begin{array}{l}\text { Home life (e.g. spend more } \\
\text { time with my children, do more } \\
\text { with my household/family, keep } \\
\text { doing gardening) }\end{array}$ & & & & \\
\hline $\begin{array}{l}\text { Personal wellbeing (e.g. keep } \\
\text { exercising, look after my health, } \\
\text { meditate) }\end{array}$ & & & \\
\hline
\end{tabular}

\section{MODULE S: Sociodemographics AND OTHER COVARIATES}

*(ALL)

H1 Where were you located during the 2019/2020 summer bushfires?

Please select one option

1. Community member in bushfire affected area

2. Holidaying in or travelling through bushfire affected area

3. Not located in a bushfire affected area

98. Not sure (EXCLUSIVE)

99. Prefer not to say (EXCLUSIVE)

*(ALL)

H2 To what degree would you say you were affected by the $2019 / 2020$ summer bushfires?

1. Not affected at all

2. Slightly affected

3. Affected a fair amount

4. Severely affected

98. Not sure (EXCLUSIVE)

99. Prefer not to say (EXCLUSIVE)

${ }^{*}(\mathrm{ALL})$ 
S1W Now I have some questions to help us analyse the results. Just to confirm, what gender do you identify as?
1. Male
2. Female
3. Non-binary
96. Other
98. Not sure (EXCLUSIVE)
99. Prefer not to say (EXCLUSIVE)

*(ALL)

S2W How old were you last birthday?

1. Age given *(RECORD AGE IN YEARS - ALLOWABLE RANGE 18 TO 99)

99. Prefer not to say (EXCLUSIVE)

*(G2=99, REFUSED AGE)

S3W Which of the following broad age groups are you in?
1. $18-24$ years
2. $25-34$ years
3. $35-44$ years
4. $45-54$ years
5. $55-64$ years
6. $65-74$ years
7. $75+$ years

99. Prefer not to say (EXCLUSIVE)

S4W What is your postcode

1. Record postcode

98. Not sure (EXCLUSIVE)

99. Prefer not to say (EXCLUSIVE)

*(S4=98 OR 99, REFUSED POSTCODE)

S5 Would you be happy to provide your locality or suburb?

1. Record locality

98. Not sure (EXCLUSIVE)

99. Prefer not to say (EXCLUSIVE)

*(ALL)

S6W Which of the following best describes your housing situation?

1. Own outright

2. Own with a mortgage

4. $\quad$ Renting

5. Occupying rent free

3. Purchasing under a shared equity scheme (A shared equity scheme is a way to share the cost of buying a home with an equity partner, such as a private investor, not-for profit organisation or government housing authority.)

6. Occupying under a life tenure scheme (A life tenure scheme is a contract to live in the dwelling for the term of your life without the full rights of ownership. This is a common arrangement in retirement villages.)

7. Some other arrangement (please specify) 
98. Not sure (EXCLUSIVE)

99. Prefer not to say (EXCLUSIVE)

*(ALL)

S7W Which of the following best describes your current relationship status? Are you...?

1. Married

2. Living with a partner

3. Widowed

4. Divorced

5. Separated

6. Never married

98. Not sure (EXCLUSIVE)

99. Prefer not to say (EXCLUSIVE)

*(ALL)

S8W Are you of Aboriginal and Torres Strait Islander origin?

1. No, not Aboriginal and Torres Strait Islander

2. Yes, Aboriginal

3. Yes, Torres Strait Islander

4. Yes, Aboriginal and Torres Strait Islander

98. Not sure (EXCLUSIVE)

99. Prefer not to say (EXCLUSIVE)

*(ALL)

S9W In which country were you born?

1. Australia (includes External Territories)

2. United Kingdom (incl. England, Scotland, Wales, Northern Ireland)

3. New Zealand

4. Italy

5. Greece

6. China

7. Vietnam

8. Lebanon

9. India

10. Philippines

96. Other (please specify)

98. Not sure (EXCLUSIVE)

99. Prefer not to say (EXCLUSIVE)

*(ALL)

S10W Do you speak a language other than English at home?

1. Yes

2. No

98. Not sure (EXCLUSIVE)

99. Prefer not to say (EXCLUSIVE)

*(ALL)

S11W What is the highest year of schooling you have completed?

1. Year 12 or equivalent

2. Year 11 or equivalent 

3. Year 10 or equivalent
4. Years 7-9 or equivalent
5. Completed primary school but did not go to high school
6. Some primary school only
7. Did not go to school
98. Not sure (EXCLUSIVE)
99. Prefer not to say (EXCLUSIVE)

${ }^{*}(\mathrm{ALL})$

$\mathrm{S} 12 \mathrm{~W}$ What is the highest post-school educational qualification that you have obtained?

\section{Apprenticeship can be coded to Cert III or IV. Traineeship can usually be coded to Cert I} or II.
1. No post school educational qualification
2. Certificate I or Certificate II
3. Certificate III or Certificate IV
4. Associate Diploma
5. Undergraduate Diploma
6. Bachelor Degree
7. Master's Degree, Postgraduate Degree or Postgraduate Diploma
8. Doctorate
96. Other (please specify)
98. Not sure (EXCLUSIVE)
99. Prefer not to say (EXCLUSIVE)

*(ALL)

S13aW Which of the following ranges best describes your <personal / household > approximate income, from all sources, before tax is taken out, up to February 2020? Please include wages and salaries, government pensions, benefits and allowances and income from interest, dividends or other sources.

*(PROGRAMMER NOTE: IF G1=1 or 6, USE PERSONAL, ELSE USE HOUSEHOLD'S)

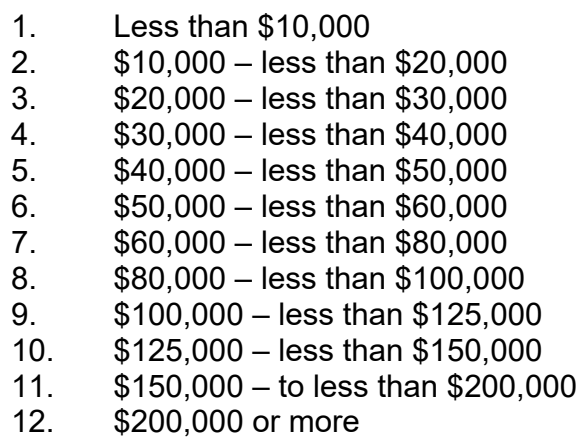

98. Not sure (EXCLUSIVE)

99. Prefer not to say (EXCLUSIVE)

*(ALL)

$\mathrm{S} 13 \mathrm{~b}$ Is your income more, less or the same now - during COVID-19 restrictions, compared to February 2020?

Please select an option

1. A lot more now

2. A little more now

3. About the same

4. A little less now

5. A lot less now 
98. Not sure (EXCLUSIVE)

99. Prefer not to say (EXCLUSIVE)

*(ALL)

S19W Over the last 12 months did you spend any time doing voluntary work through an organisation or group?

Please include voluntary work for sporting teams, youth groups, schools or religious organisations. Please exclude work in a family business or paid employment. Please exclude work to qualify for a government benefit or to obtain an educational qualification or due to a community / court order.

1. Yes, did voluntary work

2. No, did not do voluntary work

98. Not sure (EXCLUSIVE)

99. Prefer not to say (EXCLUSIVE)

*(S19=1, DONE VOLUNTEER WORK)

S20 Have you been doing more or less volunteer work during the COVID-19 restrictions?

Please select an option

1. A lot more

2. A little more

3. About the same

4. A little less

5. A lot less

98. Not sure (EXCLUSIVE)

99. Prefer not to say (EXCLUSIVE)

*(ALL)

P_DISABILITYW. Do you currently have a disability, health condition or injury that has lasted, or is likely to last, 6 months or more which restricts your everyday activities?
1. Yes
2. No
98. Not sure
99. Prefer not to say

*(ALL)

S21W Other than a Medicare card, are you the holder of a health care card or a pensioner concession card?

Health care cards are issued by Centrelink and are different to Medicare cards.

1. Yes

2. No

98. Not sure (EXCLUSIVE)

99. Prefer not to say (EXCLUSIVE)

*(ALL)

S22 In order to analyse the results of this survey at a local level, we'd like to make a note of the nearest cross street intersection to your house. This information will only be used so we can join your answers with others in your neighbourhood. It will not be used to identify you. Are you able to give me the nearest cross street intersection? 
1. Suburb

2. Postcode

3. Cross streets given (specify Street One and Street Two separately)

98. Not sure (EXCLUSIVE)

99. Prefer not to say (EXCLUSIVE)

${ }^{*}(\mathrm{ALL})$

R1 Would you be happy to be recontacted to take part in a similar survey in the future?

1 Yes

2 No

99 Prefer not to say 


\section{List of figures}

Figure 1 Satisfaction with life as a whole

Figure 2 Low-medium life satisfaction - Victorian and sub-population frequencies during first lockdown

Figure 3 Low-medium life satisfaction - Victorian and sub-population frequencies during February 2020.

Figure 4 Low-medium life satisfaction - Victorian and sub-population frequencies - comparison of first lockdown to February 2020.

Figure 5 Satisfaction with aspects of life

Figure 6 Subjective wellbeing - Victorian and sub-population scores during the first lockdown .......... 19

Figure 7 Change in satisfaction with aspects of life (more, same, less) …...................................... 20

Figure 8 High psychological distress - Victorian and sub-population frequencies during first

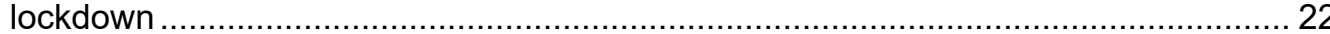

Figure 9 Changes in psychological distress indicators (more, same, less) .................................... 23

Figure 10 Agreement that respondents feel connected to others (disagree, mildly agree or disagree, agree).

Figure 11 Disagreement with the statement 'I feel connected to others' - Victorian and subpopulation frequencies (\% disagree) during the first lockdown

Figure 12 Disagreement with the statement 'I feel connected to others' - Victorian and subpopulation frequencies (\% disagree) during February 2020

Figure 13 Disagreement with the statement 'I feel connected to others' - Victorian and subpopulation frequencies (\% disagree) during the first lockdown compared to February 2020

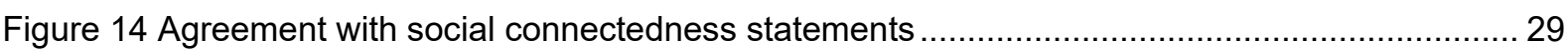

Figure 15 Social solidarity - Victorian and sub-population scores (max score of 30)......................... 30

Figure 16 Means of social connection during the first Victorian coronavirus lockdown and February 2020

Figure 17 Difficulty of staying connected with friends and family by subgroup (easy, hard, neither).

Figure 18 Difficulty (hard/very hard) staying connected with friends and family outside of the home - Victorian and sub-population frequencies

Figure 19 Quality of relationships with other people in household during the first lockdown (closer, no change, more strained).

Figure 20 Quality of relationships (more strained) with other people in household - Victorian and sub-population frequencies during the first lockdown.

Figure 21 Quality of relationships (stronger) with other people in household - Victorian and subpopulation frequencies during the first lockdown.

Figure 22 Frequency of physical activity

Figure 2330 minutes of physical activity, five or more days per week - Victorian and subpopulation frequencies during the first lockdown.

Figure 2430 minutes of physical activity five or more days per week - Victorian and subpopulation frequencies during February 2020

Figure 2530 minutes of physical activity, five or more days per week - Victorian and subpopulation frequencies during the first lockdown compared to February 2020

Figure 2630 minutes of physical activity, 1 to 0 days per week - Victorian and sub-population frequencies during the first lockdown.....

Figure 2730 minutes of physical activity, 0 to 1 days per week - Victorian and sub-population frequencies during February 2020.

Figure 2830 minutes of physical activity, 1 to 0 days per week - Victorian and sub-population frequencies during the first lockdown compared to February 2020. 
Figure 29 Levels of physical activities during the first lockdown compared to February 2020

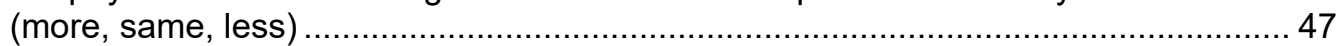

Figure 30 Main reason for less physical activity during the first lockdown....................................... 48

Figure 31 Main reason for more or the same level of physical activity during the first Victorian

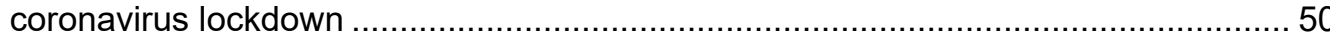

Figure 32 Activities participated in during the first Victorian coronavirus lockdown and February

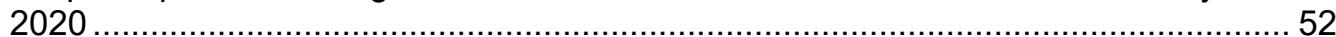

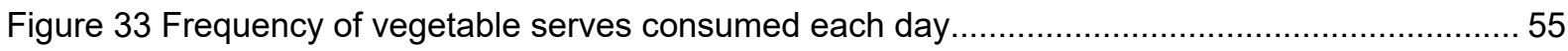

Figure 34 Consumption of 5 or more serves of vegetables per day - Victorian and subpopulation frequencies during the first lockdown...................................................... 56

Figure 35 Serves of vegetables per day - Victorian and sub-population average number of

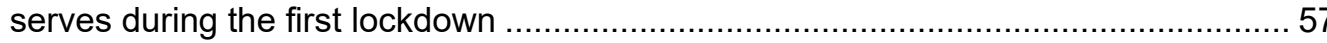

Figure 36 Levels of vegetable consumption during the first lockdown compared to February

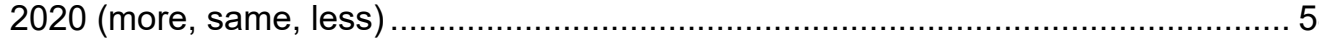

Figure 37 Sugar sweetened beverage consumption - Victorian and sub-population frequencies

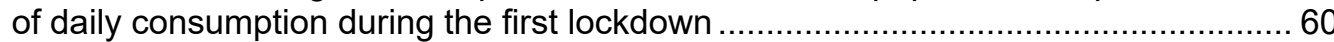

Figure 38 Sugar sweetened beverages consumption during the first Victorian coronavirus lockdown compared to February 2020 (more, same, less) ..................................... 6

Figure 39 Takeaway food consumption - Victorian and sub-population frequencies of consuming three or more times per week

Figure 40 Levels of takeaway food consumption during the first Victorian coronavirus lockdown compared to February 2020 (more, same, less)

Figure 41 Cooking dinner four or less times per week - Victorian and subpopulation frequencies during the first lockdown

Figure 42 Changes in frequency of cooking dinner during the first lockdown compared to

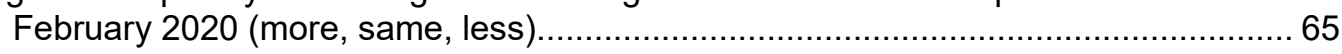

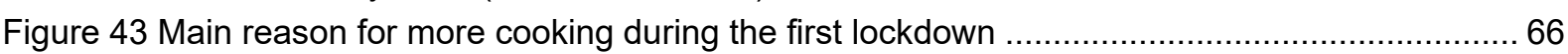

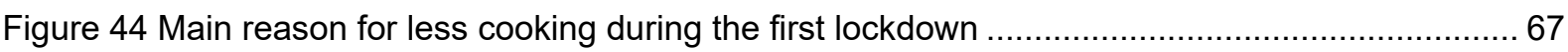

Figure 45 Food related behaviours that commenced during the first lockdown.................................... 68

Figure 46 Relied on a restricted range of low-cost unhealthy food during the first lockdown .............. 69

Figure 47 Relied on a restricted range of low-cost unhealthy food since - Victorian and subpopulation frequencies (\% yes) during the first lockdown ....

Figure 48 Ran out of food and could not afford to buy more because of a shortage of money Victorian and sub-population frequencies (\% yes) during the first lockdown

Figure 49 Ran out of food and could not afford to buy more because of a shortage of money Victorian and sub-population frequencies (\% yes) during February 2020.

Figure 50 Ran out of food and could not afford to buy more because of a shortage of money Victorian and sub-population frequencies (\% yes) during the first lockdown compared to February 2020

Figure 51 Food insecurity during the first lockdown and February 2020.

Figure 52 Frequency of alcohol consumption during the first lockdown compared to February 2020 (more, same or less number of days)

Figure 53 Levels of alcohol consumed in each drinking session during the first lockdown compared to February 2020 (more, same, less)

Figure 54 Risk of short-term harm (consumption of more than 4 standard drinks in a single session at least weekly) - Victorian and sub-population frequencies during the first lockdown .....

Figure 55 Risk of long-term harm (consumption of more than two standard drinks in a single session, 5 to 7 days a week) - Victorian and sub-population frequencies during the first lockdown

Figure 56 Main reason for drinking more alcohol during the first lockdown....................................... 82

Figure 57 Main reason for drinking less alcohol during the first lockdown....................................... 83

Figure 58 Situations preferred for alcohol consumption during the first lockdown.............................. 83 
Figure 59 Daily smoking of cigarettes, cigars, pipes or any other tobacco products - Victorian and subpopulation frequencies (\% daily smoking) during the first lockdown

Figure 60 Smoking behaviour changes during the first lockdown .................................................... 87

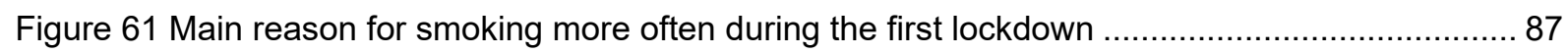

Figure 62 Main reason for smoking less often during the first lockdown ....................................... 88

Figure 63 Main reason for attempting to quit smoking during the first lockdown .................................. 89

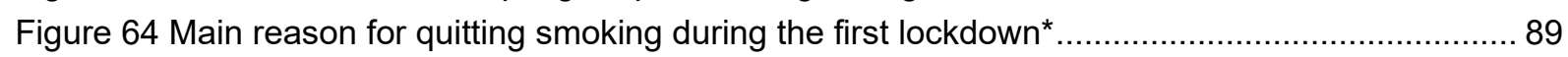

Figure 65 Financial hardship experienced during the first lockdown and February 2020.................... 91

Figure 66 Experience of financial hardship - Victorian and sub-population frequencies during

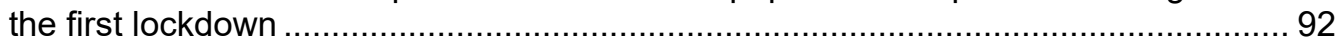

Figure 67 Experience of financial hardship - Victorian and sub-population frequencies during February 2020.

Figure 68 Experience of financial hardship - Victorian and sub-population frequencies during the first lockdown compared to February 2020

Figure 69 Concerned about stability of housing (concerned, not concerned, neither) ........................ 95

Figure 70 Concern about stability of housing - Victorian and subpopulation frequencies (\%

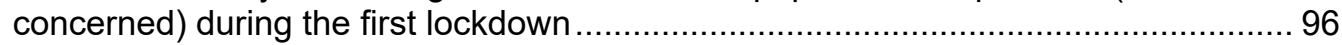

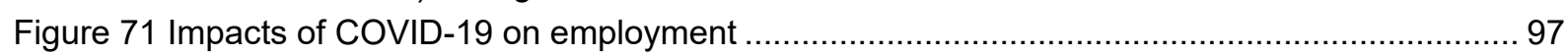

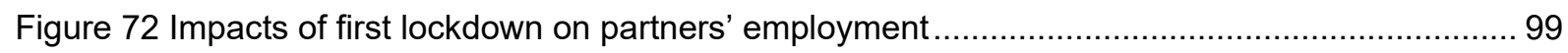

Figure 73 Usual place of work during the first lockdown and in February 2020 .............................. 100

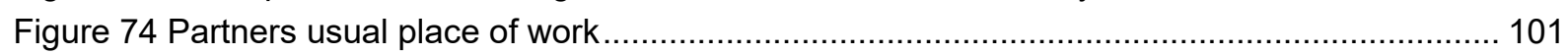

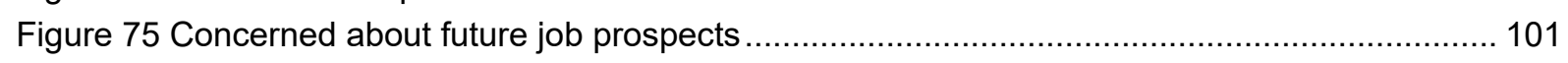

Figure 76 Concern about future job prospects - Victorian and subpopulations frequencies ( $\%$ concerned) during first lockdown ......................................................................... 103

Figure 77 Responsibility for caring for school age children during the first lockdown in two

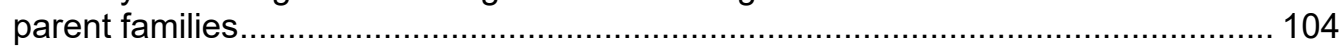

Figure 78 Responsibility for caring for pre-school aged children during the first lockdown in two

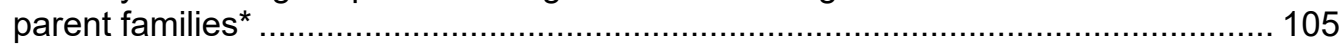

Figure 79 Positive aspects of working life to retain from the first lockdown ....................................... 106

Figure 80 Positive aspects of social life to retain from the first lockdown ....................................... 107

Figure 81 Positive aspects of home life to retain from the first lockdown ....................................... 108

Figure 82 Positive aspects of personal wellbeing to retain from the first lockdown ........................... 109 


\section{List of tables}

Table 1 Sample profile.

Table 2 Variables used for calculating final weights for the non-probability sample, with population distributions and data sources .....

Table 3 Individual social solidarity indicators - subgroups with significantly different frequencies compared to the overall Victorian frequency

Table 4 Reasons for less physical activity during the first lockdown - subpopulation frequencies that are significantly different to the overall Victorian level....

Table 5 Subgroups with differing main reasons for more or maintained physical activity subpopulation frequencies that are significantly different to the overall Victorian level.

Table 6 Reasons for cooking more dinners during the first lockdown - subpopulation frequencies that are significantly different to the overall Victorian level.

Table 7 Reasons for cooking less dinners during the first lockdown - subpopulation frequencies that are significantly different to the overall Victorian level.

Table 8 Types of employment impact due to first lockdown - subpopulation frequencies that are significantly different to the overall Victorian level.

Table 9 Indicator results for bushfire affected areas compared to Victorian result.

Table 10 Indicator results for young people aged 18 to 24 years compared to Victorian result......... 113

Table 11 Indicator results for people aged 25-34 compared to the Victorian result. 115

Table 12 Indicator results for Aboriginal and Torres Strait Islanders compared to the Victorian result ......

Table 13 Indicator results for metropolitan geographic regions compared to the Victorian result

Table 14 Indicator results for rural geographic regions compared to the Victorian result.

Table 15 Indicators results for low-income earners compared to the Victorian result 
Victorian Health Promotion Foundation

PO Box 154 Carlton South

Victoria 3053 Australia

T+61396671333 F+6139667 1375

vichealth@vichealth.vic.gov.au

vichealth.vic.gov.au

twitter.com/vichealth

facebook.com/vichealth

VicHealth is committed to health equity, which means

levelling the playing field

between people who can easily

access good health and people who

face barriers, to achieve the highest

level of health for everyone.

VicHealth acknowledges the support of the Victorian Government.

(c) VicHealth 2020

https://doi.org/10.37309/2020.P0909

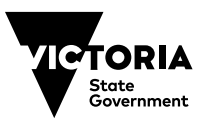

VicHealth acknowledges the Traditional Custodians of the land. We pay our respects to all Elders past, present and future. 